Guilherme Ide Marques dos Santos

\title{
Análise cladística da tribo Megacephalini Laporte, 1834 (Coleoptera: Carabidae: Cicindelinae)
}

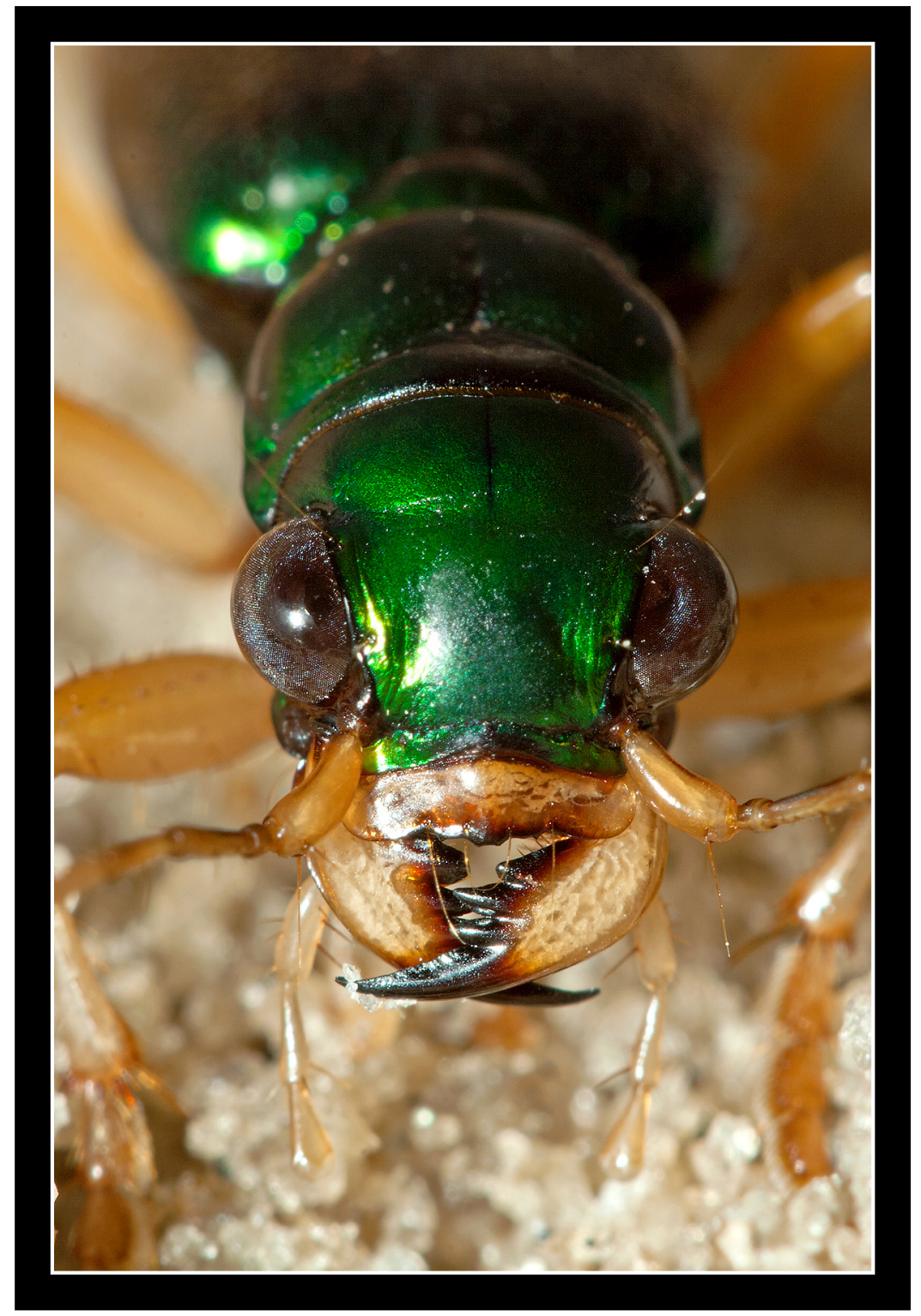

São Paulo

2012 
Esta versão contém algumas correções sugeridas pela banca examinadora.

A versão original encontra-se disponível no Instituto de Biociências da USP. 


\section{Análise cladística da tribo Megacephalini Laporte, 1834 (Coleoptera: Carabidae: Cicindelinae)}

Cladistic analysis of the tribe Megacephalini Laporte, 1834 (Coleoptera: Carabidae: Cicindelinae)

Tese apresentada ao Instituto de Biociências da Universidade de São Paulo, para a obtenção de Título de Doutor em Ciências, na Área de Zoologia.

Orientadora: $\operatorname{Prof}^{\mathrm{a}} \operatorname{Dr}^{\mathrm{a}}$ Sônia A. Casari

São Paulo 


\section{Ficha Catalográfica}

Marques-dos-Santos, Guilherme Ide

Análise cladística da tribo Megacephalini

Laporte, 1834 (Coleoptera: Carabidae:

Cicindelinae)

$226+x$ páginas

Tese (Doutorado) - Instituto de Biociências da Universidade de São Paulo.

Departamento de Zoologia.

1. Carabidae 2. Megacephalini 3. Análise cladística I. Universidade de São Paulo. Instituto de Biociências. Departamento de Zoologia.

\section{Comissão Julgadora:}




\begin{abstract}
AVISO
Essa dissertação é parte dos requerimentos necessários à obtenção do título de doutor, área de Zoologia, e como tal, não deve ser vista como uma publicação no senso do Código Internacional de Nomenclatura Zoológica (apesar de ser disponibilizada publicamente sem restrições). Desta forma, quaisquer informações inéditas, opiniões e hipóteses, bem como nomes novos, não estão disponíveis na literatura zoológica. Pessoas interessadas devem estar cientes de que referências públicas ao conteúdo deste estudo, na sua presente forma, somente devem ser feitas com aprovação prévia do autor.
\end{abstract}

\title{
NOTICE
}

This dissertation is a partial requirement for the PhD degree in Zoology and, as such, should not be considered as a publication in the sense of the International Code of Zoological Nomenclature (although it is available without restrictions). Therefore, any new information, opinions and hypotheses, as well as new names, are not available in the zoological literature. Interested people are advised that any public reference to this study, in its current form, should only be done after previous acceptance of the author. 
À minha família e amigos 


\section{Epígrafe}

"Somewhere, something incredible is waiting to be known."

Carl E. Sagan

(Cosmos, 1980) 


\section{Agradecimentos}

À Dra. Sônia Casari, minha orientadora, que há mais de uma década me ajuda, apoia, ensina e motiva, não somente em minha formação, mas também em minha vida pessoal. Sempre esteve aberta a responder minhas incontáveis dúvidas, bem como me apoiar nas mais absurdas ideias.

Aos meus pais, o apoio e confiança durante todas as curvas e obstáculos que tive que enfrentar durante minha vida de doutorando.

Aos curadores Dra. Marcela Monné, Dr. Orlando Silveira e Dr. Ayr Belo, a recepção em suas instituições, além do empréstimo de parte do material aqui estudado.

Aos curadores do exterior que enviaram material, mesmo sabendo dos riscos encontrados aqui.

Aos funcionários do Museu de Zoologia da USP, que proporcionam a todos um ótimo local de trabalho; um obrigado especial à equipe de bibliotecários pela simpatia e eficiência na localização das mais importantes informações.

Ao laboratório de Hymenoptera do MZUSP a autorização do uso e ajuda com o sistema de automontagem, tão importante para a obtenção de muitas das imagens desta tese.

Aos amigos: Biffi, Laura e Madruga, colegas de laboratório, as muitas conversas, discussões, jogatinas e risadas; Peterson, as conversas sobre os mais variados temas relacionados à minha tese, que independente da sua presença no laboratório sempre será meu grande amigo e colega; Cristiano Moreira e Leandro Vieira, a grande ajuda na fase final desta tese; Ricardo Kawada, a ajuda e muitas discussões sobre a elaboração da tese, em especial a ajuda na obtenção das imagens de automontagem e uso dos programas de filogenia; Flávia "Brasa" Fernandes, as muitas risadas, discussões e ajuda durante este estudo; Rogério Rosa, a ajuda com a codificação (ou não) dos caracteres contínuos; ao Maurício, as $12 \mathrm{~h} . .$. ops.... as risadas e ajuda com o programas para a elaboração da matriz de dados e aos demais amigos e colegas do $M Z$ pelos bons momentos juntos. Hector, muito obrigado pelo HD externo, indispensável para o transporte dos dados e criação de backups.

I would like to thank all the NMNH staff for welcoming me at the Institution and helping me with everything I had to face there during more than 6 months of research. Dr. Terry Erwin, thank you very much for the attention, discussions, and the opportunity to work at such an amazing institution with one of the most important entomologist in the world. My friends and colleagues: Lourdes Chamorro, for sharing her office, ideas, and the very kind company at the lab; Charyn Micheli for all the support given during my stay in DC and (by email) after my return to Brazil; Alexander Konstantinov for his valuable opinions; Chad Walter, Denny, and Ronan for providing the best housing in DC. Also to my friends Luisa, Sandra, Laura, Daniel, Martin, Camila, Lorian, Claudia, Carolina, Thiago, David, Leila, Cibele, Cristiano, Jeff, Ximo, Fiona, Vinita, etc. - thank you guys for the great time !!!!

Por fim, sou extremamente grato à Pró-Reitoria de Pós-Graduação pela passagem para os EUA e ao CNPq pela bolsa de estudos cedida durante o presente trabalho. 


\section{Resumo}

A tribo Megacephalini era composta por 16 gêneros e aproximadamente 230 espécies distribuídas nos continentes americano, africano, europeu e Oceania tendo como principal sinapomorfia a carena pronotal lateral projetando-se além da margem anterior do prosterno. Essa tribo já sofreu muitas modificações e atualmente, como resultado de análises filogenéticas baseadas em dados moleculares e dados morfológicos de larvas, teve sua monofilia questionada. Foi feito um estudo filogenético baseado principalmente em caracteres morfológicos de adultos para testar a monofilia do grupo, assim como investigar as relações entre os subgrupos que o forma. Para tal, 233 caracteres foram levantados, sendo 232 relacionados à morfologia externa e um sobre a biologia; alguns caracteres foram estudados pela primeira vez em uma filogenia de Carabidae, com destaque para o escutelo, que se mostrou bastante informativo para os agrupamentos das subtribos. Os quatro cladogramas igualmente mais parcimoniosos (960 passos) obtidos revelaram que a tribo aqui definida é monofilética, sendo necessário para tal apenas excluir uma espécie da hipótese inicial (Callidema boussingaultii) e incluir um ou dois gêneros (Mantica e Manticora), inicialmente considerados externos à tribo. Foi apresentada uma nova hipótese de classificação para a tribo Megacephalini, na qual essa é formada por 3 subtribos: Manticorina, Oxycheilina e Megacephalina; Manticorina grupo-irmão das outras duas subtribos, estas formando juntas um grupo monofilético. 


\section{Abstract}

The tribe Megacephalini was composed of 16 genera and approximately 230 species spread throughout the Americas, Africa, Europe, and Oceania. The main synapomorphy of the group is the lateral pronotal ridge that extends beyond the anterior margin of the mesosternum. The classification of the tribe has undergone changes through the past few decades and recently, based on molecular characters and larval data, its validity has been questioned. A phylogenetic study based mainly on morphological data was done to test the monophyly of the group as well as to investigate the relations of its subgroups. For the analysis, 233 characters were used. From those, 232 related to the external morphology and one to the biology; some characters were used for the first time in a Carabidae phylogenetic study, such as the scutellum, which has proven to be very important for subtribes determination. The four most parsimonious trees (length $=960$ ) show that the tribe is monophyletic, with the exclusion of one species (Callidema boussingaultii), and the addition of one or two genera (Mantica and Manticora), formerly not considered part of the tribe. A new classification hypothesis is presented, in which the tribe is formed by three subtribes: Manticorina, Oxycheilina, and Megacephalina; Manticorina as sister group of the other two, and those together comprising a natural group. 


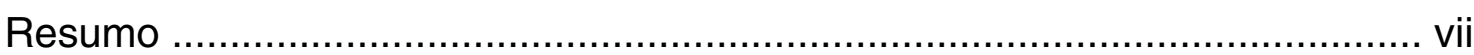

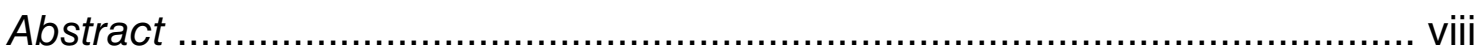

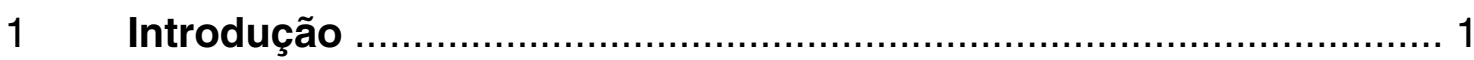

1.1 A família Carabidae e a subfamília Cicindelinae ...................... 1

$1.2 \quad$ Breve histórico ............................................................. 3

1.3 O grande grupo Megacephala Latreille, $1802 \ldots \ldots \ldots \ldots \ldots \ldots \ldots \ldots \ldots$

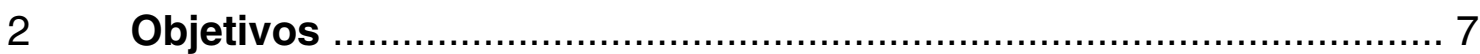

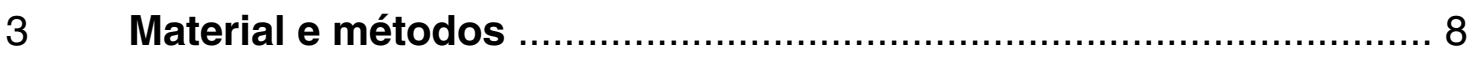

3.1 Taxonomia adotada no presente estudo ................................ 8

3.2 Material examinado ......................................................... 9

3.3 Dissecções e ilustrações .................................................... 22

3.4 Medidas ........................................................................ 24

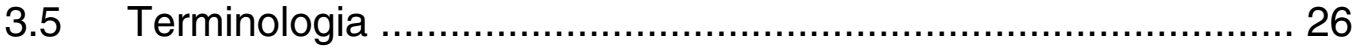

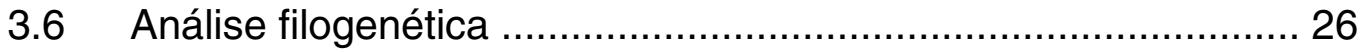

3.6.1 Escolha dos táxons............................................ 27

3.6.2 Construção da matriz de caracteres .......................... 30

3.6.3 Análise da matriz de dados ........................................ 30

3.6.4 Discussão dos caracteres ......................................... 31

3.6.5 Discussão dos grandes grupos naturais obtidos............. 33

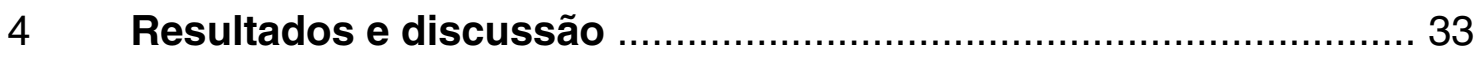

4.1 Lista de caracteres e distribuição dos estados ....................... 33 


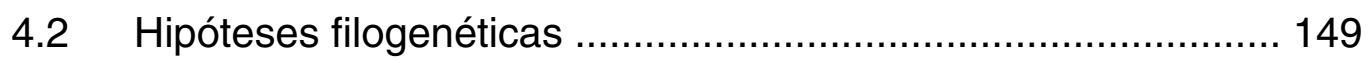

4.2.1 Monofilia de Megacephalini ......................................... 150

4.2.2 Monofilia de Manticorina ................................................. 153

4.2.3 Monofilia de Oxycheilina .................................................. 156

4.2.4 Monofilia de Megacephalina ......................................... 160

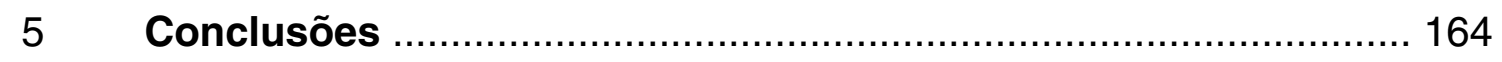

5.1 Classificação para a tribo Megacephalini aqui estabelecida.......... 164

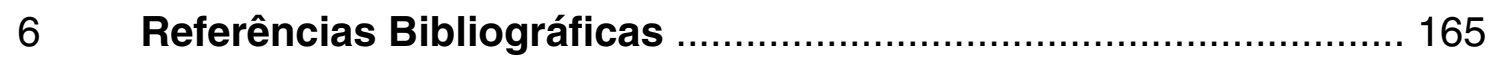

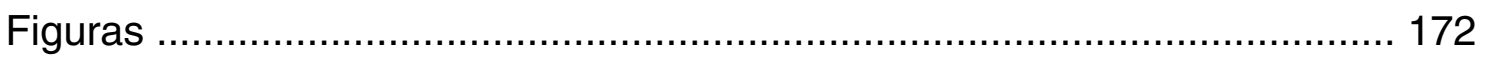

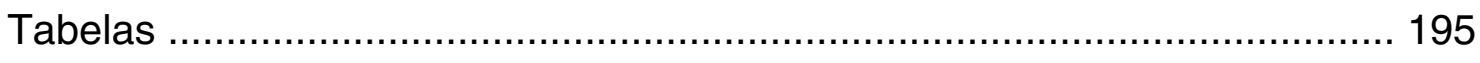

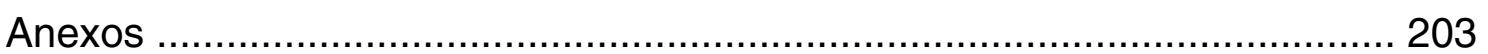




\section{INTRODUÇÃO}

\subsection{A famíla Carabidae e a subfamília Cicindelinae}

Carabidae é uma das mais diversas famílias de coleópteros, sendo composta por 15 subfamílias (ARNDT et al., 2005), 86 tribos (ERWIN, 1985), aproximadamente 1500 gêneros e mais de 40.000 espécies (ARNDT et al., 2005). É composta em sua maioria por besouros predadores, tanto em seu estágio larval como no estágio adulto, embora também existam algumas espécies herbívoras (MARINONI et al., 2001).

Os carabídeos apresentam diferentes formas e tamanhos (1 - $70 \mathrm{~mm}$ ), mas podem ser caracterizados pelas mandíbulas e palpos proeminentes; pelo metasterno encurtado com uma distinta sutura transversa; pelos élitros estriados e pelas pernas longas e afiladas.

A subfamília Cicindelinae é formada pelos besouros conhecidos como tigerbeetles e corresponde a uma das maiores subfamílias de Carabidae com mais de 2300 espécies descritas (CASSOLA \& PEARSON, 2000).

O comprimento desses besouros varia muito, havendo espécies com aproximadamente $5 \mathrm{~mm}$, enquanto os maiores ultrapassam os $4 \mathrm{~cm}$. Há muitas espécies negras, mas outras apresentam um colorido brilhante e metálico, podendo ser verdes, azuis, vermelhas e amarelas. A maior parte das espécies tem o corpo alongado e pernas longas e finas, que permitem a estes besouros atingirem grandes velocidades; algumas espécies são tão velozes que precisam dar pequenas pausas entre as corridas para fazer correções visuais e continuar a perseguição de suas presas (GILBERT, 1997).

Uma vez que são caçadores visuais, alguns cicindelíneos possuem olhos tão grandes que tornam sua cabeça mais larga que seu tórax, principalmente entre as espécies diurnas.

Os adultos possuem asas membranosas funcionais, porém espécies braquípteras não são incomuns. A braquipteria entre os cicindelíneos ocorreu independentemente em muitos gêneros, provavelmente uma adaptação que favoreceu o mimetismo com formigas e conservou energia em ambientes onde o vôo não era necessário para a dispersão nem para escapar de predadores (WAGNER \& 
LEBHERR, 1992). Em alguns ambientes, tais como altas montanhas e ilhas, o vôo pode ser um problema, pois um vento mais forte pode arremessar 0 animal montanha abaixo, onde há condições muito diferentes das encontradas no topo, ou até mesmo no mar. Para Darlington (1943, 1971), outra causa para explicar a maior ocorrência de indivíduos braquípteros em locais montanhosos está no fato de que, se houver uma mudança drástica de temperatura, umidade ou ocorrer enchentes, estes animais precisam apenas percorrer curtas distâncias para cima ou para baixo para achar a condição ideal; já os indivíduos de planície precisam mover-se centenas ou milhares de quilômetros para norte ou sul para achar tal condição.

Suas mandíbulas são geralmente finas e longas, com o ápice encurvado para dentro; o número de dentes varia. Em algumas espécies as mandíbulas são usadas como órgãos copulatórios secundários: o macho fica sobre os élitros da fêmea e a segura inserindo suas mandíbulas em sulcos ou cavidades presentes no mesepisterno dessa. Tais ornamentações são conhecidas por coupling sulcus e geralmente estão ausentes nas espécies com hábitos crepuscular e noturno (PEARson \& Vogler, 2001).

Os cicindelíneos são um dos poucos grupos de besouros que os adultos possuem um tímpano auditivo (SPANGLER, 1988) e esta estrutura aparentemente apareceu independentemente de todos os outros tímpanos de insetos (PEARSON \& VOGLER, 2001). Os tímpanos estão localizados sobre o primeiro segmento abdominal, sob a base das asas membranosas e élitros. Durante o vôo, alguns cicindelíneos respondem a ultrassom contraindo seu abdome e caindo no solo (YAGER \& SPANGLER, 1995, 1997), talvez para evitar morcegos predadores, achar alimento (FowLER, 1987) ou localizar parceiros (PEARSON \& VOGLER, 2001).

Devido a seu peculiar modo de vida dentro de galerias no solo, as larvas dos cicindelíneos são bastante similares. Geralmente são brancas e enrugadas, com a maior parte da cutícula membranosa. Apenas a cápsula cefálica e placas torácicas são mais esclerosadas e deste modo mais escuras. Possuem uma cabeça grande com até seis estemas pequenos dorsais e grandes mandíbulas ventrais (PEARSON \& VOGLER, 2001). Uma das características mais distintas está presente no dorso do quinto segmento abdominal: dois grandes ganchos voltados para cima, que tem como função fixar o animal em sua galeria (PEARSON, 1988). As galerias, dependendo da espécie, podem estar em solo plano, em paredes de barrancos, em 
folhiço e em algumas espécies, até mesmo em madeira podre (PEARSON \& VOGLER, 2001). As larvas se posicionam de modo que a entrada da galeria fique completamente tampada por sua cabeça e pronoto e, devido à cor dessas partes serem muito similares ao substrato, são muito difíceis de serem localizadas. Quando a presa se encontra a uma distância suficiente, a larva se lança para trás e agarra a presa com suas fortes mandíbulas, levando-a para dentro do túnel onde é consumida.

Os Megacephalini são bastante parecidos com os outros cicindelíneos, porém distinguem-se pela diferença na forma da cabeça e do protórax, comprimento antenal (Vogler \& PEARSON, 1996), cabeça mais ou tão larga quanto o protórax e olhos menos protuberantes. Os gêneros são bastante distintos tanto pela cor quanto pela forma geral do corpo.

\subsection{Breve Histórico}

A classificação dos Cicindelinae começou no início do século XVIII quando Carolus Linnaeus descreveu nove espécies de Cicindela. Cinquenta anos mais tarde, Fabricius descreveu outras 69 espécies e as agrupou em 3 gêneros: Cicindela, Manticora e Collyris. No mesmo período, Dejean fez a primeira organização sistemática do grupo com 200 espécies.

Porém, a principal contribuição na sistemática dos tiger-beetles veio com o cientista Walther Horn, que organizou todas as espécies conhecidas até aproximadamente 1915, representando cerca da metade das espécies conhecidas atualmente (PEARSON \& VOGLER, 2001). Horn aceitou a maior parte dos agrupamentos sugeridos por cientistas anteriores, mas a principal novidade foi a separação dos cicindelíneos em dois grupos principais: Alocosternale (metasterno reduzido a uma faixa estreita) e Platysternale (metasterno como uma faixa larga e lisa); esses dois grandes grupos correspondem às duas grandes subfamílias atualmente conhecidas como Collyrinae e Cicindelinae. Um ponto polêmico em relação à classificação feita por Horn foi a incorporação de Cicindelidae na família Carabidae, alegando que não existia caracteres fortes o suficiente para garantir sua posição como família a parte. Muitos autores subseqüentes seguiram esta 
classificação, incluindo Crowson (1955), Reichardt (1977) e Lorenz (2005). Em 1942, Jeannel reestabeleceu o status de família quando dividiu Carabidae em 25 famílias distintas. Um dos autores que mais defendeu o status de família para o grupo foi Mandl (1971), listando muitos caracteres a favor deste agrupamento, destacando os parâmeros simétricos, característica exclusiva dos cicindelídeos. Mesmo após este trabalho, muitos autores não aceitaram tal proposta, sendo que alguns usaram o status de subfamília (Cicindelinae) (Crowson, 1955; REICHARDT, 1977; LORENZ, 2005; Bouchard et al., 2011), outros de tribo (Cicindelini) (MARTINEZ, 2005; LIEBHERR \& WILL, 1998) e até mesmo supertribo (Cicindelitae) (BALL, 1979 apud PEARSON, 1988; ERWIN \& SimS, 1984; ERWIN, 1998; 2007; ERWIN \& PEARSON, 2008).

Em seu catálogo de 1926, Horn incluiu Oxycheila Dejean, 1825, Pseudoxycheila Guérin, 1838, Cheiloxya Guérin, 1855 e Eucallia Guérin, 1844 (atual Callidema Guérin, 1843) em Megacephalina, totalizando seis gêneros válidos: Aniara Hope, 1838, Megacephala Latreille, 1802, Oxychila (sic.), Pseudoxychila (sic.), Chiloxia (sic) e Eucallia. Além disso, subdividiu Megacephala em vários grupos de espécies. Omus Eschscholtz, 1829, Amblychila (sic.) Say, 1830 e Pycnochila (sic.) Motschulsky, 1856 foram colocados na subtribo Omina e Platychila M'Leay, 1825 em Platychilina. A tribo Megacephalini continha todos esses grupos.

O segundo grande pilar na classificação dos Cicindelinae foi o trabalho de Emilie Rivalier, que em 1971 publicou um trabalho extenso sobre o grupo Cicindelini. Neste trabalho revisou alguns grupos estudados por Horn e fez algumas alterações, destacando a junção dos grupos Dromicina e Prothymina no grupo mais abrangente Prothymina.

Com o advento da Sistemática Filogenética e análises moleculares, novas propostas foram tomando forma. Vogler e Pearson (1996) propuseram uma filogenia com dados moleculares da família Cicindelidae. Foram utilizados 21 gêneros, totalizando 30 espécies. A subtribo Cicindelina aparece como grupo monofilético, porém Megacephalina, como polifilético.

Em 1997, Erik Arndt e Alexander Putchkov fizeram um estudo filogenético dos Cicindelinae (tratado como família) usando apenas caracteres morfológicos larvais. Nesse trabalho foram estudados 16 gêneros, quatro deles pertencentes à Megacephalini. Usando 32 caracteres, chegaram ao resultado de que a família não deveria ser dividida em subfamílias e que a tribo Megacephalini deveria ser dividida 
em várias tribos. Não é dito no trabalho quais foram as espécies examinadas, o que compromete sua validade. Nenhuma proposta taxonômica concreta foi tomada.

Apesar da grande concordância entre as duas análises citadas anteriormente, em 1998, Vogler \& Barraclough fizeram uma análise filogenética combinando os dados dos dois trabalhos anteriores, resultando em uma hipótese mais robusta. Cicindelina continua monofilético, enquanto é proposto que Megacephalina deveria ser subdividida em grupos menores.

Dentro da tribo Megacephalini, muitas mudanças já foram propostas. Autores mais antigos a consideravam como tribo (THOMSON, 1857; FLEUTIAUX, 1892; HORN, 1926; BLACKWELDER, 1945) e ainda são seguidos por alguns mais recentes, como Cassola (1997), Galian et al. (2002), Bouchard et al. (2011) e Ball et al. (2011); na maior parte dessas classificações a subtribo Megacephalina, menos inclusiva, faz parte do grupo. Recentemente o grupo tem sido mais frequentemente considerado apenas como subtribo Megacephalina, sendo que em algumas classificações mais gêneros são considerados como parte do grupo do que em outras (WEISNER, 1992; Bousquet \& LaRochelle, 1993; Zerm et al., 2007; ERWIn \& PeARSON, 2008).

Oxycheila, Pseudoxycheila e Cheiloxya são os gêneros que mais sofreram transições. Alguns autores consideram esses gêneros ou alguns deles como parte da tribo (FleutiauX, 1892; HORN, 1926; WeISNER, 1992; VogleR \& PEARSON, 1996; CASSOLA, 1997; LORENZ, 2005; BOUCHARD et al., 2011) e outros fora da tribo (ZERM et. al., 2007). Alguns autores consideram tais gêneros mais relacionados aos Cicindelini do que com os Megacephalini (GALIAN et. al., 2002; VoGLER et al., 2007) e para outros atores eles explicitamente fazem parte de Cicindelini (VoGLER \& BarRaclough, 1998; PutChKov \& ARNDT, 1996).

Os gêneros Amblycheila, Platychile, Omus e Picnochile também parecem formar um grupo, que muitas vezes foi colocado dentro de Megacephalini (HoRN, 1926; LORENZ, 2005) ou fora da tribo, como proposto por Thomson (1857), que juntou-os com o gênero africano Manticora, formando a tribo Manticorites, e Ball et al. (2011), que usa a tribo Amblycheilini para incluir os gêneros Amblycheila, Omus e Picnochile; nesse trabalho é sugerido colocar Platychile em um grupo à parte por conter características tanto de Amblycheilini quanto de Megacephalini. 


\subsection{0 grande grupo Megacephala Latreille, 1802}

Até 1892 existiu um grande gênero denominado Megacephala. Este gênero abrangia diversas espécies de megacefalíneos que ocorriam nas Américas, Austrália e África. Neste ano, Fleutiaux dividiu este grande gênero em gêneros menores, deixando a tribo Megacephalini com cinco gêneros válidos: Aniara, Megacephala, Phaeoxantha Chaudoir, 1850, Tetracha Hope, 1838 e Metriocheila Thomson, 1857. Um dos problemas encontrados nesta classificação foi em relação à distribuição geográfica: havia espécies americanas, australianas e um representante paleártico (T. euphratica Dejean, 1822) no gênero predominantemente americano Tetracha e um representante australiano no gênero Megacephala, que tinha representantes africanos em quase sua totalidade (M. cylindrica M'Lay, 1863).

Em 1894, Fleutiaux criou o gênero Pseudotetracha para algumas espécies australianas de Tetracha de seu catálogo anterior; outras australianas permaneceram no antigo gênero.

Em seu trabalho de 1906, Sloane não concordou com Fleutiaux e colocou todas as espécies dentro de Megacephala novamente, sinonimizando Tetracha e Pseudotetracha em Megacephala.

Horn, em 1926, dividiu Megacephala em 13 grupos de espécies, sendo que o grupo Megacephala ficou restrito à região africana (também seguido por Basilewsky 1966), Pseudotetracha à região australiana e Tetracha às Américas.

Sumlin (1992) criou o subgênero Australicapitona para incluir algumas espécies de Pseudotetracha.

Weisner, em sua checklist mundial de 1992, continuou considerando Megacephala como o grande grupo original contendo os subgêneros: Megacephala Latreille, 1802, Metriocheila Thomson, 1857, Grammognatha Motschoulsky, 1850, Phaeoxantha Chaudoir, 1850, Pseudotetracha Fleutiaux, 1894 e Tetracha Westwood, 1838. O subgênero Australicapitona Sumlin, 1992 não aparece no catálogo devido a sua publicação ter acontecido no mesmo ano.

Em 1999, Pearson e colaboradores elevam Tetracha, Phaeoxantha e Metriocheila ao nível de gênero. 
Em 2005, Lorenz publicou outra lista mundial e não segue a classificação proposta por Pearson em 1999. Manteve os gêneros e subgêneros considerados por Weisner, adicionando agora o subgênero Australicapitona.

Em 2007, Roger Naviaux publicou a revisão do gênero Tetracha e propos a elevação dos seguintes subgêneros a gênero: Grammognatha, Phaeoxantha, Metriocheila, Tetracha, Pseudotetracha e Australicapitona. Neste mesmo trabalho, o autor descreve 33 nomes novos entre espécies e subespécies de Tetracha, totalizando 110 nomes. O autor também sugeriu a existência de problemas no gênero Phaeoxantha, que foram abordados um ano depois e sintetizados a seguir: a espécie tipo deste gênero foi descrita por Perty em 1830 com o nome de Megacephala laminata, porém no mesmo ano, Perty mudou o nome para Megacephala limata. Os autores subseqüentes usaram o nome $P$. laminata erroneamente para nomear exemplares das espécies $P$. nocturna Dejean, 1831 e $P$. epipleuralis Horn, 1923, que realmente a olho nu são parecidas com a espécie tipo. Com uma análise mais cuidadosa sob lupa, foi possível notar que os espécimens de $P$. laminata apresentam rugosidade elitral e pronotal muito mais aparente do que a apresentada nas outras duas espécies. As três espécies foram então redescritas e comparadas por Naviaux (2008).

\section{OBJETIVOS}

Este projeto teve como objetivo principal fazer uma análise cladística de Megacephalini visando testar o monofiletismo da tribo e estabelecer as relações entre as subtribos e gêneros. 


\section{MATERIAL E MÉTODOS}

\subsection{Taxonomia adotada no presente estudo}

Neste projeto o grupo mais amplo será tratado como subfamília de Carabidae (Cicindelinae) e o principal grupo de estudo como tribo Megacephalini. A tribo será considerada a priori com o maior número possível de gêneros nela já incluídos por formar um grupo mais inclusivo e mais interessante para um estudo investigativo. Os gêneros são os seguintes (dados combinados de HORN, 1926; LORENZ, 2005 e NAVIAUX, 2007):

- Amblycheila Say, 1830 com 7 espécies (Estados Unidos)

- Aniara Hope, 1838, monotípico (América do Sul e Central)

- Australicapitona Sumlin, 1992 com 8 espécies (Austrália)

- Callidema Guérin, 1843, monotípico (América do Sul)

- Cheiloxya Guérin, 1855 com duas espécies (América do Sul)

- Grammognatha Motchulsky, 1850, monotípico (Região Paleártica e Mediterrânea)

- Megacephala Latreille, 1802 com 12 espécies (África)

- Metriocheila Thomson, 1857, monotípico (América do Sul)

- Omus Eschscholtz, 1829 com 16 espécies (América do Norte)

- Oxycheila Dejean, 1825 com 31 espécies (América do Sul e Central)

- Phaeoxantha Chaudoir, 1850 com 12 espécies (América do Sul)

- Picnochile Motschulsky, 1856, monotípico (sul da América do Sul)

- Platychile M'Leay, 1825, monotípico (África)

- Pseudotetracha Fleutiaux, 1894 com 17 espécies (Austrália)

- Pseudoxycheila Guérin, 1838 com 21 espécies (América do Sul e Central)

- Tetracha Hope, 1838 com 94 espécies (Américas) 


\subsection{Material examinado}

Os espécimes analisados neste trabalho pertencem a sete coleções citadas a seguir, com acrônimos usados por Evenhuis (2009), com o nome dos curadores entre parênteses:

- AMSA - Australian Museum, Sydney: (David R. Britton);

- DEIC - Senckenberg Deutsches Entomologisches Institut, Müncheberg: (Stephan M. Blank);

- FIOC - Fundação Instituto Oswaldo Cruz ,Rio de Janeiro: (Ayr Belo);

- LACM - Los Angeles County Museum of Natural History, Los Angeles: (Weiping Xei);

- MNRJ - Museu Nacional [da Universidade Federal] do Rio de Janeiro, Rio de Janeiro: (Marcela L. Monné);

- MPEG - Museu Paraense Emílio Goeldi, Belém: (Orlando T. Silveira);

- MZSP - Museu de Zoologia da Universidade de São Paulo ,São Paulo: (Sônia A. Casari);

- NMNH - National Museum of Natural History, Washington, DC: (Terry Erwin).

Dos museus citados acima, os seguintes foram visitados para estudo de material: FIOC, MNRJ, MPEG; MZSP e NMNH.

As coleções das seguintes instituições foram visitadas, porém o material não foi utilizado diretamente na tese: AMNH (American Museum of Natural History, Nova lorque) e FMNH (Field Museum of Natural History, Chicago).

Poucos espécimes tipos foram vistos, porém a maior parte do material estudado foi identificada pelos principais pesquisadores de cada grupo, muitas vezes os autores das últimas revisões.

Segue abaixo a lista do material examinado neste trabalho, com países (letras maiúsculas) e estados ou províncias (sublinhados) seguindo a ordem nortesul e cidades e localidades específicas por ordem alfabética:

Amblycheila cylindriformis Say, 1823 (fig. 1E): ESTADOS UNIDOS DA AMÉRICA - Colorado: Las Animas Co., Model (Pinon Canyon, Manuver Site), Pollock det. 


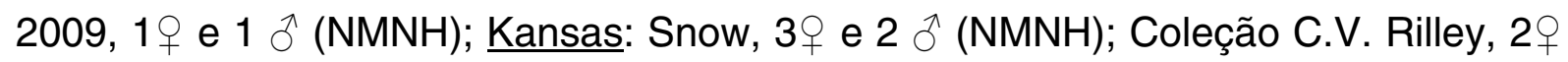
e $1 \hat{\delta}(\mathrm{NMNH})$; Collection J.B. Smith, $1 \hat{\sigma}(\mathrm{NMNH})$; Wallace Co., 2 (NMNH); Wallace, 1 ㅇ e $1 \hat{\delta}(\mathrm{NMNH})$. Texas: Plum Creek, Pullock det. 2009, 4우, 10 e $1 \mathrm{ex}$. (NMNH). New Mexico: Quay Co., 1.7mi E, 1.3mi N Tucumcari, 4100', 6 ? (NMNH).

Amblycheila picolominiii Reiche 1839 (fig. 1F): ESTADOS UNIDOS DA AMÉRICA - Utah: Captive - espécime parental de St. Geo., criado em laboratório, $1 \hat{\delta}(\mathrm{NMNH})$. New Mexico: Roswell, 10 (NMNH). Arizona: Kayenta, 10 (NMNH); 20 mi E de Tuba

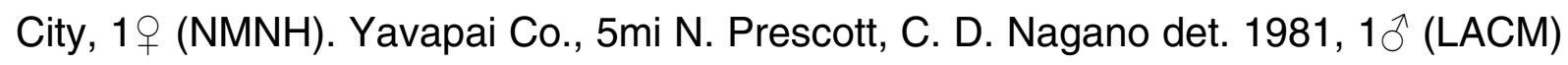
(ilustrado); Yavapai Co., Prescott, R. Willis, 3 + $(\mathrm{NMNH})$.

Aniara sepuchralis (Fabricius 1801) (fig. 3A): TRINIDAD - Erin Savannah, BWI, $1{ }^{\Uparrow}$ (NMNH). GUIANA - Cuyuni-Mazaruni: Bartica, 1 ㅇ (NMNH). Upper DemeraraBerbice: Aramatani Creek (Dubulay Ranch), 1 우 (NMNH). East Demerara-West Coast: $10 \mathrm{~km} S$ Georgetown, $2 \hat{\jmath}$ e 1ex. (NMNH). Mazaruni-Potaru: Kartabo Piont, $2 \hat{\jmath}$ (NMNH); W.E. Steiner det., $2 \circ$ e $3 \hat{0}(\mathrm{NMNH}) ;$ Kartabo, $1 \hat{\jmath}(\mathrm{NMNH})$. GUIANA FRANCESA - 1 q e 1ex. (MZSP); Cayenne (4.9333, -52.3333), 1ㅇ (FIOC). VENEZUELA - Monagas: 42km S.E. Maturin (9.7500, -63.1767), W.D. Sumlin det. 71, 2 + e $3 \hat{\jmath}$ (LACM). BRASIL - (Alto Rio Wapes), $1 \hat{\jmath}$ (NMNH). Roraima: Porto Velho (Guaporé), $1 \hat{\circ}$ (MNRJ); Surumu, 19 e $3 \hat{\circ}$ (MZSP). Amapá: Macapá, $1 \hat{\delta}$ (NMNH); Oiapoque (3.8333, -51.8333), 19 e $2 \hat{O}$ (MNRJ). Pará: 2 (NMNH); (Rio

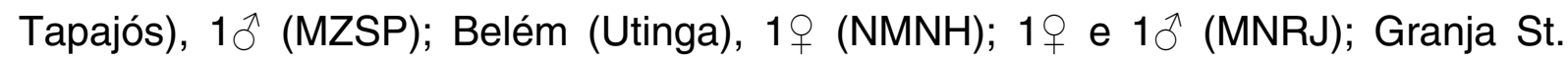
Hort., $1 \hat{\delta}$ (MZSP); km 90 F S Antonio, 1ex. e 19 det. T.L. Erwin (NMNH); Canindé

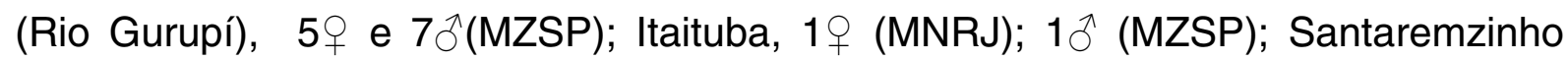
(Rio Tapajós), 4우 e 2ત (MZSP); Mocajuba (Mangabeira -2.5500, -49.5833), 1 (MNRJ); Óbidos, 19 e $1 \hat{\delta}$ (MNRJ); Colônia Rio Branco, $1 \hat{\jmath}$ (MNRJ); Traira, $2 \hat{}$ (MZSP); Santarém (Fazenda Taperinha), 19 e $4 q$ (MZSP). Amazonas: Barcelos (Rio Negro -1.0000, -62.9667), F. Zikán det, 1ð (MNRJ); Jauareté, 19 (MZSP); Joazeiro, 1914, Esatol [ilegível], $2 \hat{\jmath}$ (MZSP); Manaus, 5ㅇ, $1 \hat{0}$ e 1 ex. (MNRJ); (3.1133, -60.0253), Zellibor det., 2 e e $1 \delta^{\lambda}$ (MNRJ); (Reserva Ducke), $25 \mathrm{~km}$ E Manaus,

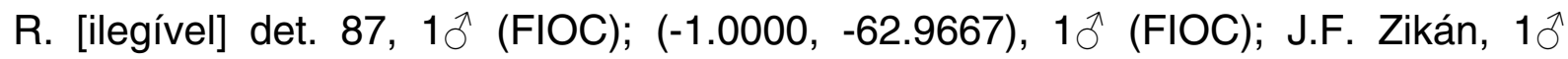
(MZSP); (Rio Tiquié), 1 ㅇ e $1 \AA$ (MNRJ); Parintins, Dr. W. Horn det. 1983, 1 ㅇ e $1 \delta^{\lambda}$ (MZSP); São Gabriel (-0.1333, -67.0833), J.F. Zikán det., 19 e $1 \hat{0}$ (MNRJ); 
Tapuruquara, $1 \hat{\delta}$ (MZSP); Taracuá (Rio Uaupés), $1 q$ e $2 \hat{\jmath}$ (MZSP); Uaupés, $2 q$ e $2 \hat{\jmath}$ (MNRJ). Bahia: Joazeiro, $1 \hat{\jmath}$ (MZSP) (asa e élitro fotografados). Rio de Janeiro: Itatiaia, $2 \hat{\jmath}$ (FIOC). Sem localidade - $1 \hat{\jmath}$ (MZSP).

Australicapitona basalis (M'Lay 1866) (fig. 4D): [AUSTRÁLIA] - [Queensland]: Cape York, $1 \hat{\delta}$ (DEIC). [Western Australia]: Nickol Bay, 1 (DEIC). Sem localidade Coleção Hacker, $1{ }^{\AA}$ (DEIC); Dr. O Nickerl, P. Denison [ilegível], Odewalm [ilegível], 1 (DEIC).

Callidema boussingaultii Guérin, 1843 (fig. 6B): EQUADOR - 10 (DEIC) e 1 우 (MZSP); (Cordellera del Quindio), 1 ㅇ (DEIC); Labuvel (Ant.) [ilegível], R.E. Acciavatti det. 2005, 1 ㅇ e $1 \hat{\delta}$ (NMNH). Loja Ostcordill., $1 \hat{\jmath}$ (DEIC). Napo: Archidona, 1 (DEIC). COLOMBIA - Provincia de Loja: 1 + (FIOC); $5 \mathrm{~km}$ S Saraguro (3039'S, 79018'W), D. L. Pearson det. 1997, 1 ㅇ e $1{ }^{\wedge}$ (LACM).

Calosoma granulatum (Perty, 1830) (fig. 6A): BRASIL - Bahia: Juquié, Reichardt det. 1969, 1 ( (MZSP). Distrito Federal: Campo Grande, 10 (MZSP). Espírito Santo: Santa Teresa, 1 + (MZSP). Rio de Janeiro: 1 i (MZSP). São Paulo: Garça, 1 ㅇ e $10^{\Uparrow}$ (MZSP); Ilha Solteira (Pomar UNESP), $1 \delta^{\hat{\gamma}}$ (MZSP); Indiana, 1 + (MZSP); Itú (Fazenda Pau d'Alho), Reichardt det. 1968, 1 (MZSP); Limeira, 29 (MZSP); Pindamonhangaba, Reichardt det. 1968, 19 (MZSP); Pirassununga (Emas), $1 \sigma^{\Uparrow}$ (MZSP); Presidente Epitácio, 1 (MZSP); Ribeirão Preto (Faculdade de Medicina), $3 \uparrow$ e $3 \hat{\jmath}$ (MZSP); Rio Preto, 19 (MZSP). Mato Grosso do Sul: Dourados, M. Jorge det. 1982, 10 (MZSP). Santa Catarina: Nova Teutônia [Seara], 1 (MZSP). Rio Grande do Sul: Canoas, $3 \hat{\circ}$ (MZSP); Porto Alegre, 29 (MZSP). ARGENTINA Buenos Aires: Villa Balester, 19 (MZSP).

Cheiloxya binotata Castelnau, 1833 (fig. 2D): VENEZUELA - 10 (FIOC); $1 \hat{\delta}$ (NMNH); $1 \widehat{\overbrace{}}$ (MZSP); (Cerro de La Neblina, Basecamp, 140m., banco do Rio Baria 0050'N 66010'W), 1 个 e 1 ㅇ (NMNH). EQUADOR - Departamento de Sucumbios: (Sacha Lodge $0.5^{\circ} \mathrm{S}, 76.5^{\circ} \mathrm{O}$ ), 290m, 1 + e $10^{\Uparrow}$ (LACM). Departamento de Napo: Pano, $1 \hat{\jmath}(\mathrm{NMNH})$. BRASIL - Amapá: Mazagão (-0.1167, -51.2833), 1 + (MNRJ). PERU - (Rio Ucayali), $1 \hat{\jmath}$ e 19 (NMNH); Santa Cecília, $2 \circ$ e $1 \hat{\jmath}(\mathrm{NMNH}) ;$ D.L. 


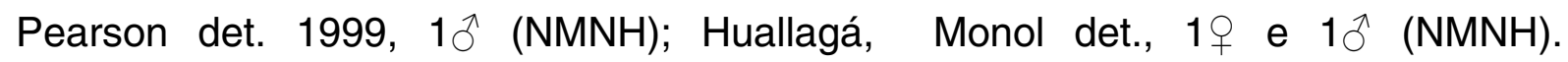
Cajamarca: Barr. det. 1925, 2 + e $1 \delta^{\Uparrow}$ (NMNH); Lima: Lima, 4 ( Dios: Madre de Dios (70058'W 12007'S), D.L. Pearson det. 1992, 1 ( Marcapata, W.D. Sumlin det. 1971, $1 \uparrow$ (LACM). Junin: Sanibeni, $1 \uparrow$ e $1 \hat{\jmath}(\mathrm{NMNH})$.

Cicindela campestris L., 1758 (fig. 6F): DINAMARCA - North Seeland: 10 (NMNH). Ribe Amt: Oksby, (55.5500, 8.1500), 2 (LACM). ALEMANHA - 2 + (LACM); ReitimWinky, C.S. Papp det., 1ㅇ (NHM). Land Brandenburg: Eberswalde, 15 e $7 \hat{\delta}(\mathrm{NMNH})$. Land Rheinland-Pfalz: Kaiserslautern, C.D. Nagano det. 1979, 1 ( (LACM). FRANÇA - Ile-de-France: Seine \& Marne (Fontainebleau), 14 e e $7 \hat{\jmath}$ (NMNH). Provence-Alpes-Cote d'Azur: Vaucluse (Mt. Ventoux), 23ㅇ e $16 \hat{\jmath}(\mathrm{NMNH})$.

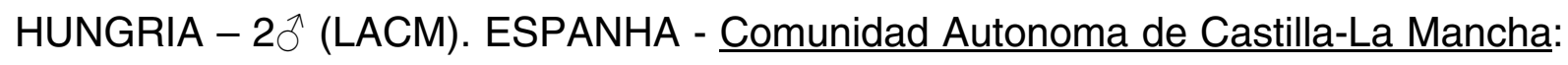
Toledo, 1 ㅇ (NMNH). Sem localidade - Seegatter 2, Einlass, C.S. PAPP det., 1 ㅇ e $1{ }^{\lambda}$ (LACM) ; Alx Bach Tal., C.S. Papp det., 1 ํ e $1 \hat{\jmath}$ (LACM) ; Europe, ex C J S B, Wickham Collection, 1 đ (NMNH).

Cicindela hybrida L., 1858 (fig. 7A): RÚSSIA - Libau, 3ڤ (NMNH). DINAMACA Ribe Amt: Henne, $(55.7333,8.2500), 2 \AA$ (LACM). ALEMANHA - Niedersachsen: Calle (52.7833, 9.0833), C.D. Nagano det 1979, 1 ㅇ (LACM). Land Brandenburg: Bernau Berlin, 1 ㅇ (NMNH). Rheinland-Pfalz: Kaiserslautern (49.4500, 7.7500), C.D.

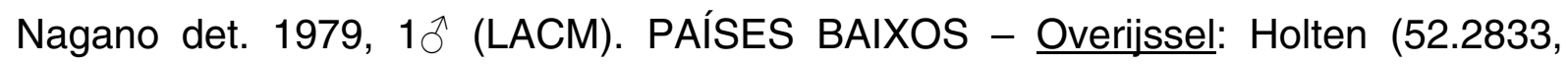
6.4333), C.V. Nidek det. 1976, 2 + (LACM). BÉLGICA - West-Vlaanderen: La Panne, 2 ( de-France: Seine \& Marne (Fontainebleau), $25 \circ$ e $11 \hat{\jmath}$ (NMNH); Bouray (SeineOisc), $3 q$ e $1 \hat{\jmath}(\mathrm{NMNH})$. Bretagne: Loperhet, 19 (NMNH). Languedoc-Roussillon: Aude (Axat), $1 \hat{\delta}(\mathrm{NMNH})$. HUNGRIA - 10 (LACM). ESPANHA - Comunidad Autonoma de Cataluna: Ripoll, 1 + e $5 \hat{\delta}(\mathrm{NMNH})$. Sem localidade - C.D. Nagano det. 1980, 1 ㅇ (LACM); rótulo em japonês, 1 ऊ (LACM).

Ctenostoma formicarium (F., 1801) (fig. 6E): GUIANA FRANCESA - Cayenne: Cayenne, $1 \delta^{\lambda}$ (DEIC); R. Naviaux det. 1998, 1 ㅇ e $1 \delta^{\Uparrow}$ (DEIC). BRASIL - Pará: Óbidos, R. Naviaux det. 2002, 2 (MNRJ). Rio de Janeiro: R. Naviaux det. 1998, $1 \delta^{\Uparrow}$ (DEIC). 
Ctenostoma unifasciatum Dejean, 1831 (fig. 6D): BRASIL - Minas Gerais: Fragoso det. 1953, 20 (MNRJ); Passa Quatro, Dr. W. Horn det. 1928, 2 + (LACM); Rio de Janeiro: Itatiaia, $1 \hat{\jmath}$ (MNRJ); Tijuca, R. Naviaux det. 2002, 2 e e $2 \hat{\gamma}$ (MNRJ). São Paulo: Guanabara (Represa Rio Grande), R. Naviaux det. 2002, 1 i (MNRJ); Peruíbe, 1 ( (MNRJ); São Paulo (Cantareira), Dr. W. Horn det. 1938, 1 (MNRJ); Dr. W. Horn det. 1938, $1 \overbrace{}^{\Uparrow}$ (MNRJ).

Cylindera nivea (Kirby, 1818) (fig. 7B): URUGUAI - Montevideo: Carrasco, $2 q$ e $1 \hat{\jmath}(\mathrm{NMNH}) ;$ Montevideo, 1 + e $2 \hat{\jmath}$ (LACM). Cerro Largo: Buena Vista (Rocha Cerro, dunas do mar) $2 \circ$ e e $2 \hat{\jmath}$ (NMNH); Cabo (Rocha Cerro), 5 ㅇ e $6 \hat{\jmath}$ (NMNH).

Euprosopus chaudoiri Thomson, 1859 (fig. 7D): BRASIL - Minas Geraes [Minas Gerais]: W. Horn det. 1921, $1 \hat{\delta}(\mathrm{NMNH})$. Espírito Santo: 19 e $2 \hat{\delta}$ (DEIC) e $1 \delta^{\lambda}$

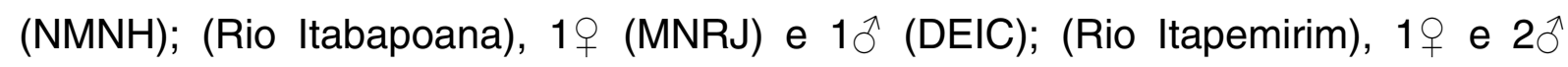
(MNRJ); Palmital, (-21.1166667, -41.1000), J.F. Zikán det., 10 (MNRJ). Rio de Janeiro: Rio de Janeiro (Corcovado), 1 ( (MNRJ). Santa Catarina: 10 (NMNH).

Euprosopus quadrinotatus (Dejean, 1822) (fig. 7C): BRASIL - F. Zinkan col., $1 \delta^{\lambda}$

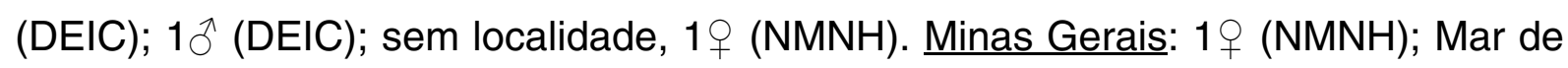
Espanha, $2 q$ (DEIC). Rio de Janeiro: Parque Nacional do Itatiaia, $3 \hat{0}$ (MNRJ). América do Sul, 1 + $(\mathrm{NMNH})$.

Grammognatha euphratica (Dejean, 1822) (fig. 5D): ESPANHA - Cartagena, $1 q$

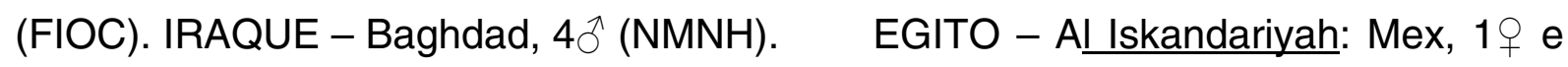
1 र (NMNH) e 1 ㅇ (MNRJ). Al Qahirah: El Gedida (Dakhla Oasis), 19 (NMNH); Helouan, 1 ㅇ (MNRJ). Fayyum: (Lake Qarun), 23ㅇ e 15^ (NMNH). New Valley Governorate: Dakhla Oasis, $12 \circ$ e $16 \hat{\jmath}$ (NMNH).

Manticora tuberculata (DeGeer, 1778) (fig. 1D): ÁFRICA DO SUL - [Limpopo]: Potgietersus, $1 \hat{\jmath}(\mathrm{NMNH})$. [Eastern Cape]: Grahamstown, 1 우 e $3 \hat{0}(\mathrm{NMNH})$. [Western Cape]: Calitzdorp, C.R. Owen det. 2002, 1 \% e $1 \hat{\delta}$ (NMNH). [Cape Province]: Cape Col[ony], $1 \hat{0}$ (DEIC); Cape Colony, $1 \hat{\jmath}$ (NMNH). [Sem estado], 


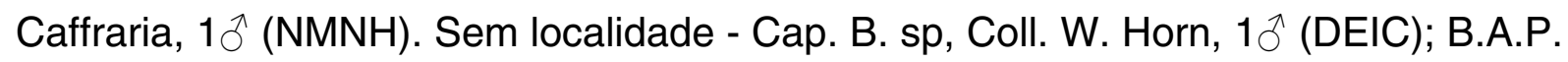
van Dam, Faugesmith, Coleção W. Horn, 10 (DEIC); Coleção W. Horn, 1 + (DEIC); Caffavi [ilegível], Coleção J. F. Zikan, 1 (q (FIOC).

Megacephala bocandei Guérin, 1848 (fig. 5F): NIGÉRIA - [East-Central]: Olokemeji, Basilewsky det. 1967, 1 + (NMNH). GUINEA - P. Basilewsky det. 1964, $1{ }^{\lambda}$ (DEIC). Sem localidade - Type Gerrin Men, ex coll Yoklt[?], DEI Berlin, Syntypus, Coll W. Horn, DEI Eberswalde, DEI Müncheberg Col - 01822, Megacephala bocandei Guèr. P. Basilewsky det. 1964, 1 ( (DEIC); Caja manea[?], Coll. V. dePoll, type!, Coll. W. Horn, DEI Berlin, Coll W. Horn, DEI Eberswalde, DEI Müncheberg Col - 01824, syntypus, Megacephala bocandei Guèr. P. Basilewsky det. 1964, $1{ }^{\Uparrow}$ (DEIC).

Megacephala megacephala (Olivier, 1790) (fig. 5E): SENEGAL - P. Basilewsky det. 1964, 1ex. (NMNH). NIGÉRIA - Kwara: Shagunnu, J.R. Mandsk [ilegível], 1 ex. (NMNH). Sem localidade - Obere Volta [ilegível], Pundo. Ol.[ilegível], P. Basilewsky det., 19 e $1 \hat{\jmath}$ (DEIC); P. Basilewsky det., $1 \hat{\jmath}$ (DEIC); Trarza Manvitavien [ilegível], P. Basilewsky det., 1 ㅇ (DEIC).

Metriocheila nigricollis (Reiche, 1842) (fig. 5B): PANAMÁ - Canal Zone: Madden Dam, 19 (LACM). EQUADOR - $1 \hat{\delta}$ (FIOC). Napo: Tena (Rio Napo) 2 우 (NMNH); Archidona (Rio Misahualli) 1 iq (NMNH). PERU - Loreto: Tarapoto (-2.1833, 74.1000), C.S.Papp det., 2 e e $1 ð$ (LACM). Cajamarca: Llangua Riv.?? [ilegível], $1+$ e $1 \hat{\delta}(\mathrm{NMNH})$. San Martin: $1 \hat{\delta}(\mathrm{NMNH})$. Huanuco: (Leonpampa region), 20 e $1 \hat{\delta}$ (NMNH); Tingo Maria, $2 \circ$ e $2 \hat{\AA}(\mathrm{NMNH})$. Pasco: Chuchurras (-10.1000, -75.1500), C.S.Papp det., 1 ㅇ (LACM). Madre de Dios: (perto de Salvacion), 1 우 (NMNH); Marcapata, C.S.Papp det., 19 (LACM). Junin: La Marced [Chachamayo], $2 q$ (NMNH); Sani Beni, 3q (NMNH). Cusco: (Pilcopata), 1ex. (NMNH); Quincemil, R.D. Ward det.1986, 1 ( $(\mathrm{NMNH})$. Ica: Chanchamayo (-13.7000, -75.8000), 2 q e $1 \delta^{\hat{0}}$ (LACM); (Valle Chanchamayo), 1우 (FIOC); Quiroz (Rio Paucartambo -12.0500, 76.9833), 1 ( (LACM). BOLÍVIA - (Rio Colorado), 4 q (NMNH); Huachi (Rio Beni), 1 + e $1 \delta^{\Uparrow}(\mathrm{NMNH})$ (usei o $\left.{ }^{\Uparrow}\right)$. ARGENTINA - Jujuy: Quemado, Dr. W. Horn DET. 1935, 


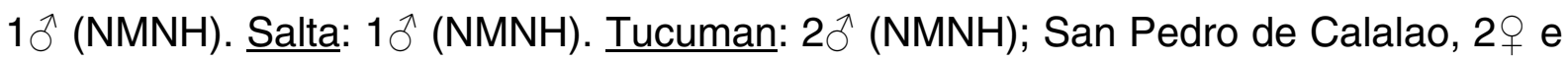
10 (NMNH).

Odontocheila cayennensis (F., 1787) (fig. 7E): VENEZUELA - Bolivar: Suapure (Rio Caura), $5 \circ$ e $6 \hat{0}$ (NMNH). BRASIL - Rondônia: (Fazenda Rancho Grande,

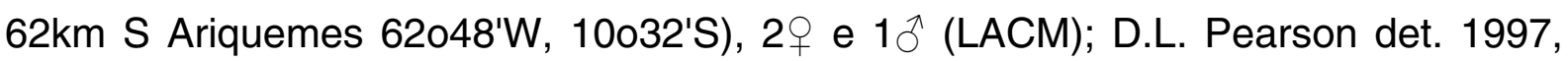

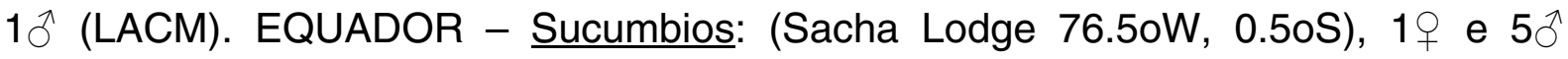
(LACM). Napo: (Yasuni Biological Reserve 76.39oW, 0.67oS), $1 \delta^{\Uparrow}$ (LACM); D.L. Pearson det. 1997, 10 (LACM). Pastaza: (Kapawi Lodge 76.82oW, 2.55oS), $2{ }^{\Uparrow}$ (LACM). PERU - Loreto: (2km acima do Rio Napo, 160km NE lquitos); $2 \AA$ (NMNH); (Rio Amazonas), $1 \hat{\jmath}$ (LACM); Tarapoto, (-2.1833, -74.1000), $1 \hat{\delta}$ (LACM); Yamamono (60km E. Iquitos), D.L. Pearson det. 1997, $10^{\Uparrow}$ (LACM). Huanuco: Tingo Maria (-9.3000, -75.9833), 1 ㅇ e $10^{\Uparrow}$ (LACM). Pasco: Chuchurras (-10.1000, 75.1500), 3 (LACM); Oxapampa (-10.5667, -75.4000), 2 + e 1 ( Azucar, 1 (으 (LACM). Madre de Dios: (Zona Reserva Manu, Pakitza), 6 ㅇ e 5 ${ }^{\lambda}$ (NMNH) (um $\widehat{O}$ foto). Arequipa: Sani, Beni, Yunin, 1 ㅇ (NMNH).

Odontocheila nodicornis (Dejean, 1825) (fig. 7F): BRASIL - Espírito Santo: R.E. Acciavatti det., $1 \widehat{\delta}(\mathrm{NMNH})$. Rio de Janeiro: (Serra da Carioca), $10(\mathrm{NMNH})$; Nova Friburgo, 19 e $2 \hat{\jmath}$ (NMNH); Itatiaia, 19 (MZSP); Petrópolis, R.E. Acciavatti det, $3 \propto$ e $1 \hat{\delta}(\mathrm{NMNH}) ;$ Rio de Janeiro, R.E. Acciavatti det., 7ð (NMNH). São Paulo: W. Horn det., 10 (MZSP); Avanhandava, 19 (MZSP); Franca, 19 (MZSP); Guarujá (Ilha

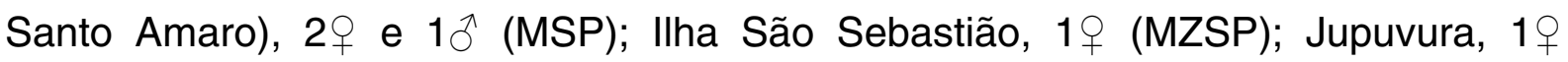
(MZSP); Juquia, 1 (MZSP); [Paranapiacaba], Estação A[lto] da S[erra], 1 (MZSP);

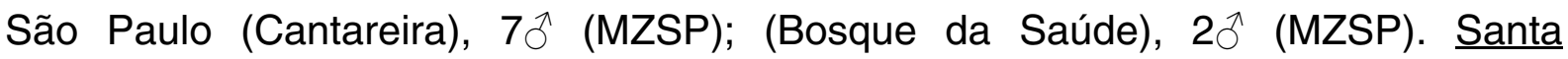
Catarina: Blumenau, W. Horn det., 19 e $3 \hat{\jmath}$ (MZSP); Brusque, $3 q$ e $2 \hat{\jmath}$ (MZSP); Joinvile, W. Horn det., 1 ㅇ e $2 \widehat{\jmath}$ (MZSP); (Rio Bracinho), 1우 (MZSP); Teresópolis, 1 ㅇ (NMNH).

Omus californicus Eschscholtz, 1829 (fig. 1C): ESTADOS UNIDOS DA AMÉRICA - Washington: 1 ㅇ (NMNH). Oregon: Benton Co., Philomat, 10 (NMNH). Califórnia: Mission Hill[s], 19 (NMNH); Monlety, $1 \hat{\jmath}(\mathrm{NMNH})$; Mendl.[?] Co, Casper, $3 \propto$ e $2 \hat{\jmath}$ (NMNH); [Alameda Co.], Alameda, 1 e e $1 \hat{\jmath}$ (NMNH); Berkeley, 1 우 (NMNH); 
Oakland, C.D. Nagano det. 1981, 1 (LACM); San Francisco Co., 1우 10 e $1 \mathrm{ex}$.

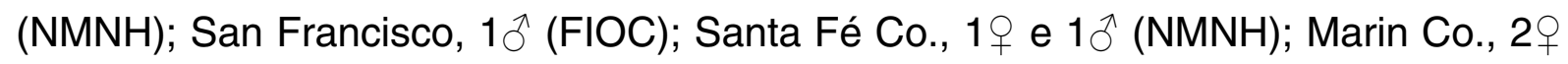
(NMNH); Napa Co, (Mt. St. Helena], 1 ( $(\mathrm{NMNH}) ;($ Spring Mountain), $2 \widehat{\jmath}(\mathrm{NMNH})$; Somona Co., 19 e $1 \hat{\jmath}$ (NMNH); [Monterey Co.], Carmel, 1 i (NMNH); Mendocino Co., 1 ㅇ (NMNH); Calaveras Co., West Point, 1 ㅇ (LACM); Eldorado Co., W.D. Sumlin

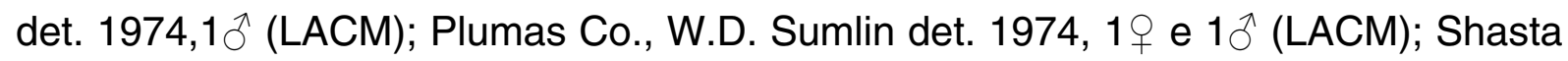
Co., Squaw Creek, 1 ( (LACM). Alabama: [Cherokee Co.], Ara.[?] Co., Piedmont, $1{ }^{\lambda}$ e 2ex. (NMNH) (edeago). Sem localidade - dry sequoia, C. D. Nagano det.1981, $1 \delta^{\lambda}$ e 1ex. (MZSP); Stanford University, W.D. Sumlin det. 1974, 1 우 (LACM); 1 우 e $1 \delta^{\lambda}$ (NMNH).

Omus dejeani Reiche, 1838 (fig. 1B): ESTADOS UNIDOS DA AMÉRICA -

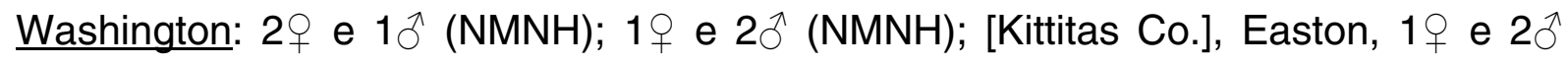
(NMNH); [Clark Co.],Vancouver (Victoria), 1q (NMNH); [Pacific Co.], Ilwaco, 1 t $(\mathrm{NMNH})$; [King Co.], Seattle, $1 \hat{\gamma}(\mathrm{NMNH})$; [Pierce Co.], Tacoma, $2 \hat{0}(\mathrm{NMNH})$. Oregon: $2 \hat{\delta}$ (FIOC); 5 우 e $2 \hat{\jmath}$ (NMNH); Vancouver (Indian River), $1 \hat{\jmath}(\mathrm{NMNH})$; [Benton Co.], Corvallis, $1 \hat{\jmath}$ (NMNH); [Clackamas Co.], Colton, $2 \hat{\jmath}(\mathrm{NMNH})$; Clatsop Co., (Montanha Saddle 2500-3280m), E.M. Fisher det. 1970, 1 \% (LACM); [Lane Co.], Florence (43.9828, -124.0986), 2 (LACM); [Lincoln Co.], Newport, $1 \hat{\jmath}$ (NMNH);

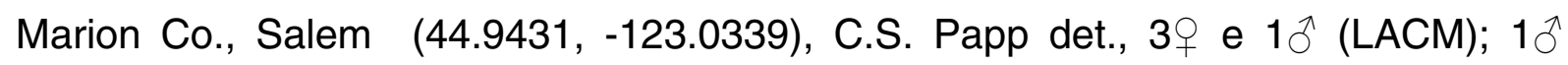
(NMNH); [Multnomah Co.], Potland, 1 ㅇ (NHMNH); Washington Co., (North Plains) (45.5972, -122.9922), 1 ㅇ e $2 \AA$ (LACM); Dilley, 1 ๙ (NMNH).

Oxycheila labiata Brullé, 1837 (fig. 2B): BRASIL - Mato Grosso: Rosário Oeste, (14.8333, -56.4167), 1 e e $1 \hat{\delta}$ (MNRJ). Bahia: Encruzilhada, Motel da Divisa, Estr.

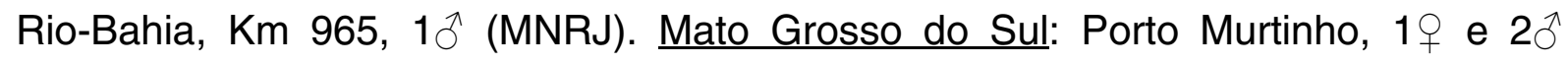
(FIOC); Salobra, 19 e $1 \hat{\jmath}$ (FIOC); Dr. W. Horn det., 1 + e $5 \hat{\jmath}$ (MZSP); J. Weisner det. 1998, 1 + (DEIC). Minas Gerais: Vilarrica, Sertão de Diamantina, Fazenda das

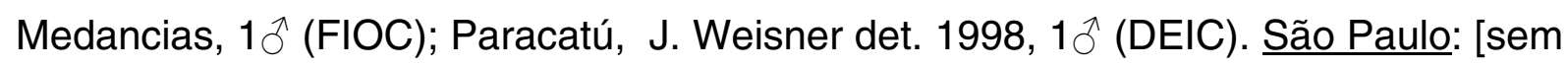
município], $2 \widehat{\jmath}$ (MZSP). [sem estado], [sem município], J. Weisner det. 1998, 1 ㅇ (DEIC). BOLÍVIA - Santa Cruz: oriental, 3ㅇ e 20 (MZSP); T.L. Erwin det. 2008, 1 + (NMNH). PARAGUAI - Guaira: Vilarrica, (-25.7500, -56.4333), Dr. W. Horn det., 1 q e $1 \hat{\jmath}$ (FIOC). ARGENTINA - Jujuy: Quemado Jujuyi, Dr. W. Horn det. 1935, 1 ㅇ 
(NMNH). [Sem país], [sem estado], [sem município], Dr. W. Horn det. 1923, $1{ }^{\widehat{ }}$ (MZSP); J. Wiesner, det.1998, $1{ }^{\Uparrow}$ (DEIC).

Oxycheila opacipennis (Waterhouse, 1889) (fig. 2C): BRASIL - Minas Gerais: Passa Quatro, $1 \hat{\delta}$ (FIOC). São Paulo: Campos do Jordão, 1 ㅇ (MNRJ); São Paulo, Dr. W. Horn det. 1937, 1 + (MZSP); Dr. W. Horn det. 1923, 1ex. (MZSP); (Cantareira), H. Zellibor det., 20 (MNRJ); $1 \hat{\jmath}$ (FIOC); T.L. Erwin det. 2008, $1 \hat{\sigma}$ (NMNH); 1ex. (MZSP); (Ipiranga), $2 \hat{0}$ (MZSP); (Jabaquara), $1 \hat{0}$ (MZSP); (Santo Amaro), $2 \hat{\jmath}$ (MZSP).

Oxycheila tristis (F., 1775) (fig. 2A): BRASIL - Minas Gerais: 1 ㅇ (MZSP); (Serra do Cipó), $2 \AA$ (MZSP); Pocinhos, Halik det. 1947, 19 (NMNH); Lambary [Lambari], Halik det. 1947, $1 \hat{\jmath}$ (NMNH). Espírito Santo: (Fazenda Jerusalem), J. F. Zikán det. 10

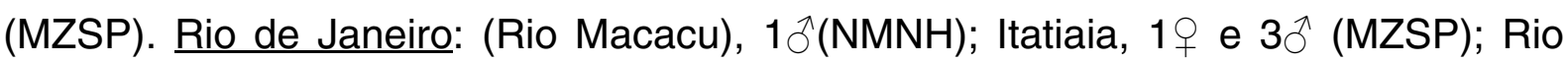
Claro (Rio Pirai), $1 \widehat{\jmath}(\mathrm{NMNH})$; Rio de Janeiro (Serra Macaé), Lüderwaldt det. 1915, 1 ( (MZSP). São Paulo: Campos do Jordão, 10 e e $1 \hat{\delta}$ (MZSP); Cubatão, $1 \hat{\delta}$ (MZSP); Mogi das Cruzes, $1 \delta^{\Uparrow}$ (MZSP); Mongaguá, Halik det. 1958, 3 ㅇ e $2 \hat{0}(\mathrm{NMNH})$; [Paranapiacaba], Estac. A.d.S.E.S.P. [Estação Alto da Serra], 19 e 10 (MZSP);

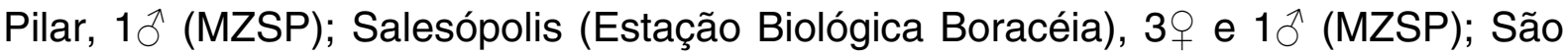
José dos Barreiros (Parque Nacional Serra da Bocaina), C. Campaner det. 2004, 1 ㅇ e $1 \hat{\jmath}$ (MZSP); [São Paulo], Lüderwaldt det. 1915, $2 \hat{\jmath}$ (MZSP); Halik det 1947, 2 e e $3 \hat{\text { ô }}(\mathrm{NMNH})$; (Cantareira), 2 ㅇ (MZSP); (Santo Amaro), 1 (q (MZSP). Santa Catarina: São Bento, 1 ㅇ (MZSP).

Phaeoxantha klugii Chaudoir, 1850 (fig. 4E): COLÔMBIA - Dr. W. Horn det. 1933, $1 \hat{\jmath}$ (MZSP). BRASIL - Horn det. 1933, 1 ㅇ (MZSP); 1 ㅇ (MZSP); (Rio Amazonas), R.D. Ward det. 1986, 2ð (NMNH). Amazonas: (Rio Juruá), W. Horn det., 1 + e $5 \AA$ (MZSP); 2 ㅇ (NMNH); R.D. Ward det. 1986, $2 \hat{\jmath}$ (NMNH); Barcelos (Rio Negro), $1 \hat{\jmath}$ (NMNH); Teffe [Tefé], 1ㅇ (NMNH); Jauarete, Dr. W. Horn, det. 1937, 1 e e $1 \hat{\delta}$ (MZSP). [Rondônia]: Porto Velho, R.D. Ward det. 1986, 1 (NMNH). Mato Grosso do Sul: Pimentel Barbosa (Rio das Mortes), 19 (MZSP). EQUADOR - Napo: Val det. 1942, 1 ㅇ (NMNH); (Rio Aguarico), R.D. Ward det. 1986, 3 ㅇ (NMNH). PERU - Loreto: (banco sudoeste do Rio Amazonas, correndo na grama à noite), 2 i (NMNH); 
Yarinacocha, 1 i (NMNH). Madre de Dios: (praia do Rio Madre de Dios, próximo ao acampamento base do Rio Los Amigos), $1 \widehat{\jmath}(\mathrm{NMNH})$; (Rio Patuyaco, acampamento La Viuda), D.L. Pearson det. 2000, 10 (NMNH); (Rio Madre de Dios, $1 \mathrm{~km} \mathrm{S.} \mathrm{Boca}$ Manu, na praia à noite), D.L. Pearson det. 1993, 19 (NMNH); (Rio Tambopata), 39 e $3 \AA$ (NMNH). Ayacucho: Santa Rosa (La Mar), R.D. Ward det. 1986, 10 (NMNH).

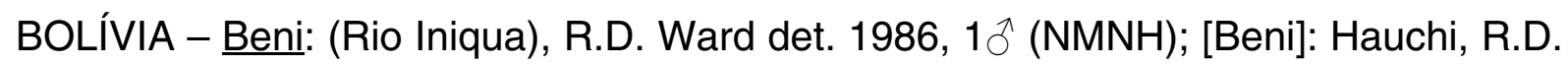
Ward det. 1986, 1 ㅇ (NMNH). Santa Cruz: 1 ㅇ e $1 \hat{\delta}$ (MZSP).

Phaeoxantha laminata (Perty, 1830) (fig. 5A): BRASIL - (Rio Tacau), R. Naviaux det. 2009, 19 (DEIC); (Rio Madeira superior), R. Naviaux det. 2009, $2 q$ (DEIC); $2 q$ (NMNH); Phaexantha asperula Westw., 2 ( $(\mathrm{NMNH})$.

Picnochile fallaciosa (Chevrolat, 1854) (fig. 1A): CHILE - 1ex. (MZSP). Magallanes: L.E. Peña G. det., 10 (MZSP); $2 \uparrow, 3 \hat{\jmath}$ e 2ex. (MZSP); Chorillo de Las Latas [ilegível], T. Cekalovic det., 1 우 (MZSP); Chorrilladela [ilegível], 1 우 (MZSP);

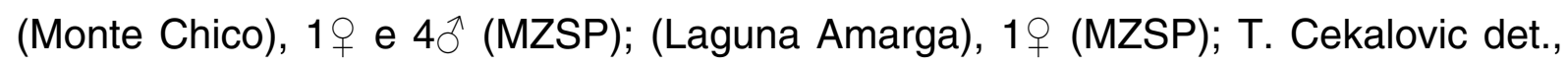
1 ㅇ (MZSP); (Estreito de Magalhães), 19 e $1 \hat{\jmath}$ (MZSP); $1 \hat{\jmath}$ (NMNH).

Platychile pallida (F., 1801) (fig. 4E): [ÁFRICA DO SUL] - [Western Cape]:

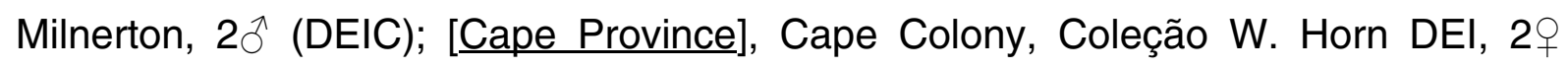
(DEIC).

Pseudotetracha cylindrica (M'Lay, 1863) (fig. 4B): AUSTRÁLIA - 2ex. (DEIC); Australia central, R. McCairns det. 1978, 1ex. (AMSA); Interior, 1 i (NMNH). Queensland: Cloncurry, 1 + (DEIC); Julia Creek (-20.6500, 141.7333), R. McCairns det. 1978, 1 ㅇ (AMSA); Longreach, 19 (DEIC); Surat (-27.1667, 149.0667), R. McCairns det. 1978, 1 ( (AMSA). Western Australia: Carnarvon (Carnarvon Rge. 24.8667, 113.6333), R. McCairns det. 1978, 2 e e $1 \hat{\jmath}$ (AMSA). South Australia: (Rio Darling, 'Kalyanka', aprox. 14km L de Wilcannia 31033'31"S, 143030'22"E), 1 + (AMSA); (Fowlers Gap., Chonopod, Shrubland 31005'49"S, 141044'07"L), 1 (AMSA); (aprox. 36km pela rodovia Dandaloo 32016'20"S, 147038'6"L), 8 e e $10^{\lambda}$ (AMSA); (Sturt National Park), 3ㅇ, 3र e 1ex. (AMSA); (Pull Pulla Stn., 40mi. W. Cobar), $1 \delta^{\Uparrow}$ (AMSA); Peake, R. McCairns det. 1978 (AMSA). New South Wales: det. 
R. McCairns det. 1978, 1 + e 1ex. (AMSA); Bourke, R. McCairns det. 1978, 1 त (AMSA). Sem localidade - MacCairns det. 1978, $10^{\wedge}$ e 3ex. (NMNH);

Pseudotetracha howitti (Castelnau, 1867) (fig. 4A): AUSTRÁLIA - Cooper Grute[?], type, Coll V. de Poll, type! Dr. W. Horn, syntypus, Coll. W. Horn, DEI Eberswalde, Howitti Cast., DEI Müncheberg Col - 01832, 1 ㅇ (DEIC); Lago Calabonna, 1 ( (DEIC).

Pseudotetracha murchisona Fleutiaux, 1896 (fig. 4C): AUSTRÁLIA - R. McCairs

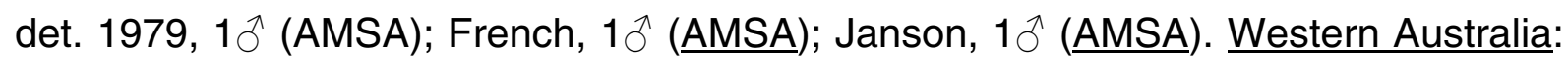
sem localidade, 1 ( (AMSA); Lake Grace, 1 ( (AMSA); Carnabys, R. Ward det. 1987,

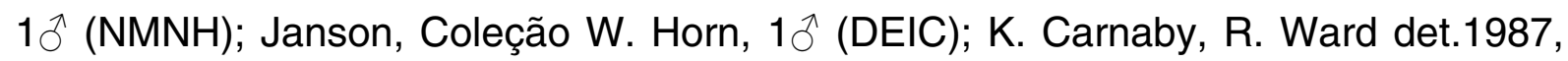
$1 \hat{\gamma}(\mathrm{NMNH})$. Victoria: Murchison [Murshison], 1 + e $1 \hat{\delta}$. Sem localidade - Donckier, Coleção W. Horn, 19 e $1 \widehat{\jmath}$ (DEIC); French, Coleção W. Horn, 10 (DEIC).

Pseudoxycheila bipustulata (Latreille, 1811) (fig. 2F): COLÔMBIA - F. Cassola det. 1996, 2q, 10 e 1ex. (NMNH) Bogotá, From Rene, F. Cassola det. 1996, 2 e e $2 \hat{\jmath}(\mathrm{NMNH}) ;$ Jericó, F. Cassola det. 1996, $1 \hat{\jmath}(\mathrm{NMNH}) ;$ Medellin, F. Cassola det. 1996, $1 q$ e $1 \delta^{\lambda}(\mathrm{NMNH})$; Serra de Santa Marta, $2 q(\mathrm{NMNH})$; Montr range, AS, F. Cassola det. 1996, 1 + e $2 \widehat{\partial}$ (NMNH); Rio Negro, F. Cassola det. 1996, 1 (NMNH). Santander: Rionegro, F. Cassola det. 1996, $1 \hat{\jmath}$ (NMNH). Val [Valle del Cauca], Cali,

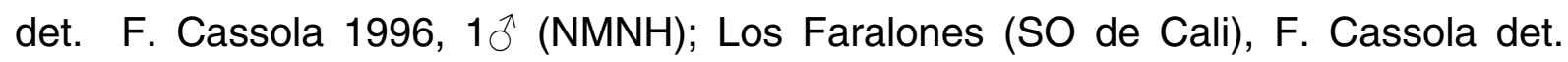
1996, 1 万 (NMNH). EQUADOR - Mapoco (Rio Pastaza), F. Cassola det. 1996, 19 (NMNH).

Pseudoxycheila ceratoma Chaudoir, 1865 (fig. 2E): EQUADOR - 1 우 e 1 수 (MZSP); 1 ㅇ (DEIC); F. Cassola det. 1995, 1 + (DEIC); San Francisco (Rio Pastaza), F. Cassola det. 1996, 1 ㅇ e $2 \widehat{\jmath}$ (NMNH); Banos, F. Cassola det. 1996, 10 (NMNH); Shell Mera, $1 \hat{\jmath}$ (NMNH); Mapoco (Rio Pastaza), 1 iq (NMNH); (Val. De Pilaton [Vale

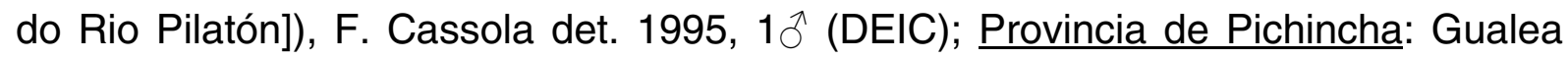
(0.1167, -78.7333), D. L. Pearson det. 1997, 1 ㅇ (LACM). [Província de Napo]: Archidona, F. Cassola det. 1998, 19 (DEIC). Provincia de Tungurahua: $(32 \mathrm{~km}$ a leste de Banos), $1 \hat{\jmath}$ (NMNH). 
Tetracha brasiliensis (Kirby, 1818) (fig. 3C): BRASIL - Monat, R. Ward det. 1977, 9 e e $6 \hat{0}(\mathrm{NMNH})$. Minas Gerais: (Organ Mt [Serra dos Órgãos]), $1 \hat{\delta}(\mathrm{NMNH})$;

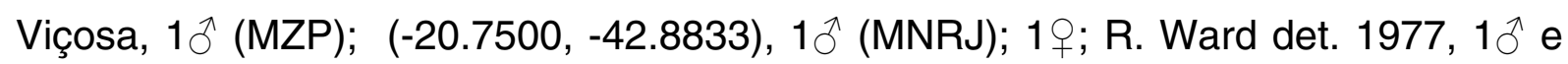
1 ( $\mathrm{NMNH}$ ). Espírito Santo: Corrego Itá [Barra do São Francisco], 1 + e $2 \hat{\jmath}$ (MNRJ);

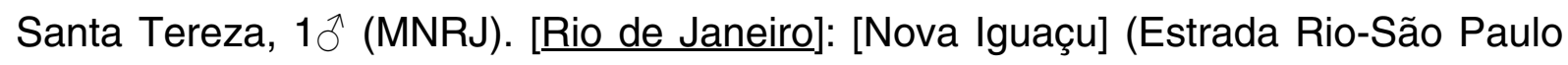
Km 47), $1 \hat{\jmath}$ (MNRJ); [Rio de Janeiro], (São Gonçalo, Colubandê), 3ð (MNRJ). São Paulo: (Represa Velha), $1 \hat{\delta}$ (MZSP); R. Ward det. 1977, 1 ㅇ e $5 \hat{\jmath}$ (NMNH) (; R. Ward det. 1977, 5^ e 1 ( (NMNH); Anhangaby [Araçatuba], E. Ward det. 1977, $2 \AA$ (NMNH); Campinas, R. Ward det. 1977, $1 \overbrace{}^{\Uparrow}(\mathrm{NMNH})$; Itirapina, R. Ward det. 1977, $1 \hat{\text { }}$ (NMNH). BOLÍVIA - Isiamas, R. Ward det. 1977, 1 ㅇ (NMNH). Santa Cruz: R. Ward det. 1977, $2 \hat{0}$ (NMNH). PARAGUAI - R. Ward det. 1977, 10 (NMNH). [Departamento Central]: Asunción, R. Ward det. 1977, 1 우 (NMNH). PERU - Rioja: San Martin, R. Ward det. 1977, 10 e 1 i (NMNH).

Tetracha carolina (L., 1767) (fig. 3D): ESTADOS UNIDOS DA AMÉRICA - №vo México: Chaves Co., (6 mi E Roswell Hwy 380, 33025'N, 103024'W), 1 ㅇ (LACM); Truth or Consequences, $1 q$ e $5 \hat{\delta}(\mathrm{NMNH})$; [Doña Ana Co.], Las Cruces, $2 q$ e $2 \hat{\sigma}$ (NMNH); [Otero Co.], Alamogordo, 1 + e $2 \hat{\jmath}(\mathrm{NMNH})$. Arizona: [Gila Co.], Globe (33.3942, -110.7865), C.D. Nagano det. 1980, 1 ㅇ e $1 \delta^{\Uparrow}$ (LACM). Texas: perto de Waco, $3 \circ$ e $2 \hat{\jmath}$ (NMNH); [Mitchell Co.], Colorado City (32.3882, -100.8646), C.D. Nagano det. 1980, $1 \hat{\jmath}$ (LACM); [Victoria Co.], Victoria, 19 e $2 \hat{\delta}(\mathrm{NMNH})$; [Colorado

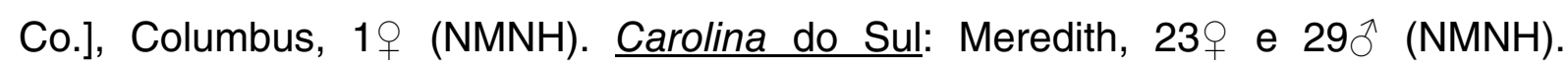
Alabama: Colbert Co, Wilson Dam (34.800833, -87.625833), C.D. Nagano det. 1980, 1 (LACM). Mississipi: Lafayette Co., Oxford, Paul K. Lago det. 1977, 1 (LACM). MÉXICO - Baixa Califórnia Sur: Todos Santos (23.4500, -110.2167), 20 (LACM).

Tetracha chilensis (Castelnau, 1834) (fig. 3E): EQUADOR - 19 (FIOC); Pozozo, R.C Ward det. 1986, 1 e e $1 \hat{\sigma}$ (NMNH). [Provincia del Guayas]: Posorja, $1 \propto$ e $3 \hat{\sigma}$

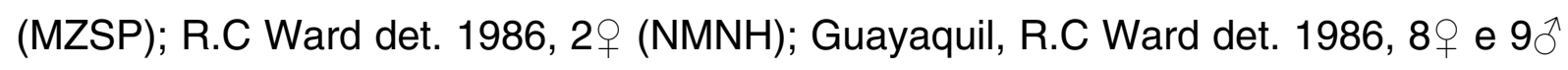
(NMNH); Chanduy, R.C Ward det. 1986, 1 i e 1 त (NMNH). PERU - [La Liberdad]:

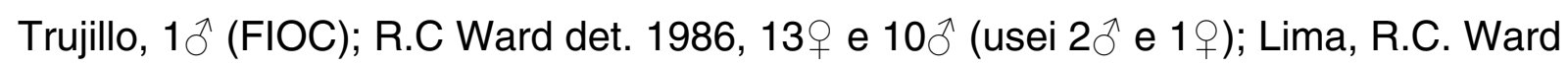




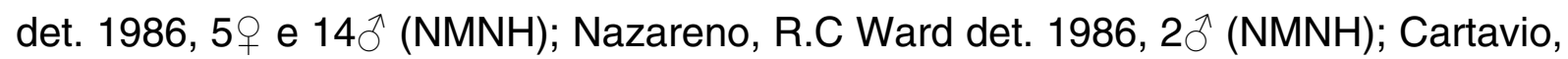
6 ㅇ e $3 \hat{\circ}$ (LACM). Piura: R.C Ward det. 1986, 3ㅇ e $1 \hat{\jmath}$ (NMNH).

Tetracha femoralis (Perty, 1830) (fig. 3B): BRASIL - Matto Grosso [Mato Grosso]: Vacaria, $2 \AA$ (MZSP). Goiás: Campinas (-14.3333, -49.1333),1 (MNRJ); Jatahy

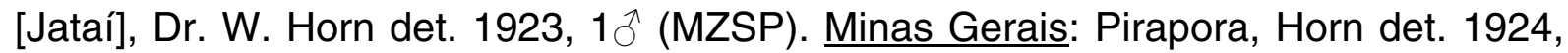

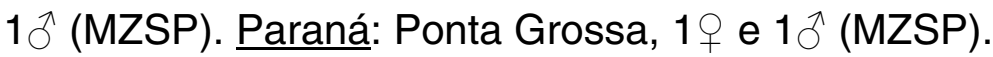

Tetracha fulgida (Klug, 1834) (fig. 3F): TRINIDAD - R.D. Ward det. 1986, $1+$ e $2 \AA$

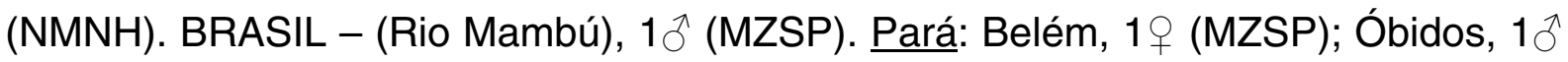
(MNRJ); (Baixo Amazonas), $1 \propto$ e $1 \hat{0}$ (MZSP); Tapajós, 2 ㅇ (MZSP). Amazonas: Borba (Rio Madeira), $1{ }^{\lambda}$ (MZSP); Indiana, 1 ㅇ (MNRJ); H. Zellibor det., 1 우 (MNRJ); Itaquatiara, $1 \hat{\sigma}$ (MNRJ); Zikán det. $1 \hat{\jmath}$ (MNRJ). Ceará: Icó, R.D. Ward det., 2 $\delta$ (NMNH). [Rondônia]: Porto Velho de Santo Antônio [Porto Velho], R.D. Ward det., 37 e $27 \hat{\circ}$ (NMNH). Acre: Alto Purús, $1 \hat{\jmath}$ (MZSP). Mato Grosso do Sul: Salobra, 1 우 (MZSP). Espírito Santo: 1 e e $3 \hat{\delta}$ (MZSP). São Paulo: Araçatuba, Dr. W. Horn det. 1939, $1 \hat{\jmath}$ (MZSP); Bauru, 1 (MZSP); Franca, 3^ (MZSP); Guarujá (Ilha S. Amaro),

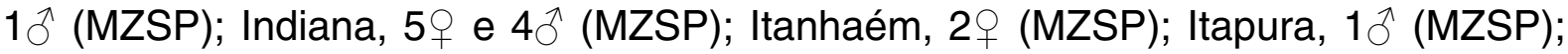
Piratininga, 1 ㅇ e $1 \hat{\jmath}$ (MZSP); Porto Tibiriçá, $2 \hat{0}$ (MZSP); Regente Feijó, $1 \hat{0}$ (MZSP);

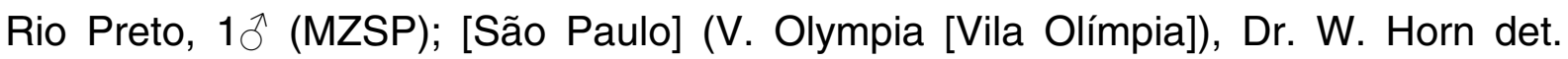
1924, 1 ㅇ (MZSP). Paraná: Bituruna (Barranca do Iguassu), 19 e $2 \hat{\delta}$ (MNRJ); Caiacanga, $1 \hat{\jmath}$ (MZSP). Rio Grande do Sul: Porto Alegre, Rivelier det., 1 i (MZSP). CHILE - Atacama, R.D. Ward det. 1986, 1 ( (NMNH). PARAGUAI - (Rio Paraguai), $1{ }^{\Uparrow}$ (MZSP). URUGUAI - Soriano (Isla del Pichon), R.D. Ward det., 11 e 9 ${ }^{\lambda}$ (NMNH). BOLÍVIA - [La Páz]: Calisaya (Rio Bopi), Horn det. 1931, 1 q cótipo

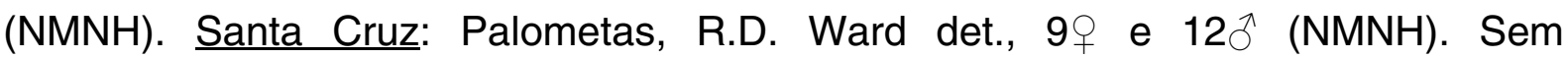
localidade $-1 \hat{\jmath}$ e 1ex. (MZSP).

Tetracha germaini (Chaudoir, 1865) (fig. 5C): ARGENTINA - Chañar, $1 \overbrace{}^{\Uparrow}$ (MZSP).

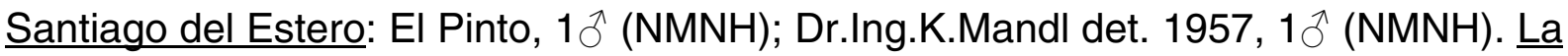
Rioja: Mascajin, $3 \hat{\delta}$ (NMNH). Mendonza: Dr. W. Horn det. 1938, $1 \hat{\jmath}$ (FIOC); 1 ㅇ e $1 \hat{\jmath}$ (NMNH); W Horn det. Mar.1921, $1 \overbrace{}^{\Uparrow}(\mathrm{NMNH})$. 
Tricondyla aptera (Olivier, 1790) (fig. 6C): INDONÉSIA - Irian Java (Monte Cyclope, $21 \mathrm{~km}$ oeste de Jayapura), 1 q (LACM); Hollandia [Jayapura], Ward det. 1977, 1 e e 2 ก (NMNH). ILHAS SALOMÃO - Guadalcanal: (9032'10"S, 160006'40"L), M.A.Cazier det. 1953, 4^ (LACM); 69 e $9 \AA$ (NMNH). PAPUA NOVA

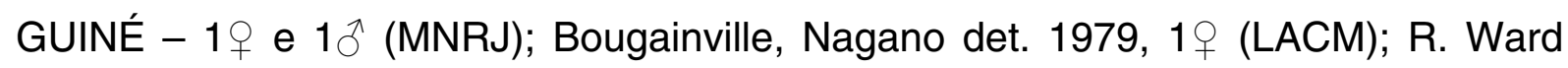
det. 1977, 3 e $2 \hat{\jmath}(\mathrm{NMNH})$. [West Sepik]: Tifalmin, 19 e $2 \hat{\jmath}(\mathrm{NMNH})$. E[ast] Sepik:

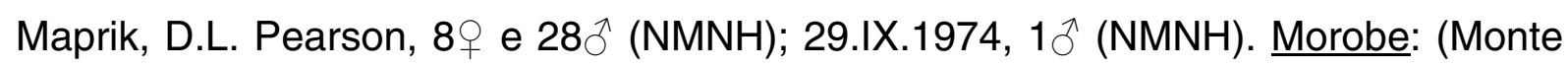
Mishiu), $1 \AA$ (LACM); (Huon Gulf), Nagano det. 1979, 1 ㅇ (LACM); Lae, (-6.7333, 147.0000), W.D. Sumlin det. 1971, 1 + e $1 \delta$ (LACM); Sattelberg, (6o28'S, 147044'L), $1 q$ (LACM); Wau, Monte Missin, $1 q$ (NMNH). Gulf: Kerema (-7.9667, 145.7667), Nagano det. 1979, 1 + e $1 \hat{\delta}$ (LACM). Sem localidade - Insb, Phil[?], $1 \hat{\jmath}$ (LACM).

\subsection{Dissecções e llustrações}

Cada espécie estudada foi dissecada (com exceção dos tipos), fotografada e/ou ilustrada a traço e as estruturas analisadas. Foram analisados: antena, cabeça, peças bucais (labro, mandíbula, maxila e lábio), pronoto, perna, élitros, asa membranosa, tergitos torácicos e abdominais e genitália do macho e estilos das fêmeas. O habitus de cada espécie também foi fotografado (fig. 1 a 7).

Para as dissecções, cada exemplar foi colocado em uma câmara úmida ou fervido durante 5 a 10 minutos em uma solução aquosa com detergente líquido para hidratação e amolecimento dos tecidos. As dissecções foram feitas em água sob lupa estereoscópica, com auxílio de estiletes, pinças e tesoura de ponta fina.

Peças bucais: cada peça foi retirada cuidadosamente com uma pinça de ponta fina, sendo que um estilete ou um alfinete foi usado para romper a musculatura que prende a peça à cabeça. Após dissecadas, foram lavadas em água corrente, passadas em álcool 70\%, secadas e coladas em um pequeno triângulo de papel cartão preto para então serem fotografadas. Após o uso, estas foram colocadas em um pequeno fraco com tampa de borracha contendo glicerina e alfinetado junto com o exemplar. 
Cabeça e protórax: foram separados cabeça, protórax e restante do corpo (mesotórax + metatórax + abdome) com o auxílio de uma pinça de ponta fina. A cabeça foi colada em um pequeno triângulo de cartolina preta; o mesmo foi feito com o protórax, que foi colado pelo dorso. O restante do corpo continuou afinetado. Após o exame, eles foram encaixados e colados novamente.

A asa foi retirada pela base com auxílio de uma pinça de ponta fina, colocada em uma lâmina com uma gota de álcool $50 \%$ e então esticada com auxílio de alfinetes e pinças. Depois, foi colocada uma ou mais lamínulas por cima da asa para esta secar em tal posição. Uma vez esticada, pequenas gotículas de glicerina coletadas com a ponta de um alfinete são colocadas em volta da lamínula para evitar que a membrana grude após a secagem. Após a secagem do material, a asa foi colada em um pedaço de cartolina branca com cola hidrossolúvel e este alfinetado junto ao exemplar. A estrutura foi fotografada na lâmina ou já colada na cartolina, dependendo do caso.

Genitália: para a genitália masculina, o mesmo processo adotado para as peças bucais foram feitos, porém, após o uso, em alguns casos, o edeago e parâmeros foram colados em pequenos triângulos de papel grosso e estes alfinetados com o exemplar. Quando foi preciso remover todo o abdome para a retirada da genitália, os esternitos foram colados novamente no exemplar. Para a observação dos estilos das fêmeas, o exemplar teve seus músculos hidratados e o ovipositor exteriorizado.

Posteriormente às dissecções, as estruturas de interesse foram ilustradas.

Alguns desenhos foram feitos a lápis e digitalizados para posteriormente serem redesenhados no computador; outros foram feitos sobre as fotografias obtidas. Em ambos os casos os desenhos finais foram feitos em uma nova camada (layer) criada sobre a imagem digital através do software Adobe Photoshop Cs5.

Os desenhos à lápis foram realizadas com auxílio de câmara clara acoplada ao microscópio estereoscópico. As fotografias foram feitas sob lupa com uma câmera acoplada. Todas as fotos foram feitas usando a técnica da automontagem, que consiste na captura de imagens em diferentes planos de foco para posterior 
montagem via software. Para fotos feitas no MZSP foi usado o equipamento do Laboratório de Hymenoptera, que consiste em uma lupa Leica M205C, câmera de vídeo Leica DFC 295 e software Leica LAS (Leica Application Suite v.3.6.0). Foram obtidas aproximadamente 1100 fotografias montadas. Para as fotos feitas no NMNH - Smithsonian Institution, foi usada uma lupa Leica M420 em um sistema EntoVision $^{\mathrm{TM}}$, além do software Archimed integrado ao mesmo sistema para as medidas. Foram obtidas aproximadamente 1350 imagens montadas. Estas fotos foram usadas para a comparação das estruturas, ilustrações do presente trabalho, assim como para a formação de um banco de imagens do grupo estudado, que poderá ser utilizado futuramente.

\subsection{Medidas}

As medidas foram obtidas com o auxílio de uma régua milimetrada ou sob lupa com uma régua micrométrica.

As relações entre as medidas das estruturas sem articulações fotografadas foram feitas com o programa Photoshop Cs5, com a ferramenta régua. Para cada medida era anotada o valor de L1 (na barra relacionada à régua) e depois a relação era feita dividindo uma medida pela outra. Medidas onde haviam articulações envolvidas, como o habitus do animal e a antena, foram obtidas a partir do desenho da estrutura feito com auxílio de uma lupa com câmara clara e, cada segmento foi desenhado separadamente com seu plano paralelo à objetiva; depois tais segmentos foram unidos e a medida feita com uma régua milimetrada, conforme exemplo abaixo. Todas as estruturas usadas em comparações foram desenhadas com o mesmo aumento. 


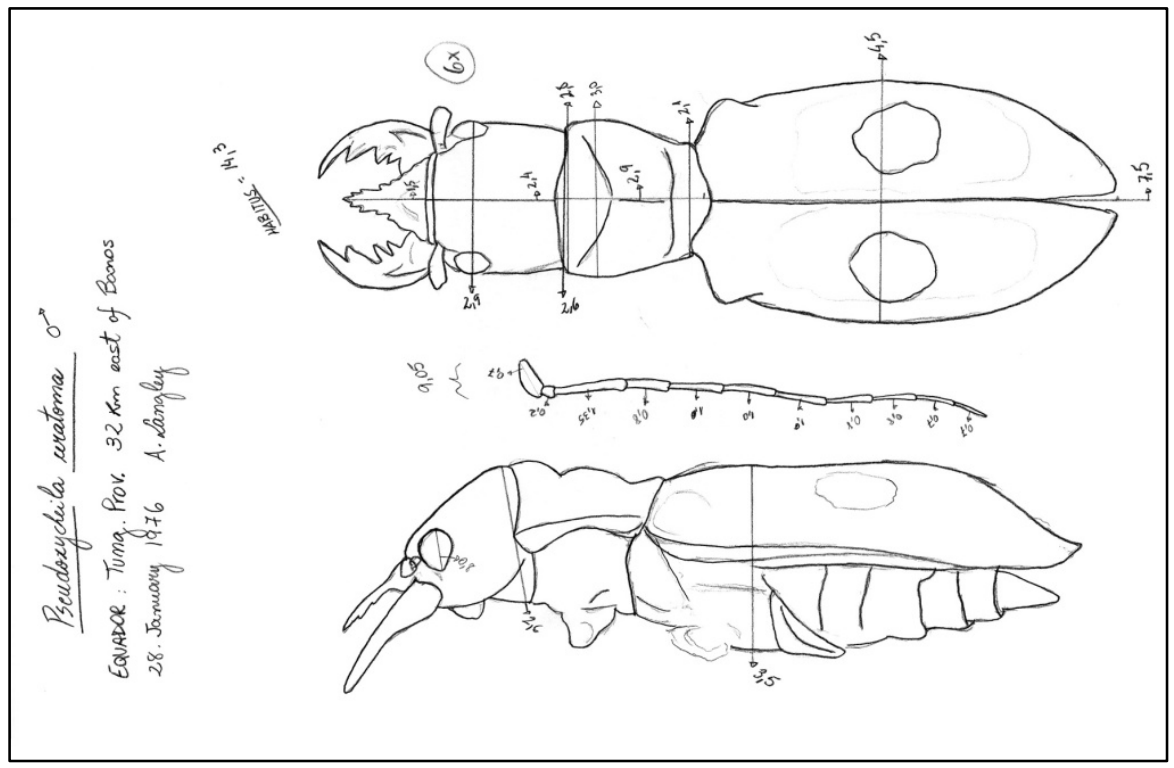

Exemplo de desenho feito através de lupa com câmara clara para a obtenção das relações entre medidas.

Para as medidas dos ângulos, a peça foi fotografada e o ângulo de interesse medido com o programa Photoshop Cs5, também com a ferramenta régua. Para fazer uma medida de um ângulo, escolhe-se a ferramenta régua (ou ruler tool), clicase em uma extremidade da estrutura e arrasta-se o mouse mantendo o botão esquerdo pressionado até que se chegue no ponto onde o ângulo será medido. Uma vez feita uma linha, segura-se o Alt (PC) e verá que aparece um símbolo de ângulo no ponteiro do mouse quando se aproximar da extremidade da linha recém feita. Então clica-se nesta região e, mantendo o botão esquerdo pressionado, arrasta-se esta segunda linha até o ponto necessário. $\mathrm{Na}$ barra relacionada à ferramenta régua é possível observar um "A" seguido de uma medida em graus; esta é a medida do ângulo obtido. 


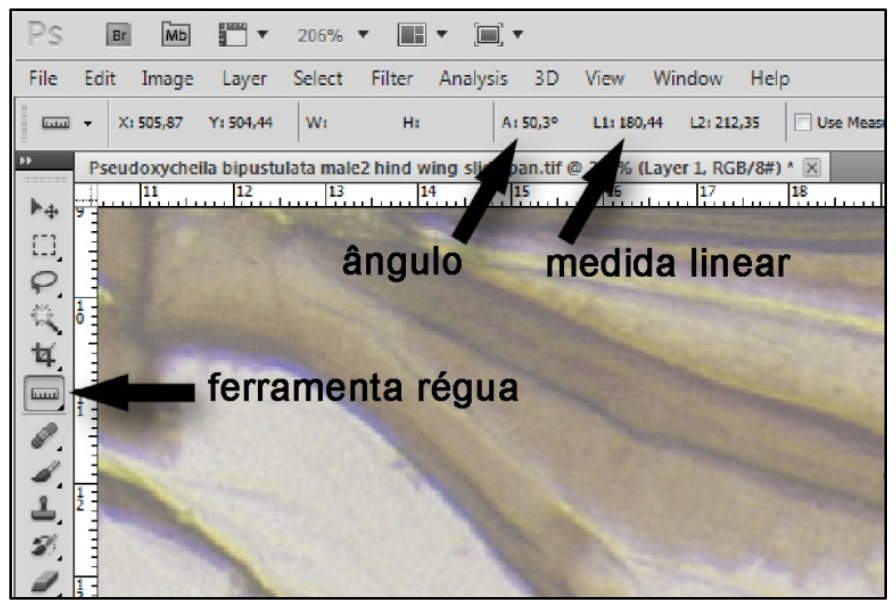

Detalhe do canto superior esquerdo da tela do software Adobe Photoshop Cs5 com setas apontando para a ferramenta régua (ruler tool), ângulo e medida linear.

\subsection{Terminologia}

A terminologia utilizada foi baseada em Sharp \& Muir (1912) e Deuve (1993) para a genitália masculina, Tanner (1927) e Deuve (1993) para a genitália feminina, Reichardt (1977), Lawrence \& Britton (1994), Martinez (2005) e Naviaux (2007) para a morfologia geral de Carabidae, Jorge-Silva (1979)) e Ball (2011) para as peças bucais e Kukalová-Peck \& Lawrence $(1993,2004)$ para a asa membranosa.

\subsection{Análise filogenética}

O método usado para se formular uma hipótese sobre a filogenia do grupo é o da Sistemática Filogenética, proposta inicialmente por Hennig.

Inicialmente foi feito o levantamento do maior número possível de caracteres comparáveis. Esses caracteres, através da semelhança morfológica, foram considerados como tendo possível homologia, que posteriormente à análise filogenética foi confirmada ou não. Os caracteres passaram por uma codificação linear não-redundante, mas, pelo princípio da parcimônia, a priori não foram polarizados nem ordenados, pois até então não há evidência alguma para a formulação adicional de quaisquer hipóteses consistentes sobre a evolução dos estados de qualquer um dos caracteres abordados. Pelo mesmo motivo, não foi 
efetuada a ponderação de caracteres. A parcimônia empregada para os caracteres morfológicos foi a de Fitch (1971), que não pressupõe ordenação alguma dos caracteres, nem proíbe quaisquer tipos de homoplasia.

Uma vez que o presente estudo investigou as relações de parentesco no grupo e testou seu monofiletismo, foi construída uma árvore não-enraizada com a inclusão dos grupos-externos, e o enraizamento foi feito a posteriori (NIXON \& CARPENTER, 1993) no nó que conecta o ramo de Calosoma granulatum Perty, 1830 ao dos demais táxons, uma vez que o gênero é considerado "mais basal" dentro da filogenia de Carabidae (MADDISON et al., 1999; HUNT, et al. 2007)

A análise propriamente dita e a otimização foram implementadas com auxílio do programa TNT 1.1 (GoloBoff et al., 2012). Posteriormente foi calculado o suporte de Bremer para verificar a robustez dos grupos obtidos (fig. 18).

\subsubsection{Escolha dos táxons}

Para a escolha dos gêneros a serem estudados foram combinados os gêneros considerados como pertencentes a Megacephalini nos trabalhos de Horn (1926), Lorenz (2005) e Naviaux (2007). Com a inclusão de todo os gêneros já utilizados anteriormente é possível discutir a análise resultante de um modo mais crítico.

As espécies de cada gênero foram escolhidas visando-se a espécie-tipo e outra presente, de preferência na coleção do MZSP, totalizando 30. Deu-se preferência por espécies com abundância de material e, na medida do possível, que pertencessem diferentes subgêneros ou grupos de espécies.

Foram analisadas 12 espécies do grupo externo, escolhidas por pertencerem a outras tribos de Cicindelinae e uma (Calosoma grannulatum) por ser reconhecidamente mais basal dentro da filogenia de Carabidae (MADDISON, 1999, HUNT, et al. 2007).

Segue abaixo uma lista com todas as espécies usadas no presente estudo, com espécies-tipo seguidas de um "*”: 
- AMBLYCHEILA Say, 1830

Amblycheila cylindriformis Say, 1823* (fig. 1E)

Amblycheila picolominiii Reiche 1839 (fig. 1F)

- ANIARA Hope, 1838

Aniara sepuchralis (Fabricius 1801)* (fig. 3A)

- Australicapitona Sumlin, 1992

Australicapitona basalis (M'Lay 1866) (fig. 4D)

- CAlLIDEMA Guérin, 1843

Callidema boussingaultii Guérin, 1843* (fig. 6B)

- CHEILOXYA Guérin, 1855

Cheiloxya binotata Castelnau, 1833* (fig. 2D)

- GRAmmognatha Motchulsky, 1850

Grammognatha euphratica (Dejean, 1822)* (fig. 5D)

- MEgacepHaLA Latreille, 1802

Megacephala bocandei Guérin, 1848 (fig. 5F)

Megacephala megacephala (Olivier, 1790)* (fig. 5E)

- METRIOCHEILA Thomson, 1857

Metriocheila nigricollis (Reiche, 1842)* (fig. 5B)

- OMUS Eschscholtz, 1829

Omus californicus Eschscholtz, 1829* (fig. 1C)

Omus dejeani Reiche, 1838 (fig. 1B)

- OxyCHEILA Dejean, 1825

Oxycheila labiata Brullé, 1837 (fig. 2B)

Oxycheila opacipennis (Waterhouse, 1889) (fig. 2C)

Oxycheila tristis (F., 1775)* (fig. 2A)

- Phaeoxantha Chaudoir, 1850

Phaeoxantha klugii Chaudoir, 1850 (fig. 4E)

Phaeoxantha laminata (Perty, 1830)* (fig. 5A)

- PICNOCHILE Motschulsky, 1856

Picnochile fallaciosa (Chevrolat, 1854)* (fig. 1A)

- PlatyChILE M’Leay, 1825

Platychile pallida (F., 1801)* (fig. 4E) 
- PSEUdotetracha Fleutiaux, 1894

Pseudotetracha cylindrica (M'Lay, 1863)* (fig. 4B)

Pseudotetracha howitti (Castelnau, 1867) (fig. 4A)

Pseudotetracha murchisona Fleutiaux, 1896 (fig. 4C)

- PSEUDOXYCHEILA Guérin, 1838

Pseudoxycheila bipustulata (Latreille, 1811)* (fig. 2F)

Pseudoxycheila ceratoma Chaudoir, 1865 (fig. 2E)

- TETRACHA Hope, 1838

Tetracha brasiliensis (Kirby, 1818) (fig. 3C)

Tetracha carolina (L., 1767)* (fig. 3D)

Tetracha chilensis (Castelnau, 1834) (fig. 3E)

Tetracha femoralis (Perty, 1830) (fig. 3B)

Tetracha fulgida (Klug, 1834) (fig. 3F)

Tetracha germaini (Chaudoir, 1865) (fig. 5C)

Espécies inicialmente externas a Megacephalini:

- Calosoma Weber, 1801- Carabinae / Carabini

Calosoma granulatum (Perty, 1830) (fig. 6A)

- CICINDELA L., 1758 - Cicindelini / Cicindelina

Cicindela campestris L., 1758* (fig. 6F)

Cicindela hybrida L., 1858 (fig. 7A)

- Ctenostoma Klug, 1821- Ctenostomini

Ctenostoma formicarium (F., 1801)* (fig. 6E)

Ctenostoma unifasciatum Dejean, 1831 (fig. 6D)

- CyLINDERA Westwood, 1831- Cicindelini / Cicindelina

Cylindera nivea (Kirby, 1818) (fig. 7B)

- EUPRosopus Dejean, 1825 - Cicindelini / Iresina

Euprosopus chaudoiri Thomson, 1859 (fig. 7D)

Euprosopus quadrinotatus (Dejean, 1822) ${ }^{\star}$ (fig. 7C)

- MANTICORA F. 1792 - Manticorini

Manticora tuberculata (DeGeer, 1778)* (fig. 1D)

- ODONTOCHEILA Laporte, 1834 - Cicindelini / Prothymina 
Odontocheila cayennensis $(\mathrm{F} ., 1787)^{\star}$ (fig. 7E)

Odontocheila nodicornis (Dejean, 1825) (fig. 7F)

- TRICONDYLA Latreille, 1822 - Collyrini

Tricondyla aptera (Olivier, 1790)* (fig. 6C)

\subsubsection{Construção da matriz de caracteres (Tabelas 1 - 8)}

A partir dos dados morfológicos foi elaborada a matriz de caracteres para a análise filogenética com o programa Mesquite 2.75 (MADDISON \& MADDISON, 2011). Os estados relacionados ao hábito de vida das espécies (noturno/diurno) foram retirados de Erwin \& Pearson (2008).

Foram codificados caracteres binários e multiestados, todos não ordenados nem polarizados a priori. Procurou-se levantar caracteres morfológicos quantivos e qualitativos que apresentassem variação suficiente para que os estados pudessem ser estabelecidos.

A matriz foi feita empregando-se algarismos arábicos para representar cada um dos estados das séries de transformação. O número não indica a ordem nem a polarização do estado, visto que esses foram obtidos após a análise. As variações intraespecíficas de um táxon terminal foram codificadas como polimórficas e estão representadas pelos estados separados por uma barra (/). O sinal de interrogação (?) se refere aos estados não observados, seja por material insuficiente para a análise, pela dificuldade de comparação ou por material danificado. O hífen (-) refere-se a estados não aplicáveis a determinado táxon, por este não apresentar a estrutura ao qual o caráter se aplica; ocorrem geralmente em caracteres de contingência.

\subsubsection{Análise da matriz de dados}

A análise filogenética foi processada com o programa TNT 1.1 (GoLOBOFF et al., 2012) com a busca heurística "traditional search", na qual a construção dos cladogramas é feita com o algorítimo de Wagner (FARRIS, 1970). A árvore foi 
enraizada no ramo que conecta Calosoma granulatum ao resto dos táxons, uma vez que esse gênero é considerado "mais basal" dentro da filogenia de Carabidae (MADDISON et al., 1999; HUNT et al., 2007). Foram pedidas 3000 réplicas, algorítimo TBR e 10 árvores salvas por réplica. A busca foi feita com o comando "collapse trees after search" ativo, que colapsa os ramos com comprimento mínimo igual a zero. A análise utilizando a "new technology" também foi feita a fim de comparar os resultados. Foram ativados todos os algorítimos (Sect. Search, Ratchet, Drift e Tree Fusing) com adição de 100 sequências aleatórias. Não houve mudança no resultado.

Depois da obtenção dos 4 cladogramas mais parsimoniosos, todas as resoluções possíveis foram salvas para a discussão sobre a distribuição dos caracteres ( fig. 18).

Para a discussão dos grupos obtidos, foi usada a árvore de consenso estrito com os estados dos caracteres plotados (fig. 19, 21 - 23).

Foi calculado também pelo TNT o suporte de Bremer (fig. 19) para todos os clados obtidos. As configurações usadas foram as padrões do script Bremer.run.

Uma lista contendo todas as transformações ocorridas nas autapomorfias e sinapomorfias comuns a todas as árvores foi fornecida (anexo 2). Nela não aparecem os caracteres com ambiguidade em seus estados, uma vez que não foram otimizados. Esta lista foi feita pelo programa TNT através do seguinte caminho (após a análise): Optimize > Synapomorphies > List common synapomorphies.

\subsubsection{Discussão dos caracteres:}

Foi feita uma lista com todos os caracteres com seus índices de consistência (ci) e de retenção (r) e seus estados usados na análise seguida de sua distribuição nos quatro cladogramas mais parcimoniosos obtidos, além de uma pequena discussão, quando pertinente. Quando foram observadas ambiguidades topológicas, o caráter foi otimizado e sua otimização apontada. Quando não houve argumentos em relação ao caráter para optar por uma otimização específica, a escolhida foi a ACCTRAN. Quando por algum motivo específico foi escolhida a ACCTRAN ou a 
DELTRAN, esta escolha foi justificada. Apesar de ter sido escolhida uma otimização em caso de ambiguidade em um clado, os índices de consistência e de retenção de cada caráter foram calculados levando em conta as ambiguidades.

$\mathrm{Na}$ discussão dos caracteres, as quatro árvores mais parcimoniosas foram discutidas ao invés de seu consenso, uma vez que não é um número grande de árvores e todas as informações sobre as possibilidades encontradas para cada caráter são preservadas. Quando uma sinapomorfia ou autapomorfia apareceu em mais de um ponto no cladograma, estas foram chamadas de sinapomorfia homoplástica e autapomorfia homoplástica, respectivamente. Nesses casos, foi indicado cada clado suportado por este evento. No caso de um clado com muitos terminais ser suportado por uma sinapomorfia, foi indicado apenas o ramo onde houve tal transformação e não os clados internos. Ser sinapomorfia homoplástica do clado $X, Y$ e $Z$ significa que tal transformação ocorreu independentemente no ancestral exclusivo de cada um desses 3 clados e não no ancestral comum aos três clados. $O$ mesmo vale para as autapomorfias homoplásticas. Quando um estado revelou-se homoplástico e apenas um clado ou terminal foi indicado, então o outro clado/terminal que também possui aquela transformação pertence ao grupo externo a Megacephalini.

A maior parte dos caracteres e seus estados foram indicados conforme Sereno ( 2007).

Além dos caracteres apresentados na lista, 12 outros relacionados principalmente às medidas foram levantados, mas não foram utilizados pela dificuldade em estabelecer a relação entre os estados. Foram realizadas várias tentativas, inclusive uma tentativa de categorização com modelos de classificação de variáveis, porém os intervalos se mostraram muito próximos para separação das espécies e possivelmente com pouco significado para análises filogenéticas, gerando uma grande quantidade de estados para cada medida; gráficos de distribuição dos valores (histogramas) não permitiram determinar quais variáveis são ou não passíveis de categorização devido a sua distribuição contínua. Esses caracteres encontram-se enumerados e ilustados no "Anexo 1". 


\subsubsection{Discussão dos grandes grupos naturais obtidos.}

Para a discussão dos clados, foi utilizada a árvore de consenso estrito (fig. 19, 21-23), uma vez que esta é uma combinação da topologia das árvores, mantendo apenas os grupos monofiléticos que estão presentes em todos os cladogramas.

A tribo e suas subtribos foram então definidas e comparadas com propostas anteriores, além de algumas sinapomorfias discutidas. Quando foi pertinente, os grupos mais restritos também foram comentados.

\section{RESULTADOS E DISCUSSÃo}

A presente análise demonstrou que a tribo Megacephalini como estabelecida pelas hipóteses anteriores (HORN, 1926; LORENZ, 2005; NAVIAUX, 2007) não é monofilética. O grupo monofilético obtido, aqui estabelecido como tribo Megacephalini, tem os seguintes caracteres utilizados na análise apontados e discutidos a seguir.

\subsection{Lista de caracteres e distribuiç̧ão dos estados}

Foram levantados 233 caracteres ( 0 a 232), sendo 232 morfológicos e 1 sobre o hábito de vida (caráter 0). Destes, 41 não são informativos para o grupo interno. $\mathrm{A}$ ordem dos caracteres segue aproximadamente o sentido anteroposterior do animal. $O$ estado plesiomórfico foi dado levando em conta o cladograma como um todo. As ilustrações são esquemas baseados em fotografias e não possuem escalas. As 4 árvores obtidas na análise foram utilizadas na discussão (fig. 17). 
0. Hábito $(c i=0,33 ; r=0,80)$ :

0. diurno

1. noturno

Distribuição dos estados:

Otimização: ACCTRAN

Plesiomórfico: 0

(0) Reversão em Picnochile fallaciosa e no grupo formado pelas duas espécies de Pseudoxycheila (70).

(1) Sinapomorfia de Megacephalini.

1. Distância entre ápice do labro até ápice do élitro (comprimento) $(c i=0,25$; $r=0,33)$ :

0. maior que $23 \mathrm{~mm}$

1. entre 13 e $23 \mathrm{~mm}$

2. menor que $13 \mathrm{~mm}$

Distribuição dos estados:

Otimização ACCTRAN

Plesiomórfico: 0

(0) Sinapomorfia homoplástica por reversão para os grupos: 44 (Manticora + Amblycheila) e 55 (as duas espécies de Megacephala). Autapomorfia homoplástica de Phaeoxantha klugii. 
(2) Autapomorfias homoplásticas das espécies Phaeoxantha laminata e Tetracha germaini.

Ambiguidade em Aniara sepulcralis, Platychile pallida, e Tetracha fulgida por haver indivíduos com comprimentos compatíveis com os estados 1 e 2 .

2. Corpo, superfície ventral metálica (ci=0,25; r=0,81) (fig. $8 \mathrm{~A}$ e 8B):

0 . presente

1. ausente

Distribuição dos estados:

Plesiomórfico: 0

(1) Sinapomorfia homoplástica de Manticorina (46) e dos clados 53 e 67.

3. Antena, coloração física (ci=1; $r=1)$ :

0. ausente

1. presente

Distribuição dos estados:

Plesiomórfico: 0

(1) Aparece apenas em um clado externo à tribo Megacephalini.

4. Antena, coloração por pigmento $(c i=1 ; r=1)$ :

0 . ausente 
1. presente

Distribuição dos estados:

Plesiomórfico: 1

(0) Aparece apenas no grupo externo à tribo Megacephalini.

Foi usado este caráter, mesmo que tenha dado o mesmo resultado do caráter 3, pois foi levantada uma hipótese da possibilidade de ser encontrado algum táxon com cor predominante pigmentar, mas com pequenas regiões iridescentes. Porém, todos os táxons que apresentavam iridescência, esta cobria $100 \%$ da superfície externa da antena.

5. Antena, coloração por pigmento, tonalidade $(c i=0,25 ; r=0,68)$ :

0. amarelada

1. castanha

2. enegrecida

Distribuição dos estados:

Plesiomórfico: 2

(0) Autapomorfia homoplástica de Oxycheila labiata e de Megacephala bocandei. Sinapomorfia homoplástica dos clados: 67 e 73.

(1) Sinapomorfia homoplástica do clado 60 que compreende a subtribo Megacephalina menos a espécie Aniara sepulcralis.

Nos táxons onde havia indivíduos com a coloração da antena enegrecida e outros com a antena castanha, foi atribuído o estado 2 (enegrecida), pois a cor mais clara foi atribuída à cutícula ainda não totalmente esclerotizada de adultos recémemergidos. 
6. Antena, escapo, cerdas apicais (ci=0,28; r=0,76) (fig. $8 F$ e $8 G$ ):

0. mais de 2

1. 2

2. 1

Distribuição dos estados:

Otimização: ACCTRAN

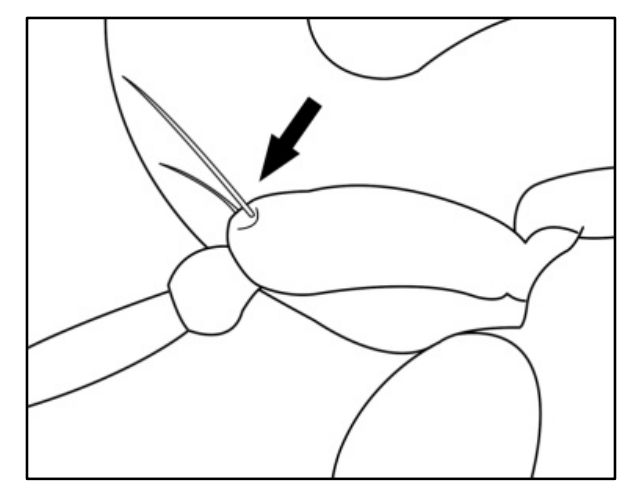

Plesiomórfico: 2

(0) Sinapomorfia homoplástica do grupo formado pelas duas espécies de Megacephala (55) e de Manticorina (46). Autapomorfia de Platychile pallida.

(1) Sinapomorfia homoplástica de Megacephalina e do clado formado pelas duas espécies de Omus (68).

Ambiguidade: algumas espécies apresentaram indivíduos com 2 ou mais cerdas. Algumas vezes, mesmo com a ausência da cerda foi possível identificar os pontos de inserção; quando isso ocorreu, o número de pontuações foi somado ao total de cerdas.

Uma cerda foi considerada apical quando esta se encontrava na região terço apical do escapo. Frequentemente estas cerdas possuem uma pontuação mais acentuada que as demais.

Nota-se que a presença de uma maior quantidade de cerdas apicais pode ser mais frequente em espécies que não voam (também presente no gênero Ctenostoma, que tem muitas espécies braquípteras). A maior parte dessas espécies apresentam geralmente antenas menores do que as espécies de grupos alados. Uma hipótese para explicar tal frequência seria atribuir uma sensibilidade mais eficaz dessas cerdas a objetos localizados próximos ao solo, enquanto que antenas longas seriam mais eficazes em raios maiores de ação. 
7. Antena, escapo, cerdas na região mediana $(c i=0,20 ; r=0,50)$ :

0. ausentes

1. presentes

Distribuição dos estados:

Otimização: ACCTRAN

Plesiomórfico: 0

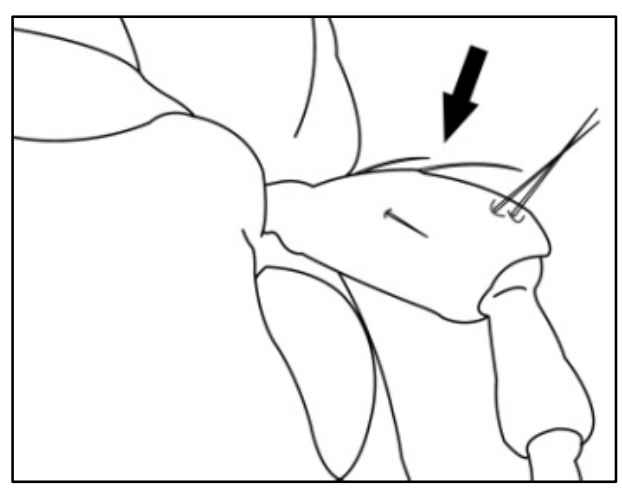

(1) Sinapomorfia homoplástica do clado 44 e autapomorfia homoplástica de Megacephala megacephala.

8. Antena, ápice do escapo mais largo e achatado nos machos (dimorfismo sexual) (não informativo):

0 . ausente

1. presente

Distribuição dos estados:

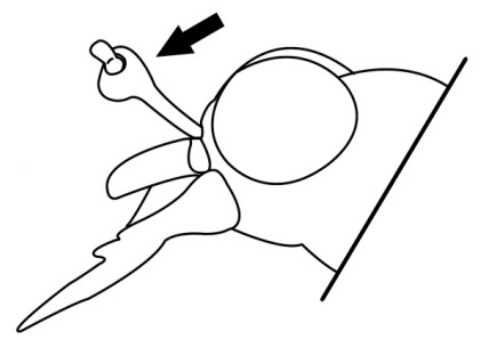

Plesiomórfico: 0

Apenas uma espécie fora de Megacephalini apresenta o estado apomórfico.

(-) Não foram analisados machos de Pseudotetracha howitii.

9. Antena, antenômero 2, cerdas (ci=0,25; r=0,66) (fig. $8 \mathrm{~F} \mathrm{e} \mathrm{8G):}$

0. presentes

1. ausentes 
Distribuição dos estados:

Plesiomórfico: 1

(0) Sinapomorfia homoplástica de Manticorini (46). Autapomorfia homoplástica de Platychile pallida e Megacephala megacephala.

10. Antena, comprimento do antenômero 3 , relação sobre o comprimento do antenômero 2 (ci=0,16; r=0,73) (fig. 8F e 8H):

0.4 ou mais

1. menos de 4

Distribuição dos estados:

Plesiomórfico: 1

(0) Sinapomorfia homoplástica de Oxycheilina (53) e dos clados 63 e 73.

11. Labro, forma $(c i=0,18 ; r=0,57)$ :

0. subtriangular

1. subtrapezoidal

2. subretangular

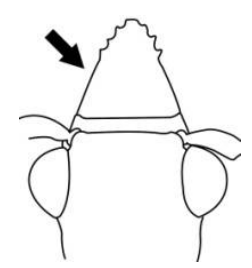

0

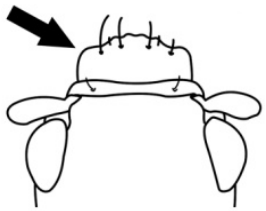

1

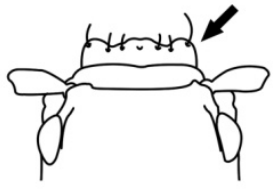

2

Distribuição dos estados:

Otimização: ACCTRAN

Dentre as 4 árvores igualmente mais parcimoniosas, temos duas configurações distintas para este caráter. 


\section{Configuração 1}

Plesiomórfico: 0

(0) Autapomorfia por reversão de Metriocheila nigricollis.

(1) Sinapomorfia homoplástica de Megacephalina e do grupo formado pelas duas espécies de Amblycheila (43). Autapomorfia homoplástica de T. fulgida.

(2) Sinapomorfia homoplástica de Manticorina (46) e do clado 58.

\section{Configuração 2}

Plesiomórfico: 2

(0) Sinapomorfia homoplástica de Oxycheilina (53) e autapomorfia homoplástica de Metriocheila nigricollis.

(1) Sinapomorfia homoplástica do grupo formado pelas duas espécies de Amblycheila (43), do clado 64 e autapomorfia homoplástica de Aniara sepulcralis, Pseudotetracha cylindrica, Tetracha femoralis e Tetracha fulgida.

Os estados deste caráter não são muito fáceis de determinar, uma vez que o labro muitas vezes encontra-se desgastado. Quando uma grande quantidade de indivíduos de uma espécie foi analisada, foi necessário examinar o formato e o comprimento dos dentes a fim de avaliar tal desgaste e codificar de maneira mais acurada.

Apesar de $M$. nigricollis apresentar um labro subtriangular, a forma é diferente, pois o que torna esse subtriangular são os dois dentes médios muito projetados, enquanto que em Oxycheilina, o "corpo" todo do labro apresenta essa forma, além de os dentes medianos não serem muito projetados. 
12. Labro, subtriangular, margens laterais nas fêmeas ( $c i=1 ; r=1$ ):

0. quasi-retas

1. marcadamente emarginadas

2. arredondadas

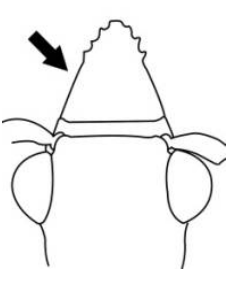

0

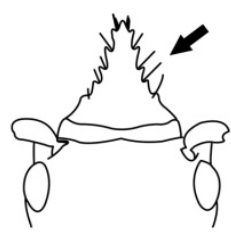

1

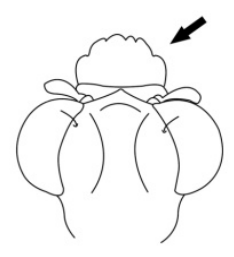

2

Distribuição dos estados:

Plesiomórfico: 1

(0) Sinapomorfia do clado 53.

(-) todos os táxons que não apresentam labro subtriangular.

13. Labro, coloração (ci=0,28; $r=0,77)$ :

0. amarelada

1. castanha

2. enegrecida

Distribuição dos estados:

Otimização ACCTRAN

Plesiomórfico: 2

(0) Sinapomorfia homoplástica dos clados 66 e 73.

(1) Sinapomorfia homoplástica do clado 60.

(2) Reversão em Pseudotetracha cylindrica.

Ambiguidade: as espécies Oxycheila labiata e Metriocheila nigricollis possuem labro bicolor, por isso não foi possível estabelecer o estado. 
14. Labro, relação do comprimento sobre a largura (vista dorsal) (ci=1; $c i=1$ ):

0. menos que 0,8

1. mais que 0,8

Distribuição dos estados:

Plesiomórfico: 0

(1) Sinapomorfia de Oxycheilina.

15. Labro, cerdas, posição das inserções (ci=0,50; $r=0,90)$ :

0. submarginal

1. marginal

Distribuição dos estados:

Plesiomórfico: 0

(1) Sinapomorfia homoplástica de Oxycheilina.

16. Labro, lobos laterais, condição (ci=0,20; r=0,78) (fig. 8C e 8D):

0 . retos ou quase retos

1. projetados

Distribuição do carácter:

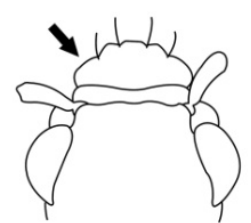

0

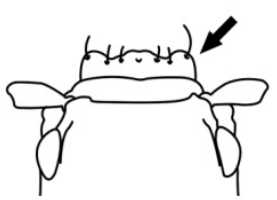

1

Plesiomórfico: 1

(0) Sinapomorfia homoplástica de Megacephalina. 
(1) Autapomorfia homoplástica por reversão de Phaeoxantha klugii e Phaeoxantha laminata.

17. Labro, lobos laterais, cerdas $(c i=0,50 ; r=0,93)$ :

0. presentes

1. ausentes

Distribuição dos estados:

Plesiomórfico: 0

(1) Sinapomorfia homoplástica do clado 50 (Oxycheilina + Megacephalina).

18. Labro, dentes medianos, relação sobre o comprimento dos lobos laterais $(c i=0,33 ; r=0)$ :

0. não ultrapassam os lobos laterais

1. ultrapassam os lobos laterais

Distribuição dos estados:

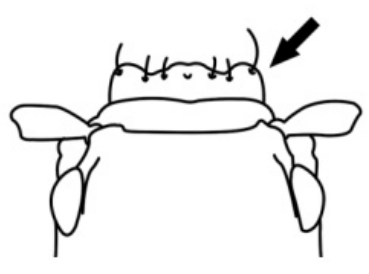

0

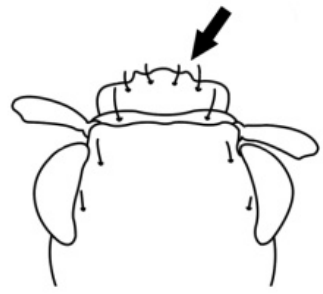

1

Plesiomórfico: 0

(0) Autapomorfia homoplástica de Picnochile fallaciosa e Omus dejeani.

Ambiguidade: Entre os espécimes estudados, foram encontrados indivíduos de $T$. carolina com os dois estados. 
19. Labro, margem anterior (não informativo):

0. com dentes

1. inerme

Distribuição dos estados:

Caráter não informativo. Apenas a espécie Calosoma granulatum, usada para o enraizamento, possui o estado apomórfico.

20. Labro, dentes medianos, quantidade (ci=0,44; $r=0,66)$ (fig. $8 \mathrm{C}$ e $8 \mathrm{E})$ :

0. mais que 7

1. 7

2. 6

3. 5

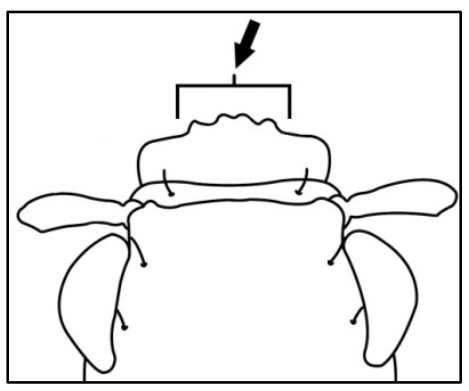

4. 4

5. 3

6. 2

Distribuição dos estados:

Plesiomórfico: 3

Otimização ACCTRAN

(0) Sinapomorfia de Oxycheilina (54).

(4) Sinapomorfia homoplástica de Megacephalini.

(5) Autapomorfia homoplástica de Aniara sepulcralis e Metriocheila nigricollis. 
(6) Autapomorfia de Picnochile fallaciosa.

Ambiguidade: grande variação encontrada em G. euphratica, sendo possíveis os estados 1,2 e 3 .

21. Labro, cerdas na margem anterior, quantidade (ci=0,37; $r=0,73)$ (fig. $8 \mathrm{C}$ e 8D):

0.4

1. 5

2. 6

3. 8

4. mais que 8

Distribuição dos estados:

Otimização ACCTRAN: esta otimização foi escolhida devido a presença de 8 cerdas na margem anterior do labro de muitos exemplares de Omus dejeani, agrupando deste modo as duas espécies do gênero.

Plesiomórfico: 4

(0) Sinapomorfia homoplástica de Megacephalina (49).

(2) Para duas árvores mais parcimoniosas obtidas, este estado se comporta como sinapomorfia do clado 67; para as outras duas, autapomorfia de Phaeoxantha klugii.

(3) Sinapomorfia do clado formado pelas duas espécies de Omus (68).

Ambiguidade: caráter bastante plástico, sendo polimórfico em várias espécies. 
22. Labro, dente central mais longo nas fêmeas (dimorfismo sexual) (ci=0,50; $r=0,50)$ :

0 . ausente

1. presente

Distribuição dos estados:
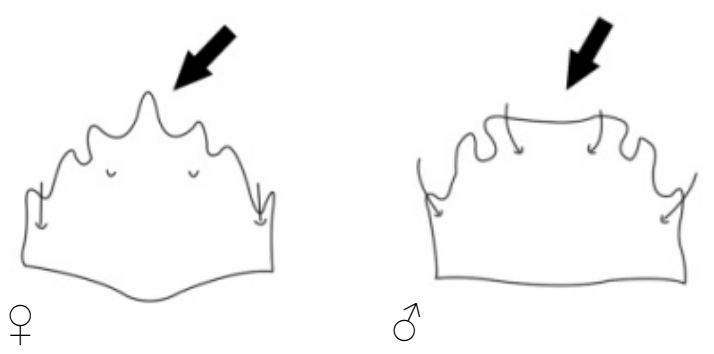

Plesiomórfico: 0

Apenas três espécies fora de Megacephalini apresentam o estado apomórfico.

23. Epifaringe, pedium (BALL, 2011) (não informativo):

0. bem desenvolvido, côncavo em forma de palato

1. curto

Otimização ACCTRAN

Plesiomórfico: 0

Apenas Calosoma granulatum, usada para o enraizamento, apresenta o estado apomórfico.

Apesar de o estado 0 estar possivelmente presente em todos os Cicindelinae, as espécies mais raras não tiveram seu labro dissecado e tal caráter não foi analisado.

24. Clípeo, comprimento, relação sobre o comprimento do labro (ci=0,40; $r=0,25)$ (fig. 8F e 8G):

0. mesmo comprimento 
1. clípeo mais curto que o labro

2. clípeo mais longo que o labro

Distribuição dos estados:

Otimização ACCTRAN

Plesiomórfico: 1

(0) Sinapomorfia de Manticorina (46)

(1) Reversão no clado formado pelas duas espécies de Omus (68).

(2) Autapormorfia homoplástica de Amblycheila picolominii e Megacephala megacephala.

25. Clípeo, cerdas laterais, quantidade de cada lado $(c i=0,28 ; r=0,66)$ :

0.3 ou mais

1. 2

2. 1

3. ausentes

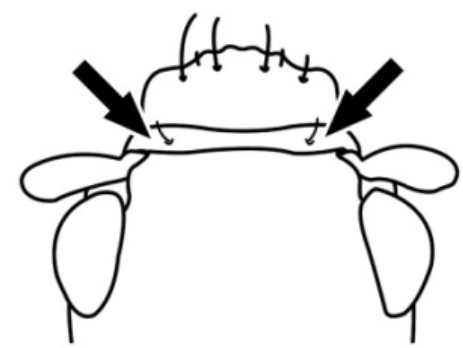

Distribuição dos estados:

Plesiomórfico: 2

(0) Autapomorfia homoplástica de Picnochile fallaciosa, Manticora tuberculata, Phaeoxantha klugii e Megacephala megacephala.

(3) Sinapomorfia homoplástica de Oxycheilina (54). 
26. Clípeo, cerdas escamiformes (não informativo):

0 ausentes

1 presentes

Distribuição dos estados:

Este caráter não se mostrou informativo, estando presente em apenas uma espécie do grupo externo (Cylindera nivea).

27. Mandíbulas, face externa (escrobo), cerdas ( $c i=0,33 ; r=0,60)$ :

0 ausentes

1 presentes

Distribuição dos estados:

Plesiomórfico: 0

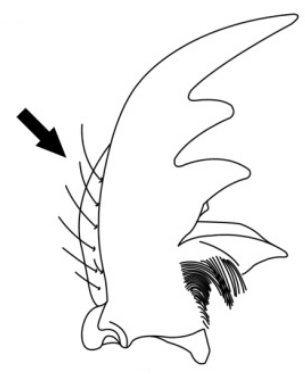

(1) Sinapomorfia homoplástica do clado 44 e do grupo formado pelas duas espécies de Megacephala (55). Autapomorfia homoplástica de Pseudotetracha cylindrica.

28. Mandíbulas, face externa mais clara $(c i=1 ; r=1)$ :

0 presente

1 ausente

Distribuição dos estados:

Plesiomórfico: 1 
(0) Este caráter está presente em apenas um clado (75) fora de Megacephalini.

29. Mandíbulas, margem externa, expansão em forma de dente (ci=1; r=1):

0 ausente

1 presente

Distribuição dos estados:

Plesiomórfico: 0

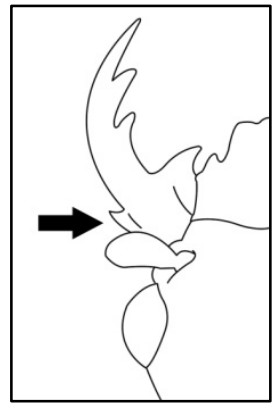

(1) Este caráter está presente apenas no clado externo a Megacephalini formado pelas duas espécies de Ctenostoma.

30. Mandíbula esquerda, dentes internos, quantidade (ci=0,37; $r=0,64)$ (fig. 9H):

0.1

1. 2

2. 3

3. 4

Distribuição dos estados:

Otimização ACCTRAN

Plesiomórfico: 0

(2) Sinapomorfia homoplástica de Oxycheilina (54) e do clado 71.

(3) Sinapomorfia do clado 69. 
Oxycheila opacipennis apresenta modificações mandibulares como dimorfismo sexual, sendo no macho bastante conspícuas, tendo dentes reduzidos, parcialmente fundidos e deslocados para próximo ao ápice da mandíbula (fig. $8 \mathrm{H}$ ). Deste modo, uma fêmea foi analisada para estabelecer o número de dentes. Tanto machos quanto fêmeas de todas as espécies foram examinados.

31. Mandíbula esquerda, dente retinacular suplementar (BALL, 2011) (ci=0,20; $r=0,66)$ (fig. 9A):

0. presente

1. ausente

Distribuição dos estados:

Otimização ACCTRAN

Plesiomórfico: 1

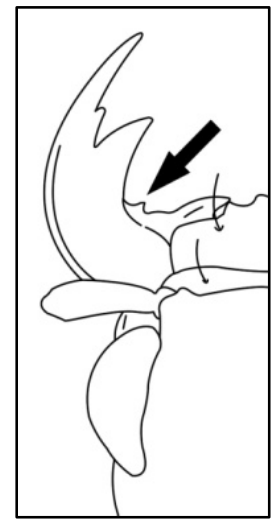

(0) Sinapomorfia de Megacephalina. Em duas árvores mais parcimoniosas, ocorre como reversão de $P$. klugii e $M$. nigricollis.

(1) Autapomorfia homoplástica por reversão de Pseudotetracha howitti, Australicapitona basalis e Tetracha femoralis. Em duas árvores igualmente parcimoniosas, também se comporta como sinapomorfia homoplástica do clado 83 (Platychile pallida + Phaeoxantha laminata); este clado está presente apenas nessas duas árvores. Nas duas outras árvores aparece como sinapomorfia homoplástica por reversão do clado 64. 
32. Mandíbula esquerda, dente interno bífido $(c i=0,16 ; r=0,44)$ :

0. presente

1. ausente

Distribuição dos estados:

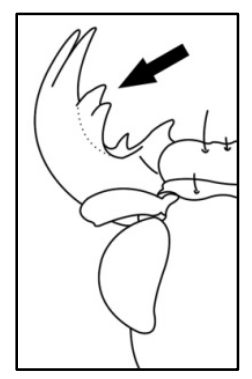

Otimização DELTRAN: a escolha de tal otimização deve-se ao fato de que, além do estado 1 ser muito mais frequente, e sob minha avaliação, mais aceitável ter aparecido algumas vezes dentro de Megacephalina, assim como ocorre nos outros grupos, esta otimização faz com que esse caráter se comporte da mesma maneira em todas as 4 árvores mais parcimoniosas obtidas.

Plesiomórfico: 1

(0) Sinapomorfia homoplástica do clado 71. Autapomorfia homoplástica de Manticora tuberculata, Aniara sepulcralis, Pseudotetracha murchisona e Tetracha femoralis.

33. Mandíbula direita, dimorfismo sexual, relação de tamanho entre primeiro e segundo dente muito maior nos machos (não informativo):

0 . presente

1. ausente

Distribuição dos estados:

Plesiomórfico: 1

(0) Autapomorfia de Grammognatha euphratica.

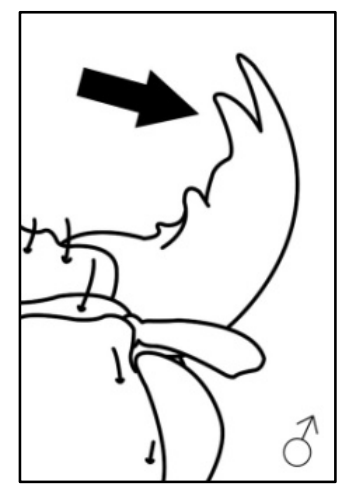

Ambiguidade: algumas espécies não foram examinadas, pois este carácter foi evidenciado após a devolução da maior parte do material emprestado. 
34. Mandíbula esquerda, dimorfismo, primeiro dente notavelmente maior nos machos $(c i=0,33 ; r=0,60)$ :

0 . presente

1. ausente

Distribuição dos estados:

Plesiomórfico: 1
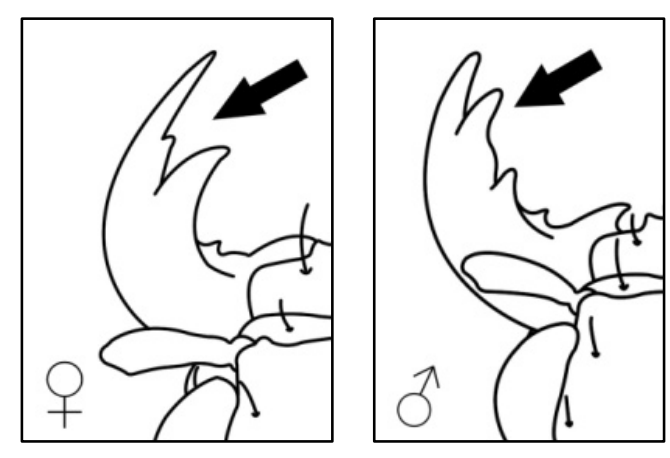

(0) Sinapomorfia homoplástica do clado 73. Autapomorfia homoplástica de Grammognatha euphratica.

Ambiguidade: algumas espécies não foram examinadas, pois este caráter foi evidenciado após a devolução da maior parte do material emprestado.

35. Mandíbula direita, dentes internos, quantidade (ci=0,42; r=0,63) (fig. 9H):

0.4

1. 3

2. 2

3. 1

Distribuição dos estados:

Otimização ACCTRAN

Plesiomórfico: 2 
(0) Sinapomorfia do clado 69.

(1) Sinapomorfia homoplástica de Oxycheilina (54) e do clado 71.

(2) Reversão de Tetracha fulgida.

36. Mandíbula direita, dente apical, macho com margem externa expandida (dimorfismo sexual) $(c i=0,50 ; r=0)$ :

0 . presente

1. ausente

Distribuição dos estados:

Plesiomórfico: 1
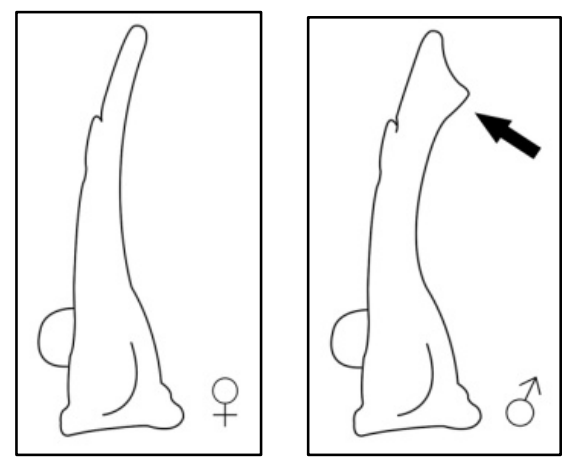

(0) Presente apenas em duas espécies que não pertence a Megacephalini (Cylindera nivea e Cicindela campestris).

- as ilustrações referem-se à vista externa da mandíbula direita.

37. Mandíbula direita, dente retinacular suplementar (BALL, 2011) (ci=0,25; $r=0,76)$ (fig. 9B):

0 presente

1 ausente

Distribuição dos estados:

Otimização DELTRAN: optei por ser um caráter equivalente ao 32, para o qual usei tal otimização.

Plesiomórfico: 1 
(0) Sinapomorfia de Megacephalina.

(1) Para duas árvores mais parcimoniosas é autapomorfia homoplástica por reversão de $T$. femoralis, $A$. basalis, $P$. pallida e $P$. laminata; para as outras duas árvores é sinapomorfia homoplástica por reversão do clado 65 e autapomorfia homoplástica por reversão de $T$. femoralis e A. basalis.

38. Mandíbula direita, dente interno bífido $(c i=0,25 ; r=0,25)$ :

0 . presente

1. ausente

Distribuição dos estados:

Otimização ACCTRAN

Plesiomórfico: 0

(0) Autapomorfia homoplástica por reversão de Oxycheila tristis e Manticora tuberculata.

39. Maxila, cardo, cerdas ( $c i=0,60 ; r=0,60)$ (fig. $9 \mathrm{C})$ :

0. mais de 2

1. 2

2. 1

3. ausentes

Distribuição dos estados:

Plesiomórfico: 3 
(2) Sinapomorfia de Manticorina.

(3) Reversão de Omus californicus.

Ambiguidade: Manticora tuberculata pode ter 2 ou mais de 2 cerdas no cardo, diferente dos outros membros examinados da subtribo Manticorina.

40. Maxila, basiestipe, cerdas $(c i=0,36 ; r=0,41)$ (fig. $9 \mathrm{C})$ :

0 . mais de 5

1.5

2. 4

3. 3

4. 2

5. 1

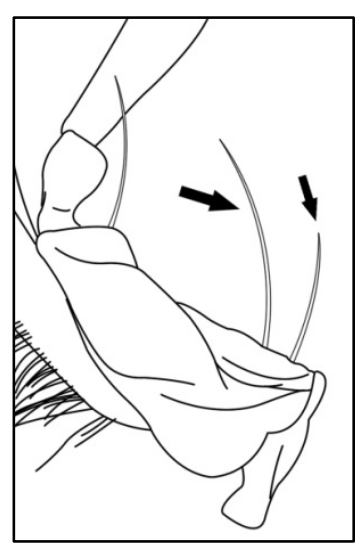

6. ausentes

Distribuição dos caracteres:

Otimização ACCTRAN

Plesiomórfico: 3

(0) Autapomorfia homoplástica de Manticora tuberculata

(2) Autapomorfia de Megacephala megacephala

(4) Sinapomorfia homoplástica de Oxycheilina (54), do clado 57 e do clado 63.

(5) Autapomorfia homoplástica de Oxycheila opacipennis. 
Caráter muito variável dentro das espécies, gerando desse modo muita ambiguidade. Porém as espécies em que o estado é constante ajuda a análise como um todo.

41. Maxila, palpífero, cerdas ( $c i=0,44 ; r=0)$ :

0.4

1. 3

2. 2

3. 1

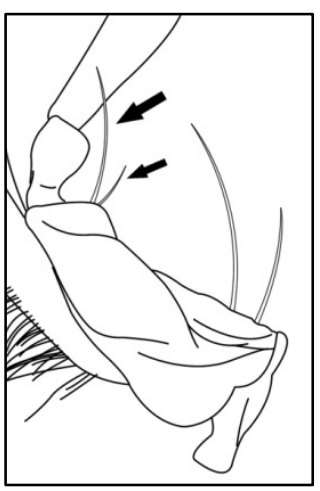

4. ausentes

Distribuição dos estados:

Otimização ACCTRAN

Plesiomórfico: 2

(0) Autapomorfia de Megacephala megacephala.

(1) Autapomorfia de Manticora tuberculata.

(3) Autapomorfia homoplástica de Picnochile fallaciosa, Metriocheila nigricollis e Tetracha brasiliensis.

Ambiguidade: número de cerdas varia nas duas espécies de Amblycheila e em Pseudoxycheila ceratoma. 
42. Maxila, palpo, comprimento do terceiro palpômero, relação sobre o comprimento do quarto $(c i=0,20 ; r=0,52)$

0. aproximadamente o mesmo comprimento

1. terceiro palpômero mais curto que o quarto

2. terceiro palpômero mais longo que o quarto

Distribuição dos estados:

Otimização ACCTRAN: apenas para resolver a ambiguidade na base do cladograma.

Plesiomórfico: 0

(0) Bastante homoplástico, aparecendo como autapomorfia homoplástica por reversão de oito espécies.

(2) Sinapomorfia dos Cicindelinae estudados.

43. Maxila, lacínia, uncus articulado $(c i=0,50 ; r=0,50)$

0 ausente

1 presente

Distribuição dos estados:

Plesiomórfico: 0
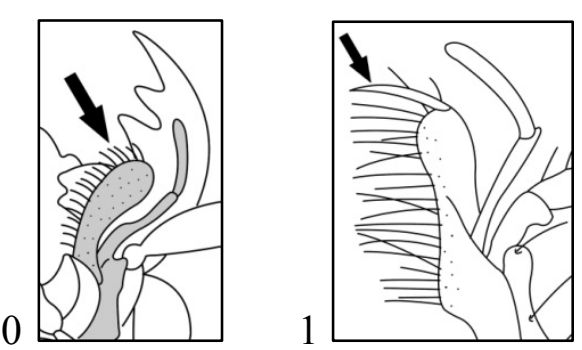

O uncus articulado é um dente presente no ápice da lacínia. De todos os exemplares de Cicindelinae examinados, apenas as espécies de Ctenostoma não apresentaram tal estrutura. Isso foi observado também por Jorge-da-Silva (1979), em sua tese sobre as peças bucais de Carabidae. 
44. Lábio, mento, dente, comprimento, relação sobre a distância entre a sutura e o ápice da invaginação (ci=0,16; $r=0)$

0 menor ou igual

1 maior

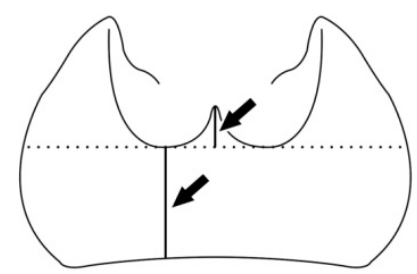

Distribuição dos estados:

Otimização ACCTRAN: apenas para resolver a ambiguidade na base do cladograma.

Plesiomórfico: 0

(0) Autapomorfia homoplástica por reversão de 3 espécies: Picnochile fallaciosa, Manticora tuberculata e Cheiloxya binotata.

(1) Sinapomorfia dos Cicindelinae analisados.

45. Lábio, mento, dente, cerdas (não informativo):

0 ausentes

1 presentes

Caráter não informativo. Estado 1 é uma autapomorfia para Pseudotetracha cylindrica.

46. Lábio, glossas fundidas (membranosas), cerdas longas (ci=0,33; $r=0,60$ ) (fig. 9D e 9E):

0 presentes

1 ausentes 
Distribuição dos estados:

Plesiomórfico: 0

(0) Reversão em Manticora tuberculata.

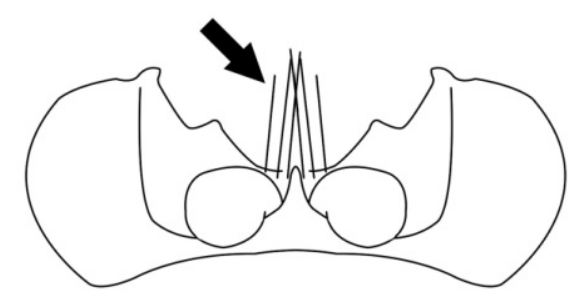

(1) Sinapomorfia homoplástica de Manticorina e autapomorfia homoplástica de Metriocheila nigricollis.

47. Lábio, largura, relação sobre o comprimento (ci=0,16; $r=0,37)$ :

$0.2,35$ ou mais

1. menos de 2,35

Distribuição dos estados:

Otimização ACCTRAN

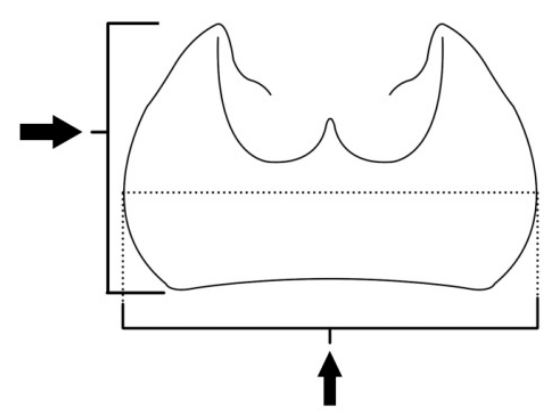

Plesiomórfico: 1

(0) Sinapomorfia homoplástica dos clados 53, 64 e 72. Autapomorfia homoplástica de Pseudotetracha howitti.

(1) Reversão do clado 69 e de Metriocheila nigricollis.

48. Lábio, palpo, penúltimo palpômero, comprimento, relação sobre o comprimento do último palpômero $(c i=0,50 ; r=0,66)$ :

0.3 ou mais

1. menos de 3

Distribuição dos estados: 
Plesiomórfico: 1

Apenas 2 clados externos a Megacephalini possuem o estado apomórfico.

49. Clípeo, largura, relação sobre a distância entre os pontos de inserção das antenas (não informativo):

0. mais estreito

1. mais largo

Distribuição dos estados:

Plesiomórfico: 0

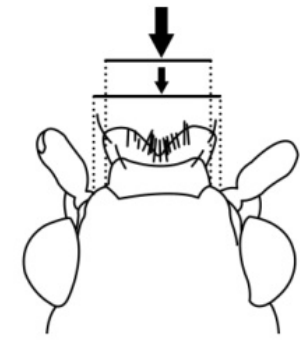

0

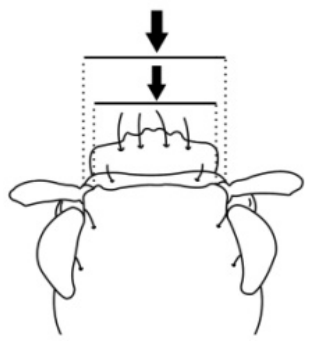

1

(1) Comum a todos os Cicindelinae.

50. Cabeça, fronte, estrias, área ocupada (ci=0,14; $r=0,66)$ :

0 . toda a fronte

1. apenas perto dos olhos

Distribuição dos estados:

Plesiomórfico: 0

(0) Reversão no clado 63 e em T. femoralis.

(1) Sinapomorfia homoplástica do clado 44 e do clado Oxycheilina + Megacephalina (50). Reversão de Metriocheila nigricollis. 
51. Cabeça, fronte, cerdas, quantidade (ci=0,33; $r=0,33)$ :

0. mais de 3 de cada lado

1. 1 de cada lado

2. ausentes

Distribuição dos estados:

Plesiomórfico: 2

(0) Autapomorfia homoplástica de Picnochile fallaciosa e Manticora tuberculata.

(1) Autapomorfia homoplástica de Megacephala megacephala.

Ambiguidade: para 3 espécies foram encontrados espécimes sem cerdas ou com 1 cerda de cada lado da fronte.

52. Cabeça, ventral, linhas da gula, forma $(c i=0,16 ; r=0,61)$ :

0. curvas

1. sinuosas

Distribuição dos estados:

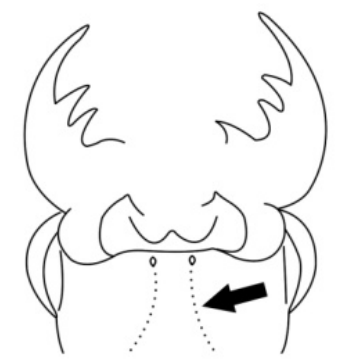

0

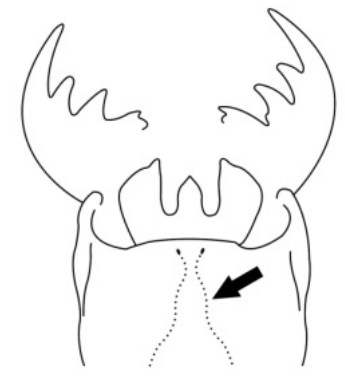

1

(1) Sinapomorfia homoplástica do clado 44 , e do clado formado pelas duas espécies de Megacephala (55). Autapomorfia homoplástica de Phaeoxantha laminata. 
53. Cabeça, ventral, gula, superfície (ci=0,33; r=0,80) (fig. 9F e 9G):

0 lisa

1 estriada

Distribuição dos estados:

Otimização ACCTRAN

Plesiomórfico: 1

(0) Sinapomorfia homoplástica de Megacephalini--

(1) Reversão de Picnochile fallaciosa.

54. Cabeça, ventral, linhas gulares, relação às fossetas $(c i=0,20 ; r=0,11)$ :

0 . fossetas acompanhando as linhas

1. fossetas situadas internamente

2. fossetas situadas externamente

Distribuição dos estados:

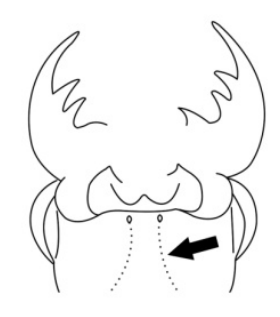

0

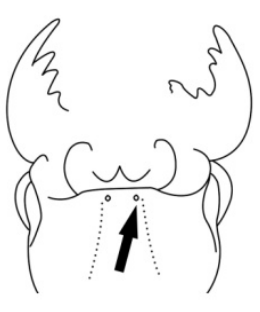

1

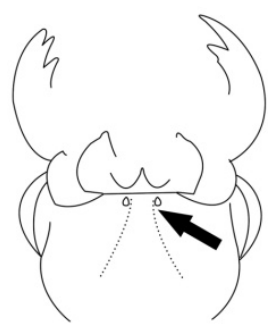

2

Otimização ACCTRAN: apenas para resolver a ambiguidade na base do cladograma.

Plesiomórfico: 0

(1) Autapomorfia homoplástica de Megacephala bocandei.

(2) Autapomorfia homoplástica de Omus californicus, Manticora tuberculata, Pseudoxycheila ceratoma e Aniara sepulcralis, 
55. Cabeça, fronte, margem anterior $(c i=0,50 ; r=0,85)$ :

0. angular

1. quasi-reta

Distribuição dos estados:

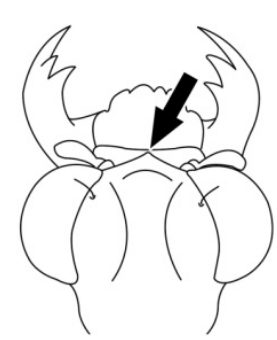

$\mathbf{0}$

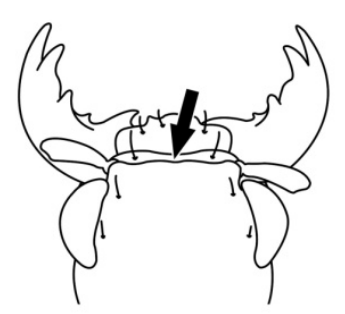

1

Plesiomórfico: 1

(0) Presente apenas no grupo externo.

56. Cabeça, vista lateral, distância entre margem dorso- e ventrobasal, relação sobre o maior diâmetro do olho (ci=0,66; $r=0,80)$ :

0. menos de 3

1. de 3 a 4

2. mais que 4

Distribuição dos estados:

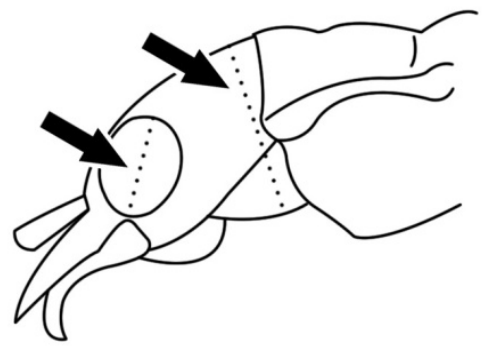

Plesiomórfico: 0

(1) Sinapomorfia homoplástica do clado 45 e do clado formado pelas duas espécies de Pseudoxycheila (70).

(2) Sinapomorfia do clado formado pelas duas espécies de Amblycheila.

57. Cabeça, cerdas, quantidade de cada lado ( $c i=0,50 ; r=0,20)$ (fig. $8 \mathrm{~F} \mathrm{e} 8 \mathrm{G}$ ):

0. mais de 7

1. 7 
2. 5

3. 4

4. 3

5. 2

6. 1

Distribuição dos estados:

Otimização ACCTRAN

Plesiomórfico: 5

(0) Sinapomorfia homoplástica de Manticorina.

(2) Sinapomorfia para as duas espécies de Omus (68)

(4) Autapomorfia de Omus dejeani.

Ambiguidade: Há uma possível reversão para o estado 5 no clado que une as duas espécies de Amblycheila, pois em vários exemplares examinados destas espécies foi encontradas apenas 2 cerdas de cada lado.

58. Cabeça, região mediana basal, estrias $(c i=0,12 ; r=0,41)(f i g .8 H)$ :

0 . ausentes

1. presentes

Distribuição dos estados:

Plesiomórfico: 1

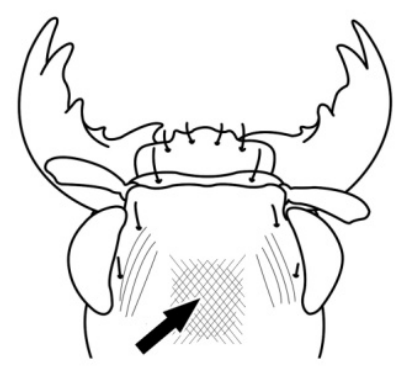


(0) Sinapomorfia homoplástica de Oxycheilina (54) e do clado 44. Autapomorfia homoplástica de Phaeoxantha laminata e Megacephala megacephala.

(1) Reversão em Oxycheila labiata.

59. Cabeça, lateral, menor distância entre a linha subgenal e o forâmen, relação sobre a distância entre a invaginação do forâmen e a base da mandíbula (não informativo):

0. menos que 0,35

1. mais que 0,35

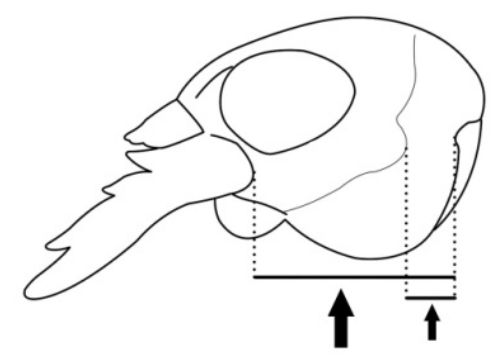

Não informativo devido ao estado 1 estar presente apenas no grupo externo usado para o enraizamento.

60. Cabeça, dorsal, sutura occipital dorsal $(c i=0,14 ; r=0,14)$ :

0. incompleta

1. completa

Distribuição dos estados:

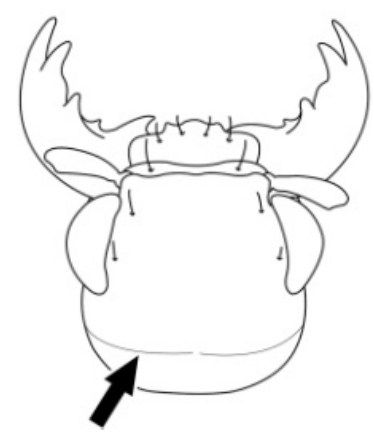

Otimização ACCTRAN: apenas para resolver a ambiguidade na base do cladograma.

Plesiomórfico: 0 
(1) Sinapomorfia homoplástica do clado que une as duas espécies de Amblycheila (43). Autapomorfia homoplástica de Picnochile fallaciosa, Oxycheila labiata, Australicapitona basalis e Megacephala bocandei.

(?) Pseudotetracha howitti não teve sua cabeça destacada do corpo para que fosse examinado o caráter devido a ser uma espécie escassa nas coleções consulatadas.

61. Cabeça, coloração visível dorsalmente (ci=0,16; r=0,72) (fig. 10A e 10B):

0. por pigmento

1. iridescente

Distribuição dos estados:

Otimização ACCTRAN

Plesiomórfico: 1

(0) Sinapomorfia homoplástica de Megacephalini. Reversão no clado 67 e em Megacephala megacephala.

(1) Reversão no clado que une as duas espécies de Pseudoxycheila (70) e do clado (60).

É possível perceber que os Cicindelinae usados como grupo externo apresentam iridescência na cabeça e em Megacephalina esta iridescência é perdida, expondo apenas a coloração pigmentar. A iridescência surge novamente em dois pontos dentro de Megacephalini: em Pseudoxycheila, com um brilho um pouco diferente dos demais cicindelíneos e em Megacephalina, no clado que exclui Aniara sepulcralis. Esta iridescência é perdida novamente nos gêneros Phaeoxantha, Platychile e Metriocheila e isoladamente em Megacephala megacephala. 
62. Cabeça, coloração por pigmento, amarelada ( $c i=1 ; r=1)$ :

0 . presente

1. ausente

Distribuição dos estados:

Otimização DELTRAN: o cladograma foi otimizado para resolver a ambiguidade do clado 63. Esta foi escolhida, pois agrupará somente os que possuem a coloração externamente, deixando de fora os não aplicáveis (por apresentarem iridescência sobre a camada pigmentar), que de certa forma não possuem também esta coloração exposta dorsalmente.

Plesiomórfico: 1

(0) Sinapomorfia do clado 67.

63. Cabeça, cor por pigmento, enegrecida (ci=0,33; $r=0,60)$ :

0 . presente

1. ausente

Distribuição dos estados:

Plesiomórfico: 0

(0) Reversão em Metriocheila nigricollis.

(1) Sinapomorfia do clado 60 . 
64. Cabeça, superfície dorsal, pontuações espalhadas por toda a superfície (ci=0,25; r=0):

0 presente

1 ausente

Distribuição dos estados:

Otimização ACCTRAN: apenas para resolver a ambiguidade na base do cladograma.

Plesiomórfico: 0

(0) Autapomorfia homoplástica de Manticora tuberculata e Australicapitona basalis.

65. Cabeça, sutura subgenal, parte inferior (ci=0,16; $r=0,58)$ (fig. 10C e 10D):

0. reta

1. sinuosa

Distribuição dos estados:

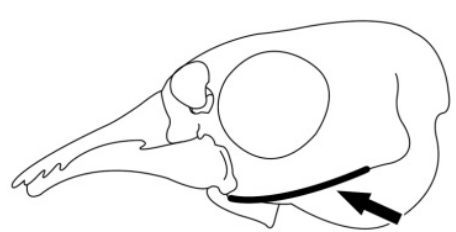

0

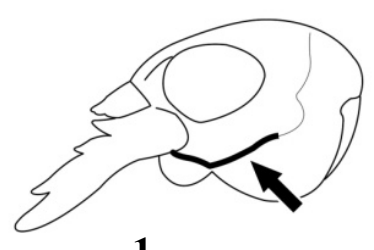

1

Plesiomórfico: 0

(0) Reversão em Platychile pallida e Tetracha femoralis.

(1) Sinapomorfia homoplástica de Megacephalina (49) e do clado 44.

(?) Pseudotetracha howitti não teve sua cabeça destacada do corpo para que fosse examinado o caráter devido a ser uma espécie escassa nas coleções examinadas. 
Provavelmente este caráter, juntamente com o 66 tenha sido usado pela primeira vez em uma análise filogenética e mostrou-se útil no agrupamento de alguns clados.

66. Cabeça, sutura subgenal, parte superior $(c i=0,25 ; r=0)$ :

0. reta

1. sinuosa

Distribuição dos estados:

Não informativo para a tribo Megacephalini, estando presente apenas em algumas espécies externas.

67. Cabeça, sutura occipital dorsalmente $(c i=0,16 ; r=0,50)$ :

0 não visível

1 visível

Distribuição dos estados:

Otimização ACCTRAN

Plesiomórfico: 1

(0) Sinapomorfia homoplástica do clado 45 e autapomorfia homoplástica de Playchile pallida.

(1) Reversão no clado formado pelas duas espécies de Amblycheila (43). 
68. Cabeça, relação olho e fronte em vista lateral $(c i=0,33 ; r=0,80)$ :

0. olho não cobre a fronte

1. olho cobre a fronte

Distribuição dos estados:

Plesiomórfico: 0

(1) Autapomorfia homoplástica de Metriocheila nigicollis.

69. Gena, cerdas $(\mathrm{ci}=0,25 ; \mathrm{r}=0,25)$ :

0 ausentes

1 presentes

Distribuição dos estados:

Plesiomórfico: 0

(1) Autapomorfia homoplástica de Manticora tuberculata e Metriocheila nigricollis.

70. Gena, superfície, estrias longitudinais (ci=0,12; r=0,58) (fig. 10C e 10E):

0 ausentes

1 presentes

Distribuição dos estados:

Otimização ACCTRAN

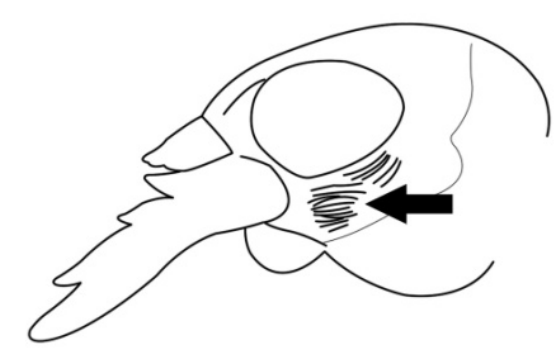

Plesiomórfico: 1 
(0) Sinapomorfia homoplástica de Oxycheilina (54), do clado 45 e do clado 67. Autapomorfia homoplástica de Pseudotetracha cylindrica e Tetracha femoralis.

(1) Reversão em Manticora tuberculata, e Metriocheila nigricollis.

71. Gena, superfície, estrias não longitudinais (ci=0,16; r=0,37) (fig. 10E e 10F):

0. presentes

1. ausentes

Distribuição dos estados:

Otimização ACCTRAN

Plesiomórfico: 1

(0) Sinapomorfia homoplástica de Manticorina (46) e do clado 56. Autapomorfia homoplástica de Pseudotetracha howitti e Australicapitona basalis.

(1) Reversão no clado 44.

72. Protórax $(c i=1 ; r=1)$ :

0 mais largo do que longo

1 mais longo do que largo

Distribuição dos estados:

Plesiomórfico: 0

Não informativo para Megacephalini. Estado 1 presente apenas em um clado do grupo externo (82). 
73. Protórax, cavidade coxal (não informativo):

0 fechada

1 aberta
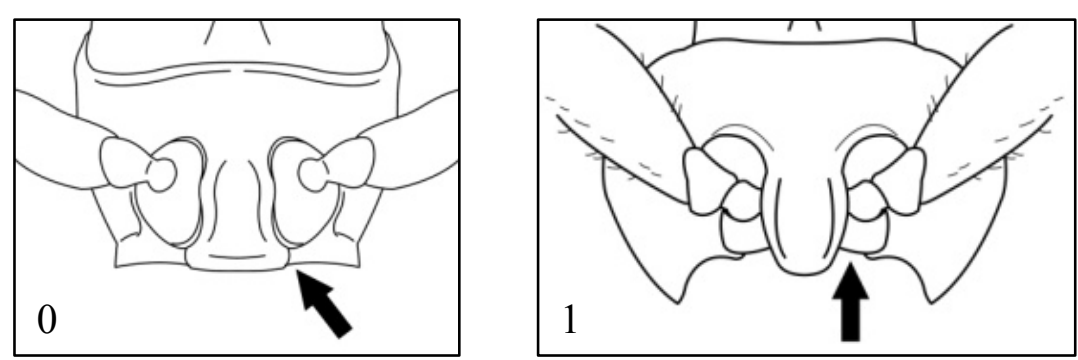

Não informativo. Estado 0 presente em todos os Cicidelinae.

74. Protórax, pronoto, comprimento, relação com a largura (ci=1; r=1):

0. 1,5 ou mais

1. menos de 1,5

Distribuição dos estados:

Plesiomórfico: 0

Não informativo para Megacephalini. Estado 1 presente apenas em um clado do grupo externo (82).

75. Protórax, pronoto, carena lateral $(c i=0,50 ; r=0,75)$ :

0. ausente

1. presente

Distribuição dos estados:

Plesiomórfico: 1

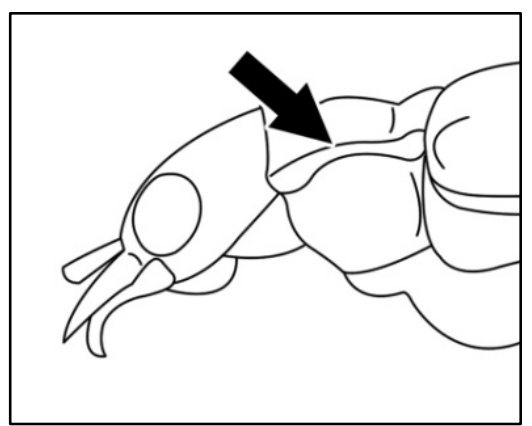


Não informativo para Megacephalini. Estado 0 presente apenas em clados do grupo externo (82 e 74).

76. Protórax, pronoto, lobos medianos (ci=0,14; $r=0,57)$ :

0. com regiões laterais bastante desenvolvidas

1. regiões laterais praticamente planas

Distribuição dos estados:

Otimização ACCTRAN

Plesiomórfico: 0
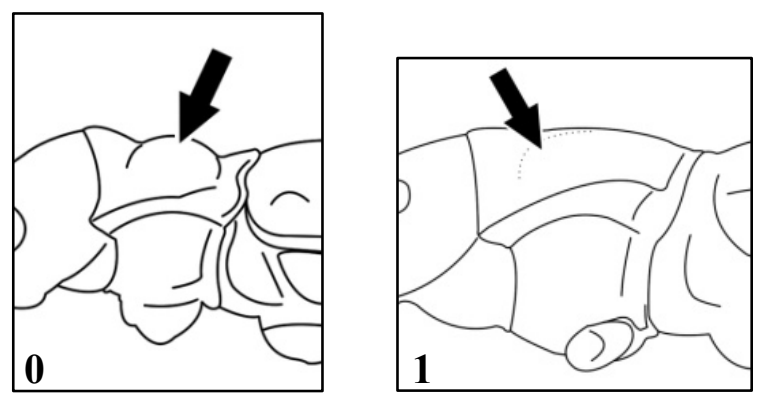

(0) Reversão em Manticora tuberculata.

(1) Sinapomorfia homoplástica do clado 45 e do clado 66. Autapomorfia homoplástica de Pseudotetracha murchisona.

77. Protórax, pronoto, cerdas (ci=0,33; r=0,71):

0. ausentes

1. presentes

Distribuição dos estados:

Plesiomórfico: 0

(1) Sinapomorfia do clado 44. 
78. Protórax, pronoto, cerdas, posição $(c i=0,66 ; r=0,50)$ :

0. muitas nas margens laterais

1. muitas espalhadas por toda a superfície

2. uma cerda em cada ângulo posterior apenas

3. duas a quatro cerdas de cada lado próximo às margens laterais

Distribuição dos estados:

Otimização ACCTRAN

Plesiomórfico: 1

(3) Sinapomorfia do clado que une as duas espécies de Ambycheila (43).

79. Protórax, pronoto, relação entre o restante do protórax $(c i=0,33 ; r=0,75)$ :

0. separado

1. fundido

Distribuição dos estados:

Plesiomórfico: 0
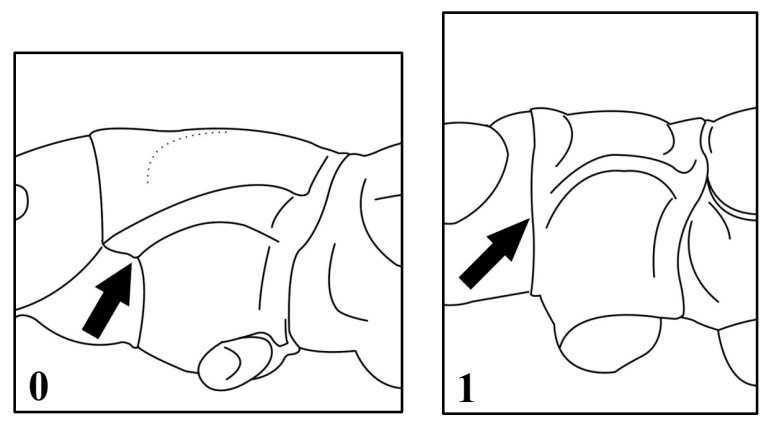

(1) Autapomorfia homoplástica de Manticora tuberculata.

80. Protórax, prosterno, margem posterior, cerdas $(c i=0,20 ; r=0,55)$ (fig. 10H):

0. presentes

1. ausentes 
Distribuição dos estados:

Otimização ACCTRAN: apenas para resolver a ambiguidade na base do cladograma.

Plesiomórfico: 0

(0) Sinapomorfia homoplástica por reversão de Oxycheilina (54) e do clado 44. Autapomorfia homoplástica por reversão de Megacephala megacephala.

(1) Reversão em Cheiloxya binotata.

81. Protórax, prosterno, margem posterior, largura, relação sobre a largura do ponto mais estreito do prosterno (vista interna) (ci=1; $r=1$ ):

0. mais que 8

1. menos que 8

Distribuição dos estados:

Plesiomórfico: 1

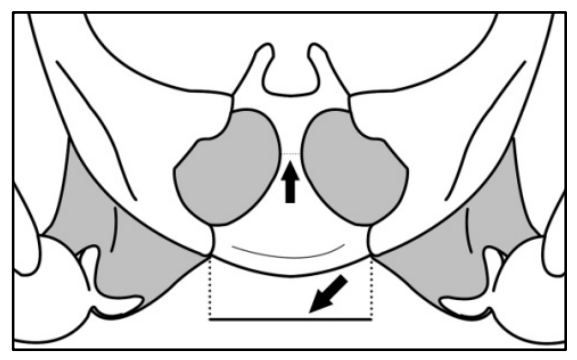

(0) Sinapomorfia do clado que une as duas espécies de Amblycheila (43).

Para a observação deste caráter, o protórax foi destacado do pterotórax e examinado com a parte posterior voltada para o observador. Na figura as regiões em cinza representam as procoxas.

82. Protórax, proepisterno, margem posterior, cerdas $(c i=0,33 ; r=0,50)$ :

0 . ausentes

1 presentes 
Distribuição dos estados:

Otimização DELTRAN

Plesiomórfico: 0

(1) Sinapomorfia homoplástica do clado 44. Autapomorfia homoplástica de Pseudotetracha murchisona e Australicapitona basalis.

83. Protórax, pronoto, coloração visível dorsalmente (ci=0,16; $r=0,73$ ):

0. por pigmeto

1. iridescente

Distribuição dos estados:

Otimização ACCTRAN

Plesiomórfico: (0)

(0) Reversão no clado 64.

(1) Sinapomorfia homoplástica do clado que une as duas espécies de Pseudoxycheila e do clado 60.

84. Protórax, pronoto, coloração por pigmento $(c i=0,50 ; r=0,50)$ :

0. escura

1. clara

Distribuição dos estados:

Otimização ACCTRAN 
Contingência.

Plesiomórfico: 0

(0) Reversão de Metriocheila nigricollis.

(1) Sinapomorfia do clado 60.

85. Protórax, pronoto, carena lateral, relação entre a margem anterior do prosterno $(c i=0,50 ; r=0,90)$ :

0. não ultrapassa

1. ultrapassa

Distribuição dos estados:

Plesiomórfico: 1
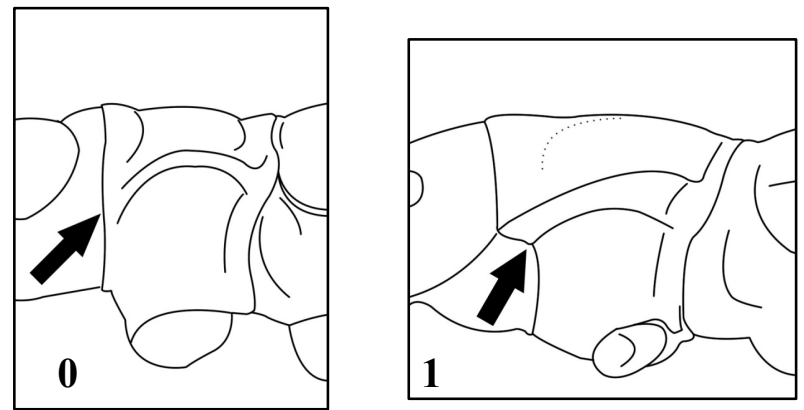

(0) Autapomorfia homoplástica de Manticora tuberculata.

86. Protórax, pronoto, carena lateral, projeção, forma (ci=0,50; r=0,91) (fig. $10 \mathrm{G}$ e 10H):

0. angulosa

1. arredondada

Distribuição dos estados:
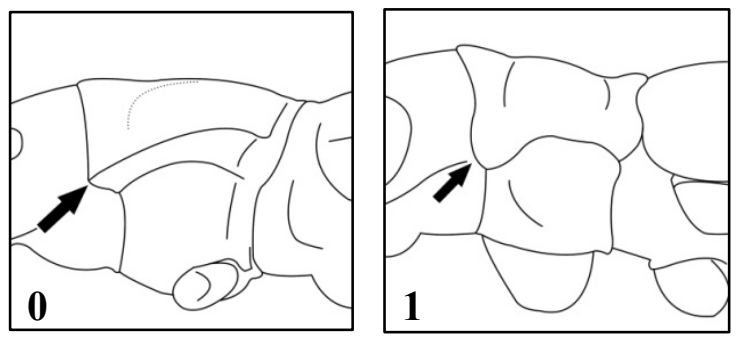

Plesiomórfico: 1

(0) Sinapomorfia de Megacephalini.

(1) Reversão em Manticora tuberculata. 
87. Protórax, margem posterior, forma $(c i=0,50 ; r=0,66)$ :

0 sinuosa

1 arredondada

Distribuição dos estados:

Plesiomórfico: 0

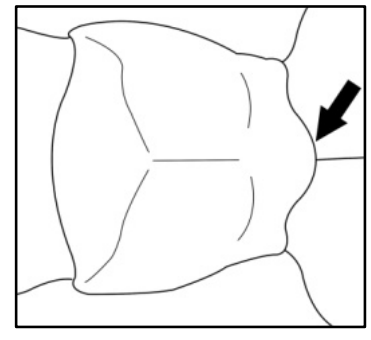

0

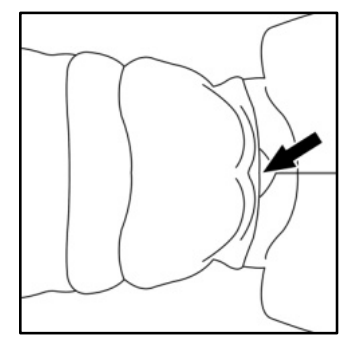

1

(1) Autapomorfia homoplástica de Manticora tuberculata.

88. Protórax, margem posterior sinuosa, região mediana $(c i=0,33 ; r=0,80)$ :

0. ultrapassa as laterais

1. não ultrapassa as laterais

Distribuição dos estados:

Contingência

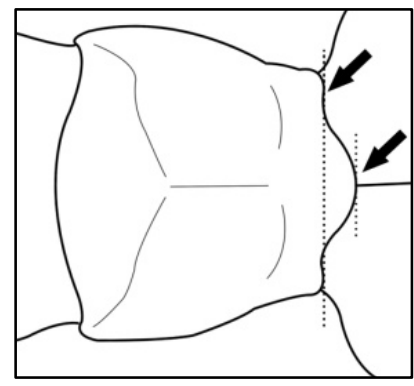

$\mathbf{0}$

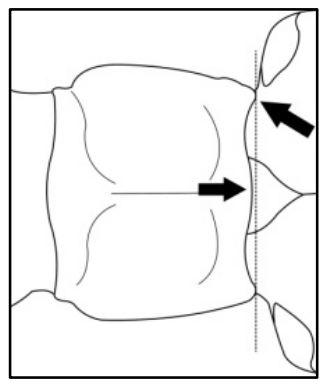

1

Plesiomórfico: 0

(1) Sinapomorfia homoplástica do clado que une as duas espécies de Omus (68). Autapomorfia homoplástica de Platychile pallida.

89. Prosterno, cerdas $(c i=0,25 ; r=0,40)$ :

0. presentes

1. ausentes

Distribuição dos estados: 
Otimização ACCTRAN

Plesiomórfico: 1

(0) Sinapomorfia do clado 44. Há também duas possibilidades dentro de Megacephalina discutidas abaixo.

Em duas das quatro árvores mais parcimoniosas, o estado 0 é uma sinapomorfia do clado 65. Já nas outras duas, é uma sinapomorfia do clado $66 \mathrm{com}$ uma reversão para o estado 1 em Platychile pallida, como ocorre também no consenso.

90. Prosterno, estrias (ci=0,12; $r=0,63)$ (fig. 11A e 11B):

0 . ausentes

1. presentes

Distribuição dos estados:

Otimização ACCTRAN

Plesiomórfico: 1

(0) Sinapomorfia homoplástica de Megacephalini. Reversão em Omus dejeani e Platychile pallida.

(1) Sinapomorfia homoplástica por reversão dos clados 45, 67 e 56. Reversão em Tetracha femoralis.

91. Proepisterno, cerdas ( $c i=0,40 ; r=0,25)$ :

0. escamiformes

1. simples 
2. ausentes

Distribuição dos estados:

Plesiomórfico: 2

(1) Autapomorfia homoplástica de Phaeoxantha laminata e Megacephala megacephala.

92. Perna anterior, quinto tarsômero, cerdas $(c i=0,33 ; r=0,33)$ :

0. Cerdas grossas e finas dispersas

1. apenas duas fileiras de cerdas grossas

Distribuição dos estados:

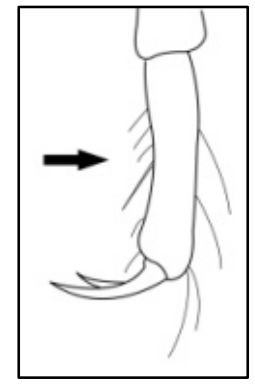

0

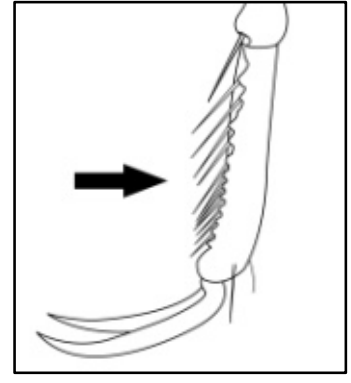

1

Otimização ACCTRAN: apenas para resolver a ambiguidade na base do cladograma.

Plesiomórfico: 0

(1) Autapomorfia homoplástica de Cheiloxya binotata.

93. Perna anterior, tarso, cerdas ventrais adesivas em fêmeas (ci=1; $r=1$ ):

0. presentes

1. ausentes

Distribuição dos estados:

Plesiomórfico: 1 
Estado 1 presente apenas no clado (82) fora de Megacephalini.

94. Perna anterior, tarso, coloração física ( $c i=1 ; c i=1)$ :

0. ausente

1. presente

Distribuição dos estados:

Plesiomórfico: 0

Estado 1 presente apenas no clado (82) fora de Megacephalini.

95. Perna anterior, tarso, dimorfismo sexual nos machos (cerdas adesivas) $(c i=1 ; r=1)$ :

0. ausente

1. presente

Distribuição dos estados:

Plesiomórfico: 1

(0) Sinapomorfia do clado 44.

96. Pró-coxa, coloração (ci=1; $r=1)$ :

0. física

1. por pigmento

Distribuição dos estados: 
Plesiomórfico: 1

Estado 0 presente em apenas um clado (78) fora de Megacephalini.

97. Pró-coxa, coloração por pigmento, tonalidade $(c i=0,28 ; r=0,75)$ :

0. amarelada

1. castanha

2. enegrecida

Distribuição dos estados:

Plesiomórfico: 2

(0) Sinapomorfia homoplástica dos clados 66 e 73.

(1) Sinapomorfia homoplástica do clado 60.

98. Pró-coxa, cerdas (ci=0,22; $r=0,63)$ :

0.2 ou mais

1. 1

2. ausentes

Distribuição dos estados:

Plesiomórfico: 0

(0) Reversão em Phaeoxantha laminata e Megacephala megacephala.

(1) Sinapomorfia homoplástica do clado que une as duas espécies de Omus (68). Autapomorfia homoplástica de Platychile pallida e Tetracha germaini. 
(2) Sinapomorfia homoplástica do clado 50 (Oxycheilina + Megacephalina).

99. Pró-coxa, cerdas escamiformes ( $c i=1 ; r=1)$ :

0. presentes

1. ausentes

Distribuição dos estados:

Plesiomórfico: 1

Estado 0 presente apenas no clado (75) fora de Megacephalini.

100. Pró-trocânter, coloração (ci=0,22; r=0,68):

0. amarelada

1. castanha

2. enegrecida

Distribuição dos estados:

Plesiomórfico: 2

(0) Sinapomorfia homoplástica dos clados 66 e 73 . Autapomorfia homoplástica de Oxycheila labiata.

(1) Sinapomorfia homoplástica do clado 60.

101. Pró-trocânter, ápice, cerdas longas (ci=0,25; $r=0,33$ ):

0. ausentes

1. 1 


\section{2 ou mais}

Distribuição dos estados:

Plesiomórfico:1

(0) Sinapomorfia homoplástica do clado 62. Autapomorfia homoplástica de Cheiloxya binotata, Metriocheila nigricollis e Grammognatha euphratica.

(1) Reversão no clado 67.

(2) Autapomorfia homoplástica de Manticora tuberculata.

Essa cerda localiza-se na porção apical do trocânter e é geralmente mais longa que o comprimento da estrutura.

102. Pró-trocânter, face interna, cerdas curtas (ci=0,25; $r=0,25)$ :

0. ausentes

1. presentes

Distribuição dos estados:

Plesiomórfico: 1

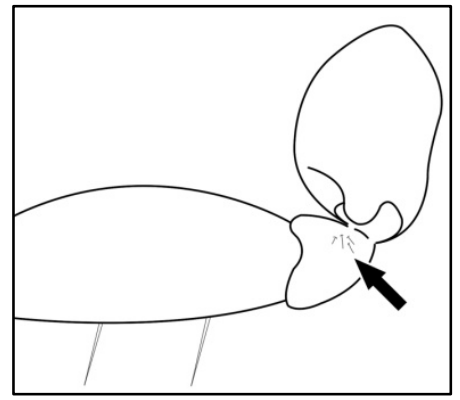

(0) Autapomorfia homoplástica de Picnochile fallaciosa e Megacephala bocandei.

103. Pró-fêmur, coloração ( $c i=1 ; r=1)$ :

0. física

1. por pigmento 
Distribuição dos estados:

Plesiomórfico:1

Estado 0 presente apenas em espécies fora de Megacephalini.

104. Pró-fêmur, coloração por pigmento, tonalidade $(c i=0,40 ; r=0,85)$ :

0. amarelada

1. castanha

2. enegrecida

Distribuição dos estados:

Plesiomórfico: 2

(0) Sinapomorfia homoplástica dos clados 66 e 73.

(1) Sinapomorfia homoplástica do clado 60.

Ambiguidade: a espécie Oxycheila labiata apresenta as duas tonalidades de cor.

105. Pró-tíbia, coloração (ci=1; r=1):

0. física

1. por pigmento

Distribuição dos estados:

Plesiomórfico: 1

Estado 0 presente apenas em espécies fora de Megacephalini. 
106. Pró-tíbia, cor por pigmento, tonalidade $(c i=0,40 ; r=0,83)(11 C-11 E)$ :

0. amarelada

1. castanha

2. enegrecida

Distribuição dos estados:

Plesiomórfico: 1

(0) Sinapomorfia homoplástica dos clados 66 e 73.

(1) Sinapomorfia homoplástica por reversão do clado 60.

(2) Sinapomorfia homoplastica de Megacephalini.

Ambiguidade: a espécie Oxycheila labiata apresenta as duas tonalidades de cor.

107. Pro-tíbia, esporões, comprimento, relação ao primeiro tarsômero (ci=0,33; $r=0,66)$ :

0. mais longos que o primeiro tarsômero

1. mais curtos que o primeiro tarsômero

Distribuição dos estados:

Plesiomórfico:1

(0) Sinapomorfia homoplástica dos clados 67 e 71.

(1) Reversão em Metriocheila nigricollis. 
108. Mesotórax, mesosterno, cerdas $(c i=0,28 ; r=0,50)$ :

0. presentes na região posterior

1. presentes na região anterior

2. ausentes

Distribuição dos estados:

Otimização ACCTRAN

Plesiomórfico: 1

(0) Sinapomorfia homoplástica do clado 45. Autapomorfia homoplástica de Cheiloxya binotata.

(2) Em duas das quatro árvores mais parcimoniosas, é sinapomorfia homoplástica do clado 66 com posterior reversão para o estado 1 em Platychile pallida, como ocorre no consenso. Nas outras duas árvores é sinapomorfia homoplástica do clado 65.

Ambiguidade: Phaeoxantha laminata e Manticora tuberculata possuem a possibilidade dos dois estados, sendo que um deles era o compartilhado pelo grupo maior.

109. Mesotórax, mesosterno, tipo (ci=0,25; r=0,25) (fig. 11F e 11G):

0. complexo

1. simples

Distribuição dos estados:

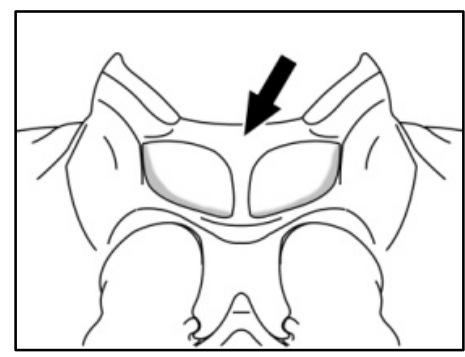

0

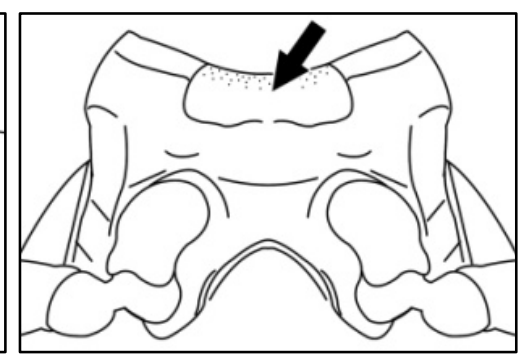

1

Otimização ACCTRAN 
(0) Reversão no clado que une as duas espécies de Omus (68).

(1) Sinapomorfia homoplástica de Manticorina. Autapomorfia homoplástica de Platychile pallida.

Ambiguidade: Manticora tuberculata possui o mesosterno com um padrão intermediário entre os dois estados e deste modo não foi codificado. Pseudotetracha howitti não teve o protórax removido para a observação do caráter devido a sua raridade nas coleções examinadas.

110. Mesotórax, mesosterno complexo, barra mediana $(c i=0,22 ; r=0,58)$ :

0 dupla

1 simples

2 ausente

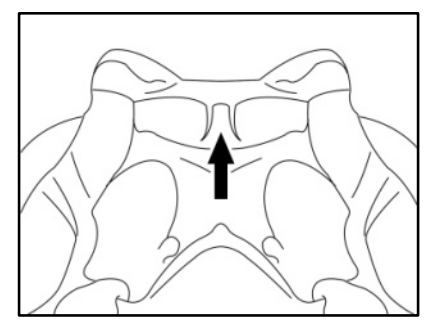

0

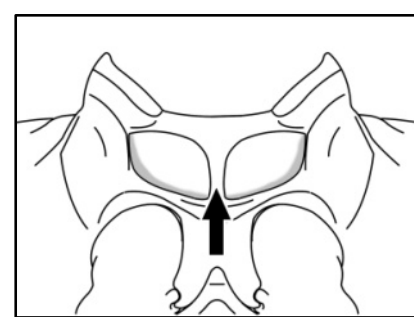

1

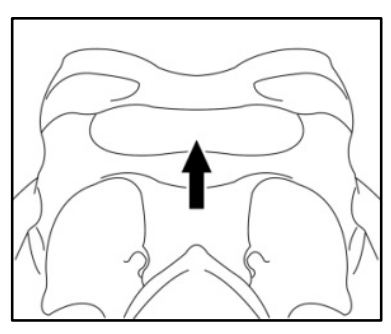

2

Distribuição dos estados:

Contingência

Otimizção ACCTRAN

Plesiomórfico: 1

(0) Sinapomorfia homoplástica dos clado 63. Para duas árvores das quatro mais parcimoniosas, é também sinapomorfia homoplástica do clado 71 e autapomorfia homoplástica de Tetracha germaini.

(1) Sinapomorfia homoplástica por reversão do clado 60. Autapomorfia homoplástica de Phaeoxantha laminata. Para duas árvores das quatro mais parcimoniosas, é também sinapomorfia homoplástica do clado 56 e 58. 
111. Mesotórax, mesosterno complexo, barra transversal posterior $(c i=0,22$; $r=0,46)$ (fig. 12A - 12C):

0 . ausente

1. incompleta

2. completa

Distribuição dos estados:

Otimização ACCTRAN

Plesiomórfico: 0

(0) Reversão em Metriocheila nigricollis.

(1) Sinapomorfia homoplástica do clado que une as duas espécies de Pseudoxycheila (70) e do clado 67. Autapomorfia homoplástica de Cheiloxya binotata.

(2) Sinapomorfia homoplástica de Megacephalini e autapomorfia homoplástica em Phaeoxantha laminata.

Devido ao fato de estar escondida sob o protórax, esta estrutura é difícil de ser examinada, sendo necessário afastar ou retirar o protórax para que esse caráter seja observado. Assim como o escutelo, possívelmente é a primeira vez que esta estrutura é utilizada em uma filogenia de um grupo de Carabidae.

112. Mesotórax, mesosterno, hexagonal groove (Beutel 1992) (não informativo):

0. presente

1. ausente

Distribuição dos estados: 
Estado 0 presente apenas no grupo externo usado para enraizar. Estado 1 presente em todos os Cicindelinae.

113. Mesotórax, mesepisterno, coupling sulcus nas fêmeas (ci=0,16; $r=0,37)$ :

0. presente

1. ausente

Distribuição dos estados:

Plesiomórfico: 1

(0) Sinapomorfia homoplástica do clado 52. Autapomorfia homoplástica de Metriocheila nigricollis, Grammognatha euphratica e Tetracha femoralis.

114. Mesotórax, mesepisterno, coupling sulcus nas fêmeas, forma (ci=0,50; $r=0,66)$ :

0. sulco

1. cavidade

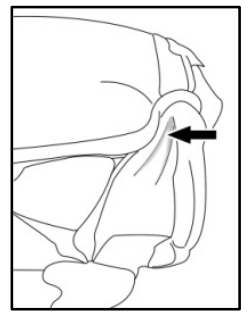

$\mathbf{0}$

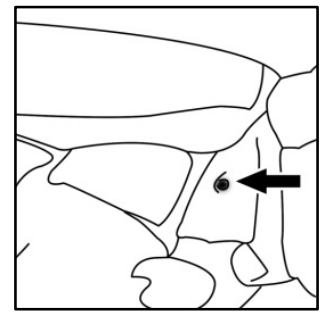

1

Otimização DELTRAN: esta foi escolhida devido ao fato de apenas uma espécie do grupo Megacephalini apresentar o estado plesiomórfico. A otimização ACCTRAN colocaria o estado 1 surgindo na base de Megacephalini (47), sendo que o estado não é aplicável em todo o grupo Manticorina (46), interno a Megacephalini.

Plesiomórfico: 0

(0) Reversão em Grammognatha euphratica.

(1) Sinapomorfia do clado 50 (Oxycheilina + Megacephalina). 
115. Mesotórax, mesepisterno e metepisterno, região mediana $(c i=0,14 ; r=0,62)$

(fig. 12D e 12E):

0. rugosa

1. lisa

Distribuição dos estados:

Otimização ACCTRAN

Plesiomórfico: 0

(0) Sinapomorfia homoplástica por reversão dos clados 65, 63 e 56. Autapomorfia homoplástica de Tetracha chilensis.

(1) Sinapomorfia homoplástica de Megacephalini. Autapomorfia homoplástica de Platychile pallida.

116. Mesotórax, mesepisterno, cerdas $(c i=0,25 ; r=0,40)$ :

0. presentes

1. ausentes

Distribuição dos estados:

Otimização ACCTRAN

Plesiomórfico: 1

(0) Autapomorfia homoplástica de Megacephala megacephala.

Para duas árvores das quatro mais parcimoniosas, o estado 0 é sinapomorfia homoplástica do clado 66 com reversão para o estado 1 em Platychile pallida. Nas outras duas o estado 0 é sinapomorfia homoplástica do clado 65. 
117. Tórax, vista lateral, distância dorso do élitro até margem lateral do élitro, relação sobre a distância da margem até o ventre do metasterno (ci=0,50; $r=0,66)$ :

0. mais de 1,5

1. menos de 1,5

Distribuição dos estados:

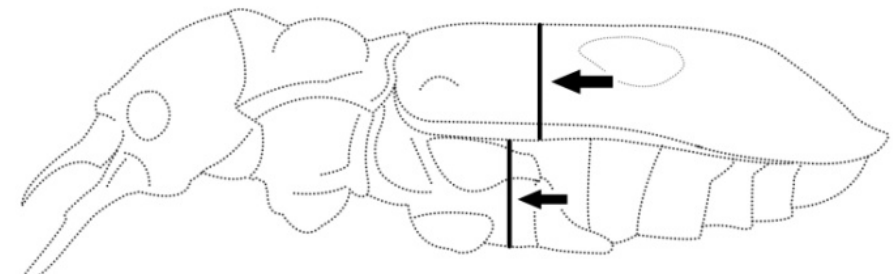

Plesiomórfico: 1

(0) Sinapomorfia homoplástica do clado 44 (Manticora + Amblycheila).

118. Escutelo (ci=0,50; $r=0,88)(12 F$ e $12 G)$ :

0. mais de $30 \%$ visível

1. menos de $30 \%$ visível

Distribuição dos estados:

Plesiomórfico: 0

(1) Sinapomorfia homoplástica de Megacephalini.

Isto ocorre devido ao fato de o pronoto apresentar uma pequena expanção da região mediana da margem posterior, além de o escutelo ser geralmente mais curto.

119. Escutelo, forma (ci=0,50; $r=0,86$ ) (fig. 13 e anexo 3):

0. elíptico ou arredondado

1. cordiforme 
3. transverso com margens laterais emarginadas anteriormente
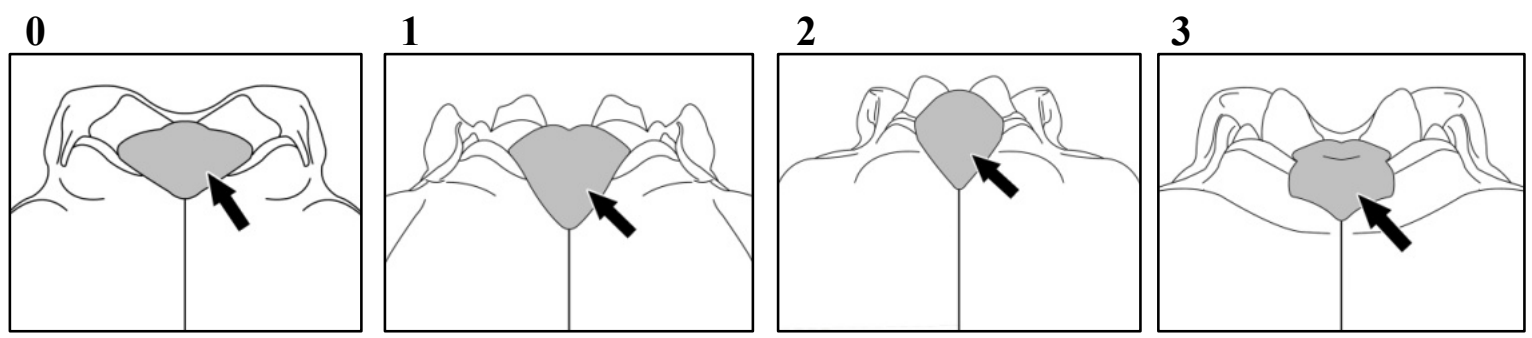

Distribuição dos estados:

Plesiomórfico: 1

(0) Sinapomorfia homoplástica de Manticorina. Autapomorfia homoplástica de Platychile pallida.

(3) Sinapomorfia de Megacephalina.

O escutelo, por ser uma estrutura que nos Cicindelinae fica escondido sob o pronoto, não tinha sido usado até então em uma análise filogenética do grupo. Mesmo nos trabalhos com Carabidade, que falam sobre tórax, não há nenhuma referência sobre essa grande variação entre os grupos. Como pode ser observado nas árvores mais parcimoniosas obtidas, a forma do escutelo é distinta nas 3 subtribos estabelecidas aqui: Manticorina, Oxycheilia e Megacephalina. Em Megacephalina, apenas a espécie do gênero africano monotípico Platychile apresenta a forma diferente dos demais táxons da subtribo a que pertence (Megacephalina), mas mesmo assim é uma forma intermediária, que segundo minha observação se assemelha mais à forma compartilhada por Manticorina. O estado 2, não apresentado na discussão, ocorre em alguns gêneros de Cicindelinae fora de Megacepahalini. A grande variação da forma do escutelo entre os diferentes gêneros estudados pode ser observada no "Anexo 3". 
120. Escutelo, margem anterior, forma $(c i=0,18 ; r=0,40)$ :

0. arredondada projetada

1. emarginada apenas no centro

2. reta

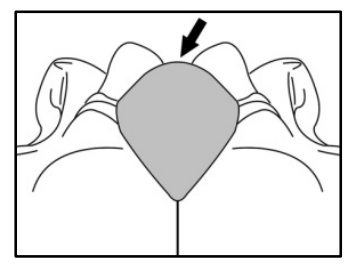

$\mathbf{0}$

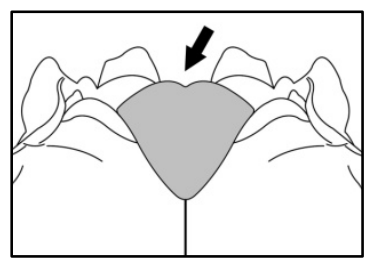

1

Distribuição dos estados:

Plesiomórfico: 1

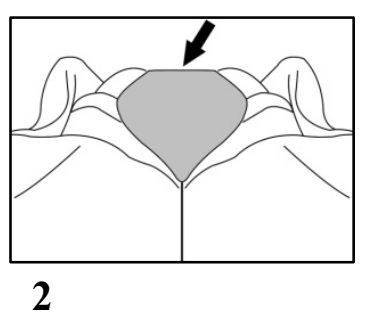

(0) Sinapomorfia homoplástica do clado que une as duas espécies de Omus (68) e do clado 67. Autapomorfia homoplástica de Cheiloxya binotata.

(1) Autapomorfia homoplástica de Platychile pallida.

(2) Sinapomorfia homoplástica dos clados 53 e 63 e autapomorfia homoplástica de Grammognatha euphratica.

121. Escutelo, margem anterior emarginada no centro, forma da emarginação $(c i=0,20 ; r=0,33)$ :

0. arredondada

1. acuminada

Distribuição dos estados:

Plesiomórfico: 0

(1) Sinapomorfia homoplástica do clado 57. Autapomorfia homoplástica de Tetracha chilensis. 
122. Escutelo, margens laterais $(c i=0,33 ; r=0,89)$ :

0 curvas

1 acuminadas anteriormente

Distribuição dos estados:

Otimização ACCTRAN

Plesiomórfico: 0

(0) Reversão no clado que une as duas espécies de Pseudoxycheila (70) e em Megacephala megacephala.

(1) Sinapomorfia do clado 50.

123. Escutelo, margem posterior ( $c i=0,27 ; r=0,60)$ (fig. 13):

0 . angulada

1. biemarginada

2. bissigmóide

3. curva

Distribuição dos estados:

Otimização ACCTRAN

Plesiomórfico: 0

(0) Reversão em Platychile pallida, Tetracha germaini e Tetracha fulgida.

(1) Sinapomorfia homoplástica de Megacephalina e do clado 45. Autapomorfia homoplástica de Oxycheila opacipennis e Oxycheila tristis. 
(2) Sinapomorfia homoplástica do clado 44.

(3) Autapomorfia de Manticora tuberculata.

124. Mesocoxa, iridescência ( $c i=1 ; r=1)$ :

0 ausente

1 presente

Distribuição dos estados:

Plesiomórfico: 0

Estado 1 presente apenas em um clado (78) fora de Megacephalini.

125. Mesocoxa, coloração por pigmento $(c i=0,28 ; r=0,73)$ :

0. amarelada

1. castanha

2. enegrecida

Distribuição dos estados:

Plesiomórfico: 2

(0) Sinapomorfia homoplástica dos clados 66 e 73.

(1) Sinapomorfia homoplástica do clado 60.

(2) Reversão em Pseudotetracha cylindrica. 
126. Mesocoxa, cerdas $(c i=0,14 ; r=0,57)$ :

0.1

1. 2 ou mais

Distribuição dos caracteres:

Otimização ACCTRAN

Plesiomórfico: 1

(0) Sinapomorfia homoplástica do clado que une as duas espécies de Omus (68) e do clado 50 (Oxycheilina + Megacephalina). Autapomorfia homoplástica de Amblycheila picolominiii.

(1) Reversão em Megacephala megacephala.

Em duas árvores das quatro mais parcimoniosas, o estado 1 é sinapomorfia homoplástica por reversão do clado 66 com posterior reversão para o estado 0 em Metriocheila nigricollis. Para as outras duas o estado 1 é sinapomorfia homoplástica do clado 83.

127. Mesocoxa, cerdas escamiformes $(c i=1 ; r=1)$ :

0. ausentes

1. presentes

Distribuição.

Plesiomórfico: 0

O estado 1 está presente apenas em um clado (75) do grupo externo. 
128. Mesotrocânter, coloração (ci=0,28; $r=0,77)$ :

0. amarelada

1. castanha

2. enegrecida

Distribuição dos estados:

Plesiomórfico: 2

(0) Sinapomorfia homoplástica do clado 66 e 73. Autapomorfia homoplástica de Oxycheila labiata.

(1) Sinapomorfia homoplástica do clado 60.

129. Mesotrocânter, ápice, cerdas longas (ci=0,33; r=0,33):

0. ausentes

1. 1

2. 2 ou mais

Distribuição dos estados:

Otimização ACCTRAN

Plesiomórfico: 1

(0) Sinapomorfia homoplástica do clado 62. Reversão em Metriocheila nigricollis e autapomorfia homoplástica de Grammognatha euphratica.

(1) Reversão no clado 67.

(2) Autapomorfia homoplástica de Manticora tuberculata. 
130. Mesotrocânter, superfície interna, cerdas curtas ( $c i=0,50 ; r=0,50)$ :

0. ausentes

1. presentes

Distribuição dos estados:

Plesiomórfico: 1

Estado 0 presente apenas em 3 espécies do grupo externo.

131. Mesotíbia, iridescência (ci=1; $r=1)$ :

0 . ausente

1. presente

Distribuição dos estados:

Plesiomórfico: 1

Estado 0 presente apenas em 3 espécies do grupo externo.

132. Mesotíbia, coloração por pigmento (ci=0,40; $r=0,84)$ :

0 amarelada

1 castanha

2 enegrecida

Distribuição dos estados:

Plesiomórfico: 2 
(0) Sinapomorfia homoplástica dos clados 66 e 73 . Autapomorfia homoplástica de Megacephala megacephala.

(1) Sinapomorfia homoplástica do clado 60.

Ambiguidade: Oxycheila labiata possui a meso-tíbia bicolor (amarelada com a base enegrecida).

133. Mesotíbia, esporões terminais (não informativo):

0. mais curtos que o primeiro tarsômero

1. mais longos que o primeiro tarsômero

Plesiomórfico: 0

Caráter não informativo. Apenas a espécie Phaeoxantha klugii possui o estado 1.

134. Mesofêmur, iridescência (ci=1; $r=1)$ :

0. ausente

1. presente

Distribuição dos estados:

Plesiomórfico: 0

Estado 1 presente apenas em 1 clado (78) do grupo externo. 
135. Mesofêmur, coloração por pigmento (ci=0,40; $r=0,84)$ :

0. amarelada

1. castanha

2. enegrecida

Distribuição dos estados:

Plesiomórfico: 2

(0) Sinapomorfia homoplástica dos clados 66 e 73.

(1) Sinapomorfia homoplástica do clado 60.

Ambiguidade: a espécie Oxycheila labiata possui a meso-tíbia bicolor (amarelada com a base enegrecida).

136. Élitros, comprimento, relação sobre a largura $(c i=1 ; r=1)$ :

$0.2,6$ ou mais

1. menos de 2,6

Distribuição dos estados:

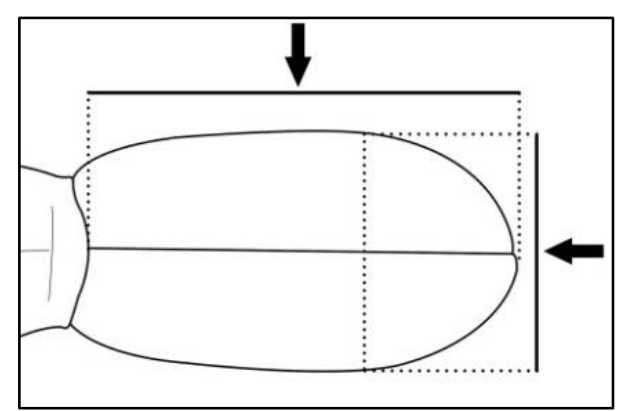

Plesiomórfico: 1

Estado 0 presente apenas em um clado (82) fora de Megacephalini.

137. Élitro, ápice, margem $(c i=0,25 ; r=0,25)$ :

0 . lisa 
1. serrilhada

Distribuição dos estados:

Otimização ACCTRAN

Plesiomórfico: 0

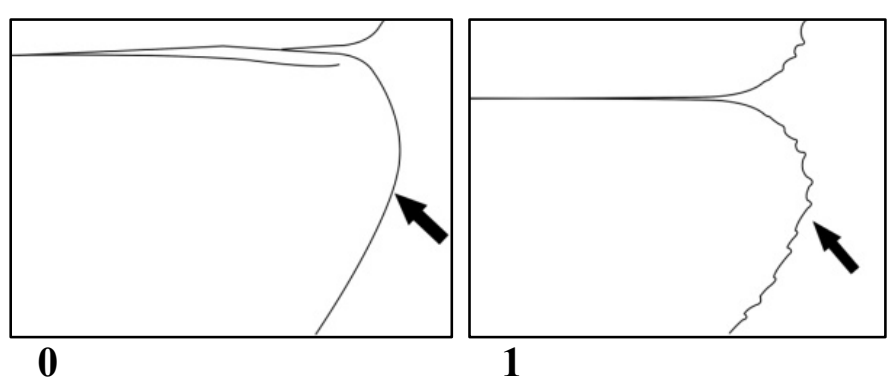

(0) Reversão em Platychile pallida.

(1) Sinapomorfia homoplástica do clado 67. Autapomorfia homoplástica de Tetracha germaini e Tetracha fuldiga.

138. Élitro, máculas apicais (ci=0,33; $r=0,33)$ :

0 . divergentes anteriormente

1. convergentes anteriormente

Distribuição dos estados:

Otimização ACCTRAN

Plesiomórfico: 0

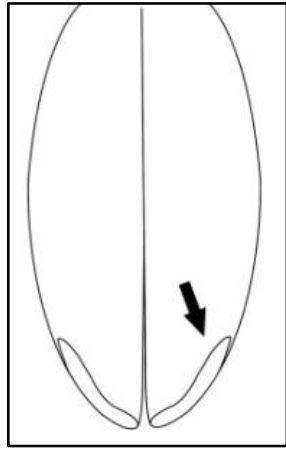

0

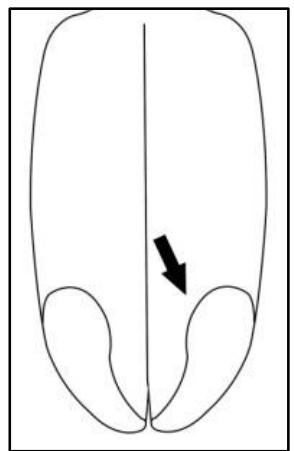

1

(0) Reversão no clado 55.

(1) Sinapomorfia homoplástica do clado 59.

139. Élitro, epipleura, coloração metálica $(c i=0,20 ; r=0,55)$ :

0 . presente

1. ausente

Distribuição dos estados: 


\section{Otimização ACCTRAN}

Plesiomórfico: 0

Em duas das quatro árvores mais parcimoniosas, o estado 0 é sinapomorfia homoplástica por reversão do clado $84 \mathrm{com}$ posterior reversão para o estado $1 \mathrm{em}$ Tetracha brasiliensis. Para as outras duas, o estado 0 é sinapomorfia homoplástica do clado 73 e autapomorfia homoplástica de Tetracha femoralis. Em todas as árvores o estado 1 é sinapomorfia homoplástica de Megacephalini.

Aparentemente esta iridescência nos Megacephalini é inexistente, porém ao analisar os indivíduos sob lupa e mudando o ângulo de incidência da luz, é possível verificar o brilho iridescente.

140. Élitro, superfície, pits catenulados (ci=0,25; r=0,40):

0 . presente

1. ausente

Distribuição dos estados:

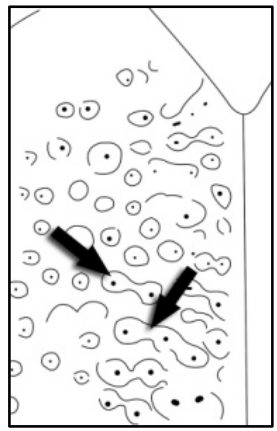

Estado 0 presente apenas em espécies fora de Megacephalini.

141. Élitro, superfície dorsal, iridescência $(c i=0,16 ; r=0,70)$ :

0 . presente

1. ausente

Distribuição dos estados: 
Otimização DELTRAN: neste caso foi escolhido este tipo de otimização, pois o estado plesiomórfico é a presença da estrutura, ou seja, a otimização DELTRAN favorece um único aparecimento da iridescência e posteriores perdas.

Plesiomórfico: 0

(1) Sinapomorfia homoplástica de Manticorina, do clado 53 e do 67. Autapomorfia homoplástica de Aniara sepulcralis e Pseudotetracha murchisona.

142. Élitro, superfície dorsal, coloração por pigmento (ci=0,20; $r=0,33)$ :

0 . presente

1. ausente

Distribuição dos estados:

Plesiomórfico: 0

(1) Sinapomorfia homoplástica do clado que une as duas espécies de Pseudoxycheila (70) e do clado 61. Autapomorfia homoplástica de Megacephala megacephala.

143. Élitro, superfície dorsal, coloração por pigmento, amarelada fosca (ci=0,14; r=0,68):

0 . presente

1. ausente

Distribuição dos estados:

Plesiomórfico: 1

Otimização ACCTRAN 
(0) Sinapomorfia homoplástica dos clados 52 e 64.

Para duas árvores das quatro mais parcimoniosas, o estado 0 é sinapomorfia homoplástica do clado $58 \mathrm{com}$ posterior reversão para o estado 1 em Megacephala megacephala. Para as outras duas, o estado 0 é sinapomorfia homoplástica do clado 59 com posterior mudança para o estado $1 \mathrm{em}$ Megacephala megacephala e Tetracha femoralis.

Para codificar os 21 próximos caracteres, que são relacionados à presença ou ausência de um tipo de pigmentação no élitro, este foi dividido em 10 partes esquematizadas na figura abaixo:

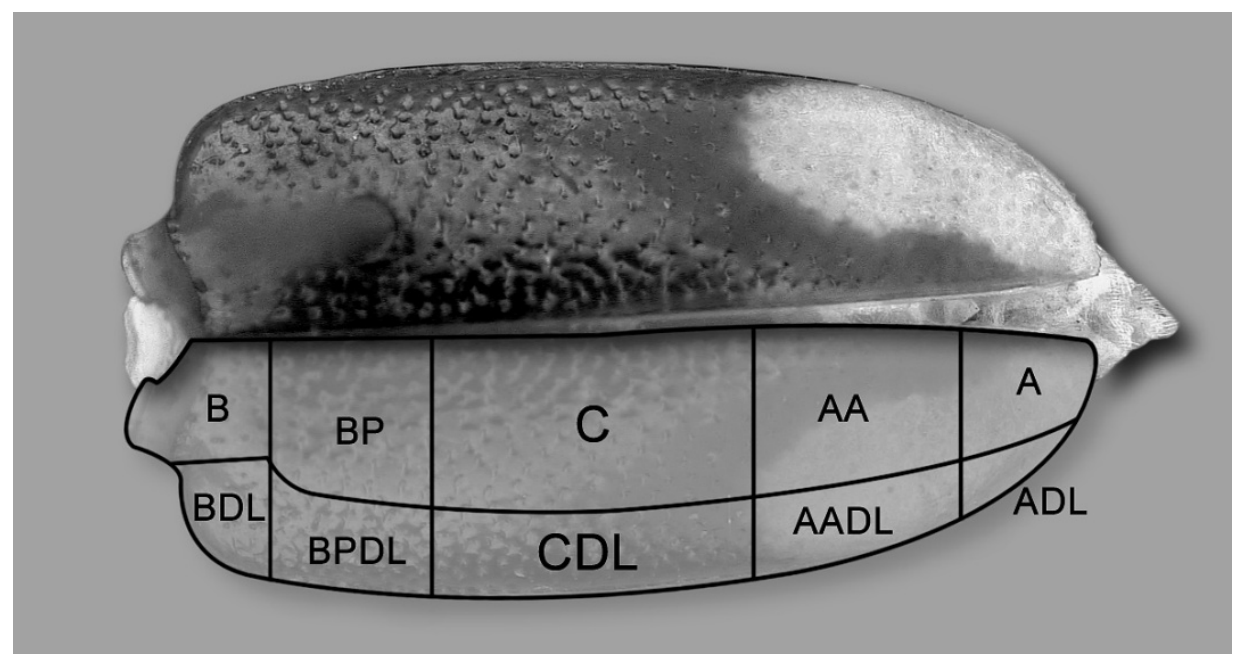

Regiões elitrais definidas para o levamentamento dos caracteres de coloração. B. basal; BDL. basal dorsolateral; BP. basal posterior; BPDL. basal posterior dorsolateral; C. central; CDL. central dorsolateral; AA. apical anterior; AADL. apical anterior dorso lateral; A. apical; ADL. apical dorsolateral.

Para as espécies com toda a cobertura elitral iridescente, todos os caracteres relacionados foram tabulados na matriz como (-).

Primeiramente foi levantado um caráter relativo à um tipo de coloração. Os que foram considerados como coloração ausente, foram codificados como (-) nos caracteres relacionados com a posição de tal coloração. 
144. Élitro, superfície dorsal, posição basal dorsolateral (BDS), coloração por pigmento, amarelada fosca ( $c i=0,50 ; r=0,87)$ :

0 . ausente

1. presente

Distribuição dos estados:

Plesiomórfico: 0

(1) Sinapomorfia homoplástica do clado 62.

145. Élitro, superfície dorsal, posição basal (B), coloração por pigmento, amarelada fosca $(c i=0,25 ; r=0,50)$ :

0 . ausente

1. presente

Distribuição dos estados:

Plesiomórfico: 0

(0) Reversão em Australicapitona basalis e Metriocheila nigricollis.

(1) Sinapomorfia homoplástica do clado 62.

146. Élitro, superfície dorsal, posição basal posterior dorsolateral (BPDL), coloração por pigmento, amarelada fosca $(c i=0,33 ; r=0,81)$ :

0 . ausente

1. presente 
Distribuição dos estados:

Plesiomórfico: 0

(1) Sinapomorfia homoplástica do clado 62.

147. Élitro, superfície dorsal, posição basal posterior (BP), coloração por pigmento, amarelada fosca ( $c i=0,20 ; r=0,42)$ :

0 . ausente

1. presente

Distribuição dos caracteres:

Plesiomórfico: 0

(0) Reversão em Australicapitona basalis e Metriocheila nigricollis.

(1) Sinapomorfia homoplástica do clado 62.

148. Élitro, superfície dorsal, posição central dorsolateral (CDL), coloração por pigmento, amarelada fosca $(c i=0,25 ; r=0,62)$ :

0 . ausente

1. presente

Distribuição dos caracteres:

Otimização ACCTRAN: apesar de o estado plesiomórfico ser a presença da coloração, não julgo ser menos provável seu aparecimento do que sua perda, já que na sua ausência, outra coloração estará no lugar.

Plesiomórfico: 1 
(0) Sinapomorfia homoplástica do clado 59.

(1) Reversão em Tetracha germaini.

149. Élitro, superfície dorsal, posição central (C), coloração por pigmento, amarelada fosca $(c i=0,16 ; r=0,54)$ :

0. ausente

1. presente

Distribuição dos estados:

Otimização ACCTRAN

Plesiomórfico: 0

(0) Sinapomorfia homoplástica do clado 59.

(1) Autapomorfia de Tetracha germaini.

150. Élitro, superfície dorsal, posição apical anterior dorsolateral (AADL), coloração por pigmento, amarelada fosca (ci=0,14; r=0,45) (fig. 14C e 14D):

0 . ausente

1. presente

Distribuição dos estados:

Otimização ACCTRAN

Plesiomórfico: 0 
(0) Sinapomorfia homoplástica por reversão do clado 56. Reversão em Australicapitona basalis, Metriocheila nigricollis.

(1) Sinapomorfia homoplástica de Megacephalina.

151. Élitro, superfície dorsal, posição apical anterior (AA), coloração por pigmento, amarelada fosca (ci=0,20; $r=0,63$ ) (fig. 14C e 14D):

0 . ausente

1. presente

Distribuição dos estados:

Otimização ACCTRAN

Plesiomórfico: 0

(0) Sinapomorfia homoplástica por reversão do clado 56. Autapomorfia homoplástica de Tetracha brasiliensis.

(1) Sinapomorfia homoplástica de Megacephalina.

152. Élitro, superfície dorsal, posição apical anterior dorsolateral (AADL), coloração por pigmento, amarelada fosca $(c i=0,33 ; r=0,60)$ :

0 . ausente

1. presente

Distribuição dos estados:

Otimização ACCTRAN

Plesiomórfico: 1 
(0) Sinapomorfia homoplástica de Oxycheilina.

153. Élitro, superfície dorsal, posição apical (A), coloração por pigmento, amarelada fosca (ci=0,25; r=0,50) (fig. 14C e 14D):

0 . ausente

1. presente

Distribuição dos estados:

Otimização ACCTRAN

Plesiomórfico: 0

(1) Sinapomorfia homoplástica de Megacephalina.

154. Élitro, superfície dorsal, coloração por pigmento, amarelada brilhante (ci=1; $r=1$ ):

0 . ausente

1. presente

Distribuição dos estados:

Plesiomórfico: 0

(1) Sinapomorfia do clado que une as duas espécies de Pseudoxycheila (70). 
155. Élitro, superfície dorsal, coloração por pigmento, enegrecida (ci=0,25; $r=0,82)$ :

0 . presente

1. ausente

Distribuição dos estados:

Plesiomórfico: 0

(0) Reversão em Metriocheila nigricollis.

(1) Sinapomorfia homoplástica do clado 60.

156. Élitro, superfície dorsal, posição basal dorsolateral (BDL), coloração por pigmento, enegrecida $(c i=0,50 ; r=0,50)$ :

0 . ausente

1. presente

Distribuição dos estados:

Otimização DELTRAN: foi escolhida tal otimização, pois há apenas uma espécie dentro do grande grupo Megacephalina com o estado apomórfico (0). Assim, optei por assumir um evento isolado para essa espécie (Metriocheila nigricollis) em vez de uma sinapomorfia para todo o grupo que apenas é expressa em uma espécie.

Plesiomórfico: (1)

(0) Sinapomorfia homoplástica do clado que une as duas espécies de Pseudoxycheila (70) e autapomorfia homoplástica de Metriocheila nigricollis. 
157. Élitro, superfície dorsal, posição basal (B), coloração por pigmento, enegrecida ( $c i=1 ; r=1)$ :

0 . ausente

1. presente

Distribuição dos estados:

Plesiomórfico: (1)

(0) Sinapomorfia do clado que une as duas espécies de Pseudoxycheila (70).

158. Élitro, superfície dorsal, posição basal posterior dorsolateral (BPDL), coloração por pigmento, enegrecida (não informativo):

0 . ausente

1. presente

Distribuição dos estados:

Plesiomórfico (1)

Caráter não informativo. Estado apomórfico (0) presente em apenas uma espécie de Megacephalini (Metriocheila nigicollis).

159. Élitro, superfície dorsal, posição basal posterior (BP), coloração por pigmento, enegrecida (não informativo):

0 . ausente

1. presente

Distribuição dos estados: 
Plesiomórfico (1)

Caráter não informativo. Estado apomórfico (0) presente em apenas uma espécie de Megacephalini (Metriocheila nigicollis).

160. Élitro, superfície dorsal, posição central dorsolateral (CDL), coloração por pigmento, enegrecida (não informativo):

0 . ausente

1. presente

Distribuição dos estados:

Plesiomórfico (1)

Caráter não informativo. Estado apomórfico (0) presente em apenas uma espécie de Megacephalini (Metriocheila nigicollis).

161. Élitro, superfície dorsal, posição central (C), coloração por pigmento, enegrecida (não informativo):

0. ausente

1. presente

Distribuição dos estados:

Plesiomórfico: 1

Caráter não informativo. Nenhuma espécie apresenta o estado apomórfico. 
162. Élitro, superfície dorsal, posição basal posterior dorsolateral (BPDL), coloração por pigmento, enegrecida (não informativo):

0. ausente

1. presente

Distribuição dos estados:

Plesiomórfico: 1

Caráter não informativo. Nenhuma espécie apresenta o estado apomórfico.

163. Élitro, superfície dorsal, posição apical anterior (AA), coloração por pigmento, enegrecida (não informativo):

0 . ausente

1. presente

Distribuição dos estados:

Plesiomórfico: 1

Caráter não informativo. Nenhuma espécie apresenta o estado apomórfico.

164. Élitro, superfície dorsal, posição apical dorsolateral (ADL), coloração por pigmento, enegrecida (ci=0,50; $r=0,50)$ :

0 . ausente

1. presente

Otimização DELTRAN: foi escolhida tal otimização, pois há apenas uma espécie dentro do grande grupo Megacephalina com o estado apomórfico (0). 
Assim, optei por assumir um evento isolado para essa espécie (Metriocheila nigricollis) em vez de uma sinapomorfia para todo o grupo que apenas é expressa em uma espécie.

Plesiomórfico: (1)

(0) Sinapomorfia homoplástica do clado que une as duas espécies de Pseudoxycheila (70) e autapomorfia homoplástica de Metriocheila nigricollis.

165. Élitro, superfície dorsal, posição apical (A), coloração por pigmento, enegrecida ( $c i=1 ; r=1)$ :

0. ausente

1. presente

Distribuição dos estados:

Plesiomórfico: (1)

(0) Sinapomorfia do clado que une as duas espécies de Pseudoxycheila (70).

166. Élitro, face interna, base, carenas (ci=0,28; r=0,50) (fig. 14E - 14G):

0.2

1. 1

2. ausentes

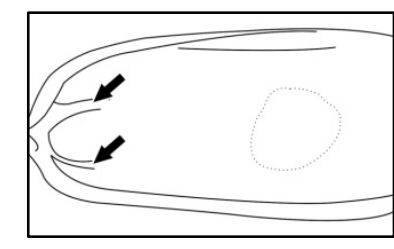

0

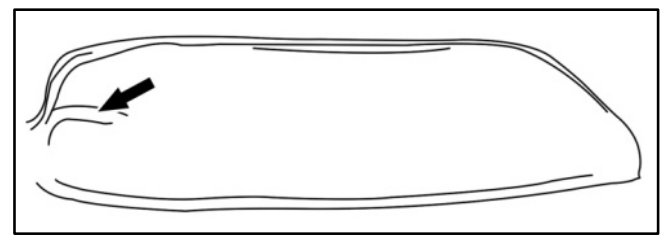

1

Distribuição dos caracteres:

Otimização ACCTRAN

Plesiomórfico: 1 
(0) Sinapomorfia homoplástica do clado que une as duas espécies de Pseudoxycheila (70). Autapomorfia homoplástica de Pseudotetracha murchisona.

(2) Sinapomorfia homoplástica de Manticorina e do clado que une as duas espécies de Megacephala (55).

Várias espécies não tiveram seus élitros removidos para a observação deste caráter. Alguns por terem o os élitros fundidos e outros por serem espécies raras nas coleções examinadas.

167. Élitro, superfície interna, pontuação (não informativo):

0. arredondadas e aleatoriamente distribuídas

1. quadrangulares e organizadas em fileiras ordenadas

Distribuição dos estados:

Plesiomórfico: 0

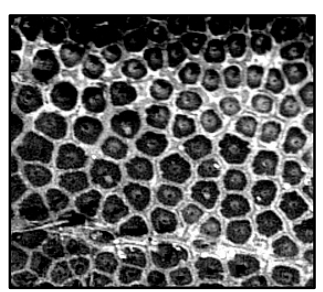

0

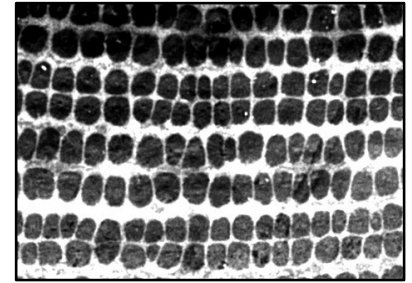

1

Caráter não informativo. Apenas a espécie usada para o enraizamento apresenta o estado apomórfico.

168. Élitro, superfície interna, margem sutural (ci=0,20; $r=0,63)$ (fig. 14E - 14G):

0. emarginada próxima ao ápice

1. reta ou arredondada em toda a extensão

Distribuição dos estados:

Otimização ACCTRAN

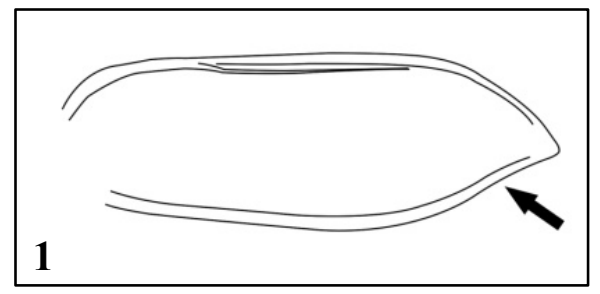


Plesiomórfico: 0

(1) Sinapomorfia homoplástica de Manticorina e dos clados 52, 62 e 56.

169. Élitro, superfície interna, prega sublateral (ci=0,33; r=0,60) (fig. $14 \mathrm{G}$ e 14H):

0. muito fraca, desaparecendo na região mediana

1. acentuada em toda a extensão

2. muito fraca na região do terço posterior

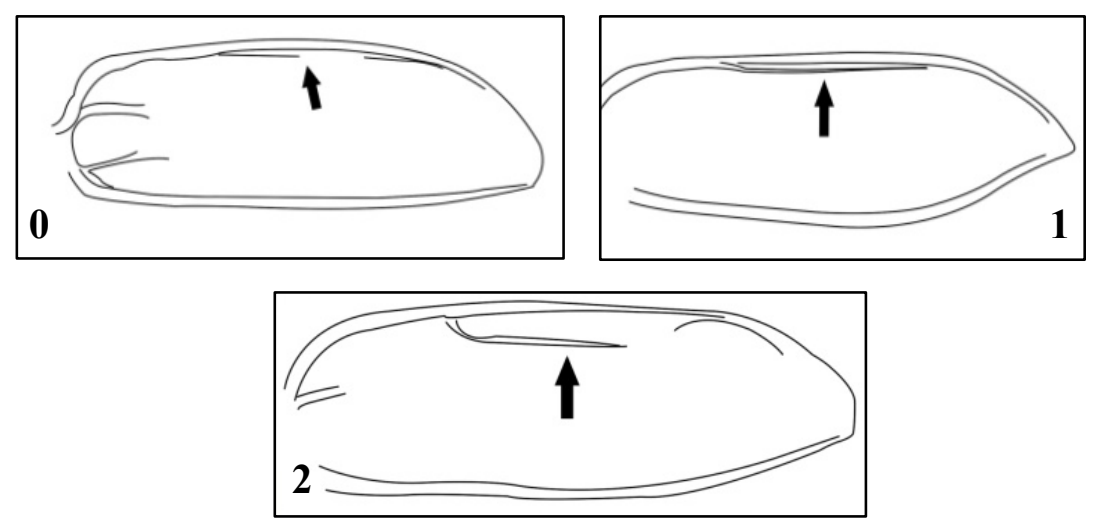

Distribuição dos estados:

Otimização ACCTRAN

Plesiomórfico: 1

(1) Sinapomorfia homopástica por reversão no clado 62 e no clado 56.

(2) Sinapomorfia homoplástica de Megacephalina e autapomorfia homoplástica de Picnochile fallaciosa. 
170. Élitro, superfície interna, margem lateral $(c i=0,66 ; r=0,83)$ :

0 reta

1. emarginada na região mediana

2. arredondada em toda a extensão

Distribuição dos estados:

Otimização ACCTRAN
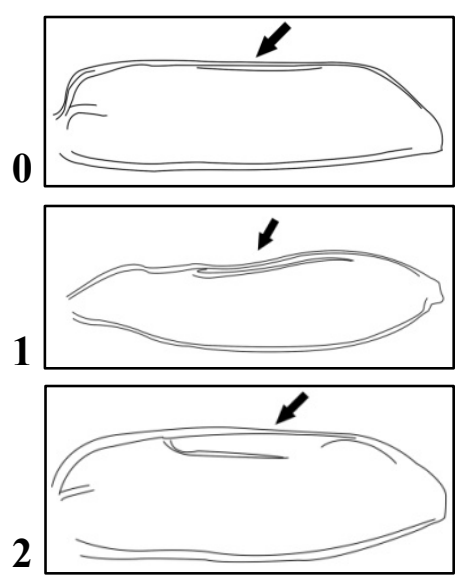

Plesiomórfico: 1

(2) Sinapomorfia de todos os Cicindelinae usados na análise.

171. Élitro, metade posterior $(c i=0,33 ; r=0,50)$ :

0 . igual ou mais estreita que a metade anterior

1. mais larga que a metade anterior

Distribuição dos estados:

Plesiomórfico: 0

(1) Autapomorfia homoplástica de Cheiloxya binotata e Phaeoxantha klugii.

172. Élitro, superfície, depressões (pits) $(c i=0,14 ; \mathrm{r}=0,33)$ :

0 . ausentes

1. presentes 
Distribuição dos estados:

\section{Otimização DELTRAN}

Plesiomórfico: 1

(0) Sinapomorfia homoplástica do clado 56. Autapomorfia homoplástica de Picnochile fallaciosa, Manticora tuberculata e Oxycheila opacipennis.

Para duas das quatro árvores mais parcimoniosas, o estado 0 é autapomorfia homoplástica também para Platychile pallida e Phaeoxantha laminata; para as outras duas é sinpomorfia homoplástica do clado que as une (83).

173. Élitro, superfície, projeções $(c i=0,12 ; r=0,12)$ :

0. ausentes

1. presentes

Distribuição dos estados:

Otimização ACCTRAN

Plesiomórfico: 0

(0) reversão em Megacephala bocandei.

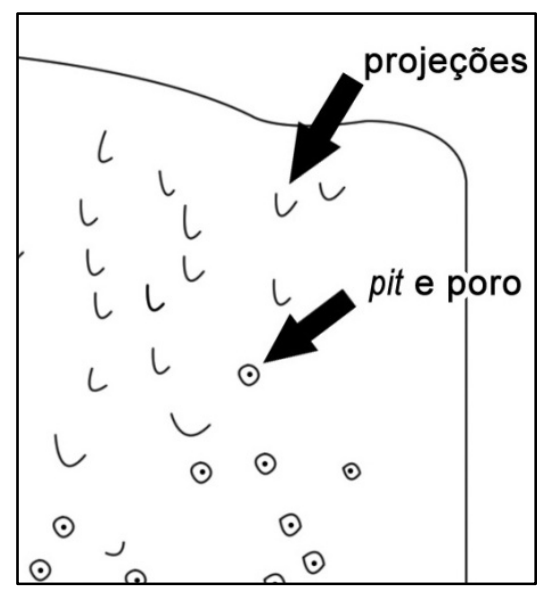

(1) Sinapomorfia homoplástica do clado 57.

Para duas das quatro árvores mais parcimoniosas, o estado 1 é também sinapomorfia homoplástica do clado 65; para as outras duas é sinapomorfia homoplástica do clado 66 com reversão para o estado 1 em Platychile pallida. 
174. Élitros, suturas elitrais (ci=0,25; $r=0,50)$ (fig. 15A e 15B):

0 . presentes

1. fundidas

Distribuição dos estados:

Plesiomórfico: 0

(0) Reversão em Omus dejeani.

(1) Sinapomorfia homoplástica de Manticorina (46). Autapomorfia homoplástica de Megacephala megacephala.

175. Élitro, pontuações $(r=0,33 ; r=0)$ :

0. aleatoriamente espalhadas

1. formando fileiras

Distribuição dos estados:

Plesiomórfico: 0

(1) Autapomorfia homoplástica de Amblycheila picolominii, Pseudotetracha cylindrica e Megacephala bocandei.

176. Élitro, porcentagem de cobertura por pontuações fortes $(c i=0,12 ; r=0,65)$ :

$0.70 \%$ ou mais

1. menos de $70 \%$

Distribuição dos estados: 
Plesiomórfico: 1

(0) Sinapomorfia homoplástica dos clados 45 e 67 . Autapomorfia homoplástica de Oxycheila labiata, Aniara sepulcralis e Tetracha femoralis.

177. Élitro, carenas (ci=0,25; r=0,25):

0. ausentes

1. presentes

Distribuição dos estados:

Otimização ACCTRAN

Plesiomórfico: 0

(1) Sinapomorfia homoplástica do clado que une as duas espécies de Amblycheila (43) e autapomorfia homoplástica de Picnochile fallaciosa.

178. Élitros, carenas $(c i=1 ; r=1)$ :

0. não chegam ao ápice

1. atingem o ápice separademente

2. unem-se no ápice

Distribuição dos estados:

Optimização DELTRAN: optei por esta optimização, pois o caráter é aplicável apenas para um clado dentro de Megacephalini. Usando ACCTRAN, o estado compartilhado por este clado aparecia dando suporte a um clado muito mais abrangente, sendo que para a maioria das espécies não é aplicável. 
Plesiomórfico: 1

(0) Sinapomorfia do clado que une as duas espécies de Amblycheila (43).

179. Élitro, vista lateral, ápice $(c i=0,25 ; r=0)$ :

0 dirigido dorsalmente

1 horizontal

Distribuição dos estados:
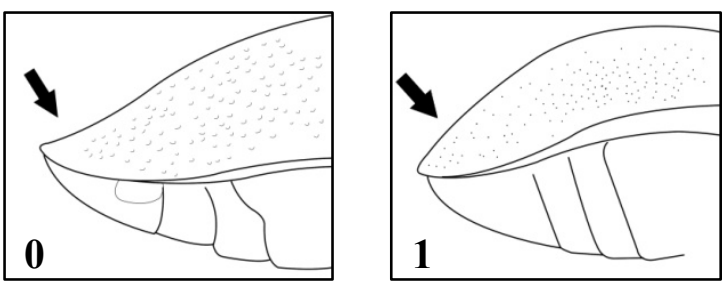

Plesiomórfico: 1

(0) Autapomorfia homoplástica de Picnochile fallaciosa, Pseudoxycheila ceratoma, Aniara sepulcralis e Tetracha germaini.

180. Élitro, ápice no macho (ci=0,14; r=0,53) (fig. 14D):

0. arredondado

1. levemente truncado

Distribuição dos estados:

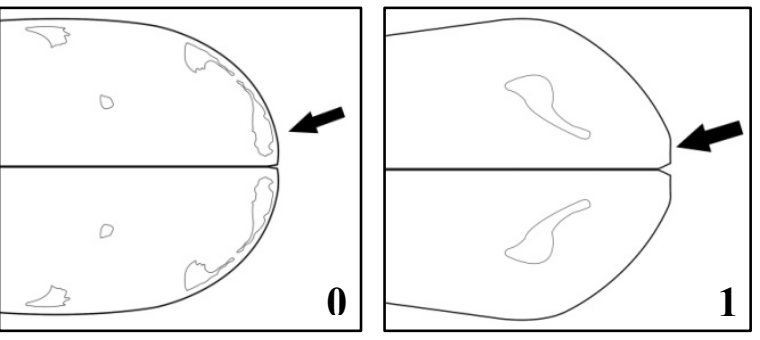

Otimização ACCTRAN

Plesiomórfico: 0

(0) Reversão em Pseudoxycheila ceratoma.

(1) Sinapomorfia homoplástica de Oxycheilina (54) e do clado 72. Autapomorfia homoplástica de Phaeoxantha klugii. 
181. Élitro, ápice, prolongamento espiniforme na fêmea ( $c i=0,20 ; r=0,20)$ :

0. ausente

1. presente

Distribuição dos estados:

Otimização ACCTRAN

Plesiomórfico: 0

(0) Reversão no clado 69.

(1) Sinapomorfia homoplástica do clado 53. Autapomorfia homoplástica de Phaeoxantha laminata.

182. Asa membranosa (ci=0,20; $r=0,69)$ (fig. $15 \mathrm{C}-15 \mathrm{E})$ :

0. reduzida

1. desenvolvida

Distribuição dos estados:

Plesiomórfico: 1

(0) Sinapomorfia homoplástica de Manticorina (46), dos clados 61 e 55 .

Poucos trabalhos de Coleoptera utilizam caracteres alares em um nível taxonômico inferior (WARD, 1979). Podem ser citados: Good (1925) propôs uma filogenia de Buprestidae norte-americanos e J. Wilson (1930), S. Wilson (1934) e Saalas (1936) estudaram outras famílias de Polyphaga. Goodlife (1939) e BalfourBrowne (1943) fizeram uma tentativa semelhante com os adéfagos aquáticos e King (1956) fez uma filogenia bastante superficial das famílias de Adephaga baseando-se 
somente no padrão geral da asa; apenas foi feita uma filogenia "mental" com uma asa hipotética ancestral na base. Sendo bastante comum a redução das asas metatorácicas em carabídeos, a maior parte dos artigos relacionados à família indica apenas se as espécies apresentam braquipteria ou não, como foi verificado em uma pesquisa para o presente texto: 98 trabalhos relacionados à sistemática de Carabidae do período de 1993 a 2010 foram obtidos usando o sistema de busca "Google" e a base de dados Zoological Records Online. Os resultados obtidos foram correspondentes à busca por "Carabidae description" e apenas os artigos disponíveis foram examinados. De todos os trabalhos obtidos, apenas dois não utilizaram características do élitro. Devido à grande influência dos élitros no padrão de dobra da asa membranosa, era de se esperar muitos trabalhos em que caracteres relacionados a estas fossem usados, porém apenas 54 usaram a asa membranosa de alguma forma, sendo a grande maioria (52) apenas classificando em asas desenvolvidas ou reduzidas, não descrevendo nenhuma estrutura alar. Um único trabalho apresentou desenhos da asa desenvolvida com suas nervuras.

Além da condição reduzida ou desenvolvida, outros 5 caracteres relacionados a asa foram usados na presente análise. A maioria não foi muito útil para a resolução do grupo interno, porém mostraram-se bastante úteis para o grupo Cicindelinae.

183. Asa membranosa, wedge cell (célula anal), formato (ci=1; $r=1)$ :

0. retangular

1. subquadrada

Distribuição dos estados:

Otimização ACCTRAN

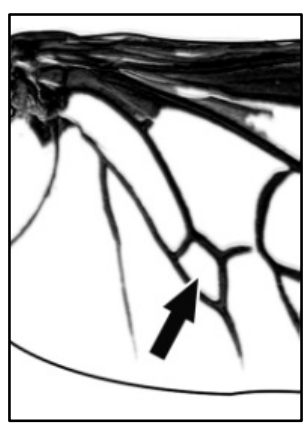

0

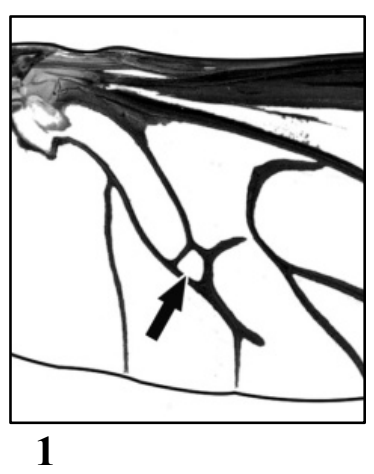

Plesiomórfico: 0

Apenas um clado (80) fora de Megacephalini apresenta o estado apomórfico. 
184. Asa membranosa, ramo que sai da wedge cell e vai até a margem posterior da asa (AA3) $(c i=1 ; r=1)$ :

0. simples

1. bifurcado

Distribuição dos estados:

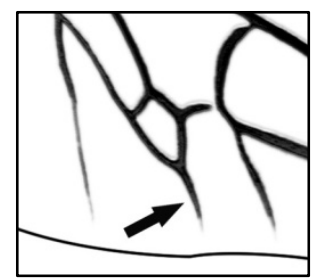

0

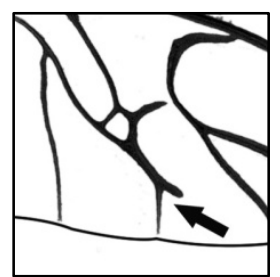

1

Otimização ACCTRAN

Plesiomórfico: 0

Apenas um clado (80) fora de Megacephalini apresenta o estado apomórfico.

185. Asa membranosa, alça anal, apêndice (ci=0,33; $r=0,80$ ) (fig. 15F e 15G):

0 . presente

1. ausente

Distribuição dos estados:

Otimização ACCTRAN

Plesiomórfico: 0

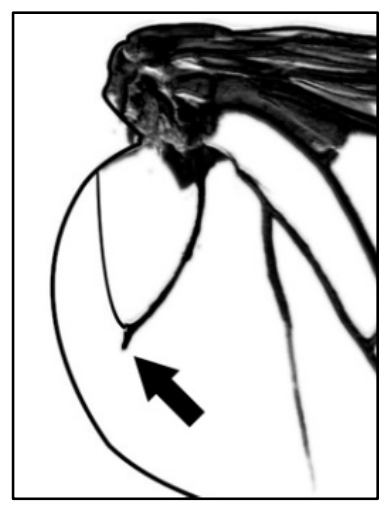

(1) Sinapomorfia homoplástica de Megacephalina e do clado 69. 
186. Asa membranosa, célula oblonga (não informativo):

0 . presente

1. ausente

Distribuição dos estados:

Otimização ACCTRAN

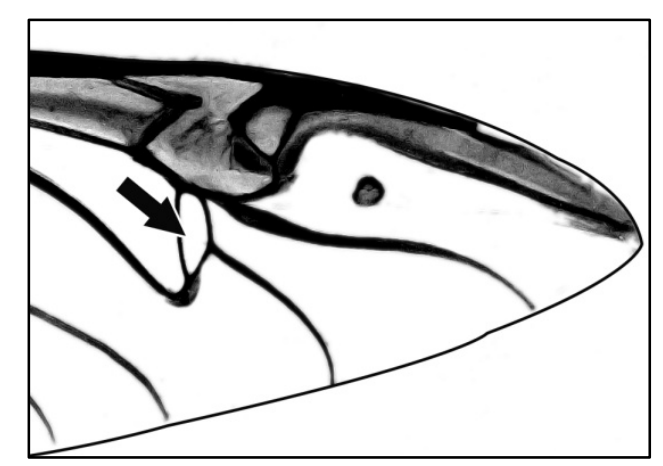

Plesiomórfico: 0

Caráter não informativo. Apenas a espécie usada para o enraizamento possui o estado apomórfico.

187. Asa membranosa, nervura cr e MP1+2, ângulo (ci=1; $r=1)$ :

0 . menor que 30 graus

1. maior que 40 graus

Distribuição dos estados:

Plesiomórfico: 0

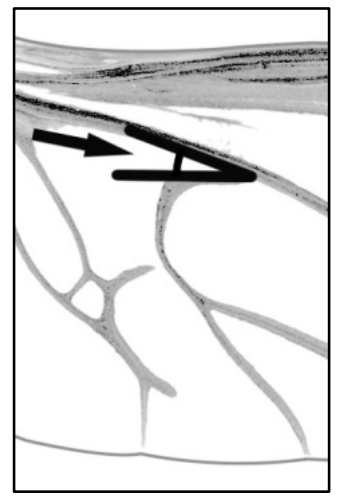

0

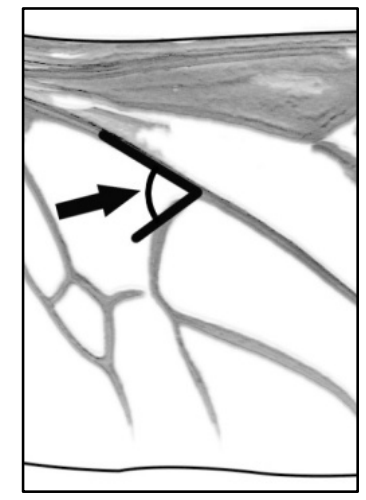

1

(1) Sinapomorfia do clado que une as duas espécies de Pseudoxycheila (70). 
188. Metatórax, metacoxas $(c i=0,50 ; r=0,66)$ :

0. separadas

1. tocam-se em algum ponto

Distribuição dos estados:

0

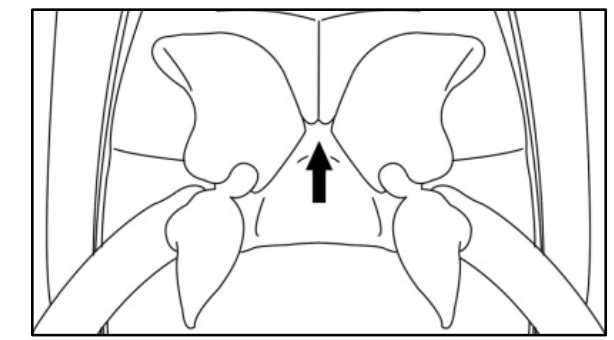

Otimização ACCTRAN

Plesiomórfico: 0

(0) Reversão em Manticora tuberculata.

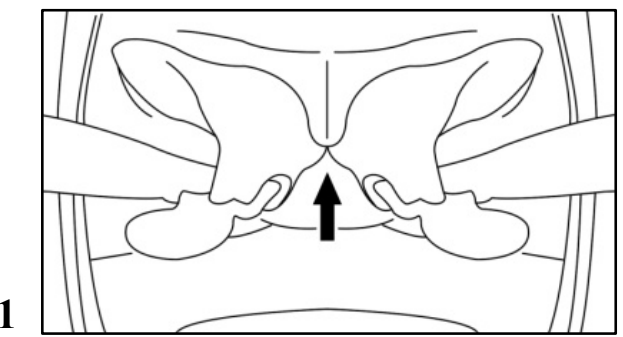

(1) Sinapomorfia do clado 45.

189. Metacoxa, coloração ( $c i=0,28 ; r=0,66)$ :

0. amarelada

1. castanha

2. enegrecida

Distribuição dos estados:

Plesiomórfico: 2

(0) Sinapomorfia do clado 66 .

(1) Sinapomorfia homoplástica do clado 60.

(2) Reversão em Pseudotetracha cylindrica, Tetracha brasiliensis e Megacephala megacephala. 
190. Metacoxa, iridescência (ci=0,20; $r=0,42)$ :

0 . ausente

1. presente

Distribuição dos estados:

Plesiomórfico: 0

(1) Sinapomorfia homoplástica do clado que une as duas espécies de Pseudoxycheila (70). Autapomorfia homoplástica de Australicapitona basalis e Tetracha femoralis.

191. Metacoxa, cerdas na superfície interna perto do trocânter ( $c i=0,25 ; r=0,84)$ :

0 . presentes

1. ausentes

Distribuição dos estados:

Otimização ACCTRAN

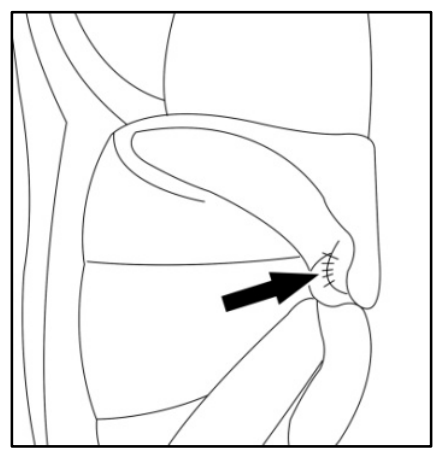

Plesiomórfico: 0

(0) Sinapomorfia homoplástica dos clados 45, 64 e 59. 
192. Metacoxa, base, cerdas $(c i=0,28 ; r=0,58)$ :

0. ausentes

1. 1

2. 2 ou mais

Distribuição dos estados:

Plesiomórfico: 2

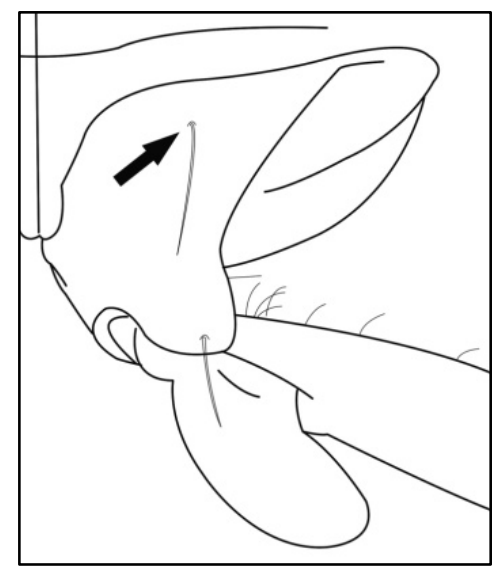

(0) Autapomorfia de Platychile pallida.

(1) Sinapomorfia homoplástica do clado 50 (Oxycheilina + Megacephalina).

(2) Reversão em Metriocheila nigricollis e Megacephala megacephala.

Ambiguidade: Algumas espécies apresentaram espécimes com 1 ou duas cerdas.

193. Metacoxa, borda interna, cerdas ( $c i=0,40 ; r=0,57)$ :

0. escamiformes

1. simples

2. ausentes

Distribuição dos estados:

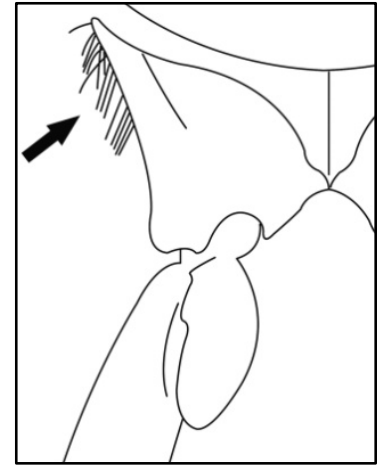

Plesiomórfico: 2

(1) Autapomorfia homoplástica de Manticora tuberculata e Metriocheila nigricollis. 
194. Metacoxa, ápice, cerdas ( $c i=0,66 ; r=0)$ :

0.2 ou mais

1. 1

2. ausentes

Distribuição dos estados:

Plesiomórfico: 1

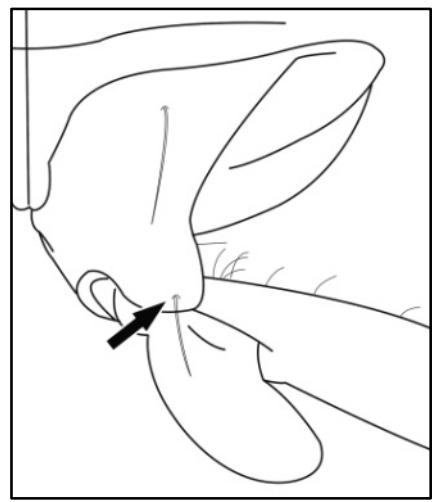

(0) Autapomorfia homoplástica de Manticora tuberculata.

195. Metatrocânter, coloração $(c i=0,33 ; r=0,80)$ :

0. amarelada

1. castanha

2. enegrecida

Distribuição dos estados:

Plesiomórfico: 2

(0) Sinapomorfia homoplástica dos clados 66 e 73 . Autapomorfia homoplástica de Oxycheila labiata.

(1) Sinapomorfia do clado 60.

196. Metatrocânter, superfície interna adjacente à base, cerdas curtas $(c i=0,25$; $r=0)$ :

0 . presentes 
1. ausentes

Distribuição dos estados:

Plesiomórfico: 0

(1) Autapomorfia homoplástica de Pseudotetracha murchisona, Platychile pallida e Tetracha chilensis.

197. Metatrocânter, fileira de cerdas da base até próximo à metade na superfície interna (ci=1; $r=1)(f i g .15 H)$ :

0 . ausente

1. presente

Distribuição dos estados:

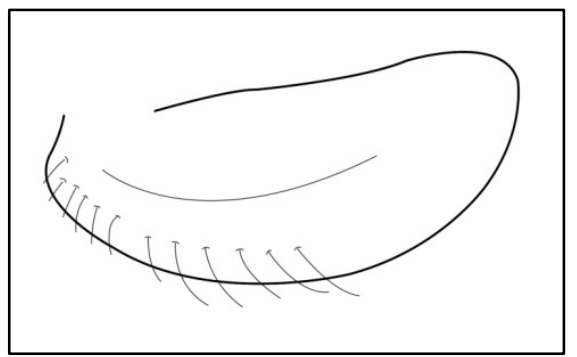

Plesiomórfico: 0

(1) Sinapomorfia de Manticorina (46).

198. Metatrocânter, superfície externa, cerdas $(c i=0,33 ; r=0)$ :

0. ausentes

1. presentes

Distribuição dos estados:

Plesiomórfico: 0

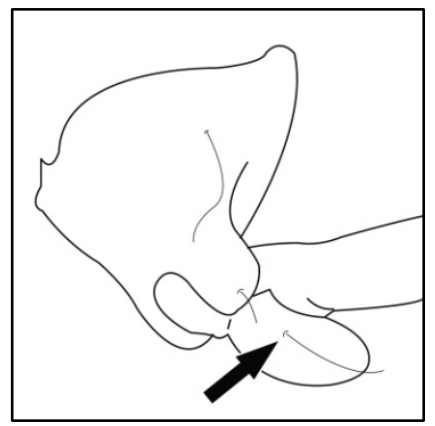

(1) Autapomorfia homoplástica de Manticora tuberculata e Megacephala megacephala. 
199. Metatrocânter, dimorfismo sexual $(c i=0,50 ; r=0,50)$ :

0. ápice mais fino e alongado nos machos

1. semelhante ao da fêmea

Distribuição dos estados:

Otimização ACCTRAN

Plesiomórfico: 0

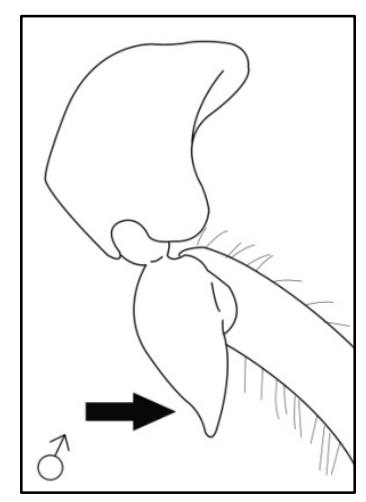

(0) Sinapomorfia homoplástica do clado que une as duas espécies de Amblycheila (43).

200. Metasterno, cerdas $(c i=0,16 ; r=0,37)$ :

0 . presentes

1. ausentes

Distribuição dos estados:

Otimização ACCTRAN

Plesiomórfico: 1

(0) Autapomorfia homoplástica de Manticora tuberculata e de Megacephala megacephala.

Para duas das quatro árvores mais parcimoniosas, o estado 0 é sinapomorfia homoplástica do clado 66 com reversão para o estado 1 em Platychile pallida. Para as duas outras, o estado 0 é sinapomorfia homoplástica do clado 65. 
201. Metasterno, distância da sutura transversal até a base da meso-coxa, relação sobre a distância da sutura transversal até a base da meta-coxa (ci=0,33; r=0,78) (fig. 16A-16C):

0 mais de 4

1 entre 2 e 4

2 menos ou aproximadamente 1

Distribuição dos estados:

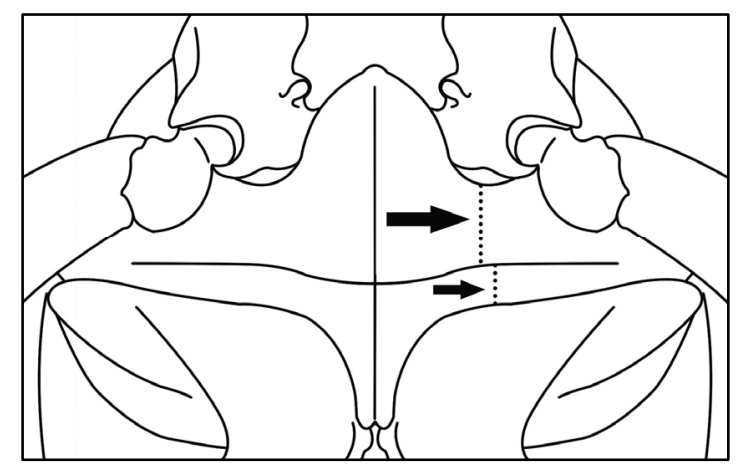

Plesiomórfico: 1

(0) Sinapomorfia homoplástica do clado 53 (subgrupo de Oxycheilina).

(2) Sinapomorfia homoplástica de Manticorina e do clado que une as duas espécies de Megacephala (55).

O encurtamento do metasterno, está relacionado à condição braquíptera, porém foram observados dois níveis diferentes de encurtamentos, sendo o presente em Manticorina, o mais drástico. A condição intermediária é compartilhada tanto por indivíduos braquípteros como por macrópteros. A condição compartilhada pelos Manticorina também aparece em um clado que une duas espécies braquípteras de Megacephalina.

202. Metepisterno, região central, cerdas ( $c i=0,40 ; r=0,25)$ :

0. escamiformes

1. simples

2. ausentes

Distribuição dos estados: 
Plesiomórfico: 2

(1) Autapomorfia homoplástica de Manticora tuberculata, Pseudotetracha howitti e Megacephala megacephala.

203. Metepisterno, margem externa, região anterior, cerdas (ci=0,20; $r=0,75)$ (fig. 16D):

0. presentes

1. ausentes

Distribuição dos estados:

Otimização ACCTRAN

Plesiomórfico: 0

(0) Sinapomorfia homoplástica por reversão em Oxycheilina (54), Metriocheila nigricollis e Grammogantha euphratica.

(1) Sinapomorfia homoplástica de Megacephalini.

204. Metepisterno, pontuações (ci=0,20; $r=0,20)$ :

0. presentes

1. ausentes

Distribuição dos estados:

Otimização ACCTRAN

Plesiomórfico: 0 
(0) Autapomorfia homoplástica de Manticora tuberculata, Cheiloxya binotata e Megacephala megacephala.

205. Metatíbia, iridescência (ci=0,50; $r=0,66)$ :

0. ausente

1. presente

Distribuição dos estados:

Otimização ACCTRAN: usada apenas para resolver a ambiguidade na base.

Plesiomórfico: 0

Estado 1 presente apenas em um clado (78) fora de Megacephalini.

206. Metatíbia, coloração $(c i=0,50 ; r=0,88)$ :

0. amarelada

1. castanha

2. enegrecida

Distribuição dos estados:

Otimização ACCTRAN

Plesiomórfico: 1

(0) Sinapomorfia homoplástica dos clados 66 e 73.

(1) Reversão no clado 60.

(2) Sinapomorfia de Megacephalini. 
Ambiguidade: Oxycheila labiata possui a metatíbia bicolor.

207. Metafêmur, coloração (ci=0,40; $r=0,83)$ :

0. amarelada

1. castanha

2. enegrecida

Distribuição dos estados:

Otimização ACCTRAN

Plesiomórfico: 1

(0) Sinapomorfia homoplástica dos clados 66 e 73.

(1) Reversão no clado 60.

(2) Sinapomorfia homoplástica de Megacephalini.

Ambiguidade: Oxycheila labiata possui o metafêmur bicolor.

208. Abdome, ventritos $(c i=0,33 ; r=0,50)$ :

0. metálicos

1. opacos

Distribuição dos estados:

Plesiomórfico: 1

(0) Apenas clados fora de Megacephalini apresentaram ventritos totalmente metálicos. 
Ambiguidade: muitos táxons apresentam ventritos metálicos e opacos.

209. Abdome, ventrito $I$, cerdas $(c i=0,50 ; r=0,33)$ :

0. escamiformes

1. simples

2. ausentes

Distribuição dos estados:

Otimização ACCTRAN: apenas para resolver a ambiguidade da base.

Plesiomórfico: 1

(1) Autapomorfia homoplástica por reversão de Megacephala megacephala.

210. Abdome, ventrito II, cerdas ( $c i=0,40 ; r=0,50)$ :

0. escamiformes

1. simples

2. ausentes

Distribuição dos estados:

Plesiomórfico: 1

(1) Sinapomorfia homoplástica por reversão do clado 44 e autamoporfia homoplástica de Megacephala megacephala.

Ambiguidade: Amblycheila picolomonii pode apresentar uma ou nenhuma cerda. 
211. Abdome, ventrito III, cerdas ( $c i=0,33 ; r=0,60)(16 F$ e 16G):

0. escamiformes

1. mais de 4 simples

2. 4 simples

3. 2 simples

4. ausentes

Distribuição dos estados:

Otimização ACCTRAN

Plesiomórfico: 3

(1) Sinapomorfia homoplástica de Manticorina (46). Autapomorfia homoplástica de Megacephala megacephala.

(2) Autapomorfia homoplástica de Playchile pallida e Grammognatha euphratica.

(4) Sinapomorfia homoplástica do clado 59 e autapomorfia homoplástica de Metriocheila nigricollis.

Ambiguidade: caráter muito plástico em Manticorina (46) e Oxycheilina (54).

212. Abdome, ventrito IV, cerdas $(c i=0,25 ; r=0,25)(16 F$ e $16 G)$ :

0. escamiformes

1. mais de 4 simples

2. 4 simples 
3. 2 simples

4 ausentes

Distribuição dos estados:

Otimização ACCTRAN

Plesiomórfico: 3

(1) Sinapomorfia homoplástica de Manticorina e do clado 55.

(2) Sinapomorfia homoplástica do clado 57. Autapomorfia homoplástica de Aniara sepulcralis, Pseudotetracha cylindrica e Platychile pallida.

(4) Autapomorfia homoplástica de Metriocheila nigricollis e Megacephala bocandei.

Ambiguidade: caráter muito plástico em Manticorina (46) e Oxycheilina (54).

213. Abdome, ventrito $V$, cerdas $(c i=0,27 ; r=0,33)(16 F$ e $16 G)$ :

0. escamiformes

1. mais de 4 setáceas

2. 4 setáceas

3. 2 setáceas

4. ausentes

Distribuição dos estados:

Otimização ACCTRAN

Plesiomórfico: 3 
(1) Sinapomorfia homoplática de Manticorina e do clado 55.

(2) Sinapomorfia homoplática do clado 57. Autapomorfia de Aniara sepulcralis, Pseudotetracha cylindrica e Platychile pallida.

(4) Autapomorfia homoplástica de Metriocheila nigricollis e Megacephala bocandei.

Ambiguidade: caráter muito plástico em Manticorina (46), Oxycheilina (54) e em Pseudotetracha murchisona.

214. Abdome, ventrito VI, cerdas (ci=0,33; $r=0,50)$ (fig. $16 \mathrm{G})$ :

0. escamiformes

1. mais de 4 simples

2. 4 simples

3. 2 simples

4. ausentes

Distribuição dos estados:

Otimização ACCTRAN

Plesiomórfico: 1

(1) Reversão em Grammognatha euphratica.

(2) Sinapomorfia do clado que une as duas espécies de Pseudoxycheila (70).

(3) Sinapomorfia homoplástica de Megacephalina. Autapomorfia homoplástica de Amblycheila cylindriformis e Cheiloxya binotata.

Ambiguidade: Phaeoxantha klugii pode apresentar duas ou nenhuma cerda. 
215. Abdome, ventrito III, comprimento, relação sobre o comprimento do esternito IV (macho) $(c i=0,50 ; r=0)$ :

0. menos de 1,45

1. 1,45 ou mais

Distribuição dos estados:

Plesiomórfico: 1

(0) Autapomorfia homoplástica de Oxycheila opacipennis e Pseudotetracha cylindrica.

216. Abdome, ventritos III e IV muito desenvolvidos, ventritos V e VI encurtados e escondidos sob o IV nas fêmeas (ci=1; r=1) (fig. 16E):

0. ausente

1. presente

Distribuição dos estados:

Plesiomórfico: 0

(1) Sinapomorfia de Oxycheilina.

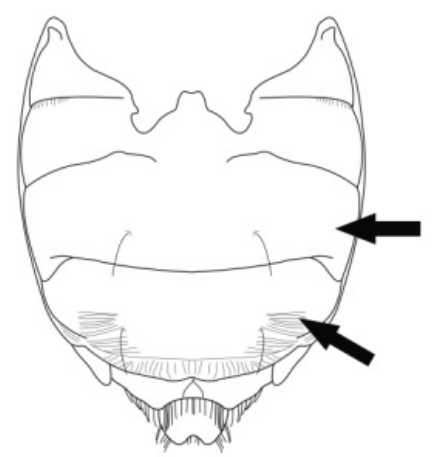


217. Abdome, ventritos III e IV, estrias transversais laterais (ci=0,16; $r=0,66$ ) (fig. 17A- 17B):

0. presentes

1. ausentes

Distribuição dos estados:

Otimização ACCTRAN

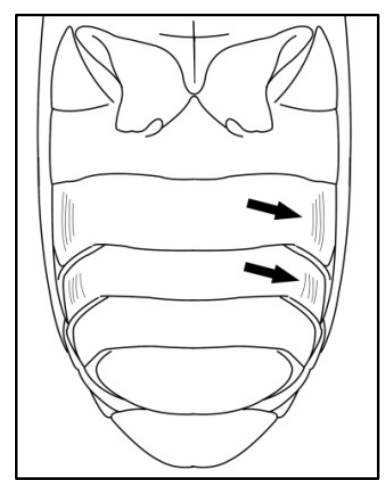

Plesiomórfico: 1

(0) Sinapomorfia homoplástica de Megacephalini.

(1) Sinapomorfia homoplástica por reversão de Oxycheilina e autapomorfia de Phaeoxantha laminata.

218. Abdome, pigmento amarelado nas laterais dos últimos ventritos $(c i=0,20$; $r=0,69$ ) (fig. 16G):

0 . ausente

1. presente

Distribuição dos estados:

Plesiomórfico: 0

(0) Reversão em Pseudotetracha howitti, Tetracha femoralis, Tetracha germaini e Megacephala megacephala.

(1) Sinapomorfia de Megacephalina. 
219. Adome, máculas claras, localização $(c i=0,50 ; r=0)$ :

0. ventrito IV apenas

1. ventritos IV ao VI

Distribuição dos estados:

Caráter de contingência.

Otimização ACCTRAN

Plesiomórfico: 0

(0) Reversão no clado 61.

(1) Sinapomorfia do clado 60.

220. Abdome, projeção lateral dos ventritos em direção ao ápice do élitro (ci=0,33; $r=0,33$ ):

0. ausente

1. presente

Distribuição dos estados:

Otimização ACCTRAN

Plesiomórfico: 1

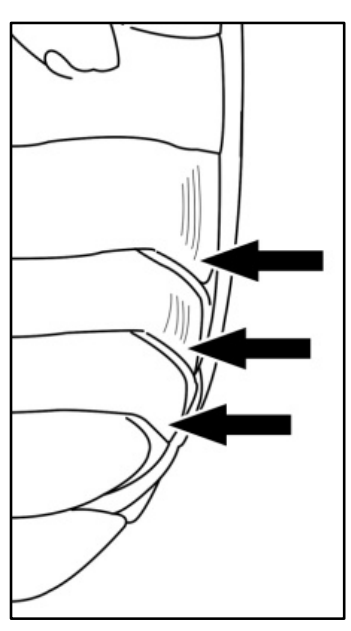

(0) Sinapomorfia homoplástica do clado 45 e de Platychile pallida.

(1) Reversão no clado que une as duas espécies de Amblycheila (43). 
221. Abdome, ventrito VI dos machos, forma (ci=0,33; $r=0,50)$ :

0. completo

1. bilobado

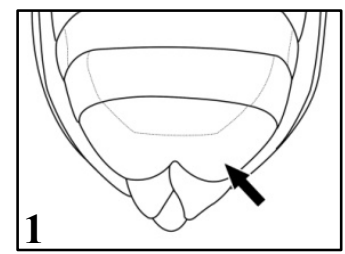

Distribuição dos caracteres:

Otimização ACCTRAN: apenas para resolver a ambiguidade na base do cladograma.

Plesiomórfico: 0

(0) Sinapomorfia homoplástica por reversão no clado 44 e autapomorfia homoplástica de Megacephala megacephala.

222. Abdome, ventrito VI, cerdas apenas nas fêmeas (ci=1; $r=1)$ :

0 . ausentes

1. presentes

Distribuição dos estados:

Plesiomórfico: 0

(1) Sinapomorfia do clado que une as duas espécies de Amblycheila (43).

223. Abdome, sutura entre segundo e terceiro ventritos (ci=0,12; $r=0,50)$ :

0. muito fraca ou incompleta

1. completa e forte

Distribuição dos estados: 


\section{Otimização ACCTRAN}

Plesiomórfico: 0

(0) Sinapomorfia homoplástica por reversão no clado 50.

(1) Sinapomorfia homoplástica por reversão do clado que une as duas espécies de Pseudoxycheila (70). Autapomorfia de Megacephala megacephala.

Em duas das quatro árvores mais parcimoniosas, o estado 1 é sinapomorfia homoplástica do clado $66 \mathrm{com}$ reversão para o estado $0 \mathrm{em}$ Metriocheila nigricollis. Para as outras duas árvores, o estado 1 é sinapomorfia homoplástica do clado 83.

224. Edeago, lobo médio, ponta pós abertura $(c i=0,18 ; r=0,55)$ (fig. 17C - 17E):

0 . virada pra cima

1. reta

$\mathbf{0}$

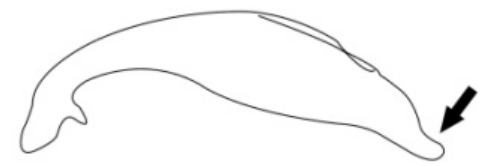

2. virada pra baixo

Distribuição dos estados:

$$
1
$$

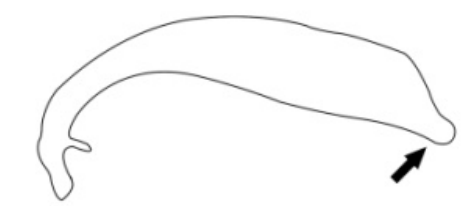

Otimização ACCTRAN

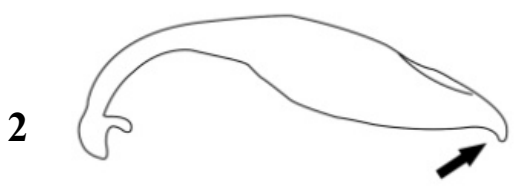

Plesiomórfico: 2

(0) Sinapomorfia homoplástica de Megacephalina. Autapomorfia de Pseudoxycheila bipustulata.

(1) Sinapomorfia homoplástica dos clados 56 e 62 . Autapomorfia homoplástica de Picnochile fallaciosa, Oxycheila opacipennis, Pseudotetracha howitti e Pseudotetracha murchisona. 
225. Edeago, lobo médio, margens dorsal e ventral ( $c i=0,50 ; r=0,66)$ :

0. não paralelas na região mediana

1. paralelas na região mediana

Distribuição dos estados:

Plesiomórfico: 0

(1) Sinapomorfia homoplástica do clado que une as duas espécies de Omus (68) e do clado 72.

226. Edeago, lobo médio, região mediana ( $c i=1 ; r=1)$ :

0. curva

1. reta

0

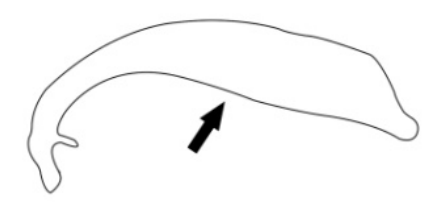

Distribuição dos estados:

Plesiomórfico: 0

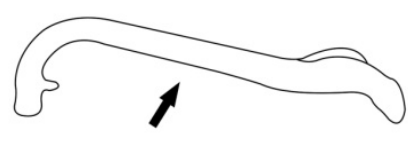

(1) Sinapomorfia do clado que une as duas espécies de Omus.

Seguem abaixo 6 caracteres relacionados ao ovipositor. Devido a esses caracteres terem sido examinados próximo do final da conclusão deste trabalho, 17 das 42 espécies não tiveram esses caracteres analisados devido à indisponibilidade de parte do material. 
227. Ovipositor, gonocoxitos, dentes (não informativo):

0.1

1. 2

Distribuição dos estados:

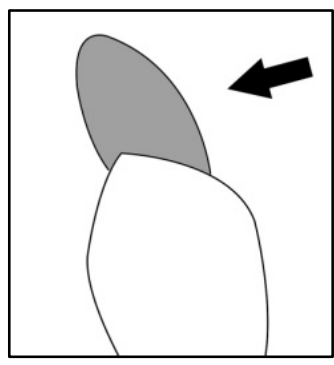

0

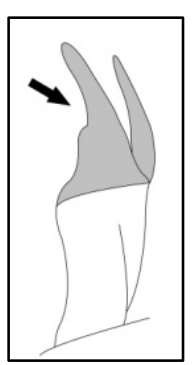

1

Otimização ACCTRAN: apenas para resolver a ambiguidade da base do cladograma.

Plesiomórfico: 0

Apenas a espécie (Calosoma granulatum) usada para o enraizamento do cladograma possui o estado 0 .

228. Ovipositor, gonocoxitos, dente externo ( $c i=0,33 ; r=0,50)$ :

0. simples

1. bífido

Distribuição dos estados:

Plesiomorfico: 0
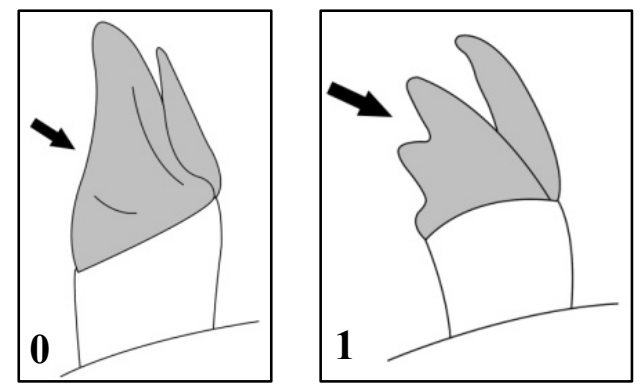

(1) Sinapomorfia homoplástica de Tetracha femoralis e Tetracha carolina. 
229. Ovipositor, gonocoxitos, dente externo bífido, tamanho relativo dos lobos (ci=1; $r=1)$ :

0. menor que metade do tamanho do dente

1. maior que a metade do tamanho do dente

Distribuição dos estados:

Otimização ACCTRAN
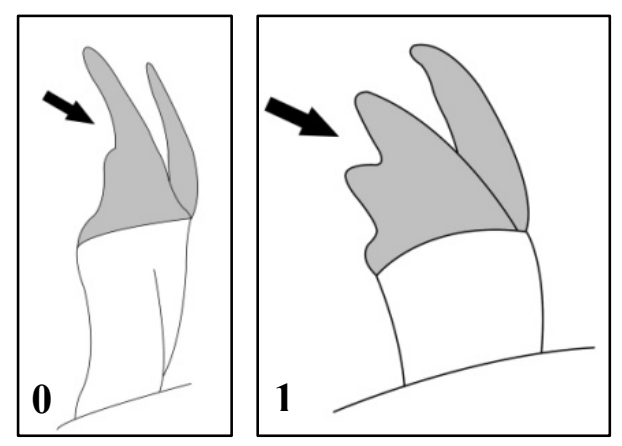

Plesiomórfico: 0

Apenas um clado (82) fora de Megacephalini apresenta o estado apomórfico.

230. Ovipositor, gonocoxitos, dentes (ci=1; $r=1$ ) (fig. 17F):

0. fundidos

1. articulados

Distribuição dos estados:

Plesiomórfico: 1

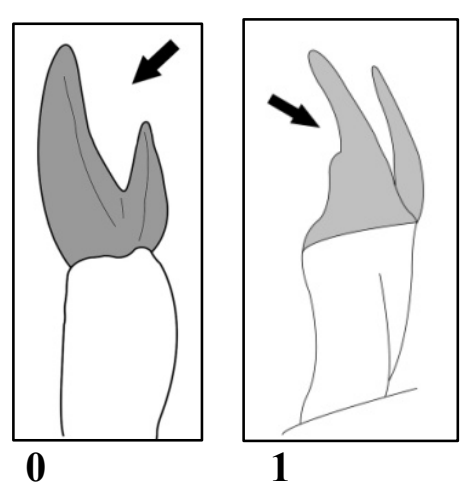

(0) Sinapomorfia de Manticorina (46).

231. Ovipositor, gonocoxitos, dente interno, relação sobre o externo (ci=0,50; $r=0)$ :

0. menor

1. maior

Distribuição dos estados: 
Plesiomórfico: 0

Apenas duas espécies do grupo externo apresentam o estado apomórfico.

232. Ovipositor, gonocoxitos, dente interno menor que o externo, proporção (ci=0,33; r=0,66) (fig. 17G):

0. mais de $75 \%$ do tamanho

1. menos de $75 \%$ do tamanho

Distribuição dos estados:

Otimização ACCTRAN

Plesiomórfico: 0

(0) Sinapomorfia homoplástica por reversão de Megacephalina. Autapomorfia homoplástica de Cheiloxya binotata.

(1) Sinapomorfia de Megacephalini.

\subsection{Hipóteses filogenéticas}

A análise filogenética dos 233 caracteres não ordenados, não polarizados a priori e com pesos iguais resultou em 4 árvores igualmente mais parcimoniosas com 960 passos (fig. 18). Os índices de consistência $(0,31)$ e de retenção $(0,63)$ indicam que apesar do número elevado de homoplasias, muitas delas são informativas e representam sinapomorfias.

Para a análise dos grupos naturais obtidos, foi feito o consenso estrito das 4 árvores resultando em uma árvore de consenso (fig. 19) com 966 passos, índice de consistência 0,31 e de retenção 0,63 . As tricotomias nos nós 66 e 59 indicam haver 
mais de uma possibilidade de resolução. Estas possibilidades foram discutidas na distribuição dos caracteres e estão ilustradas na figura 18.

\subsubsection{Monofilia de Megacephalini (clado 47)}

As quatro árvores resultantes da análise demonstraram que a tribo Megacephalini considerada a priori não é monofilética. De todos os gêneros já um dia considerados como parte dessa tribo, a análise mostrou que Callidema não pertence à tribo e Manticora, algumas vezes considerado pertencente a outro grupo de Cicindelinae, mostrou-se pertencer à Megacephalini na subtribo Manticorina. Este resultado não foi nenhuma surpresa, pois a maioria dos trabalhos, com exceção de Horn 1926, não considera Callidema parte do grupo formado pelos megacefalíneos e Manticora já foi colocado em agrupamentos junto com gêneros aqui pertencentes a Manticorina (THOMSON, 1857).

Deste modo, a tribo Megacephalini aqui definida é monofilética e formada por todos os gêneros da hipótese inicial, exceto Callidema, e incluindo o gênero Manticora (e provavelmente Mantica devido a sua grande semelhança). A tribo está definida pelas sinapomorfias: hábito noturno $\left(0_{1}\right)$ carena lateral do protórax com ápice anguloso avançando além do prosterno (860), não compartilhado apenas por Manticora; metatíbia enegrecida (2062), não compartilhado pelo clado 60 e ovipositor com dentes externos maiores que os internos, numa proporção menor que $75 \%$ $\left(232_{1}\right)$, não compartilhado por Cheiloxya binotata e pela subtribo Megacephalina (49).

As sinapomorfias homopláticas que suportam a subtribo são:

- Labro com 4 dentes medianos (204): ocorre na maioria das espécies analisadas. Ocorreu independentemente em uma espécie do grupo externo (Tricondyla aptera).

- gula estriada (530): a única espécie de Megacephalini com gula lisa é Picnochile fallaciosa. Ocorre independentemente no clado do grupo externo formado pelas duas espécies de Ctenostoma. 
- coloração por pigmento visível dorsalmente na cabeça (610): ocorre em todos os Manticorina, e em Oxycheilina ocorre em Cheiloxya e Oxycheila, sendo que as espécies de Pseudoxycheila apresentam iridescência. Em Megacephalina, a minoria das espécies apresentam esta coloração pigmentar.

- prosterno sem estrias (900): esta característica está presente em todas as espécies de Oxycheilina, porém nas outras duas subtribos há também espécies com prosterno estriado.

- pró-tíbia enegrecida (1062): todos os representantes de Manicorina e Oxycheilina apresentam tal característica, com exceção de Oxycheila labiata que também apresenta pigmentação amarelada (bicolor). Em Megacephalina apenas Aniara sepulcralis tem a pró tíbia negra.

- barra transversal posterior do mesosterno completa $\left(111_{2}\right)$ : presente na maior parte das espécies. O clado 67 apresenta a barra transversal incompleta, porém há uma reversão para a barra completa novamente em $P$. laminata.

- região mediana do mesepisterno e metepisterno lisa (1151): há uma reversão em Platychile pallida, que faz parte de um clado (63) sustentado pela presença destas regiões rugosas.

- menos de $30 \%$ do escutelo visível (1181): presente em todas as espécies de Megacephalini analisadas.

- perda da coloração metálica da epipleura (1391): ocorre na maior parte das espécies, com exceção de 3 espécies de Tetracha ( $T$. femoralis, T. fulgida, $T$. carolina e T. chilensis).

- presença de pigmentação amarelada fosca na região central da superfície dorsal dos élitros (1491): presente em parte das espécies de Oxycheilina, porém, apesar de as espécies de Pseudoxycheila apresentarem uma mancha amarela nesta posição, esta mancha é brilhante, diferente da espécie de Cheiloxya e das espécies com manchas de Oxycheila. Está presente também em todo um clado (62) de Megacephalina e em uma espécie do outro clado da mesma subtribo (T. germani), 
que tem a mancha apical do élitro bastante grande; as outras espécies deste clado, apesar de possuir a mancha amarelada fosca, esta não chega a tal região elitral.

- região anterior da margem externa do metepisterno sem cerdas (203 1 ): esta característica está presente na maioria das espécies, porém está ausente em Oxycheilina e nas espécies $M$. nigricollis e G. euphratica, pertencentes à Megacephalina.

- metafêmur enegrecido (2072): o metafêmur com coloração mais clara está presente apenas apenas no clado composto pelas espécies de Megacephalina, com excessão de Aniara (60).

- presença de estrias laterais nos ventritos III e IV (2172): ausente em Oxycheilina e Phaeoxantha laminata.

Essa hipótese filogenética se assemelha com hipóteses mais antigas baseadas em caracteres morfológicos dos adultos sem uma análise filogenética, assim como na lista mais atual de nomes supra genéricos de Coleoptera (BouCHARD et al., 2011), que tem como Megacephalini os mesmos gêneros aqui considerados, com exceção dos Manticorina, que estão divididos em duas tribos: Amblycheilini e Manticorini, este último formado pelas espécies de Mantica e Manticora. Apesar da semelhança das classificações apontadas acima, estas diferem muito em relação às análises apenas com caracteres morfológicos larvais (ARNDT \& PUTCHKOV, 1997), caracteres moleculares (VOGLER \& PEARSON, 1996) e com estes dados combinados (Vogler \& BARRAClough, 1998), onde a tribo se comporta como um grupo polifilético, incluindo Cicindelini nos clados mais apicais.

A presente análise mostrou que a tribo Megacephalini aqui estabelecida é subdividida em 3 clados bem suportados, considerados como subtribos: Manticorina (clado 46), Oxycheilina (clado 54) e Megacephalina (clado 49). 


\subsubsection{Monofilia de Manticorina (Clado 46)}

Esta subtribo é composta por 4 ou 5 gêneros formados por indivíduos braquípteros (Picnochile, Omus, Manticora, Amblycheila e provavelmente Mantica). O gênero Mantica não foi analisado devido a sua extrema raridade em coleções, porém é muito provável que também faça parte da mesma subtribo, devido a grande semelhança em relação a Manticora (MARES, 2002).

A presença de asas reduzidas poderia levar-nos a pensar que a braquipteria e os caracteres que derivam de tal condição fossem a maioria dos caracteres que sustentam o grupo, porém são 3 as sinapomorfias da subtribo, nenhuma relacionada à condição braquíptera. Estas são: clípeo com comprimento semelhante ao do labro (240), maxila com uma cerda no cardo $\left(39_{2}\right)$ (ausente em Omus californicus), metatrocânter com uma fileira de cerdas da base até aproximadamente a metade da estrutura $\left(197_{1}\right)$ e o ovipositor com os dois dentes do estilo fundidos (230).

As sinapomorfias homopláticas que suportam a subtribo são:

- a perda da iridescência ventral $\left(2_{1}\right)$ : ocorre em todos os Manticorina, mas ocorre independentemente também em dois outros clados: um em cada uma das outras subtribos. Este caráter não está ligado à iridescência dorsal, uma vez que algumas espécies são opacas dorsalmente, mas preservam a iridescência ventral.

- escapo com mais de 2 cerdas apicais (60): esta condição ocorre também em 3 espécies de Megacephalina ( $P$. pallida e nas duas espécies de Megacephala), porém as duas espécies de Omus apresentam apenas uma cerda apical no escapo.

- presença de cerdas no antenômero $2\left(9_{0}\right)$ : ocorre em todos os Manticorina, mas apareceu independentemente como duas autapomorfias dentro de Megacephalina.

- perda das cerdas longas da glossa (461): esta perda não ocorre em Manticora tuberculata e ocorre de forma independente em Metriocheila nigricollis, da subtribo Megacephalina. 
- mais de 7 cerdas em cada lado da cabeça (570): esta grande quantidade de cerdas na cabeça em Picnochile fallaciosa e Manticora tuberculata, esta última podendo apresentar apenas 7 em alguns espécimes.

- estrias não longitudinais presentes na superfície da gena (710): ocorre também em algumas espécies de Megacephalina, porém tais estrias estão ausentes nas espécies analisadas de Manticora e Amblycheila.

- escutelo elíptico ou arredondado (1190): ocorre em todos os Manticorina, porém aparece no gênero Platychile, também braquíptero. Em Platychile, o escutelo, de certo modo, é uma forma intermediária entre o tipo presente em Manticorina e Megacephalina, porém foi codificado de tal forma por ter sido julgado mais próximo da descrição do estado 0 . Mesmo sendo o escutelo uma estrutura bastante relacionada com os élitros, que por sua vez sofre frequentes modificações relacionadas ao desenvolvimento da asa membranosa, não podemos dizer que esta semelhança se deu devido à condição braquíptera, uma vez que dentro de Megacephalina há outros braquípteros com o escutelo com outro formato.

- perda da iridescência no dorso dos élitros (1411): todas as espécies de Manticorina apresentam essa condição. Tal perda ocorreu_de maneira independente em Oxycheilina no clado formado pelas espécies de Oxycheila e Cheiloxya (53); ocorreu tembém em Aniara, P. murchisona e no clado formado por 4 espécies de Megacephalina (67).

- perda das carenas basais na superfície interna dos élitros (1662): esta perda ocorre em todos os Manticorina analisados, porém algumas espécies não tiveram esta estrutura investigada, pois os élitros eram bastante espessos e fortemente fundidos, impossibilitando sua abertura. Aparentemente as carenas basais estão relacionadas com as asas desenvolvidas, pois todas as espécies braquípteras examinadas, tanto do grupo interno quanto do externo, não apresentaram tal estrutura.

- margem sutural do élitro (em vista ventral) reta ou arredondada em toda a extensão $\left(168_{1}\right)$ : presente nas duas únicas espécies examinadas $(P$. fallaciosa e $O$. californicus), pois nas outras os élitros se encontravam fundidos e foi e não possível remover um deles para coloca-lo na mesma posição (com a superfície interna 
voltada para cima). Ocorre também independentemente em grupos de Oxycheilina e Megacephalina.

- élitros fundidos (1741): a ocorrência de tal condição está restrita aos indivíduos braquípteros, porém nem todos estes possuem esta fusão. Isto foi facilmente observado em Omus dejeani, única espécie examinada da subtribo que não ofereceu resistência alguma na região da sutura elitral quando o élitro foi forçado a abrir. A fusão dos élitros ocorre também em Megacephala megacephala da subtribo Megacephalina.

- asa membranosa reduzida (1820): condição amplamente distribuída dentro dos Insecta, a redução da asa membranosa ocorreu independentemente também inúmeras vezes dentro dos coleópteros. Muitos pesquisadores já investigaram tal condição em Carabidae, destacando Philip Jackson Darlington Jr, que também discutiu as razões para que indivíduos braquípteros fossem selecionados em montanhas e ilhas $(1943,1971)$. Além de todas as espécies de Manticorina apresentarem tal condição, a redução da asa membranosa ocorreu em dois pontos isolados dentro de Megacephalina.

- relação da distância da sutura transversal do metasterno até a base da mesocoxa e a distância da sutura transversal até a base da metacoxa menor ou igual a 1 (2012): presente em todos os Manticorini e também compartilhada pelas duas espécies de Megacephala (Megacephalina), ambas também braquípteras.

- presença de mais de 4 cerdas no ventrito III $\left(211_{1}\right)$, IV $\left(212_{1}\right)$ e V $\left(213_{1}\right)$ : a presença de mais de 4 cerdas em tais ventritos ocorre em todas as espécies de Manticorina, porém para a maioria das espécies pode ocorrer em quantidades menores em alguns espécimes. Apenas Manticora tuberculata e A. picolominii apresentaram tal quantidade em todos os exemplares examinados. Dentro de Megacephalini a presença de mais de 4 cerdas nesses ventritos aparece independentemente também em Megacephala megacephala.

Este grupo, aqui denominado Manticorina, já tinha sido proposto por Thomson (1857), onde incluia, além dos gêneros aqui considerados, também o gênero monotípico africano Platychile. Apesar de apresentar algumas semelhanças 
morfológicas com os Manticorina, muitas devido à condição braquíptera, o gênero Platychile mostrou-se pertencer à Megacephalina. Ball (2011) também notou algo semelhante em relação a posição de Platychile ao sugerir a criação de um novo grupo para este gênero, uma vez que apresenta características tanto dos gêneros de Amblycheilini (aqui Manticorina), quanto de Megacephalini (aqui Megacephalina).

Horn (1926) distribui esses gêneros em grupos menores: coloca Manticora, juntamente com o gênero Mantica, em uma tribo separada (Mantichorini) e Omus, Picnochile e Amblycheila na subtribo Omina, dentro de Megacephalini. Lorenz (2005) mantém o grupo formado por Mantica e Manticora, porém dentro da tribo Cicindelini, a qual Megacephalina também faz parte. Assim, mais uma vez Manticora é separado dos demais gêneros.

Porém, Galian et al. (2002), em sua análise usando cromossomos sexuais, verificou que de todos os gêneros de Cicindelinae estudados, apenas Amblycheila e Manticora compartilhavam a presença de 8 loci no rDNA, enquanto Omus e os outros Megacephalini, 6 loci. Esta relação de proximidade entre Manticora e Amblycheila foi fortemente corroborada, visto que o suporte de Bremer (fig. 20) foi 11 no ramo que sustenta os dois gêneros. Deste modo, Manticora e Amblycheila fazem sim parte do mesmo grupo, juntamente com Omus e Picnochile, formando a subtribo Manticorina, tendo como suporte de Bremer nesta análise o valor 9.

\subsubsection{Monofilia de Oxycheilina (Clado 54)}

Esta subtribo é composta por 3 gêneros, que, ao longo dos estudos sobre os cicindelíneos, sempre foram colocados juntos (Pseudoxycheila, Oxycheila e Cheiloxya).

Cheiloxya e Oxycheila são bastante parecidos e aparecem na presente análise formando um só clado, estando Cheiloxya inserido entre as espécies de Oxycheila, demonstrando que o último não é monofilético. Os dois gêneros são formados por espécies associadas a ambientes aquáticos; já o outro gênero da subtribo, Pseudoxycheila, é formado por espécies associadas a regiões altas e terrestres. 
As sinapomorfias que sustentam o grupo são: a relação entre o comprimento e a largura do labro maior que $0,8\left(14_{1}\right)$, labro com mais de 7 dentes medianos $\left(20_{0}\right)$ e o abdômen das fêmeas com os ventritos III e IV muito desenvolvidos sobrepondo os ventritos V e VI que são bastante curtos $\left(216_{1}\right)$.

As sinapomorfias homoplásticas são:

- antenômero 3 pelo menos 4 vezes mais longo que o antenômero 2 (100): condição presente em todas as espécies analisadas de Oxycheilina, porém, apesar de estar ausente em Manticorina, é encontrado também em dois clados (63 e 73) dentro de Megacephalina.

- Labro subtriangular (110): esta característica ocorre em todos os Oxycheilina e independentemente apenas em $M$. nigricollis

- cerdas inseridas marginalmente no labro (151): característica presente em todas as espécies de Oxycheilina e ausente nos demais Megacephalini. Num primeiro momento aparenta ser uma condição restrita às espécies com labro triangular, porém está presente também em um clado do grupo externo, que apresenta espécies com labro de outro formato.

- perda das cerdas do clípeo (253): outra condição presente em todos os Oxycheilina e exclusiva dentro dos Megacephalini, mas ocorre também em outro clado do grupo externo. Caráter bastante fácil de observar e, apesar de características ligadas a cerdas serem geralmente inconstantes, esta condição é bastante estável dentro do grupo.

- mandíbula esquerda com 3 dentes internos $\left(30_{2}\right)$ : este estado aparece suportando também um clado dentro de Megacephalina. Dentro de Oxycheilina, há uma mudança em um clado formado por Oxycheila labiata + Oxycheila tristis, que consiste no aparecimento de um quarto dente, sinapomorfia deste pequeno clado.

- mandíbula direita com 3 dentes internos (351): mesma discussão do caráter anterior. 
- basiestipe com 2 cerdas $\left(40_{4}\right)$ : todos os Oxycheilina analisados apresentam esta característica, com excessão de 0 . opacipennis (apenas 1 cerda), porém alguns exemplares das espécies de Pseudoxycheila tinham apenas 3 cerdas.

- perda das estrias na região médio basal da cabeça $\left(58_{0}\right)$ : característica presente em quase todos os Oxycheilina, estando ausente apenas em O. labiata. Este caráter mostrou-se bastante homoplástico, com a perda das estrias ocorrendo também dentro de Manticorina e Megacephalina.

- perda das estrias longitudinais da gena $\left(70_{0}\right)$ : nenhum Oxycheilina apresenta tais estrias. Esta perda ocorreu independentemente em clados internos a Manticorina e Megacephalina.

- cerdas na margem posterior do prosterno (800): o único gênero que não apresentou esta característica foi Cheiloxya. Fora de Oxycheilina, este estado ocorre também dentro das outras duas subtribos. Esta característica também está presente em algumas espécies de Megacephalina, porém em nenhuma espécie de Manticorina

- presença de pigmentação amarelada fosca na posição apical dorsolateral do élitro (1520): apenas 3 espécies apresentaram tal caráter, uma vez que as duas de Pseudoxycheila são iridescentes e $O$. opacipennis é completamente escura. Nenhuma outra espécie de Megacephalini analisada apresenta tal característica.

- élitro dos machos com ápice levemente truncado (1801): entre os Oxycheilina, apenas $P$. ceratoma não apresenta $O$ élitro dos machos truncado. Em Megacephalini, além dos Oxycheilina, apenas as espécies $P$. klugii, T. carolina e $T$. chilensis, todas da subtribo Megacephalina, apresentam esta característica.

- presença de cerdas na região anterior da margem externa do metepisterno (2030): esta característica está presente em todas as espécies analisadas de Oxycheilina. Ocorre independentemente em M. nigricollis e em G. euphratica, ambas da subtribo Megacephalina.

- ventritos III e IV sem estrias transversais laterais (2171): presente em todos os Oxycheilina. As estrias são também perdidas independentemente apenas em $P$. laminata, da subtribo Megacephalina. 
O grupo Oxycheilina, sendo tribo, subtribo, ou qualquer outro nível de agrupamento, já passou por muitas mudanças. Alguns autores o consideram como parte da tribo Megacephalini (FLeUtiauX, 1892; HORN, 1926; WeISNER, 1992; VogleR \& PeARSON, 1996; CASSOla, 1997; LORENZ, 2005) e outros fora da tribo (Zerm et al., 2007). Outros autores consideram o grupo mais relacionado aos Cicindelini do que aos Megacephalini (GALIAN et al., 2002; VogLER et al., 2007) ou ainda explicitamente fazendo parte de Cicindelini (VogLER \& BARRACLOUGH, 1998; PUTCHKOV \& ARNDT, 1996; BALL, 2011).

Oxycheilina aparece neste trabalho como grupo-irmão de Megacephalina e, se considerada uma tribo separada, a subtribo Manticorina não poderia fazer parte de Megacephalini, já que é grupo irmão de Oxycheilina + Megacephalina. Tal situação desmembraria completamente a tribo, demonstrada aqui monofilética (com a exclusão de Callidema e adição de Manticora). O suporte de Bremer do ramo que une Oxycheilina e Megacephalina não é muito alto (3), porém, ainda assim indica a existência desta relação. Cassola (1997), em sua revisão da tribo Pseudoxycheila também defende a formação da subtribo Oxycheilina pelos gêneros aqui considerados, dentro de Megacephalini.

Por outro lado, a subtribo Oxycheilina como parte de Megacephalina, não foi a opção recuperada como propõem Naviaux (2007) entre outros, por duas razões principais: visualmente as espécies dos dois grupos são bastante distintas, tanto pela semelhança de sua cabeça e apêndices relacionados, quanto por características singulares presentes exclusivamente nos ventritos dos Oxycheilina; o suporte de Bremer para o clado que une Oxycheilina + Megacephalina (3) é a metade do valor para cada clado individual (6 para Megacephalina e 7 para Oxycheilina).

Devido a todos os fatores apontados acima, a conclusão é que a subtribo Oxycheilina é um grupo natural, grupo irmão de Megacephalina e faz parte da tribo Megacephalini.

Oxycheila aparece como grupo parafilético, tendo o gênero Cheiloxya inserido dentro daquele. Era realmente esperado que $O$. tristis e 0 . labiata formassem um grupo monofilético, pois ambas pertencem ao grupo labiata, enquanto $O$. 
opacipennis, ao grupo raminagrobis (Weisner 1999), porém a inserção de Cheiloxya entre eles foi algo inesperado. Devido à amostagem de Oxycheila ter sido baixa (3 espécies para as mais de 46 espécies existentes) e o suporte que une Cheiloxya às espécies de Oxycheila ser apenas 1, afirmo aqui a grande necessidade não só de uma revisão, mas também uma filogenia incluindo todas as espécies da subtribo Oxycheilini. Só dessa forma será possível estabelecer os limites de Cheiloxya e Oxycheila.

\subsubsection{Monofilia de Megacephalina (Clado 49)}

Esta subtribo é formada por 9 gêneros, sendo a maioria já considerada pertencente ao gênero Megacephala. Visualmente são semelhantes, com excessão dos gêneros monoespecíficos Aniara, Platychile e Metriocheila.

As sinapomorfias que sustentam o grupo são:

- a presença de um dente retinacular complementar nas duas mandíbulas (310 e 370): este dente é observado facilmente entre a região molar e o último dente terebral. Está presente na maioria dos Megacephalina, porém ocorrem diversas mudanças dentro do grupo independente da distribuição geográfica e do gênero. Mostra-se um pouco mais constante no grupo Tetracha + Megacephala, que apenas uma das 10 espécies examinadas não apresenta o dente complementar ( $T$. femoralis).

- escutelo transverso com margens laterais emarginadas anteriormente $\left(119_{3}\right)$ : a única espécie com estado diferente é Platychile pallida, espécie africana que sempre teve sua posição controversa dentro de Cicindelinae. Seu escutelo apresenta uma forma intermediária entre a dos Megacephalina e dos Manticorina, porém, devido ao seu formato mais arredondado, foi codificado com elíptico.

- presença de pigmentação amarelada nas laterais dos últimos ventritos abdominais (2181): característica presente na grande maioria dos Megacephalina, estando ausente e representando reversões autapomórficas em apenas em 4 das 18 
espécies analisadas; são elas: $P$. howitti, $T$. femoralis, $T$. germaini e $M$. megacephala.

As sinapomorfias homoplásticas são:

- escapo com duas cerdas apicais (6 $\left.6_{1}\right)$ : característica exclusiva dentro de Megacephalini, há o ganho de mais cerdas nos gêneros braquípteros africanos (Megacephala e Platychile). Duas espécies australianas do gênero Paratetracha também podem apresentar mais de duas cerdas em alguns indivíduos.

- lobos laterais do labro retos ou quase retos (160): condição exclusiva dentro dos Megacephalini, com reversão para o estado plesiomórfico nas duas espécies do gênero neotropical Phaeoxantha.

- labro com 4 cerdas na margem anterior (210): mais uma característica exclusiva dentro do Megacephalini, uma vez que os outros gêneros apresentam maior quantidade de cerdas. Esta característica sofre mudanças em $P$. pallida, P. klugii e M. megacephala, os quais apresentam maior quantidade de cerdas. A quantidade de cerdas do labro mostrou-se plástica em $P$. cylindrica e $P$. howitti, que possuem indivíduos com quatro ou 6 cerdas.

- parte inferior da sutura subgenal sinuosa (651): característica também compartilhada por um grupo dentro de Manticorina. Em Megacephalina há reversão para o estado plesiomórfico em $P$. pallida e em $T$. femoralis.

- margem posterior do escutelo biemarginada (123 1 : apesar de a forma geral do escutelo em Megacephalina ser única (1193), a margem posterior biemarginada é também compartilhada por espécies de Manticorina e Oxycheilina. Duas espécies de Tetracha e $P$. pallida apresentam margem angulada não biemarginada.

- presença de pigmentação amarelada fosca na posição apical anterior dorsolateral do élitro 150(1): dentro de Megacephalini é exclusiva de Megacephalina. Não está presente nos gêneros Australicapitona, Metriocheila e Grammognatha, além da espécie Aniara sepulcralis e $M$. megacephala, que não têm este pigmento em nenhuma parte do élitro. 
- presença de pigmentação amarelada fosca na posição apical anterior do élitro 151(1): dentro de Megacephalini é exclusiva de Megacephalina. Não está presente nos gêneros Grammognatha, Megacephala e Aniara, além da espécie T. brasiliensis.

- presença de pigmentação amarelada fosca na posição apical do élitro (1531): dentro de Megacephalini é exclusiva de Megacephalina. Todas as espécies que apresentavam a coloração amarelada fosca no élitro, esta estava presente nessa posição; o caráter não foi aplicável nas espécies $A$. sepulcralis, $M$. megacephala e T. femoralis.

- prega sublateral da superfície interna do élitro muito fraca na região do terço anterior (1692): dentro de Megacephalini não é exclusiva dos Megacephalina, ocorrendo também em $P$. fallaciosa (Manticorina). Em Megacephalina ocorre em Aniara e nas espécies de Tetracha.

- presença de um apêndice na alça anal da asa posterior (1851): ocorre em todas as espécies de Megacephalina que tiveram sua asa membranosa examinada. Ocorre independentemente no clado (69) formado pelas espécies $O$. tristis e O. labiata (Oxycheilina).

- perda das cerdas do ventrito VI (2143): apenas G. euphratica apresenta cerdas; alguns espécimens de $P$. klugii podem apresentar duas cerdas. As cerdas são perdidas independentemente em A. cylindriformis (Manticorina) e em C. binotata (Oxycheilina).

- ponta pós abertura do lobo médio virada para cima (2240): caráter bastante homoplástico, sofrendo muitas mudanças dentro de Megacephalini.

- gonocoxitos com dente interno maior que o externo, numa proporção maior que $75 \%$ (2320): característica presente em todas as espécies de Megacephalina que tiveram o ovipositor examinado, ocorrendo independentemente em C. binotata (Oxycheilina).

A subtribo tem em sua base o gênero monoespecífico Aniara, sendo grupo irmão de todas as outras espécies. A grande maioria dos caracteres que fazem com 
que este gênero fique separado dos demais é sua coloração negra; muitos caracteres ligados à coloração suportam o clado 60 , composto por todos os Megacephalina, com excessão de Aniara. A coloração também teve grande influência na posição de Platychile. Apesar de o uso da coloração em análise filogenética ser bastante questionada, mostrou-se bastante útil no agrupamento de alguns clados e aparentemente não prejudicou no agrupamento das tribos e subtribos, foco principal deste trabalho.

Além de Aniara, dois outros grandes clados foram formados dentro de Megacephalina: um composto em sua maioria por espécies australianas e neotropicais (clado 62) e outro formado por espécies africanas e neotropicais (clado 63). A única excessão foi Platychile, gênero africano dentro do clado 62. Thomson, (1857), assim como Gallian (2002) coloca Platychile junto com os Manticorina. Esta relação pode ser observada no presente trabalho, visto a grande quantidade de estados de caracteres compartilhados, porém, a soma de todos os caracteres o coloca em Megacephalina. O mesmo foi observado por Ball (2011), que opta por sugerir colocar o gênero em um grupo a parte por conter características tanto de Amblycheilini (Manticorina menos Manticora e Mantica) quanto de Megacephalini (equivalente aos Megacephalina).

Poucos gêneros mostraram-se monofiléticos como resultado da presente análise. $O$ gênero australiano Pseudotetracha apresentou uma espécie ( $P$. murchisona) agrupada com um clado diferente das demais, formando um grupo junto com Australicapitona, Phaeoxantha, Platychile e Metriocheila. O gênero neotropical Phaeoxantha teve suas duas espécies que foram aqui usadas divididas, corroborando com Naviaux (2007), quando disse que a espécie tipo P. laminata era muito diferente das demais; $P$. klugii apareceu como grupo irmão dos diferentes agrupamentos formados por $P$. laminata junto com os gêneros monotípicos Platychile e Metriocheila. O grande gênero Tetracha mostrou-se parafilético, formando um grupo natural junto com o gênero africano Megacephala. Devido à baixa amostragem de espécies para certos gêneros, como 6 espécies de Tetracha para mais de 90 existentes, não é possível afirmar mais do que a importância de mais estudos filogenéticos de Megacephalina para um investigação mais detalhada ao nível de gênero e espécie, já que esta subtribo se mostrou problemática. Todos 
esses já foram um dia considerados do mesmo gênero Megacephala e ao longo de anos, esse grande grupo foi sendo dividido não com base em análises filogenéticas, mas principalmente por distribuição geográfica (continentes) e taxonomia alfa.

\section{CONCLUSÕES}

As conclusões alcançadas, frutos dos resultados obtidos pela análise cladística baseada no levantamento de 233 caracteres para os 42 táxons estudados são as seguintes:

- A tribo Megacephalini com proposta por Horn (1926), Lorenz (2005) e Naviaux (2007) não é monofilética;

- A tribo Megacephalini como aqui definida é monofilética;

- o gênero Manticora faz parte da tribo e pertence à subtribo Manticorina;

- o gênero monotípico Callidema não pertence à tribo;

- Megacephalini, grupo natural estabelecido aqui como tribo é subdividida em 3 subtribos, compostas pelos seguintes gêneros:

- subtribo Manticorina: Picnochile, Omus, Manticora e Amblycheila (e provavelmente Mantica).

- subtribo Oxycheilina: Pseudoxycheila, Oxycheila e Cheiloxya.

- subtribo Megacephalina: Aniara, Pseudotetracha, Australicapitona, Phaeoxantha, Platychile, Metriocheila, Tetracha, Grammognatha e Megacephala.

- baseado nas espécies estudadas de cada gênero, alguns deles se mostraram parafilético como: Pseudotetracha, Phaeoxantha e Tetracha. Apenas futuras revisões e análises cladísticas poderão delimitar essses gêneros. 


\subsection{Classificação para a tribo Megacephalini aqui estabelecida}

\section{Tribo MegacephalinI Laporte, 1834}

SUBTRIBO MANTICORINA Laporte, 1834

Picnochile Motschulsky, 1856

Omus Eschscholtz, 1829

Manticora Fabricius, 1781

Mantica Kolbe, 1896*

Amblycheila Say, 1830

SUBTRIBO OXYCHEILINA Chaudoir, 1860

Pseudoxycheila Guérin, 1855

Oxycheila Dejean, 1825

Cheiloxya Guérin, 1855

Subtribo Megacephalina Horn, 1910

Aniara Hope, 1838

Pseudotetracha Fleutiaux, 1894

Australicapitona Sumlin, 1992

Phaeoxantha Chaudoir, 1850

Platychile M'Leay, 1825

Metriocheila Thomson, 1857

Tetracha Westwood, 1838

Grammognatha Motschoulsky, 1850

Megacephala Latreille, 1802

* o gênero Mantica não foi examinado no presente estudo devido a sua raridade nas coleções. Porém, visto a grande semelhança com o gênero Manticora, há uma grande possibilidade de também fazer parte da mesma subtribo (Mares 2002).

\section{REFERÊNCIAS BIBLIOGRÁFICAS}

Arndt E.; R. G. Beutel \& K. Will. 2005. Carabidae Latreille, 1802. In: Rolf G. Beutel \& Richard A. B. Leschen (Ed.). Handbuch der Zoologie. Walter de Gruyter, Berlin - New York, 567p. 
ARndt, E. \& A. V. Putchkov. 1996/97. Phylogenetic Investigation of Cicindelidae (Insecta: Coleoptera) Using Larval Morphological Characters. Zoologischer Anzeiger 235: 231-241.

BALL, G. E. 1979. Conspectus of carabid classification: History, holomorphology and higher taxa. In: Carabid Beetles: Their Evolution, Natural History, and Classification, ed. T. L. Erwin, G. E. Ball, D. R. Whitehead, 1:63-111. Boston/ London/The Hague, Junk. 635 p.

BALL, G. E., J. H. AcORN, D. ShPELEY. 2011. Mandibles and labrum-epipharynx of tiger beetles: basic structure and evolution (Coleoptera, Carabidae, Cicindelitae). Zookeys 147: 39-83.

BAsILEWSKY, P. 1966. Revision dês Megacephala d'Afrique (Coleoptera Carabidae Cicindelinae). Musee Royal de L'Afrique Centrale, Tervuren, Belgique, $\mathrm{n}^{\circ}$ 152, 151p.

Beutel, R. G. 1992. Phylogenetic analysis of thoracic structures of Carabidae (Coleoptera: Adephaga). Journal of Zoological Systematics and Evolutionary Research 30(1): 53- 74.

BLACKWELDER, R. E. 1945. Checklist of the Coleopterous Insects of Mexico, Central America, the West Indies, nd South America. Bulletin of the United States National Museum 185(3): 443-550.

Bouchard, P., Yves Bousquet, Anthony E. Davies, Miguel A. Alonso-Zarazaga, John F. Lawrence, Chris H. C. Lyal, Alfred F. Newton, Chris A. M. Reid, Michael SCHMitT, S. AdAm ŚLIPIŃSKI, ANDREW B. T. SMITH. 2011. Family-group names in Coleoptera (Insecta). Zookeys 88: 1-972.

Bousquet, Y. \& A. LAROCHELlE. 1993. Catalogue of the Geadephaga (coleopteran: Trachypachidae, Rhysodidae, Carabidae including Cicindelini) of America North of Mexico. Memoirs of the Entomological Society of Canada 125(167): 1397.

Cassola F. \& D. L. Pearson. 2000. Global patterns of tiger beetle species richness (Coleoptera: Cicindelidae): their use in conservation planning. Biological Conservation 95, 197-208.

CASSOLA, F. 1997. Studies on tiger beetles. XC. Revision of the neotropical genus Pseudoxycheila Guerin, 1839 Coleoptera, Cicindelidae. Fragmenta Entomologica 29(1): 1-121.

Crowson, R. A. 1955. The Natural Classification of the Families of Coleoptera. London, Nathaniel \& Lloyd Co. 187 p. 
DARLINGTON JR, P. J. 1943. Carabidae of mountains and islands: data on the evolution of isolated faunas, and on atrophy of wings. Ecological Monographs 13: 37-61, 8 fig.

DARLINGTON JR, P. J. 1971. The carabid beetles of New Guinea. Part IV. General considerations; analysis and history of fauna; taxonomic supplement. Bulletin of the Museum of Comparative Zoology 142: 129-337.

DeuVE, T. 1993. L'abdomen et lês genetalia dês femelles de Coléoptères Adephaga. Mémoires Du Muséum National D’histoire Naturale 155: 1-184.

ERWIN, T. L. 1985. The taxon pulse: a general pattern of lineage radiation and extinction among carabid beetle. In: G. E. Ball (Ed.). Taxonomy, Phylogeny and Zoogeography of Beetles and Ants. A volume dedicated to the memory of Philip Jackson Darlington, Jr. (1904-1983). Boston, Lancaster, Dordrecht, Dr. W. Junk Publishers, 437-472.

ERWIN, T. L. 2007. A Treatise on the Western Hemisphere Caraboidea (Coleoptera): Their Classification, Distribution, and Ways of Life. Volume 1 (Trachypachidae, Carabidae - Nebriformes 1). Sofia - Bulgaria, Pensoft Publishers, 323p. + 22pr.

ERWIN, T. L. \& D. L. PEARSON. 2008. A Treatise on the Western Hemisphere Caraboidea (Coleoptera): Their Classification, Distribution, and Ways of Life. Volume 2 (Carabidae - Nebriformes 2 - Cicindelitae). Sofia - Bulgaria, Pensoft Publishers, 365 p. +33 pls.

ERWIN, T. L. \& L. L. SIMS. 1984. Carabid Beetles of the West Indies (Insect: Coleoptera): A Synopsis of the Genera and Checklist of Tribes of Caraboidea, and of the West Indian Species. Quaestiones Entomologicae 20:351-466.

Evenhuis, N. L. 2012. The Insect and Spider Collections of the World Website. Disponível em: http://hbs.bishopmuseum.org/codens/codens-r-us.html. Acesso em: 07.V.2012.

FARRIS, J. S. 1970. Methods for computing Wagner trees. Systematic Zoology 19: 83-92.

FITCH, W. M. 1971. Toward defining the course of evolution: Minimum change for a specific tree topology. Systematic Zoology 20: 406-416.

FleutiauX, E. 1892. Catalogue des Cicindelidae: Décrits Depuis Linné par Ed. Fleutiaux. Liége: H. Vaillant Carmanne, $186 \mathrm{p}$.

FleutiauX, E. 1894. Les Megacephalidae d'Australie. Revue d'Entomologie (Caen) 13: $123-128$.

FoWLER, H. G. 1987. Predatory behavior of Megacephala fulgida (Coleoptera: Cicindelidae). The Coleopterists' Bulletin 41(4):407-408. 
Galian, J., J. E. Hogan, A. P. Vogler. 2002. The Origin of Multiple Sex Chromosomes in Tiger Beetles. Molecular Biology and Evolution 19(10): 1792-1796.

GILBERT, C. 1997. Visual control of cursorial prey pursuit by tiger beetles (Cicindelidae). Journal of Comparative Physiology A 181: 217-230.

GolobofF, P. A., J. S. FarRIS \& K. C. NixON. 2008. TNT, a free program for phylogenetic analysis. Cladistics 24: 774-786.

GolobofF, P. A., J. S. FARRIS \& K. C. NIXON. 2012. TNT - Tree analysis using new technology. v. 1.1., Willi Hennig Society, Nova lorque.

GooD, H. G. 1925. Wing venation of Buprestidae. Annals of the Entomological Society of America 18: 251-276.

HORN, W. 1926. Carabidae: Cicindelidae. In: Junk \& Schenkling (Ed.). Coleopterorum Catalogus, 345 p..

hunt, T., J. Bergsten, Z. Levkanicova, A. Papadopoulou, O. St. John, R. Wild, P. M. Hammond, D. Ahrens, M. Balke, M. S. Caterino, J. Gómez-Zurita, I. Ribera, T. G. Barraclough, M. Bocakova, L. Bocak, A. P. Vogler. 2007. A Comprehensive Phylogeny of Beetles Reveals the Evolutionary Origins of a Superradiation. Science 318: 1913-1916.

JEANNEL, R. 1942. Coléoptères carabiques I. Faune de France 39: 1-571.

JORGE-SILVA, M. E. 1979. Morfologia comparada das peças bucais de Carabidae (Coleoptera) Neotropicais. Tese [não publicada] apresentada ao Instituto de Biociências da Universidade de São Paulo como parte dos requisitos para a obtenção do título de Doutor em Ciências na área de Zoologia, 114 p., 803 fig.

KING, E. W. 1956. Wing venation in the Adephaga and its contributions to phylogeny. lowa Academy of Science 63: 697-699.

KukAlovÁ-PeCK, J. \& J. F. LAWREnCE. 1993. Evolution of the hind wing in Coleoptera. The Canadian Entomologist 125: 181-258.

KuKALOVÁ-PECK, J. \& J. F. LAWRENCE. 2004. Relationships among coleopteran suborders and major endoneopteran lineages: Evidence from hind wing characters. European Journal of Entomology 101: 95-144.

LAWrence, J. F. \& E. B. Britton. 1994. Australian Beetles, Carlon, Victoria, Melbourne University Press, $\mathrm{x}+192 p$.

LIEBHERR, J. K. \& K. W. WILL. 1998. Inferring phylogenetic relationships within Carabidae (Insecta, Coleoptera) from characters of the female reproductive tract. pp. 107-170 In: G. E. Ball, A. Casale, and A. V. Taglianti, eds., Phylogeny 
and Classification of Caraboidea (Coleoptera: Adephaga). Turin, Italy: Museo Regionale di Scienze Naturali.

LORENZ, W. 2005. Systematic List of Extant Ground Beetles of the World (Insecta Coleoptera "Geadephaga": Trachypachidae and Carabidae incl. Paussinae, Cicindelinae, Rhysodinae). Published by the author, Tutzing, Germany, i-iii+530p.

Maddison, D. R., M. D. BaKeR, K.A. Ober. 1999. Phylogeny of carabid beetles as inferred from 18S ribosomal DNA (Coleoptera: Carabidae). Systematic Entomology 24: 103- 138.

MAdDISON, W. P. \& D. R. MADDISON. 2011. Mesquite: A modular system for evolutionary analysis, v. 2.75.

MANDL, K. 1971. Wiederherstellung des Familienstatus der Cicindelidae (Coleoptera). Beitraege zur Entomologie 21(3/6): 507-508.

MARES, J. 2002. Manticora - A Monograph of the Genus. Hradek Králové, Czech Rebuplic: Taita Publishers, $205 \mathrm{p}$.

Marinoni, R. C., Ganho, N. G., Monné, M. L. \& J. R. M. Mermudes. 2001. Hábitos Alimentares em Coleoptera (Insecta): compilação, organização de dados e novas informações sobre alimentação nas famílias de coleópteros. Ribeirão Preto, Holos Editora, 64 p.

MARTíneZ, C. 2005. Introducción a los Escarabajos Carabidae (Coleoptera) de Colombia. Bogotá, Colômbia. Instituto de Investigaciones de Recursos Biológicos Alexander von Humboldt, 546p.

NaviauX, R. 2007. Tetracha (Coleoptera, Cicindelidae, Megacephalina): Révision du Genre et Descriptions de Nouveaux Taxons. Mémoires de La SEF v.7, 197p.

Nixon, K. C. \& J. M. CARPEnTER. 1993. On outgroups. Cladistics 9: 413-426.

Pearson, D. L., J. Buestan \& R. NavarRete. 1999. The tiger beetles of Ecuador: their identification, distribution and natural history (Coleoptera: Cicindelidae). Contributions on Entomology International 3: 189-315.

Pearson, D. L. \& A. P. Vogler. 2001. Tiger Beetles: the evolution, ecology, and diversity of the cicindelids. Ithaca, Cornell University Press, 333p.

PeARSON, D. L. 1988. Biology of Tiger Beetles. Annual Review of Entomology 33: 123-147.

PutchKov A.V. \& E. ARNDT. 1996. Description of the larvae of Oxycheila tristis (F.) and taxonomical state of the genus Oxycheila Dejean, 1825 (Insecta:Coleoptera, Cicindelidae). Entomologische Abhandlungen Dresden 57:201-206. 
REICHARDT, H. 1977. A synopsis of the genera of Neotropical Carabidae (Insecta: Coleoptera). Quaestiones Entomologicae 13: 346-493.

RivalieR, E. 1971. Remarques sur La tribu des Cicindelini (Col: Cicindelidae) et as subdivision em sous-tribus. Nouvelle Revue d'Entomologie 1: 135-143.

SAALAS, U. 1936. Uber das Flügelgeäder und die phylogenetische Entwicklung der Cerambyciden. Suomalaisen Elain-ja Kasvitieteellisen Seuran Venamon Elaintieteellisia Julkaisuja 4: 1-198.

SERENO, P. C. 2007. Logical basis for morphological characters in phylogenetics, Cladistics 23: 565- 587.

SHARP, D. \& F. MUIR. 1912. The comparative anatomy of the male genital tube in Coleoptera. Transactions of the Entomological Society of London 477-642, illust. (Reprinted without change, 1969).

SloANe, T. G. 1906. Revision of the Cicindelidae of Australia. Proceedings of The Linnean Society of New South Wales 31:309-360.

SpangleR, H. G. 1988. Hearing in tiger beetles (Cicindelidae). Physiological Entomology 13: 447-452.

SumLIN, W. D. (1992). Studies on the Australian Cicindelidae VIII: notes on Megacephala and Cicindela with descriptions of new taxa (Coleoptera). Cicindelidae Bulletin of Worldwide Research 4 (1): 7- 26.

SumLIN, W. D. (1992). Studies on the Australian Cicindelidae X: notes on Megacephala and Cicindela with the description of a new species (Coleoptera). Cicindelidae Bulletin of Worldwide Research 4 (1): 27- 30.

TANNER, V. M. 1927. A preliminary study of the genitália of female Coleoptera. Transactions of the American Entomological Society 53: 5-50, 15 pls.

Thomson, M. J. 1857. Monographie des Cicindélides ou Exposé Méthodique et Critique dês Tribus, Genres et Espèces de Cette Famille par M. James Thomson, Tome Premier. Paris, J.-B. Baillière, New York.

Vogler, A. P. \& D. L. Pearson. 1996. A Molecular Phylogeny of the Tiger Beetles (Cicindelidae): Congruence of Mitochondrial and Nuclear rDNA Data Sets. Molecular Phylogenetics and Evolution 6(3): 321-338.

Vogler, A. P. \& T. G. Barraclough. 1998. Reconstructing shifts in diversification rate during the radiation of Cicindelidae (Coleoptera), 251-260. In: Phylogeny and Classification of Caraboidea, XXth International Congress of Entomology (1996), Florence, Italy, 543 p. 
Vogler, A. P., F. A. Welsh \& J. M. Hancock. 1997. Phylogenetic Analysis of Slippage-like Sequence Variation in the V4 rRNA Expansion Segment in Tiger Beetles (Cicindelidae). Molecular Biology and Evolution 14(1): 6-19.

WAGNeR, D. L. \& J. K. LeBHERR. 1992. Flightlessness in insects. Trends in Ecoogy and Evolution 7:216-220.

WARD, R. D. 1979. Metathoracic wing structures as phylogenetic indicators in the Adephaga (Coleoptera). In: Erwin, T.L., G.E. Ball, D.R. Whitehead and A.L. Halpen (eds.), Carabid Beetles: Their Evolution, Natural History, and Classification. W. Junk, The Hague.

WeISNeR, A. P. 1992. Checklist of the Tiger Beetles of the World: (Coleoptera, Cicindelidae). Verlag Erna Bauer, Keltern, Germany, $364 \mathrm{p}$.

WILSON, J. W. 1930. The genitalia and wing venation of the Cucujidae and related families. Annals of the Entomological Society of America 23: 305-358.

WILson, S. J. 1934. The anatomy of Chrysochus auratus Fab., (Coleoptera: Chrysomelidae) with an extended discussion of the wing venation. Journal of the New York Entomological Society 42: 65-85.

YAGER, D. D. \& H. G. SpANGLER. 1995. Characterization of auditory afferents in the tiger beetle, Cicindela marutha Dow. Journal of Comparative Physiology A 176: 587-599.

YAGER, D. D. \& H. G. SPANGLER. 1997. Behavioral response to ultrasound by the tiger beetle Cicindela marutha Dow combines aerodynamic changes and sound production. The Journal of Experimental Biology 200: 649-659.

Zerm, M., J. Wiesner, J. Ledezma, D. Brzoska, U. Drechsel, A.C. Cicchino, J.P. RodrígueZ, L. Martinsen, J. AdIS, L. BACHMANN. 2007. Molecular phylogeny of Megacephalina Horn, 1910 tiger beetles (Coleoptera: Cicindelidae). Studies on Neotropical Fauna and Environment 42(3): 211-219. 


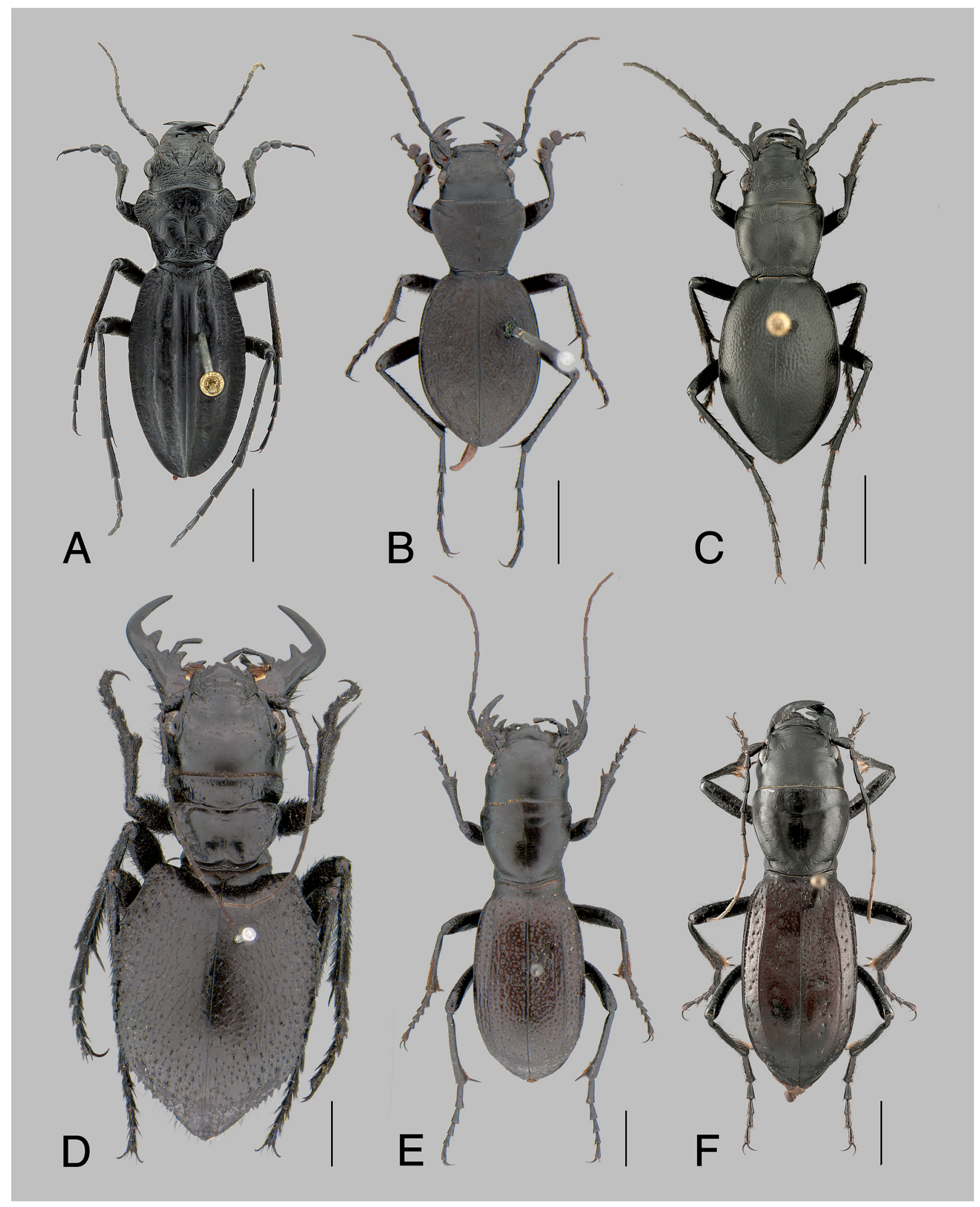

Figura 01: Habitus. A. Picnochile falaciosa (macho); B. Omus dejeani (macho); C. Omus californicus (fêmea); D. Manticora tuberculata (macho); E. Amblycheila cylindriformis (macho); F. Amblycheila picolominii (macho). As barras correspondem a $5 \mathrm{~mm}$. 


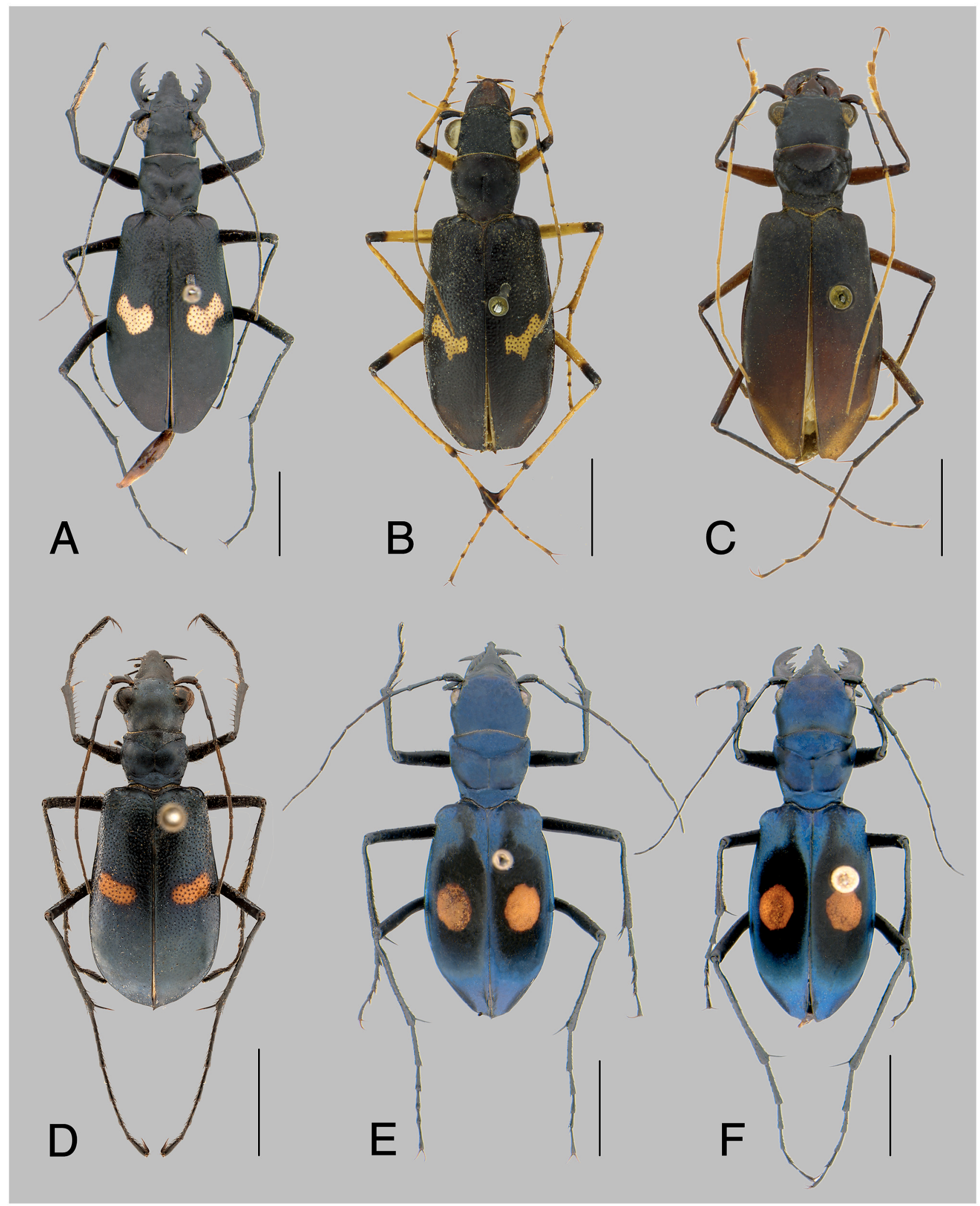

Figura 02: Habitus. A. Oxycheila tristis (macho); B. Oxycheila labiata (fêmea); C. Oxycheila opacipennis (macho); D. Cheiloxya binotata (fêmea); E. Pseudoxycheila ceratoma (fêmea); F. Pseudoxycheila bipustulata (macho). As barras correspondem a $5 \mathrm{~mm}$. 


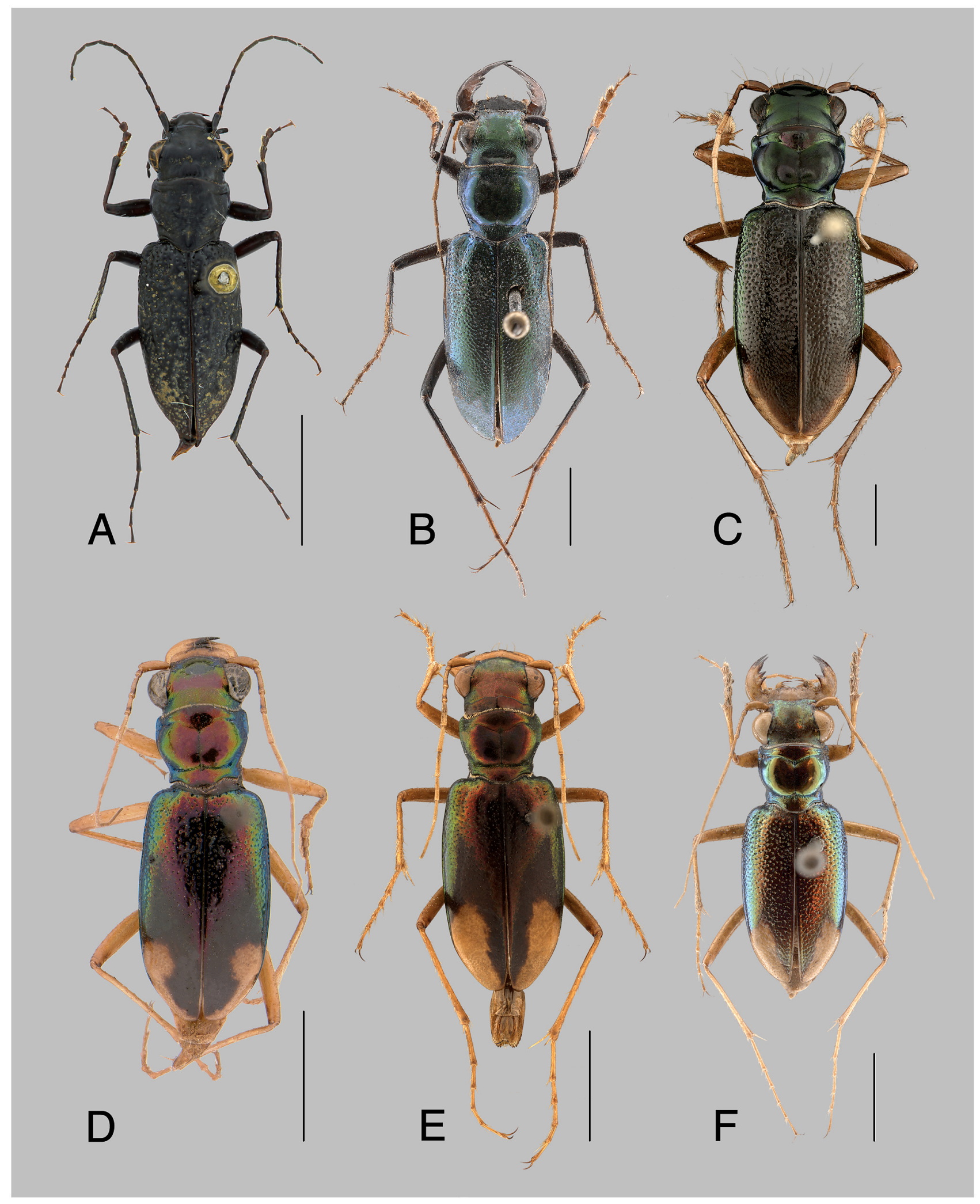

Figura 03: Habitus. A. Aniara sepulcralis (macho); B. Tetracha femoralis (macho); C. Tetracha brasiliensis (macho); D. Tetracha carolina (macho); E. Tetracha chilensis (fêmea); F. Tetracha fulgida (macho). As barras correspondem a $5 \mathrm{~mm}$. 

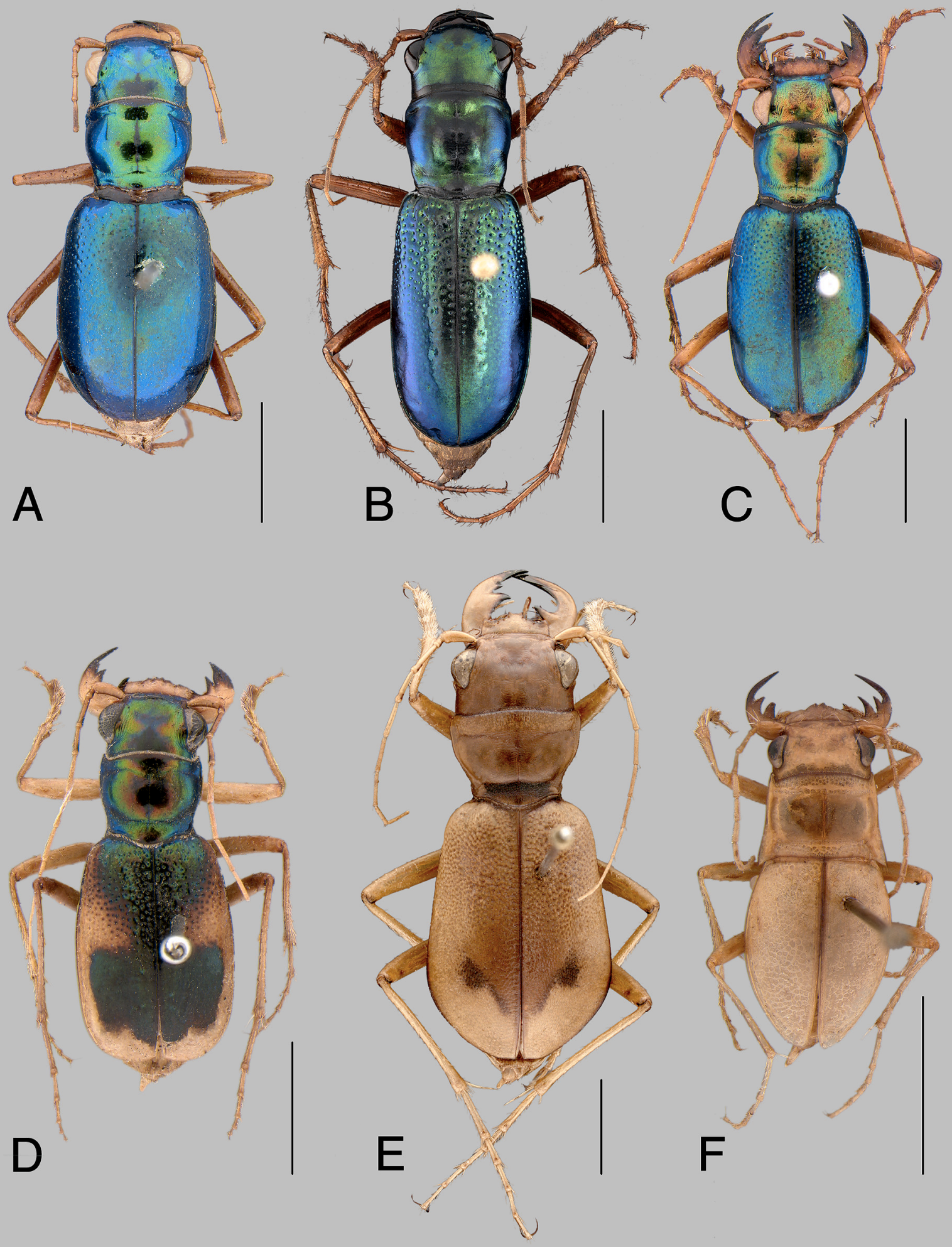

Figura 04: Habitus. A. Pseudotetracha howitii (fêmea, síntipo); B. Pseudotetracha cylindrica (macho); C. Pseudotetracha murchisona (macho); D. Australicapitona basalis (macho); E. Phaeoxantha klugii (macho); F. Platychile pallida (macho). As barras correspondem a $5 \mathrm{~mm}$. 


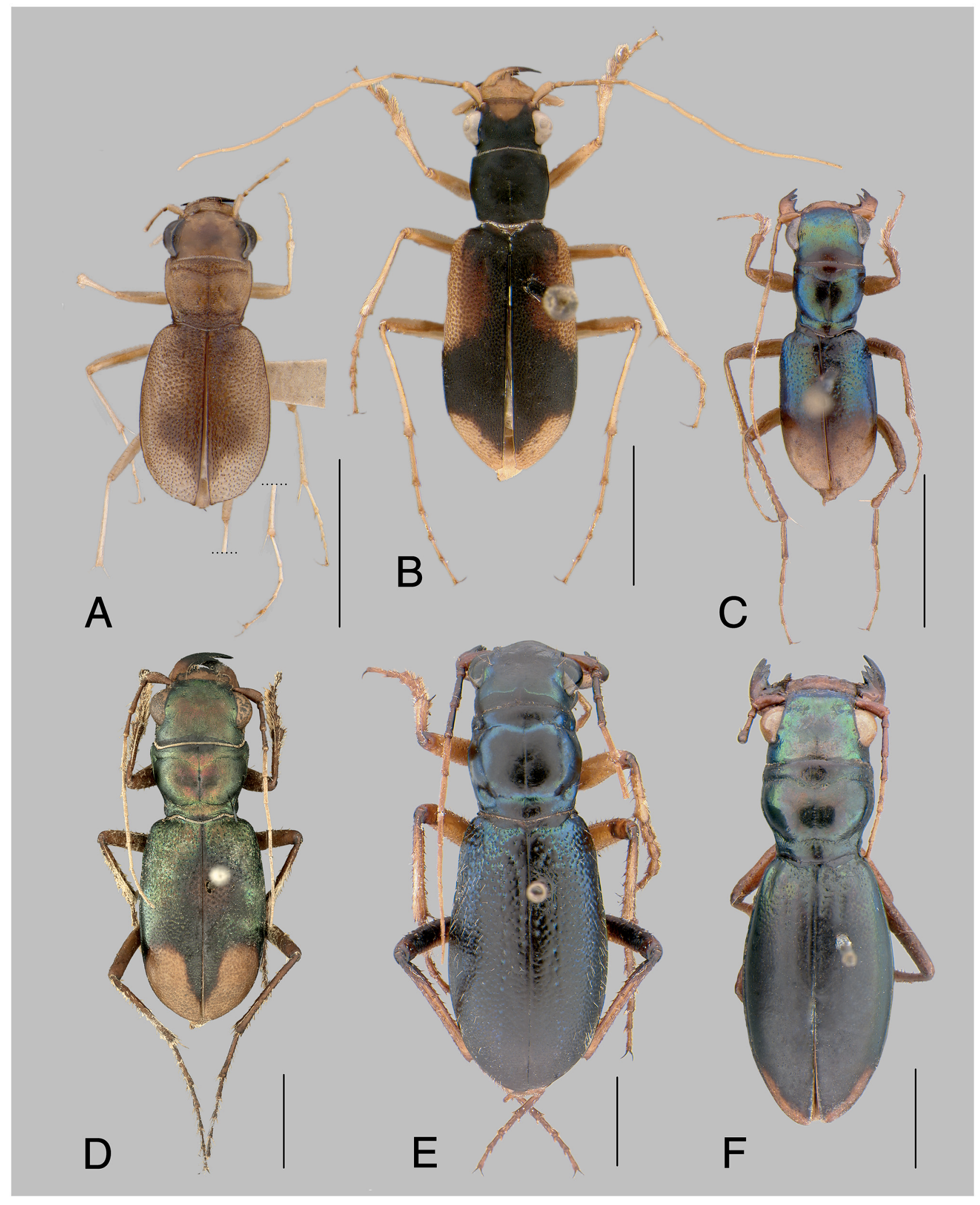

Figura 05: Habitus. A. Phaeoxantha laminata (fêmea); B. Metriocheila nigricolis (macho); C. Tetracha germaini (macho); D. Grammognatha euphratica (macho); E. Megacephala megacephala (macho); F. Megacephala bocandei (macho). As barras correspondem a $5 \mathrm{~mm}$. 

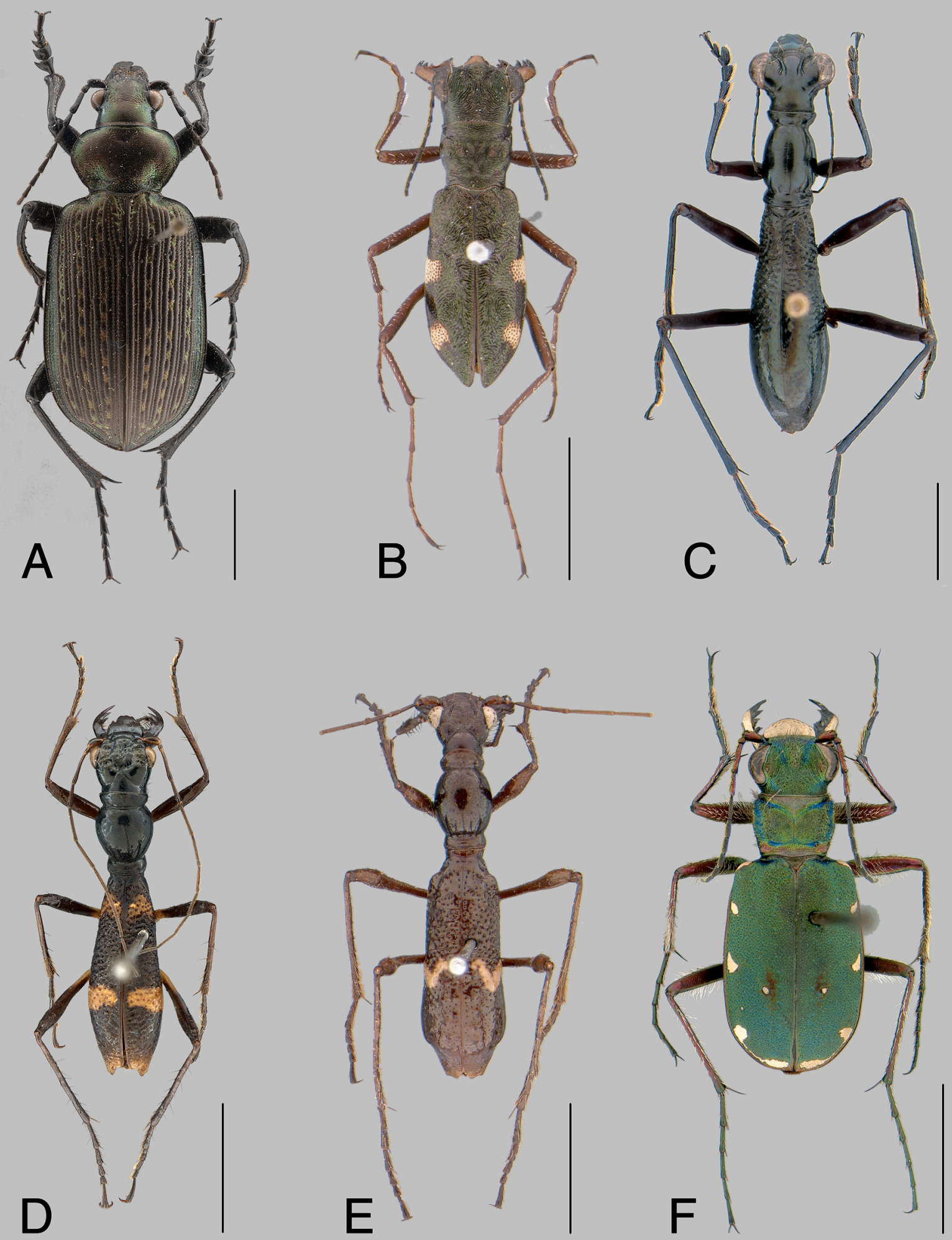

Figura 06: Habitus. A. Calosoma granulatum (macho); B. Callidema boussingaultii (macho); C. Tricondyla aptera (macho); D. Ctenostoma unifasciatum (macho); E. Ctenostoma formicarium (macho); F. Cicindela campestris (macho). As barras correspondem a $5 \mathrm{~mm}$. 

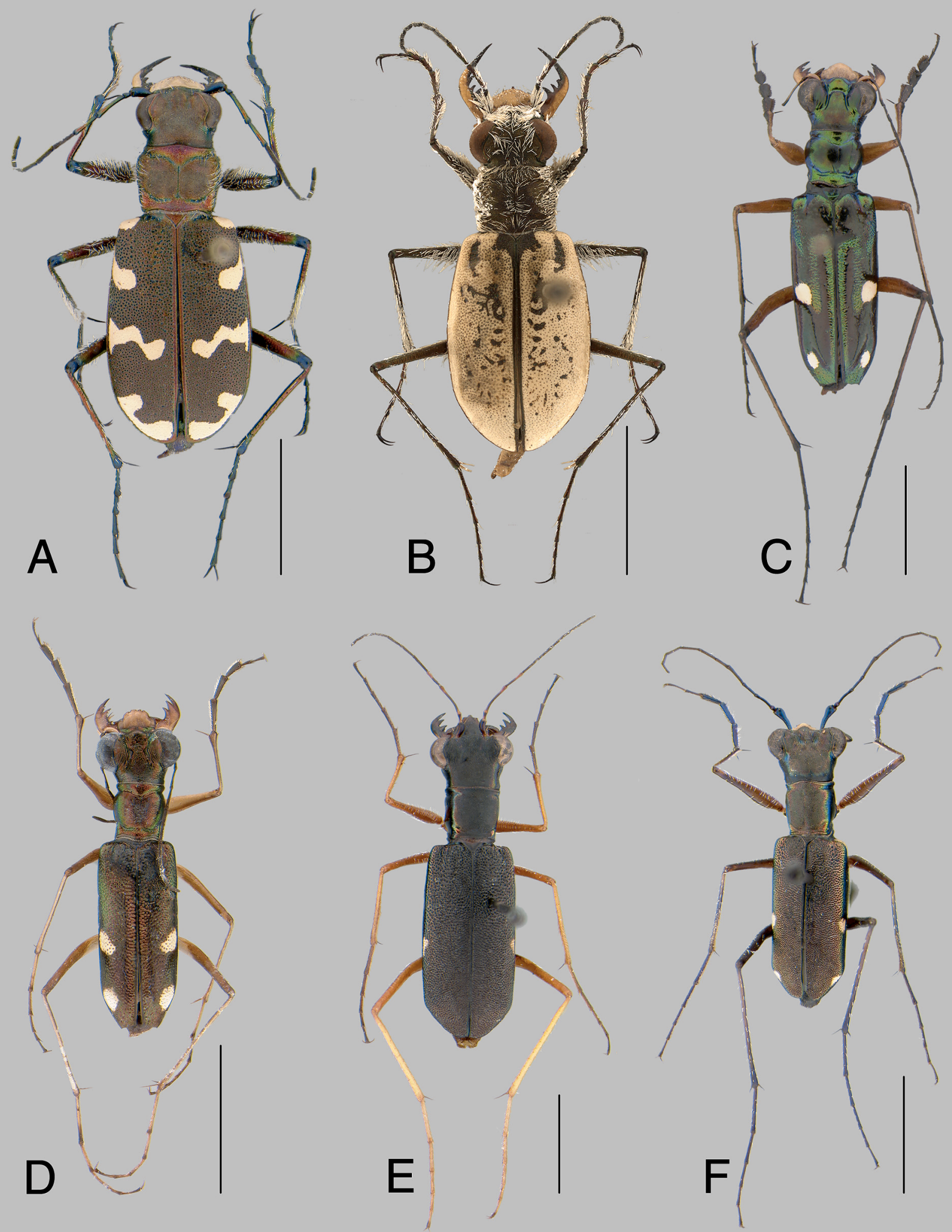

Figura 07: Habitus. A. Cicindela hybrida (macho); B. Cylindera nivea (macho); C. Euprosopus quadrinotatus (macho); D. Euprosopus chaudoiri (macho); E. Odontocheila cayennensis (fêmea); F. Odontocheila nodicornis (macho). As barras correspondem a $5 \mathrm{~mm}$. 

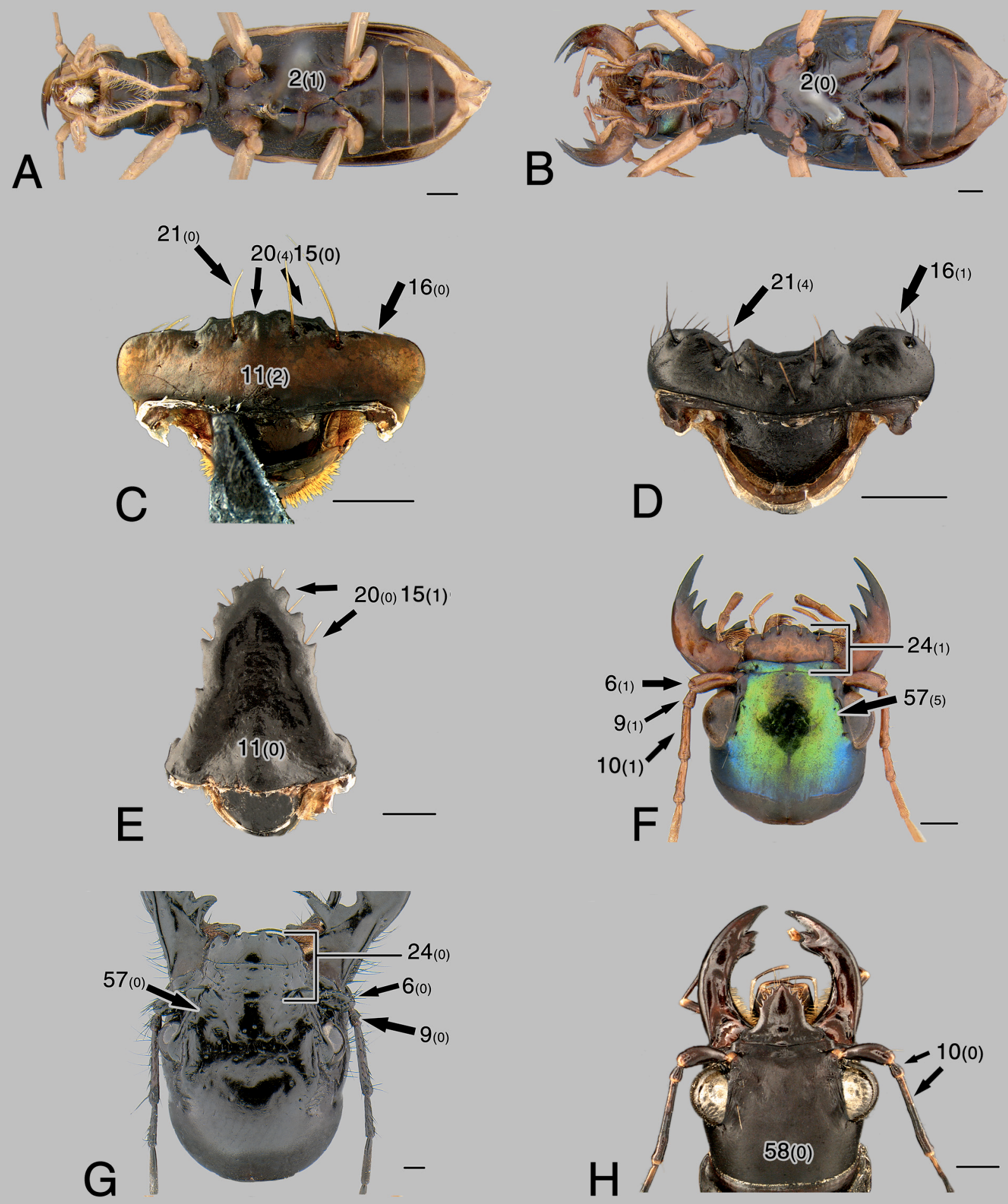

Figura 08: Sinapomorfias e sinapomorfias homoplásticas. Vista ventral do corpo: A. Metriocheila nigricollis, superfície ventral metálica ausente (21); B. Pseudotetracha murchisona, superfície ventral metálica presente (20). Labro: C. Tetracha brasiliensis, lobos laterais retos (160), 4 dentes medianos (204), 4 cerdas na margem anterior (210); D. Picnochile fallaciosa lobos laterais projetados (161), mais de 8 cerdas na margem anterior (214); E. Oxycheila tristis, mais de 7 dentes medianos. Cabeça: F. Pseudotetracha cylindrica, escapo com 2 cerdas apicais (61), antenômero 2 sem cerdas (91), antenômero 3 menos de 4 vezes maior que o antenômero 2 (101), clípeo mais curto que labro (241), cabeça com 2 cerdas de cada lado (575); G. Manticora tuberculata, escapo com mais de 2 cerdas apicais (60), segundo antenômero com cerdas (90), labro com mesmo comprimento que clípeo (240), cabeça com mais de 7 cerdas de cada lado (570); H. Oxycheila opacipennis, antenômero 3 mais de 4 vezes maior que o antenômero 2 (100), região mediobasal da cabeça sem estrias (580). As escalas correspondem a $1 \mathrm{~mm}$. 

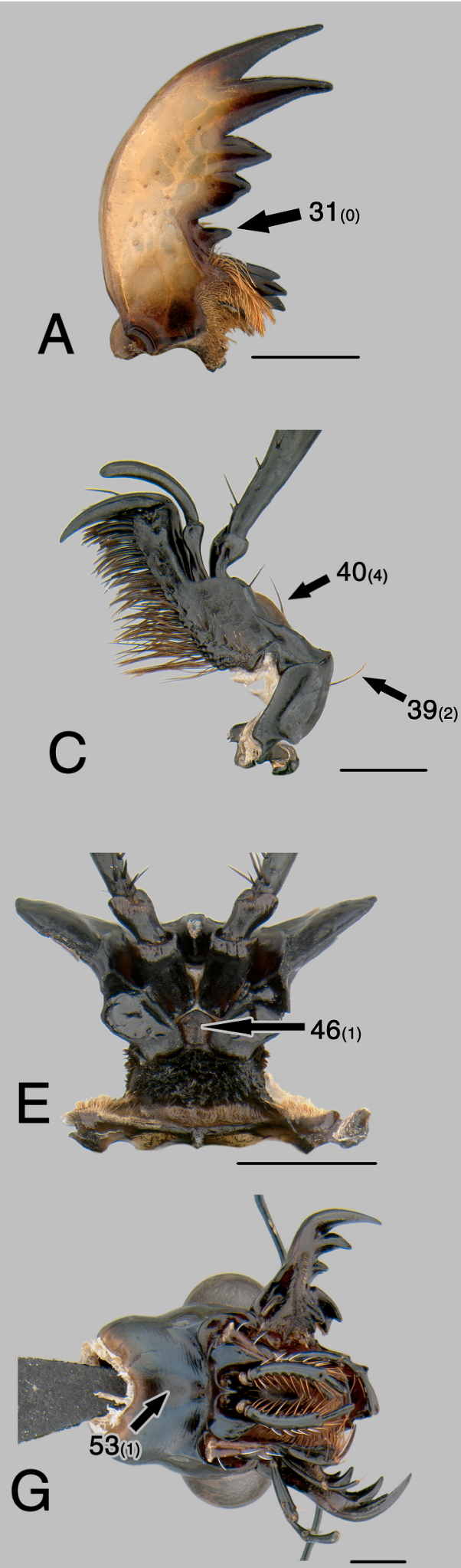
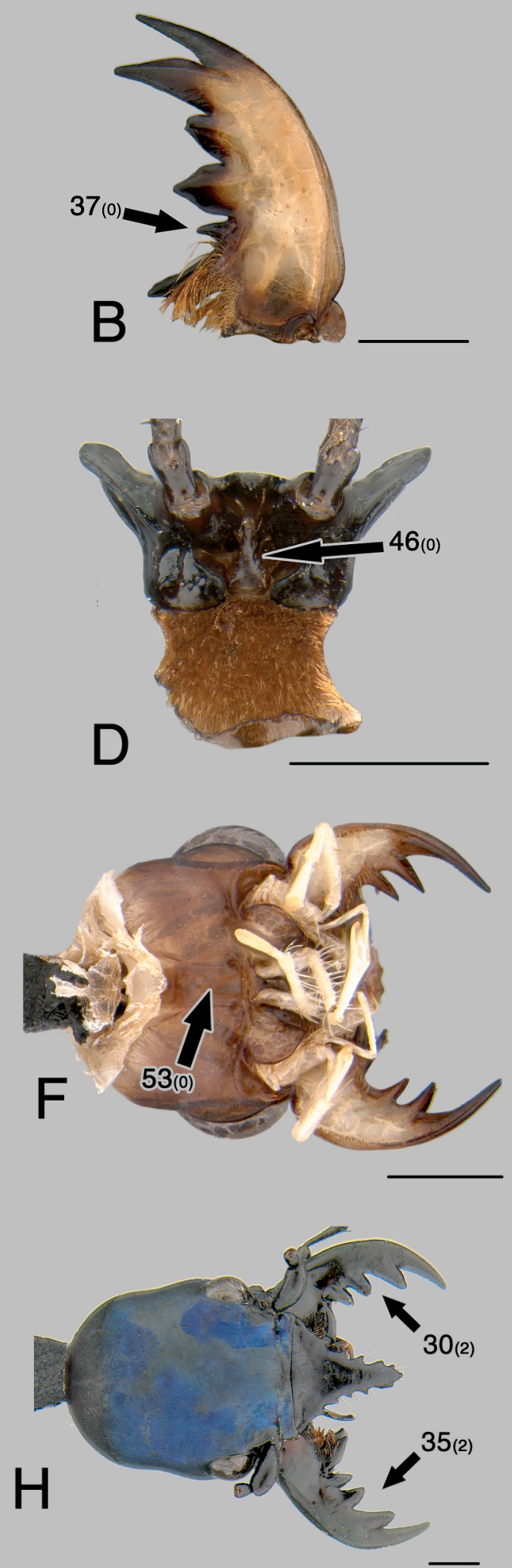

Figura 09: Sinapomorfias e sinapomorfias homoplásticas. Mandíbula (vista dorsal): A. esquerda de Tetracha carolina, dente retinacular suplementar presente (310); B. direita de Tetracha carolina, dente retinacular suplementar presente (370). Maxila: C. Amblycheila cylindriformis, cardo com uma cerda (392), basiestipe com uma cerda (404). Lábio (vista dorsal): D. Pseudoxycheila bipustulata, glossas com cerdas (460); E. Omus dejeani, glossa sem cerdas (461). Cabeça (vista ventral): F. Phaeoxantha laminata, gula lisa (530); G. Odontocheila cayennensis, gula estriada (531). Cabeça (vista dorsal): H. Pseudoxycheila ceratoma, mandíbula esquerda com 3 dentes medianos (302), mandíbula direita com 3 dentes medianos (352) As escalas representam $1 \mathrm{~mm}$. 

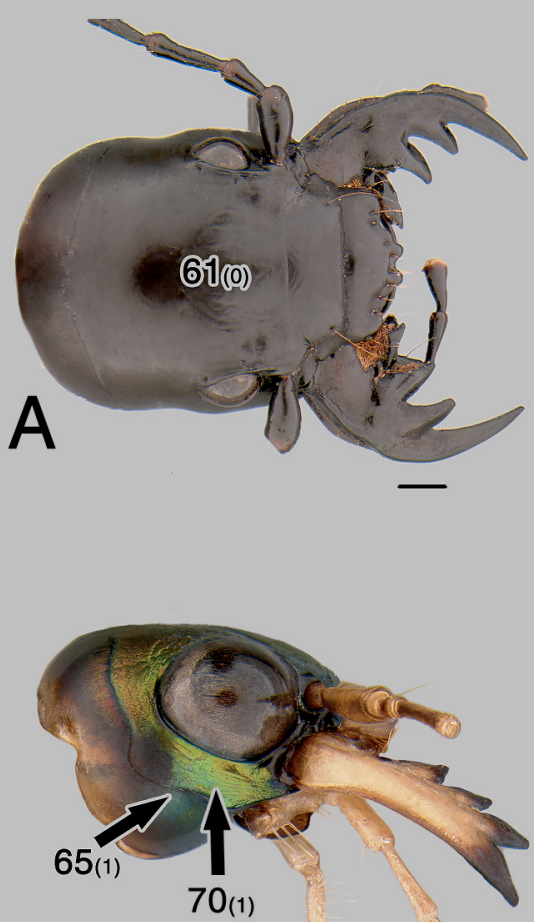

C
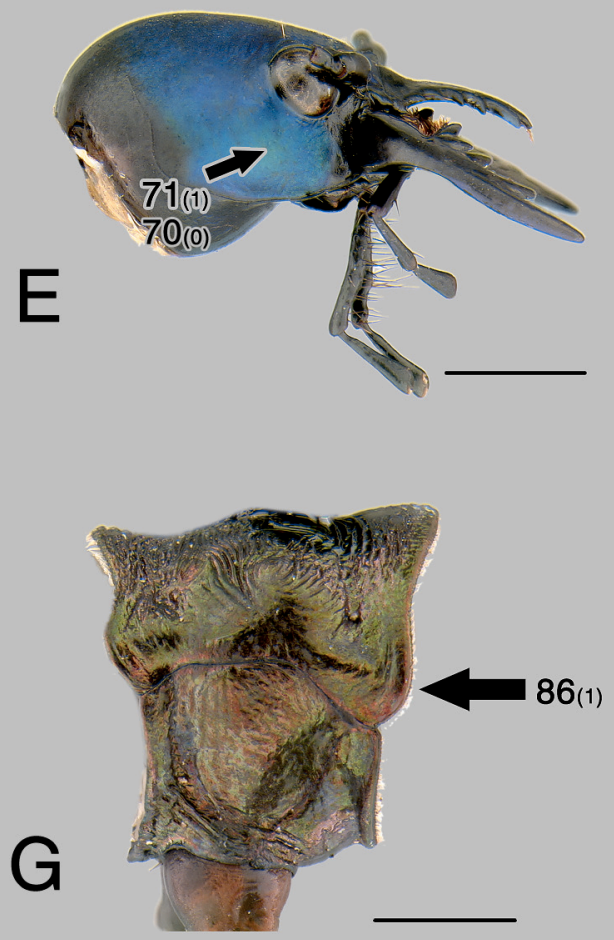
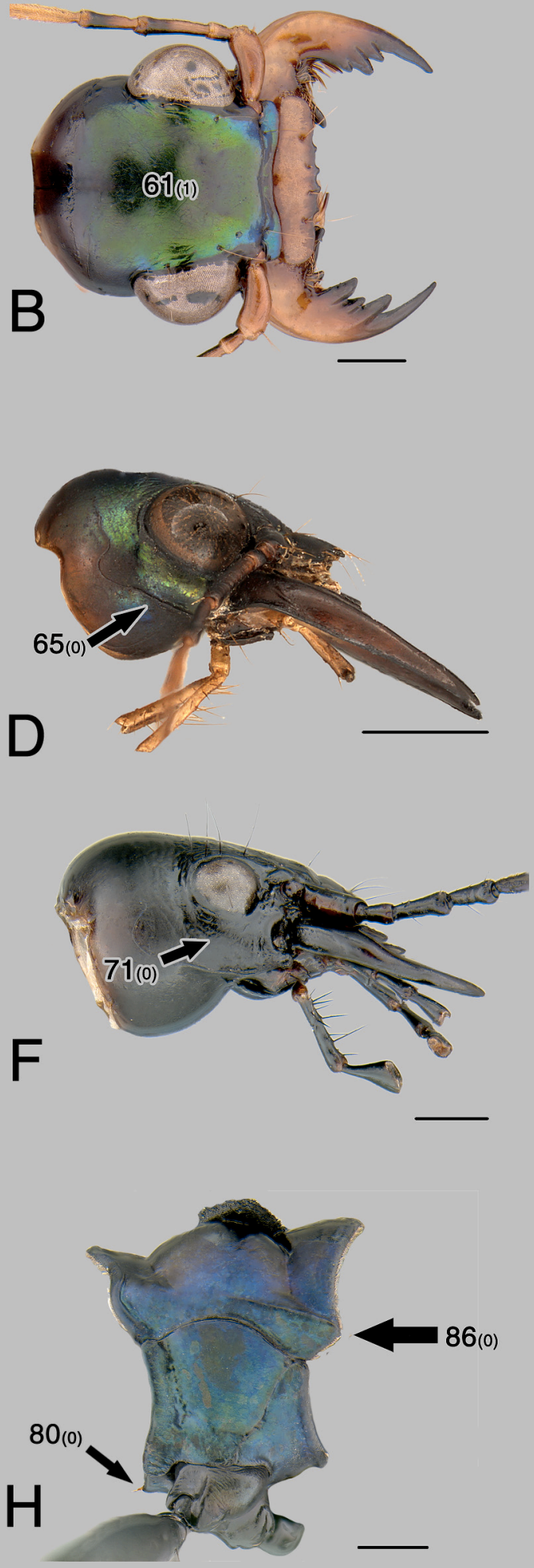

Figura 10: Sinapomorfias e sinapomorfias homoplásticas. Cabeça (vista dorsal): A. Amblycheila picolominii, coloração por pigmento (610); B. Tetracha brasiliensis, coloração iridescente (611). Cabeça (vista lateral): C. Tetracha chilensis, parte inferior da sutura genal sinuosa (651), gena com estrias longitudinais (701); D. Tetracha femoralis, parte inferior da sutura genal reta (650); E. Pseudoxycheila ceratoma, gena sem estrias longitudinais (700), gena sem estrias não longitudinais (711); F. Omus californicus, gena com estrias não longitudinais (710). Protórax (vista lateral): G. Callidema boussingaultii, projeção da carena lateral do pronoto arredondada (região anterior) (861); H. Pseudoxycheila ceratoma, prosterno com cerdas na margem posterior (800), projeção da carena lateral do pronoto angulosa (860). As escalas representam $1 \mathrm{~mm}$. 


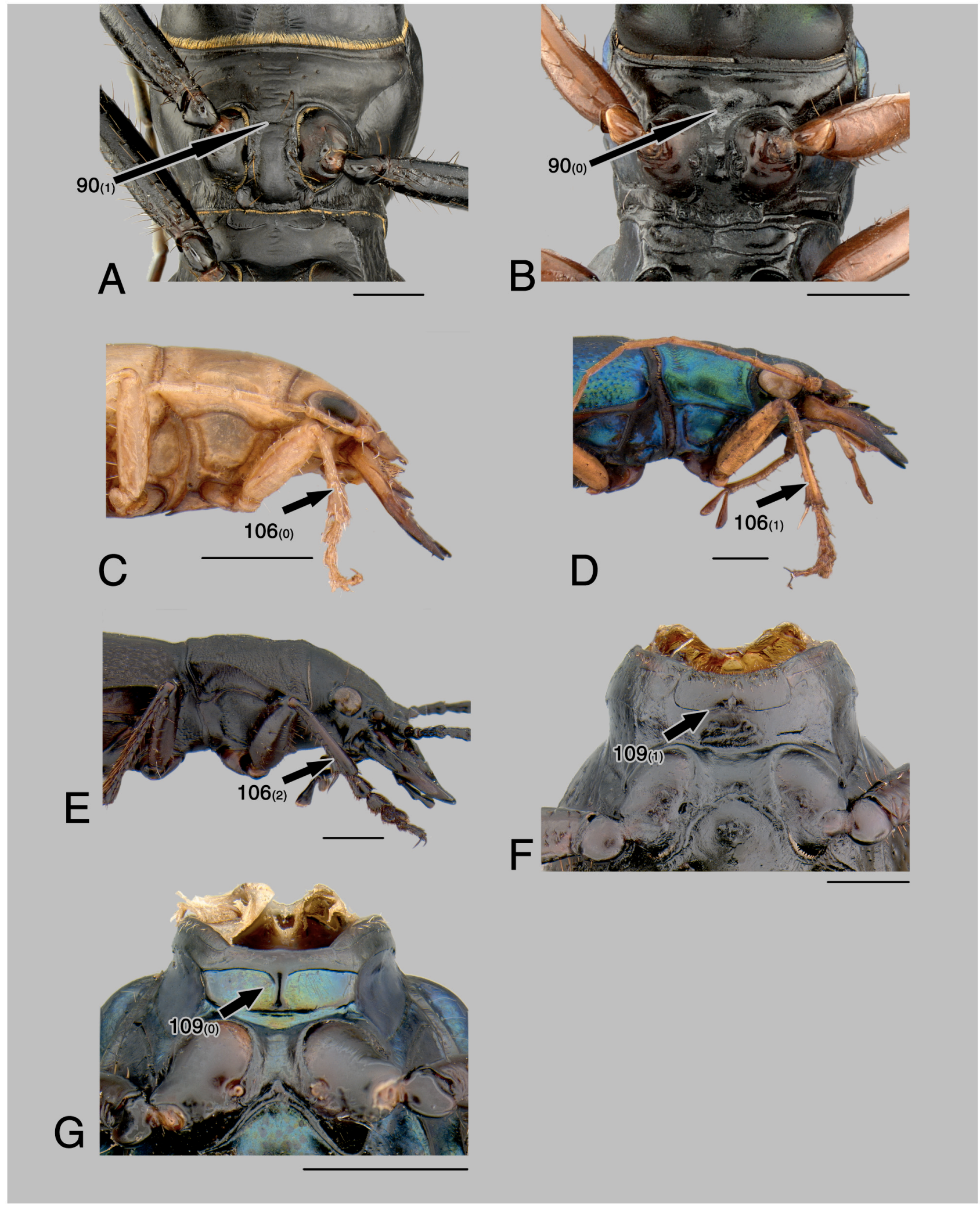

Figura 11: Sinapomorfias e sinapomorfias homoplásticas. Protórax (vista ventral): A. Amblycheila picolominii, prosterno com estrias (901); B. Pseudotetracha cylindrica, prosterno sem estrias (900). Região medioanterior (vista lateral): C. Platychile pallida, protíbia amarelada (1060); D. Pseudotetracha murchisona, protíbia castanha (1061); E. Omus dejeani, protíbia enegrecida (1062). Mesosterno (vista ventral com protórax removido): F. Amblycheila cylindriformis, mesosterno simples (1091); G. Pseudoxycheila bipustulata, mesosterno complexo (1090). As escalas representam $2 \mathrm{~mm}$. 


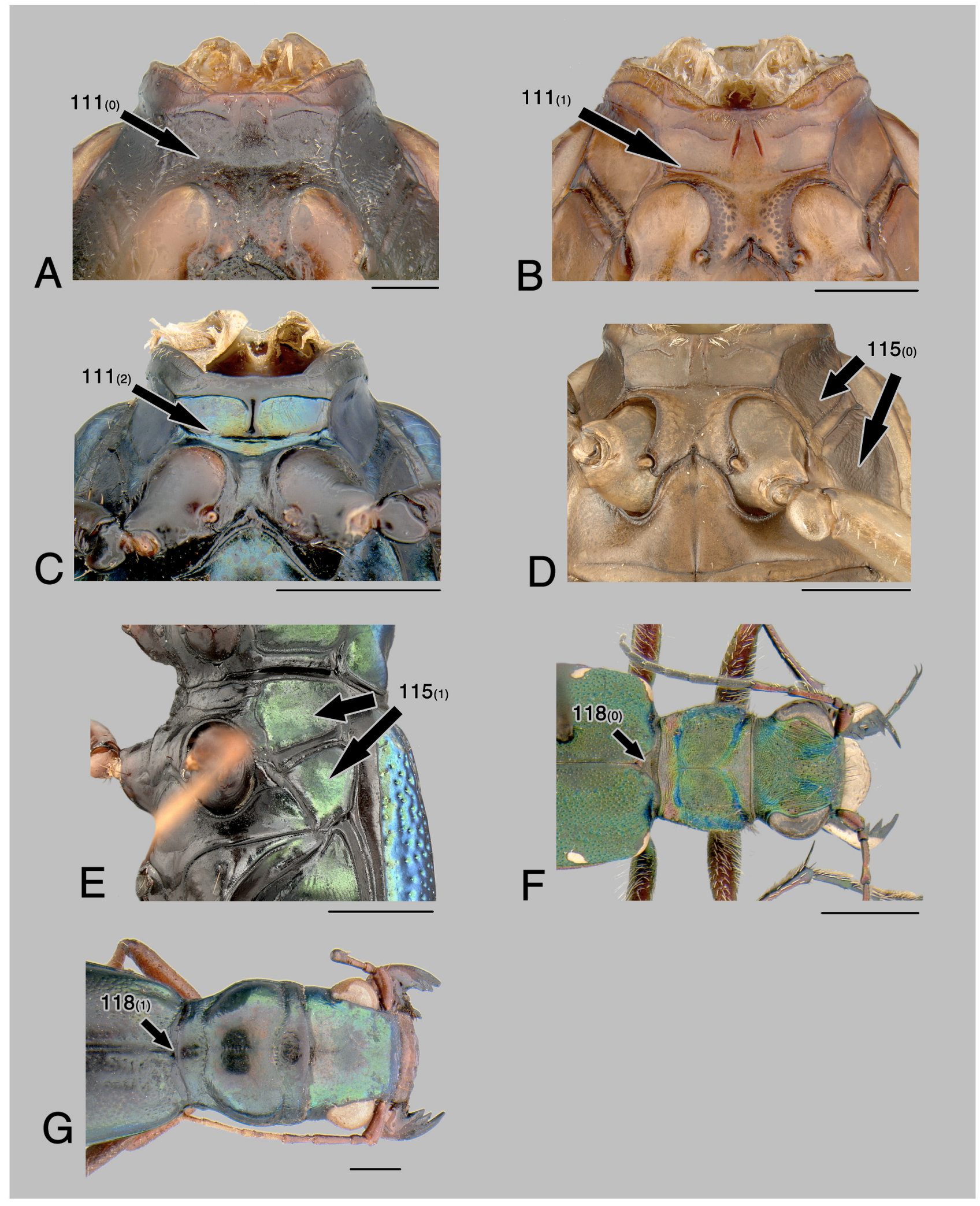

Figura 12: Sinapomorfias e sinapomorfias homoplásticas. Mesotórax (vista ventral com protórax removido): A. Metriocheila nigricollis, barra transversal posterior ausente (1110); B. Phaeoxantha klugii, barra transversal posterior incompleta (1111); Pseudoxycheila bipustulata, barra transversal posterior completa (1112). Meso- e metatórax: D. Phaeoxantha klugii (vista ventral), meso- e metepisterno com região mediana rugosa (1150); E. Pseudotetracha cylindrica (vista ventrolateral), meso- e metepisterno com região mediana lisa (1151). Região medioanterior (vista dorsal): F. Cicindela campestris, mais de $30 \%$ do escutelo visível (1180); G. Megacephala bocandei, menos de $30 \%$ do escutelo visível (1181). As escalas representam $2 \mathrm{~mm}$. 


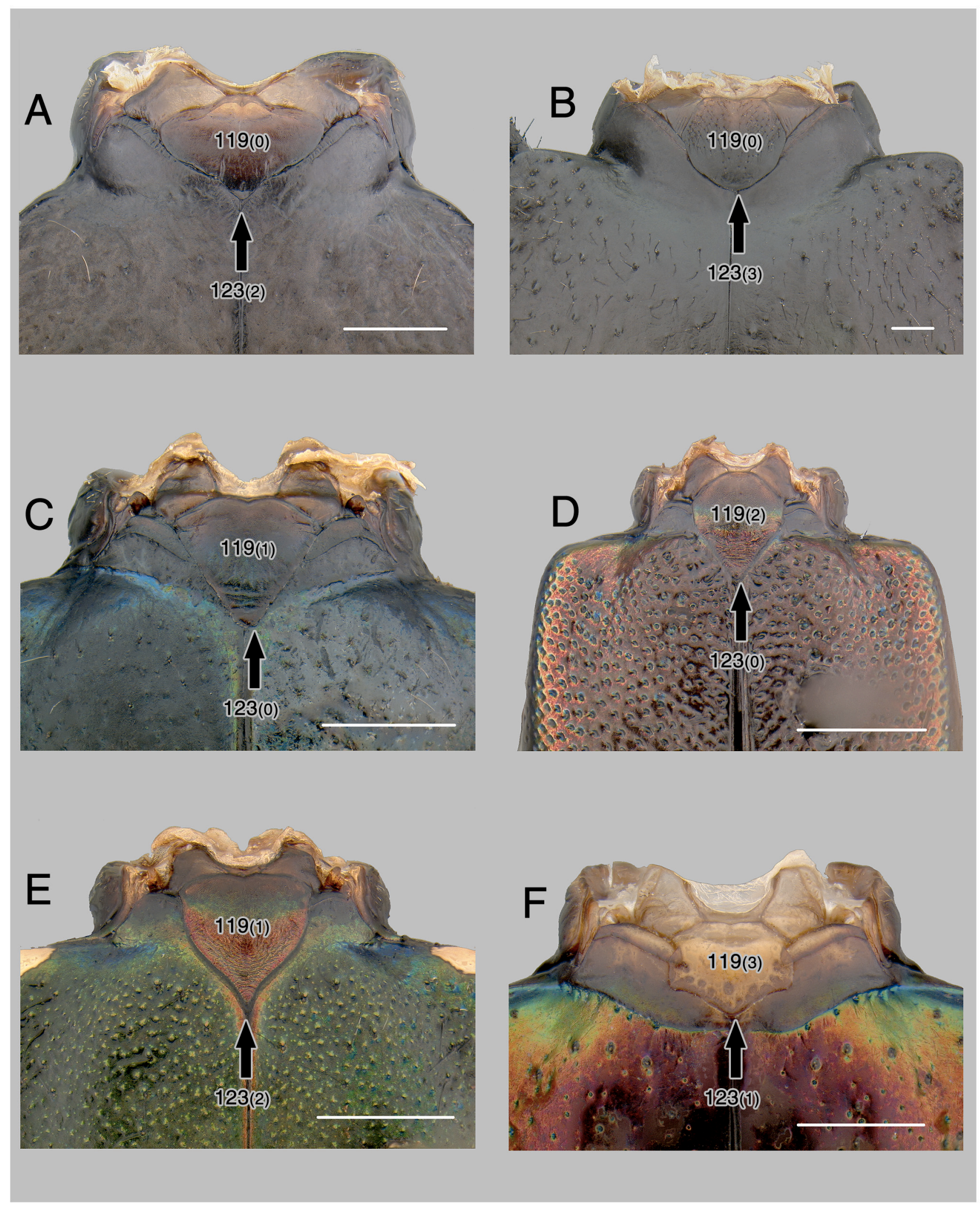

Figura 13: Sinapomorfias e sinapomorfias homoplásticas. Mesotórax (vista dorsal com protórax removido) - Escutelo: A. Omus dejeani, forma arredondada ou elíptica (1190), margem posterior bissigmóide (1232); B. Manticora tuberculata, arredondada ou elíptica (1190), margem posterior arredondada (1233); C. Pseudoxycheila bipustulata, forma cordiforme (1191), margem anterior angulada (1230); D. Oxycheila cayennensis, forma cordiforme com margem anterior muito projetada anteriormente (1192), margem posterior angulada (1230); E. Cicindela campestris, forma cordiforme (1191), margem posterior bissigmóide (1232); Tetracha chilensis, forma transversa com margens laterais emarginadas anteriormente (1193), margem posterior biemarginada (1231). As escalas correspondem a 1 $\mathrm{mm}$. 


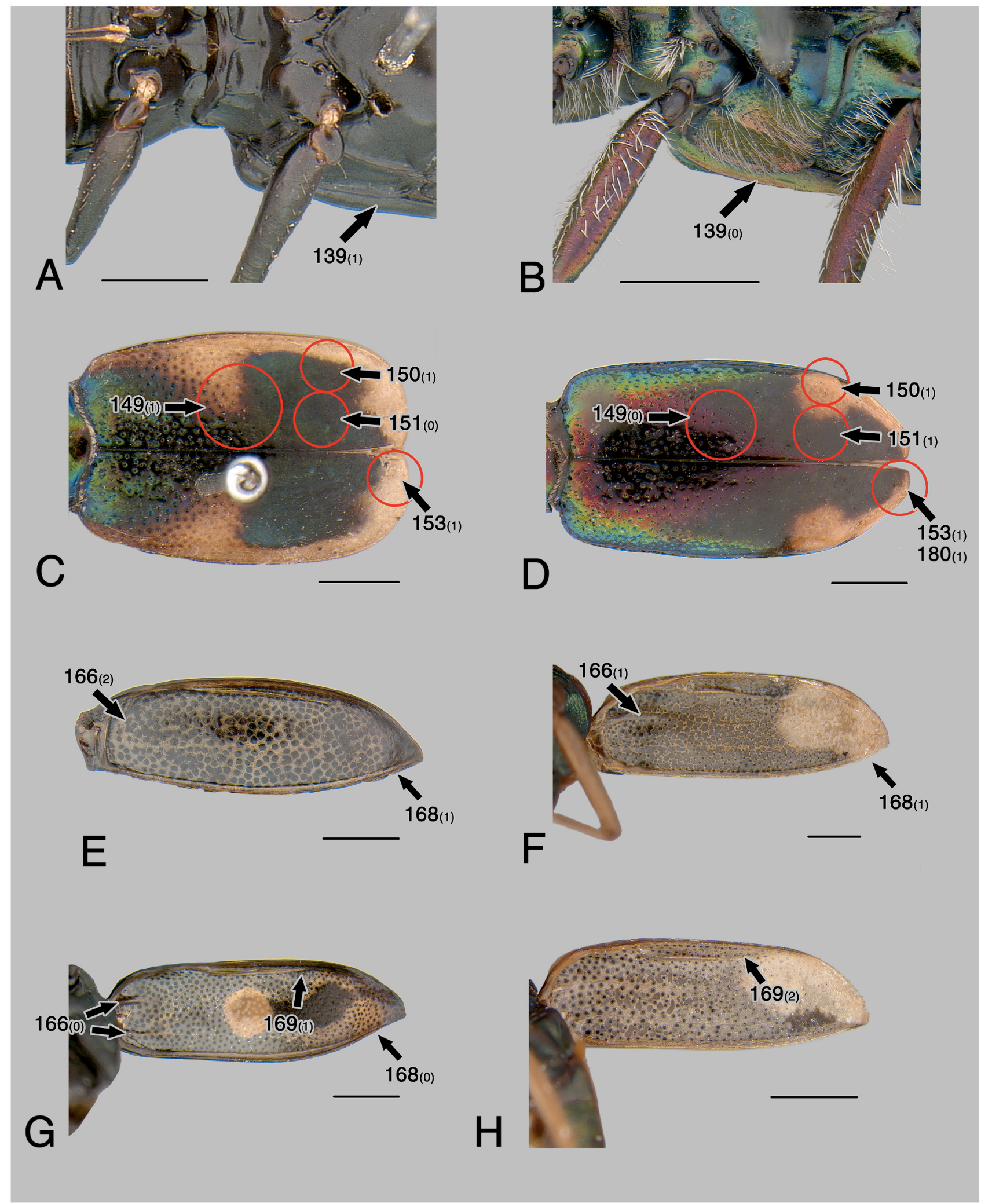

Figura 14: Sinapomorfias e sinapomorfias homoplásticas. Tórax (vista ventral): A. Oxycheila opacipennis, epipleura sem coloração metálica (1391); B. Cicindela campestris (vista ventral), epipleura com coloração metálica (1390); Élitros: C. Australicapitona basalis, presença de coloração amarelada na posição C (1491), presença de coloração amarelada na posição AADL (1501), ausência de coloração amarelada na posição AA (1510), presença de coloração amarelada na posição A (1531); D. Tetracha carolina, ausência de coloração amarelada na posição C (1490), presença de coloração amarelada na posição AADL (1501), presença de coloração amarelada na posição AA (1511), presença de coloração amarelada na posição A (1531), macho com ápice do élitro levemente truncado (1801). Élitro (vista interna): E. Omus californicus, ausência de carenas (1662), margem sutural arredondada em toda a extensão (1681); F. Grammognatha euphratica, presença de 1 carena (1661), margem sutural arredondada em toda extensão (1681); G. Pseudoxycheila bipustulata, presença de 2 carenas (1660), margem sutural emarginada próximo ao ápice (1680), prega sublateral acentuada em toda a extensão (1691); H. Tetracha fulgida, prega sublateral muito fraca na região do terço posterior (1692). As escalas representam $2 \mathrm{~mm}$. 


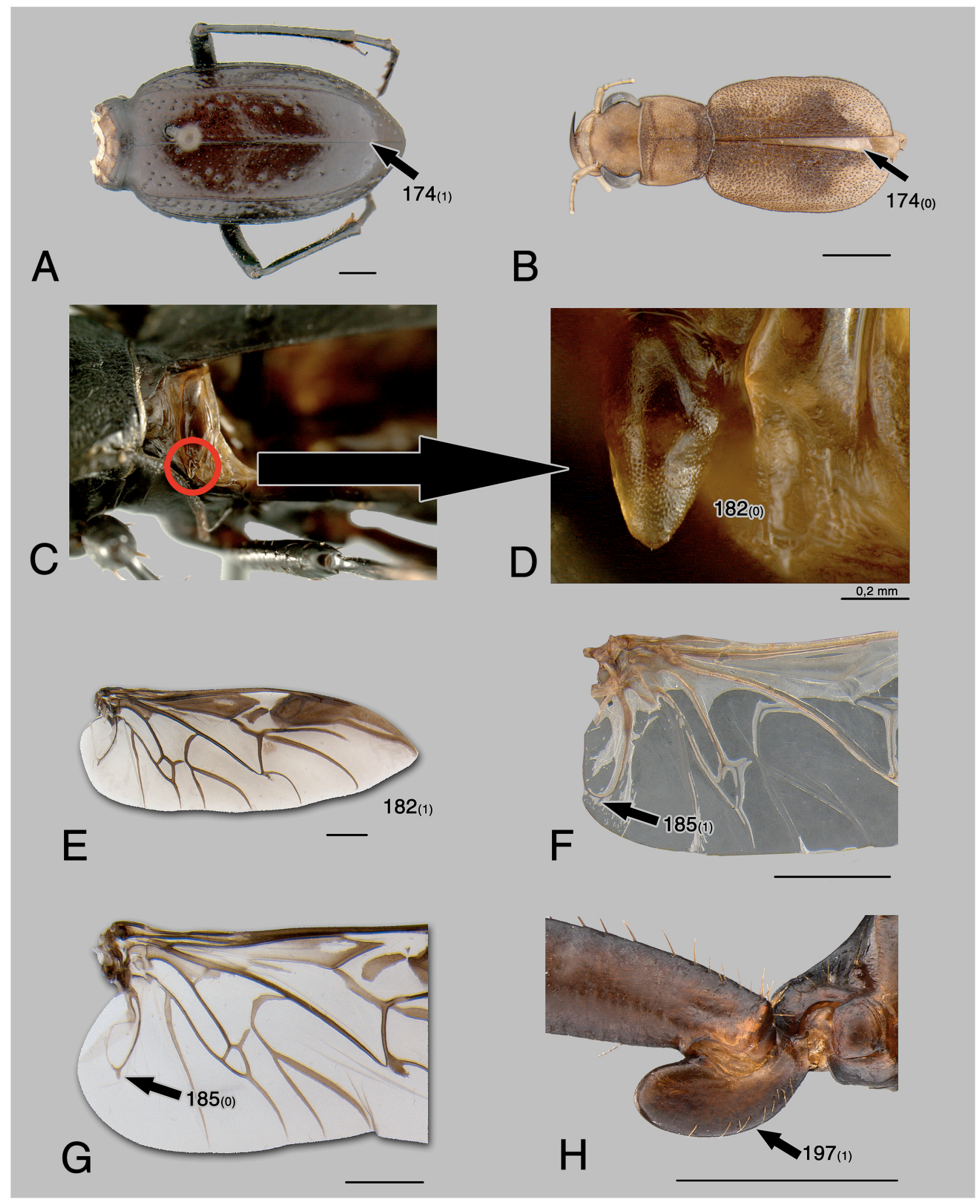

Figura 15: Sinapomorfias e sinapomorfias homoplásticas. Pterotórax (vista dorsal): A. Amblycheila picolominii, suturas elitrais fundidas (1741). Habitus: B. Phaeoxantha laminata, suturas elitrais não fundidas (1740). Mesotórax (élitro esquerdo retirado): C. Omus dejeani. Mesotórax (close na asa membranosa): D. Omus dejeani, asa membranosa reduzida (1820). Asa membranosa: E. Pseudoxycheila ceratoma, asa membranosa desenvolvida (1821); F. Grammognatha euphratica, alça anal sem apêndice (1851); G. Cheiloxya binotata, alça anal com apêndice (1850). Perna posterior (detalhe e vista ventral): H. Omus dejeani, metatrocanter com fileira de cerdas indo da base até próximo à região mediana (1971). As escalas representam $2 \mathrm{~mm}$, exceto $\mathrm{D}$. 


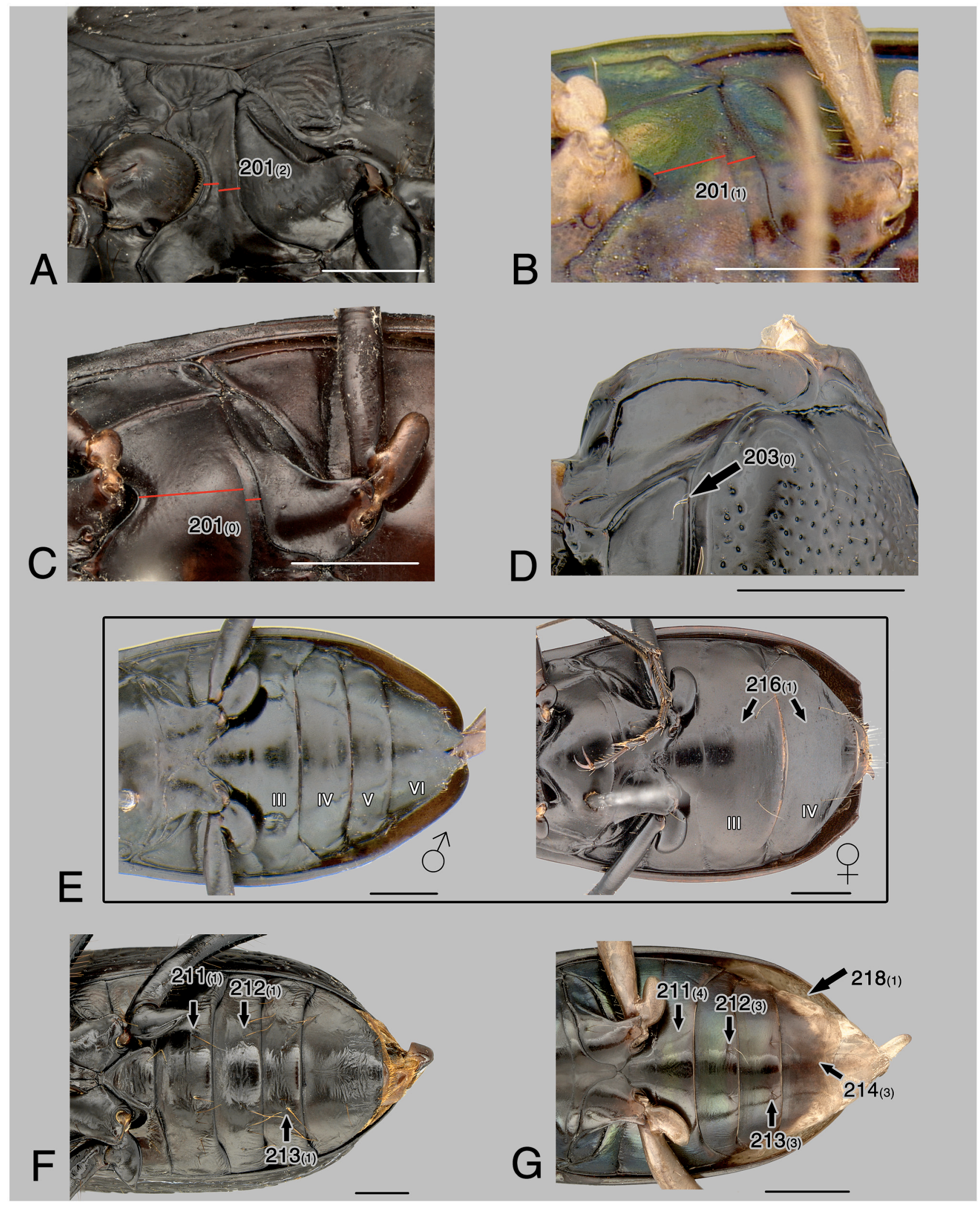

Figura 16: Sinapomorfias e sinapomorfias homoplásticas. Meso-e metatórax (detalhe em vista ventral), relação da distância entre a linha transversal do metasterno até a base da mesocoxa sobre a distância entre a linha transversal até a base da metacoxa: A. Amblycheila picolominii, menos ou aproximadamente 1 (2012); B. Tetracha chilensis, entre 2 e 4 (2011); C. Oxycheila opacipennis, mais de 4 (2010). Meso-e metatórax (vista lateral): D. Oxycheila tristis, metepisterno com cerdas na região anterior da margem externa (2030). Metatórax e abdômen (vista ventral): E. Oxycheila tristis, fêmeas com ventritos III e IV muito desenvolvidos e ventritos IV e V curtos e alojados sob o IV (2161); F. Amblycheila picolominii, mais de 4 cerdas simples no ventrito III (2111), mais de 4 cerdas no ventrito IV (2121), mais de 4 cerdas no ventrito V (2131); G. Tetracha brasiliensis, ventrito III glabro (2114), 2 cerdas no ventrito IV (2123), 2 cerdas no ventrito V (2133), ventrito VI glabro (2143). As escalas representam $2 \mathrm{~mm}$. 


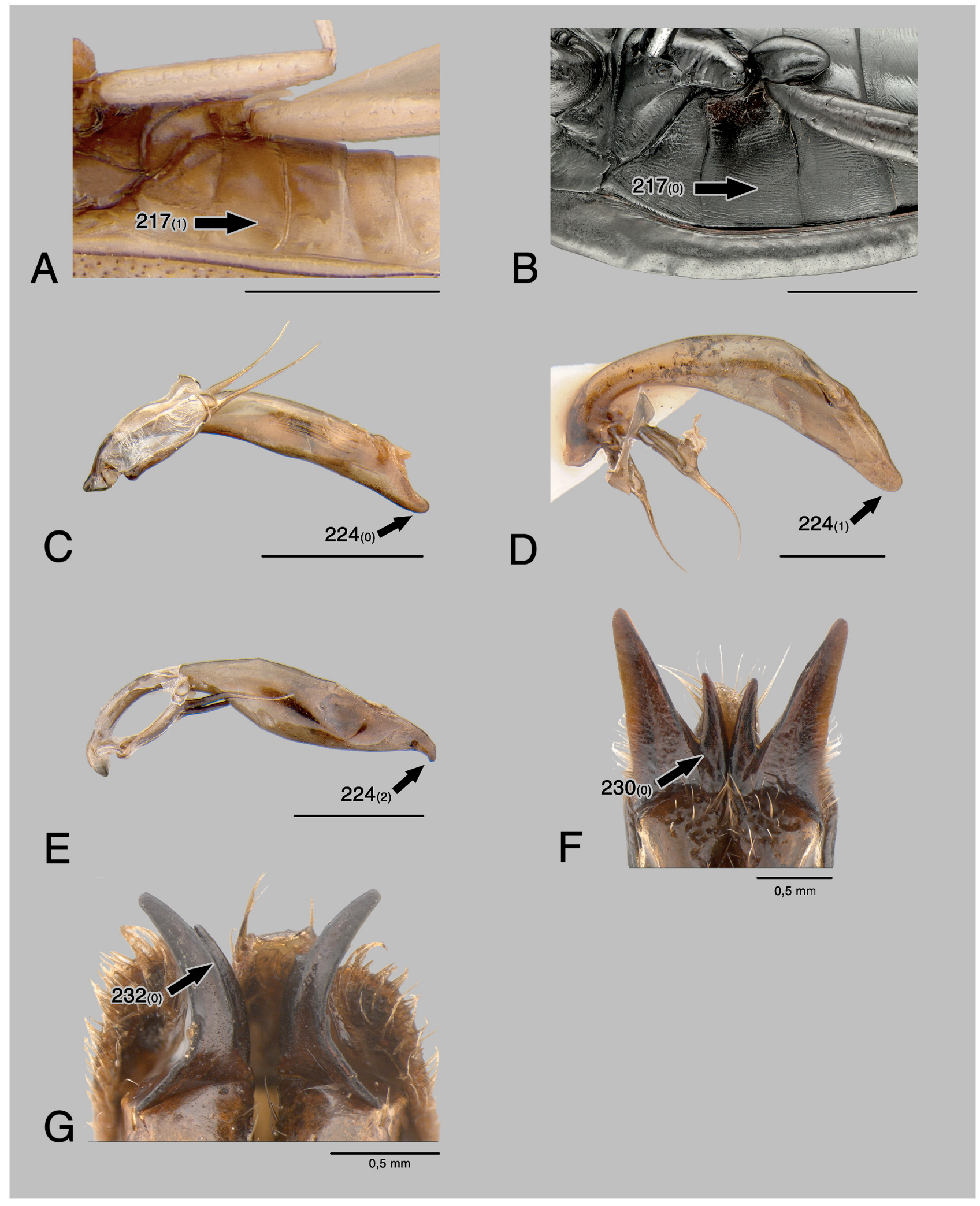

Figura 17: Sinapomorfias e sinapomorfias homoplásticas. Metatórax e abdômen (detalhe em vista ventrolateral): A. Phaeoxantha laminata, ventritos III e IV sem estrias laterais (2171); B. Picnochile fallaciosa, ventritos III e IV com estrias laterais (2170). Edeago (vista lateral): C. Tetracha chilensis, lobo médio com ponta pós abertura virada para cima (2240); D. Megacephala bocandei, lobo médio com ponta pós abertura reta (2241); E. Cheiloxya binotata, lobo médio com ponta pós abertura virada para baixo (2242). Ovipositor (coxitos em vista ventral): F. Picnochile fallaciosa, dentes dos estilos fundidos na base (2300); G. Tetracha brasiliensis, dente interno menor que externo com mais de $75 \%$ do tamanho deste (2320). As escalas representam $2 \mathrm{~mm}$, exceto em $\mathrm{F} \mathrm{e} \mathrm{G}$. 

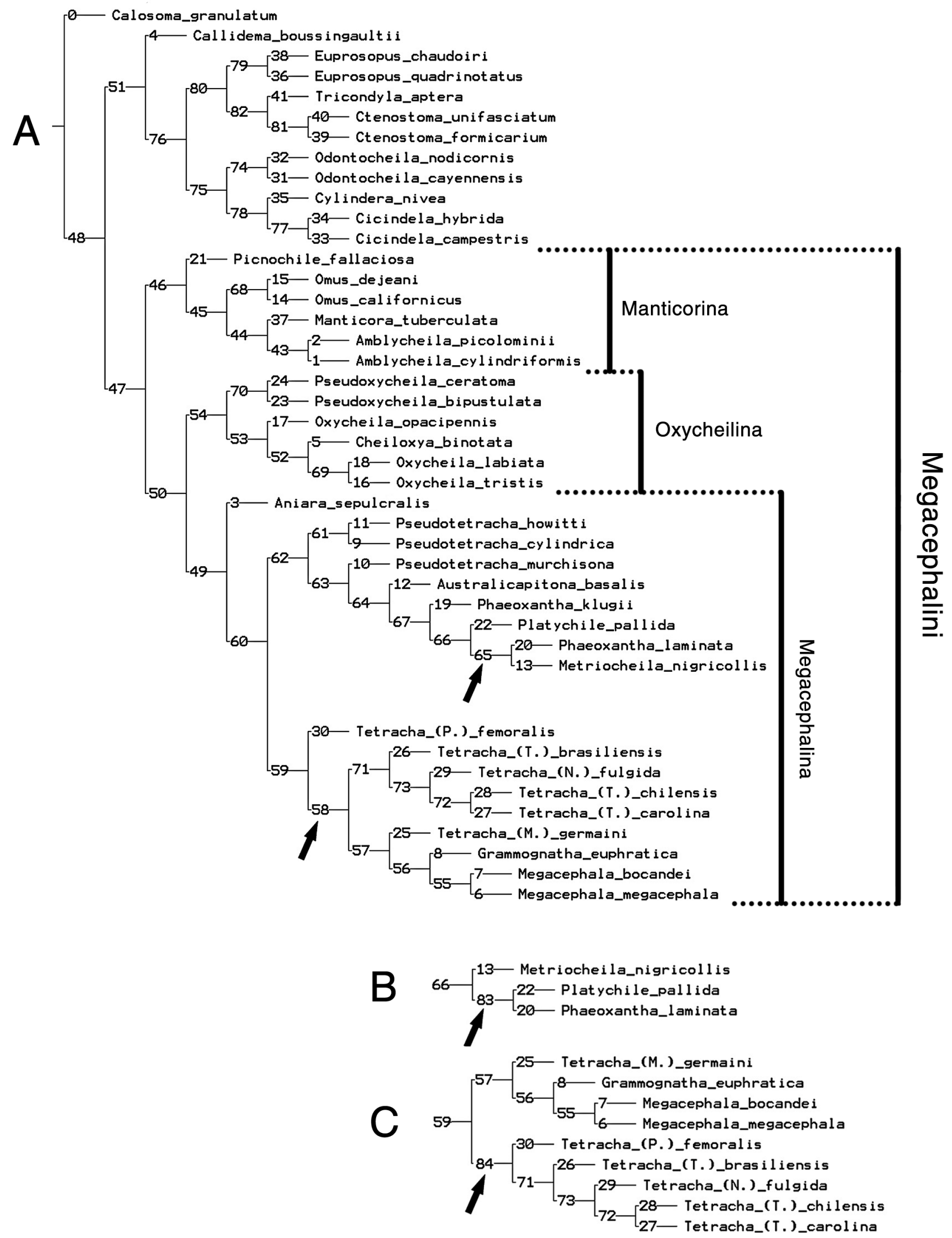

Figura 18. Hipóteses filogenéticas obtidas das 4 árvores mais parcimoniosas para a tribo Megacephalini. Enraizamento em Calosoma granulatum; 960 passos, índice de consistência 0,31 e índice de retenção 0,63. A. uma das 4 árvores mais parcimoniosas. B. resolução alternativa para o clado 66. C. resolução alternativa para o clado 59. Os números indicam nós e clados. As setas indicam os clados exclusivos de cada resolução. 


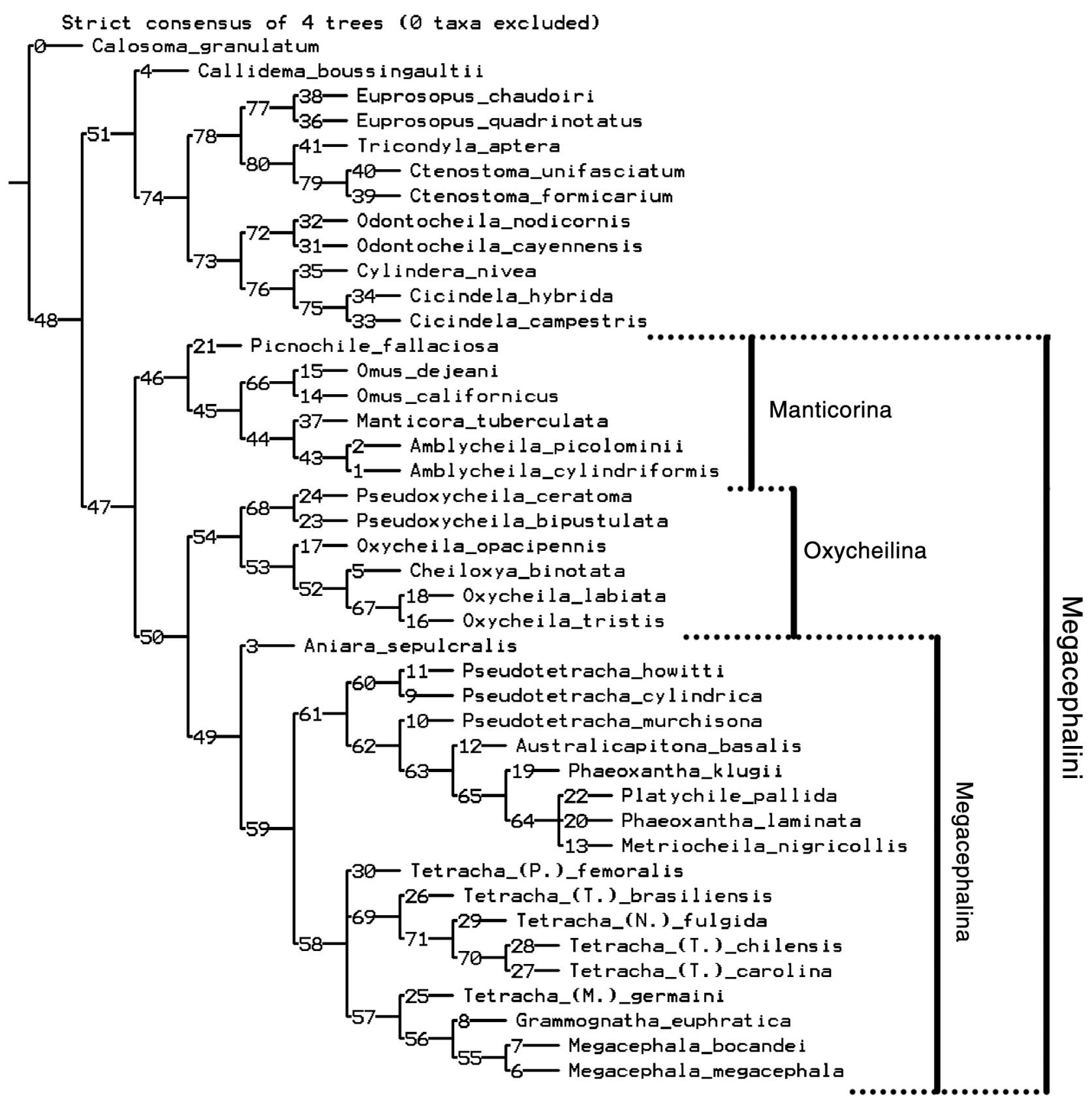

Figura 19. Cladograma de consenso estrito das 4 hipóteses filogenéticas mais parcimoniosas para a tribo Megacephalini. Enraizamento em Calosoma granulatum; 966 passos, índice de consistência 0,31 e índice de retenção 0,63 . Os números indicam nós e clados. 


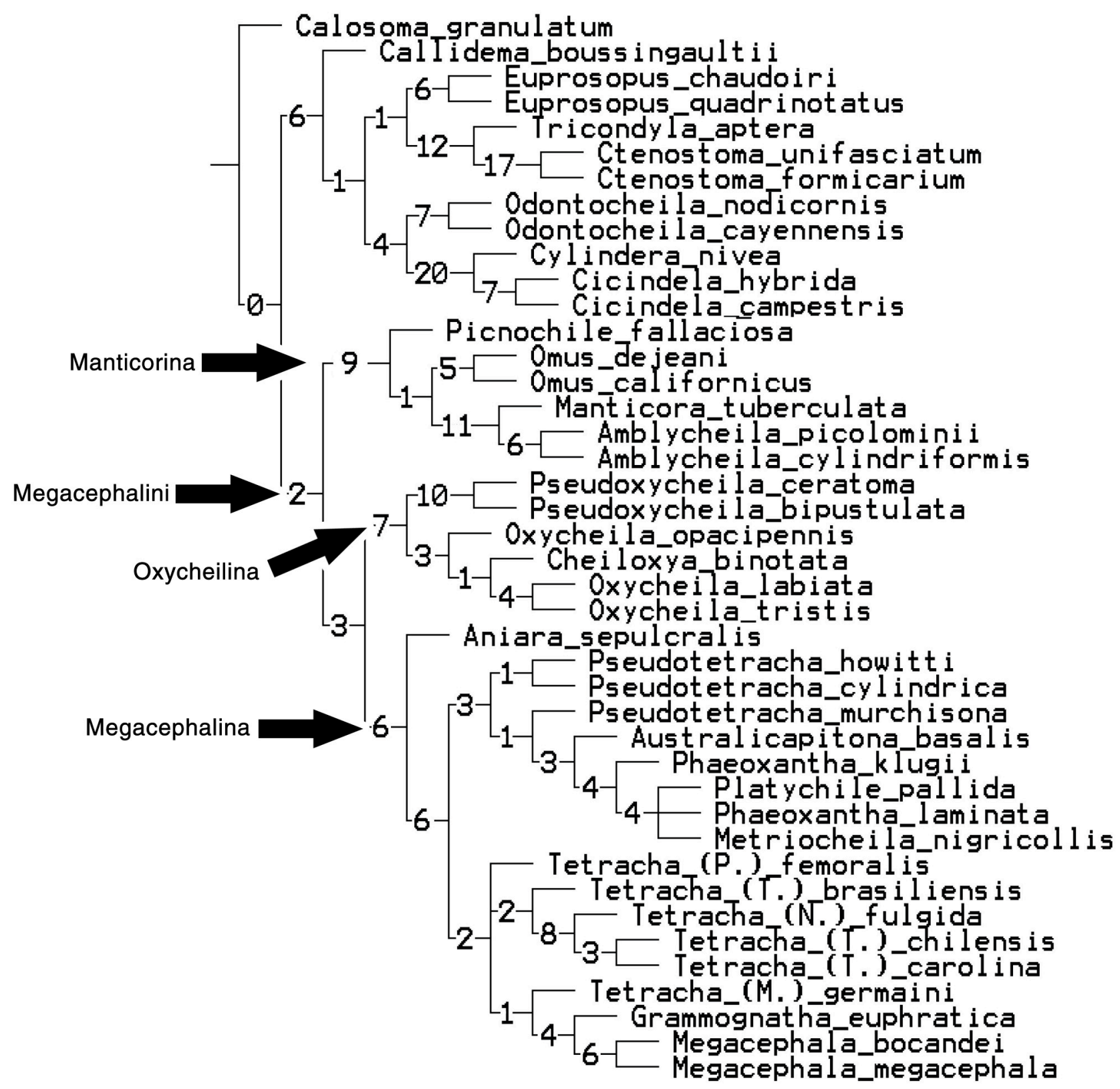

Figura 20. Cladograma de consenso estrito das quatro hipóteses filogenéticas mais parcimoniosas para a tribo Megacephalini. Enraizamento em Calosoma granulatum; 966 passos, índice de consistência 0,31 e índice de retenção 0,63 . Os números representam os valores de suporte de Bremer. As setas indicam os nós da tribo e subtribos de Megacephalini. 

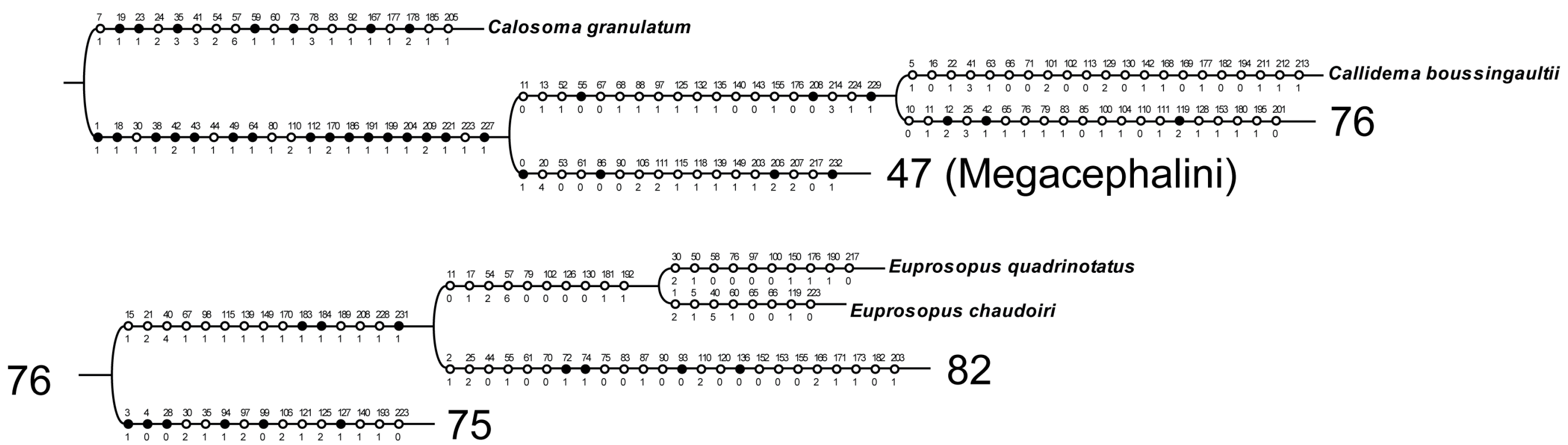

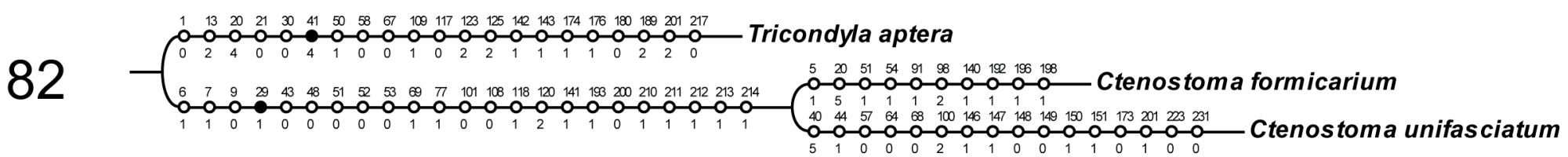

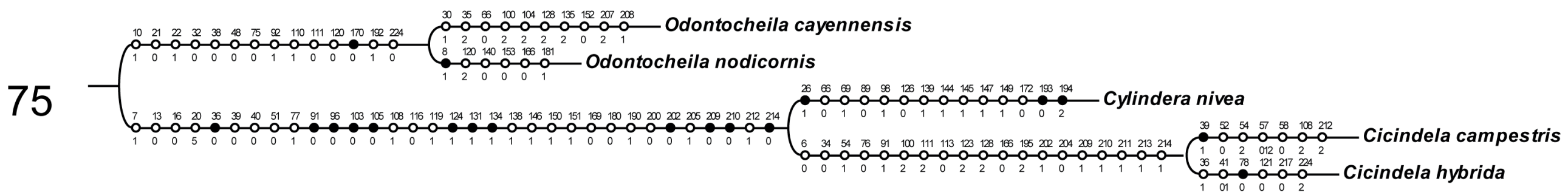

Figura 21. Consenso estrito das 4 árvores mais parcimoniosas. Componentes: raíz, 76, 82 e 75 (ver figura 17). Em branco, nos ramos, passos homoplásticos; em preto, sinapomorfias. 


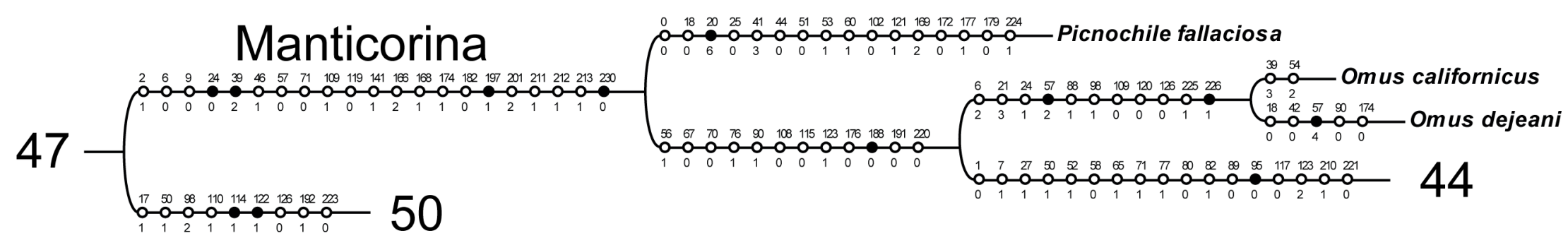

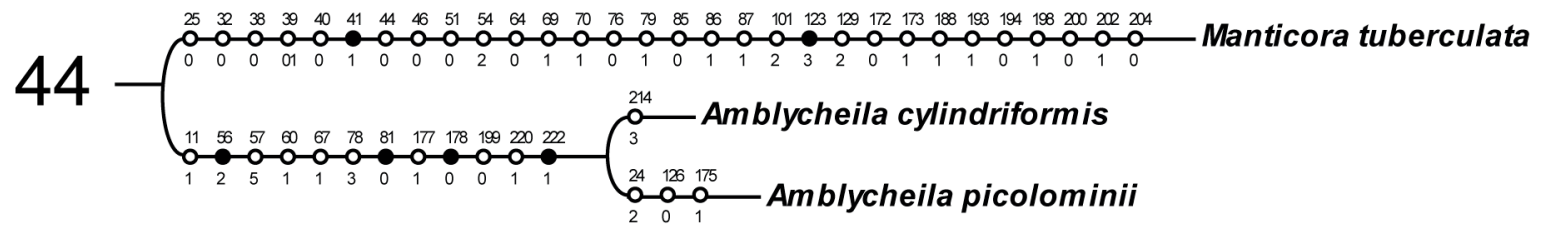
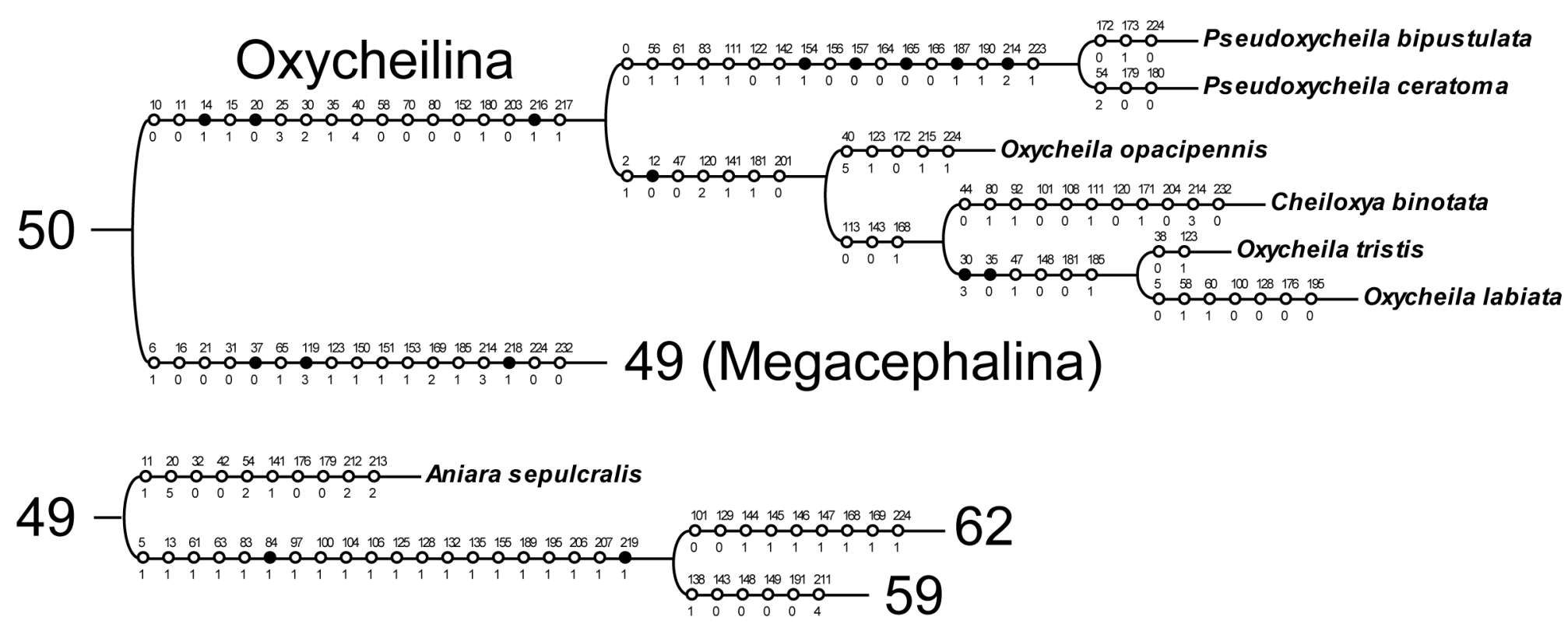

Figura 22. Consenso estrito das 4 árvores mais parcimoniosas. Componentes: $44,47,50$ e 49 (ver figura 17). Em branco, nos ramos, passos homoplásticos; em preto, sinapomorfias. 

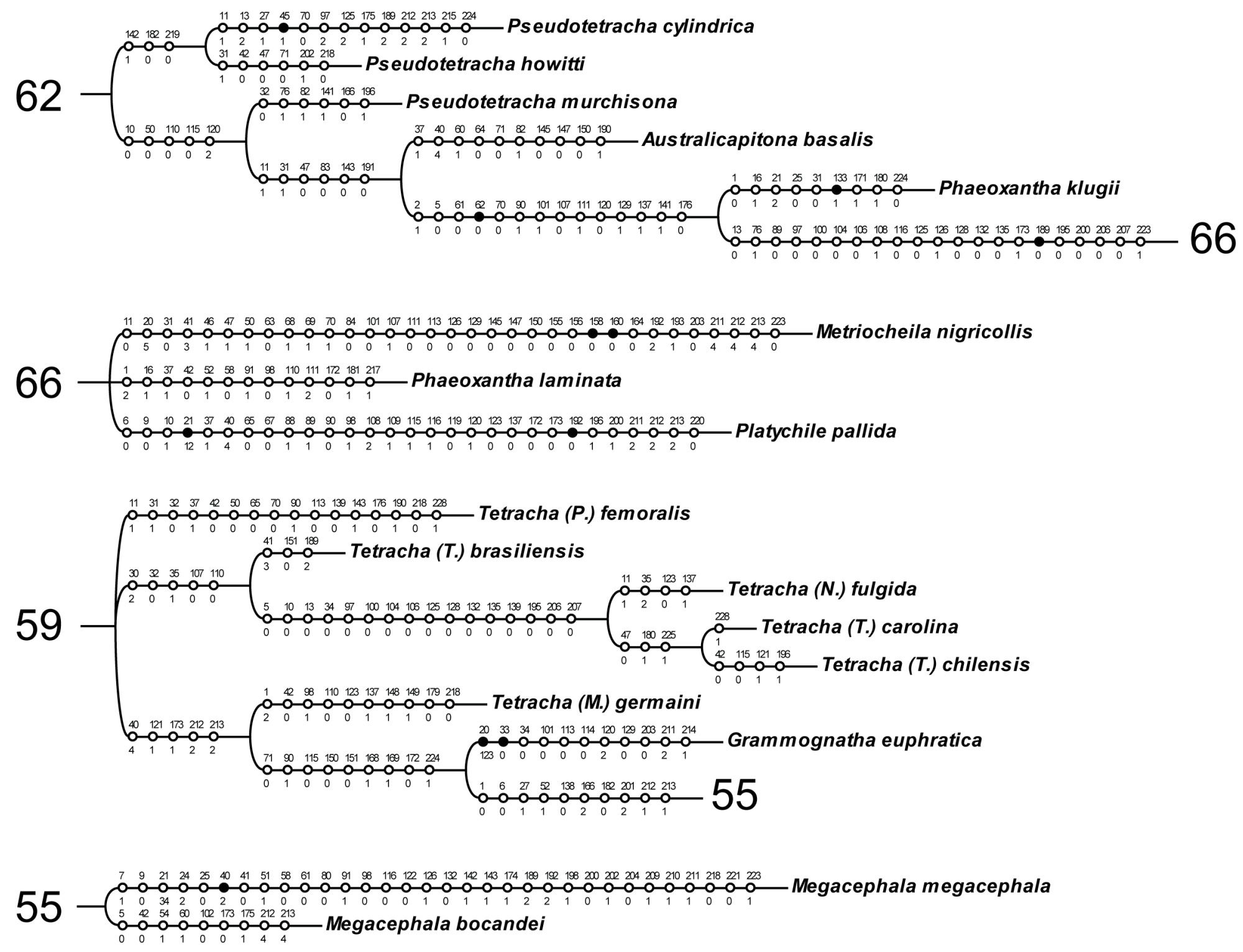

Figura 23. Consenso estrito das 4 árvores mais parcimoniosas. Componentes: 55, 59, 62 e 66 (ver figura 17). Em branco, nos ramos, passos homoplásticos; em preto, sinapomorfias. 


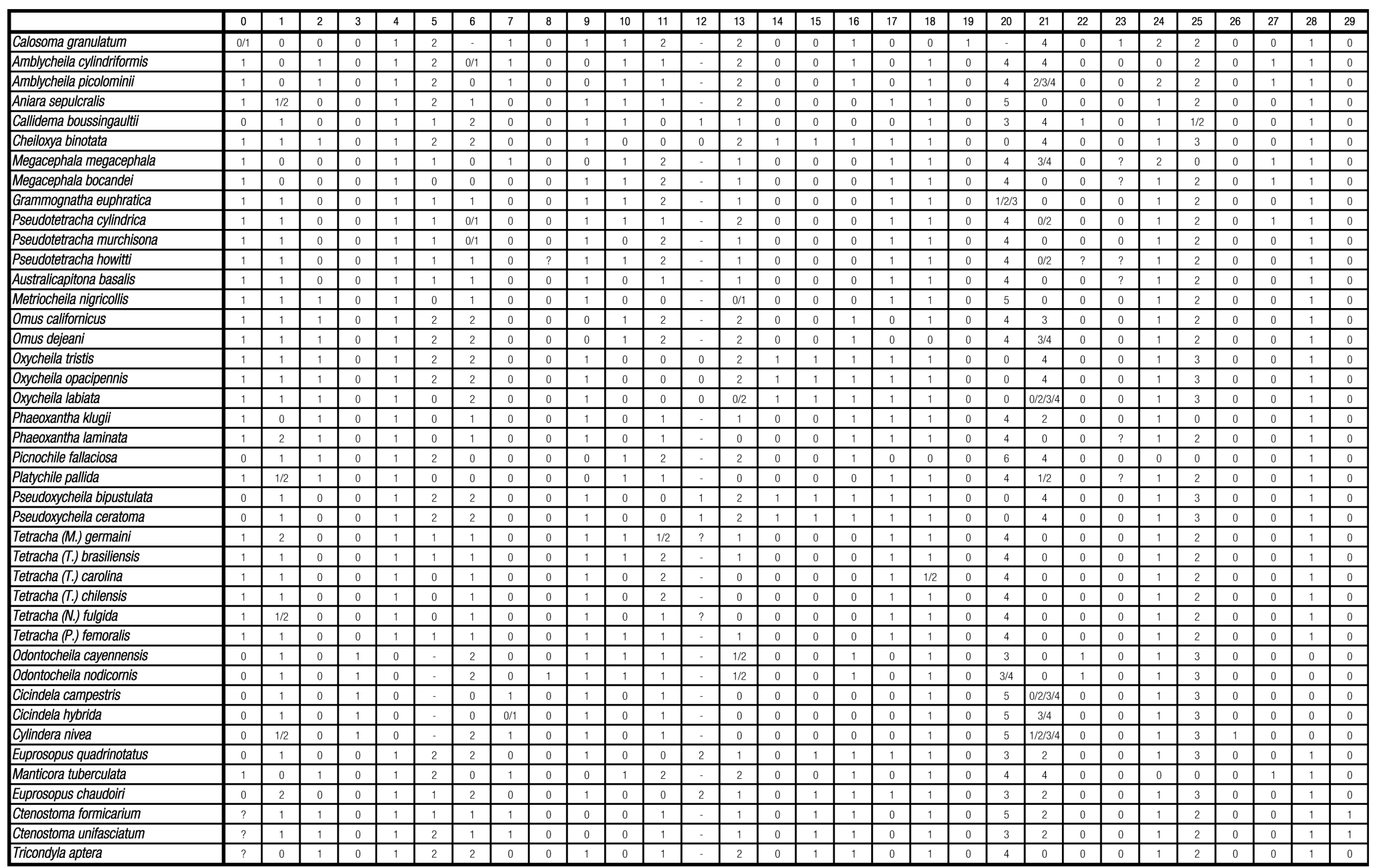

Tabela 1. Matriz de caracteres. Caracteres 0 ao 29. 


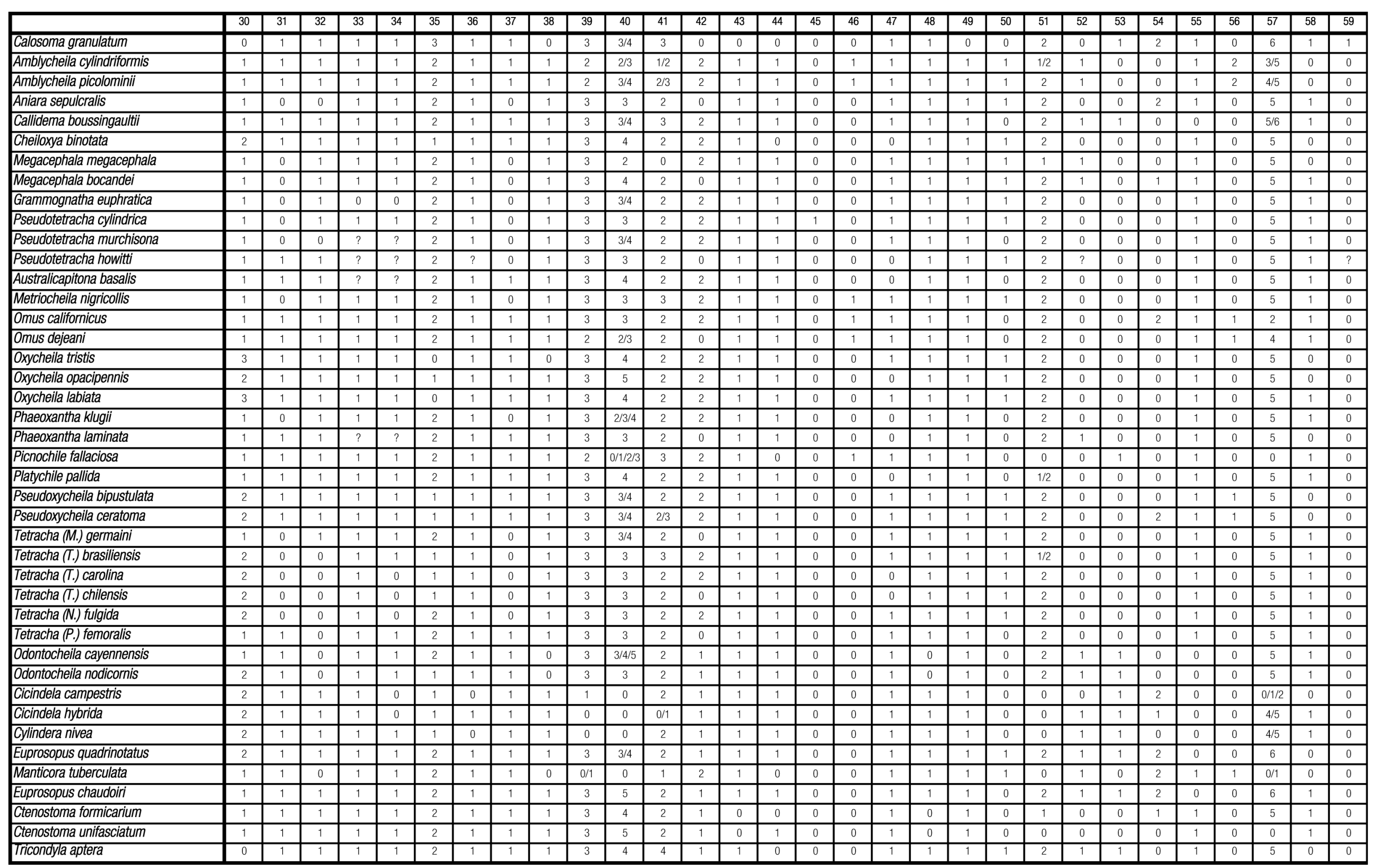

Tabela 2. Matriz de caracteres. Caracteres 30 ao 59. 


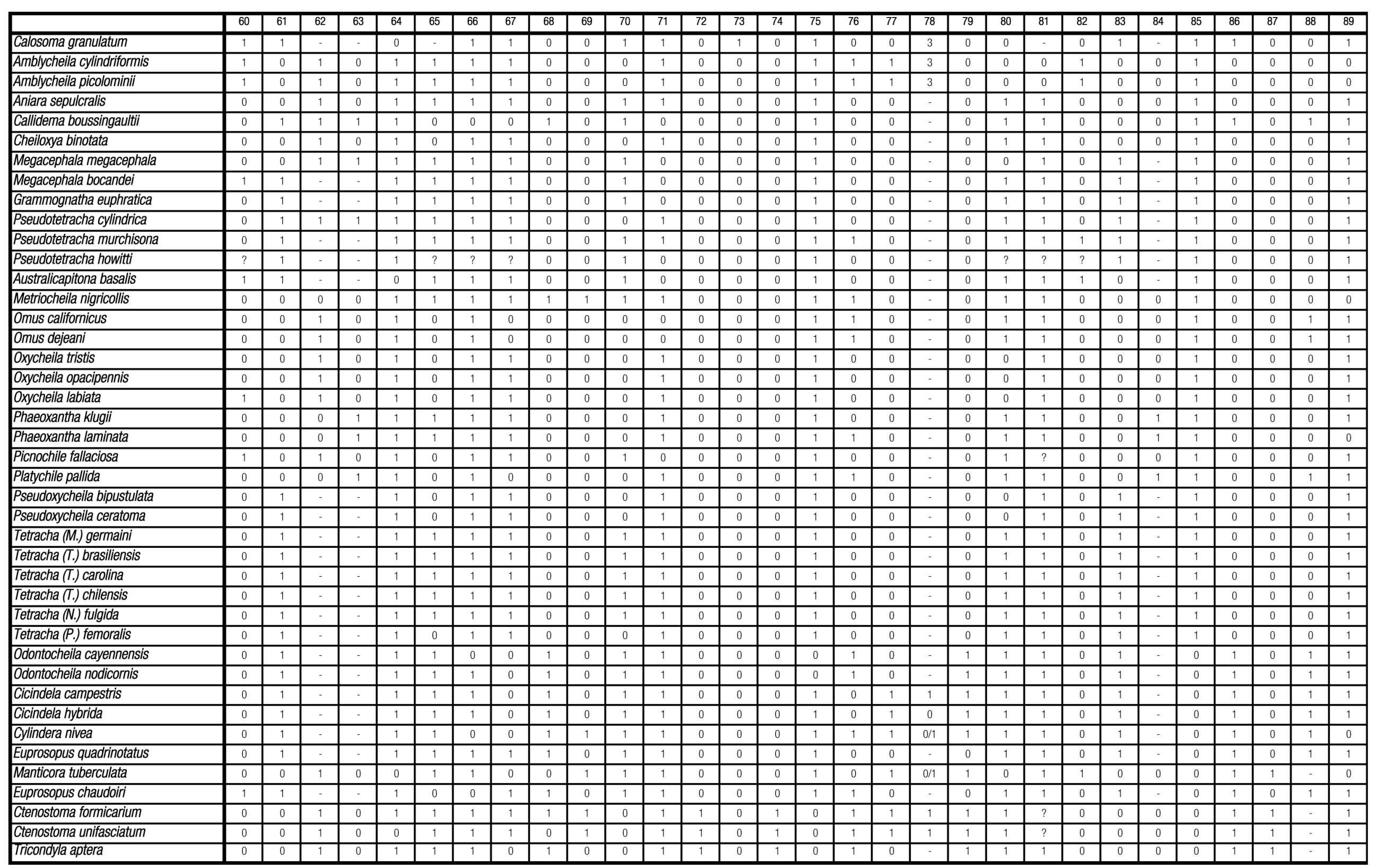

Tabela 3. Matriz de caracteres. Caracteres 60 ao 89. 


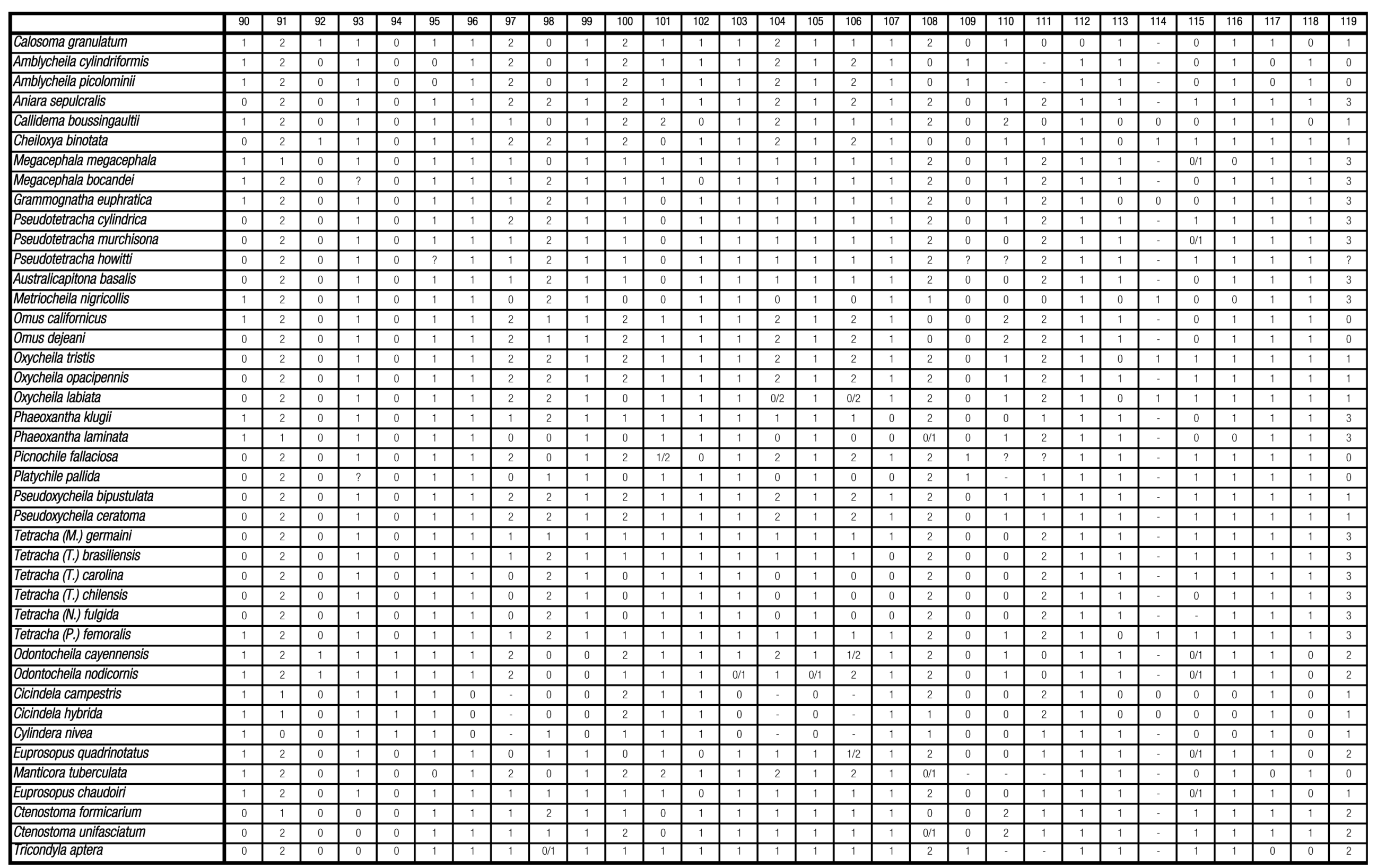

Tabela 4. Matriz de caracteres. Caracteres 90 ao 119. 


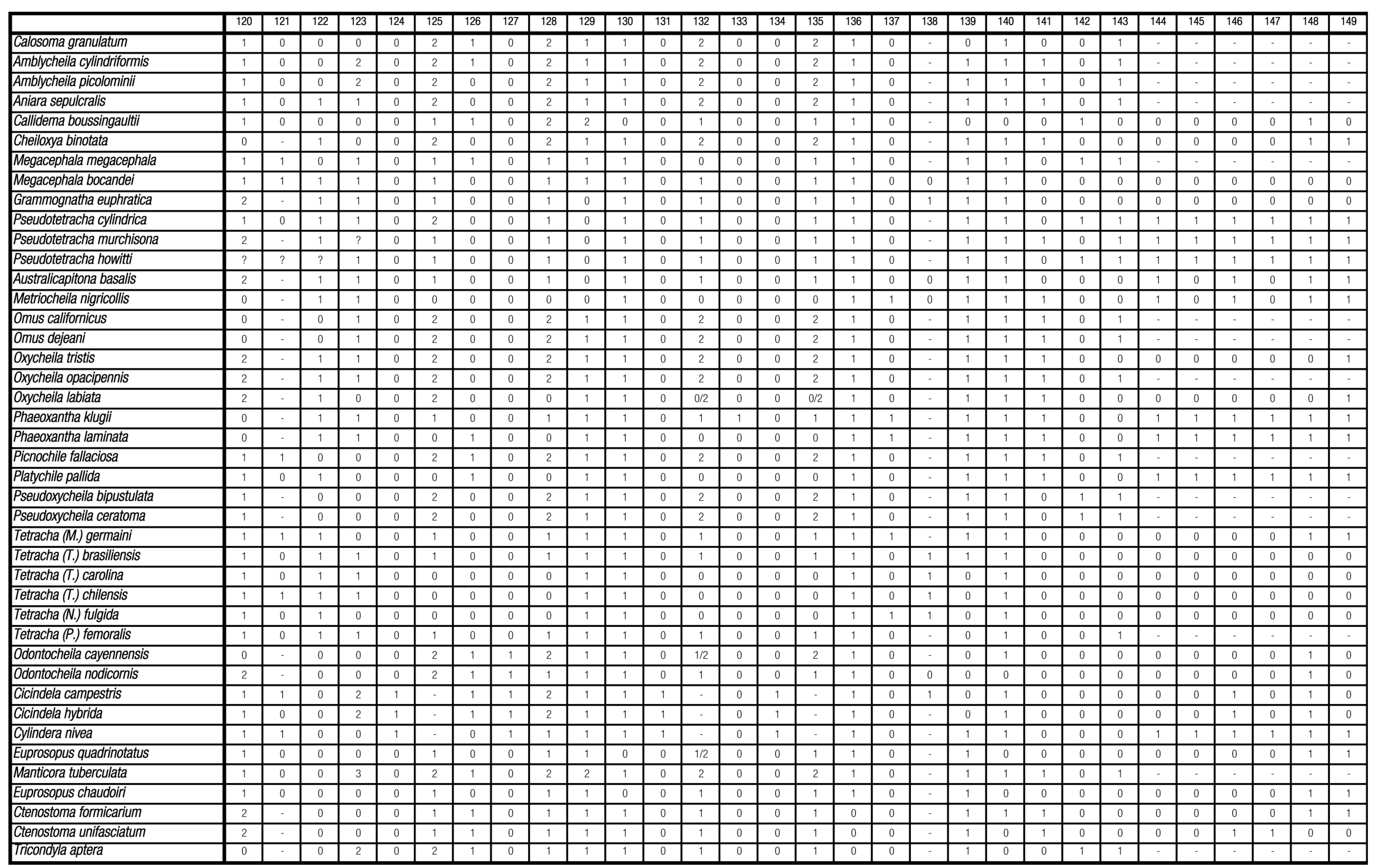

Tabela 5. Matriz de caracteres. Caracteres 120 ao 149. 


\begin{tabular}{|c|c|c|c|c|c|c|c|c|c|c|c|c|c|c|c|c|c|c|c|c|c|c|c|c|c|c|c|c|c|c|}
\hline & 150 & 151 & 152 & 153 & 154 & 155 & 156 & 157 & 158 & 159 & 160 & 161 & 162 & 163 & 164 & 165 & 166 & 167 & 168 & 169 & 170 & 171 & 172 & 173 & 174 & 175 & 176 & 177 & 178 & 179 \\
\hline Calosoma granulatum & & & & & 0 & 0 & 1 & 1 & 1 & 1 & 1 & 1 & 1 & 1 & 1 & 1 & 1 & 1 & - & 1 & 1 & 0 & 1 & 0 & 0 & 0 & 1 & 1 & 2 & 1 \\
\hline Amblycheila cylindriformis & - & - & - & - & 0 & 0 & 1 & 1 & 1 & 1 & 1 & 1 & 1 & 1 & 1 & 1 & $?$ & $?$ & ? & $?$ & $?$ & $?$ & 1 & 0 & 1 & 0 & 0 & 1 & 0 & 1 \\
\hline Amblycheila picolominii & - & - & - & - & 0 & 0 & 1 & 1 & 1 & 1 & 1 & 1 & 1 & 1 & 1 & 1 & $?$ & $?$ & $?$ & $?$ & $?$ & $?$ & 1 & 0 & 1 & 1 & 0 & 1 & 0 & 1 \\
\hline Aniara sepulcralis & - & - & - & - & 0 & 0 & 1 & 1 & 1 & 1 & 1 & 1 & 1 & 1 & 1 & 1 & 1 & 0 & 0 & 2 & 2 & 0 & 1 & 0 & 0 & 0 & 0 & 0 & - & 0 \\
\hline Callidema boussingaultii & 0 & 0 & 1 & 0 & 0 & 1 & 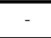 & - & - & - & - & - & - & - & - & - & 1 & 0 & 1 & 0 & 2 & 0 & 1 & 0 & 0 & 0 & 0 & 1 & - & 1 \\
\hline Cheiloxya binotata & 0 & 0 & 0 & 0 & 0 & 0 & 1 & 1 & 1 & 1 & 7 & 1 & 1 & 1 & 1 & 1 & 1 & 0 & 1 & 1 & 2 & 1 & 1 & 0 & 0 & 0 & 1 & 0 & - & 1 \\
\hline Megacephala megacephala & - & - & - & - & 0 & 1 & - & - & - & - & - & - & - & - & - & - & $?$ & $?$ & $?$ & $?$ & $?$ & $?$ & 0 & 1 & 1 & 0 & 1 & 0 & - & 1 \\
\hline Megacephala bocandei & 0 & 0 & 1 & 1 & 0 & 1 & - & - & - & - & - & - & - & - & - & - & 2 & 0 & 1 & 1 & 2 & 0 & 0 & 0 & 0 & 1 & 1 & 0 & 1 & 1 \\
\hline Grammognatha euphratica & 0 & 0 & 1 & 1 & 0 & 1 & - & - & - & - & - & - & - & - & - & - & 1 & 0 & 1 & 1 & 2 & 0 & 0 & 1 & 0 & 0 & 1 & 0 & - & 1 \\
\hline Pseudotetracha cylindrica & 1 & 1 & 1 & 1 & 0 & 1 & - & - & - & - & - & - & - & - & - & - & 1 & 0 & 1 & 1 & 2 & 0 & 1 & 0 & 0 & 1 & 1 & 0 & - & 1 \\
\hline Pseudotetracha murchisona & 1 & 1 & 1 & 1 & 0 & 1 & - & - & - & - & - & - & - & - & - & - & 0 & 0 & 1 & 1 & 2 & 0 & 1 & 0 & 0 & 0 & 1 & 0 & - & 1 \\
\hline Pseudotetracha howitti & 1 & 1 & 1 & 1 & 0 & 1 & - & - & - & - & - & - & - & - & - & - & $?$ & $?$ & $?$ & $?$ & $?$ & $?$ & 1 & 0 & 0 & 0 & 1 & 0 & - & 1 \\
\hline Australicapitona basalis & 0 & 1 & 1 & 1 & 0 & 1 & - & - & - & - & - & - & 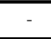 & - & - & - & $?$ & $?$ & $?$ & $?$ & $?$ & $?$ & 1 & 0 & 0 & 0 & 1 & 0 & - & 1 \\
\hline Metriocheila nigricollis & 0 & 1 & 1 & 1 & 0 & 0 & 0 & 1 & 0 & 1 & 0 & 1 & 1 & 1 & 0 & 1 & 1 & 0 & 1 & 1 & 2 & 0 & 1 & 1 & 0 & 0 & 0 & 0 & - & 1 \\
\hline Omus californicus & - & - & - & - & 0 & 0 & 1 & 1 & 1 & 1 & 1 & 1 & 1 & 1 & 1 & 1 & 2 & 0 & 1 & 1 & 2 & 0 & 1 & 0 & 1 & 0 & 0 & 0 & - & 1 \\
\hline Omus dejeani & - & - & - & - & 0 & 0 & 1 & 1 & 1 & 1 & 1 & 1 & 1 & 1 & 1 & 1 & $?$ & $?$ & $?$ & $?$ & $?$ & $?$ & 1 & 0 & 0 & 0 & 0 & 0 & - & 1 \\
\hline Oxycheila tristis & 0 & 0 & 0 & 0 & 0 & 0 & 1 & 1 & 1 & 1 & 1 & 1 & 1 & 1 & 1 & 1 & 1 & 0 & 1 & 1 & 2 & 0 & 1 & 0 & 0 & 0 & 1 & 0 & - & 1 \\
\hline Oxycheila opacipennis & - & - & - & - & 0 & 0 & 1 & 1 & 1 & 1 & 1 & 1 & 1 & 1 & 1 & 1 & 1 & 0 & 0 & 1 & 2 & 0 & 0 & 0 & 0 & 0 & 1 & 0 & - & 1 \\
\hline Oxycheila labiata & 0 & 0 & 0 & 0 & 0 & 0 & 1 & 1 & 1 & 1 & 1 & 1 & 1 & 1 & 1 & 1 & 1 & 0 & 1 & 1 & 2 & 0 & 1 & 0 & 0 & 0 & 0 & 0 & - & 1 \\
\hline Phaeoxantha klugii & 1 & 1 & 1 & 1 & 0 & 1 & - & - & - & - & - & - & - & - & - & 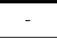 & 1 & 0 & 1 & 1 & 2 & 1 & 1 & 0 & 0 & 0 & 0 & 0 & - & 1 \\
\hline Phaeoxantha laminata & 1 & 1 & 1 & 1 & 0 & 1 & - & - & - & - & - & - & - & - & - & - & $?$ & 0 & $?$ & $?$ & $?$ & $?$ & 0 & 1 & 0 & 0 & 0 & 0 & - & 1 \\
\hline Picnochile fallaciosa & - & - & - & - & 0 & 0 & 1 & 1 & 1 & 1 & 1 & 1 & 1 & 1 & 1 & 1 & 2 & 0 & 1 & 2 & 2 & 0 & 0 & 0 & 1 & 0 & 1 & 1 & 1 & 0 \\
\hline Platychile pallida & 1 & 1 & 1 & 1 & 0 & 1 & - & - & - & - & - & - & - & - & - & - & $?$ & $?$ & $?$ & $?$ & $?$ & $?$ & 0 & 0 & 0 & 0 & 0 & 0 & - & 1 \\
\hline Pseudoxycheila bipustulata & - & - & - & - & 1 & 0 & 0 & 0 & 1 & 1 & 1 & 1 & 1 & 1 & 0 & 0 & 0 & 0 & 0 & 1 & 2 & 0 & 0 & 1 & 0 & 0 & 1 & 0 & - & 1 \\
\hline Pseudoxycheila ceratoma & - & - & - & - & 1 & 0 & 0 & 0 & 1 & 1 & 1 & 1 & 1 & 1 & 0 & 0 & 0 & 0 & 0 & 1 & 2 & 0 & 1 & 0 & 0 & 0 & 1 & 0 & - & 0 \\
\hline Tetracha (M.) germaini & 1 & 1 & 1 & 1 & 0 & 1 & - & - & - & - & - & - & - & - & - & - & 1 & 0 & 0 & 2 & 2 & 0 & 1 & 1 & 0 & 0 & 1 & 0 & - & 0 \\
\hline Tetracha (T.) brasiliensis & 1 & 0 & 1 & 1 & 0 & 1 & - & - & - & - & - & - & - & - & - & - & 1 & 0 & 0 & 2 & 2 & 0 & 1 & 0 & 0 & 0 & 1 & 0 & - & 1 \\
\hline Tetracha $(T$.$) carolina$ & 1 & 1 & 1 & 1 & 0 & 1 & - & - & - & - & - & - & - & - & - & - & 1 & 0 & 0 & 2 & 2 & 0 & 1 & 0 & 0 & 0 & 1 & 0 & - & 1 \\
\hline Tetracha (T.) chilensis & 1 & 1 & 1 & 1 & 0 & 1 & - & - & - & - & - & - & - & - & - & - & 1 & 0 & 0 & 2 & 2 & 0 & 1 & 0 & 0 & 0 & 1 & 0 & - & 1 \\
\hline Tetracha (N.) fulgida & 1 & 1 & 1 & 1 & 0 & 1 & - & - & - & - & - & - & - & - & - & - & 1 & 0 & 0 & 2 & 2 & 0 & 1 & 0 & 0 & 0 & 1 & 0 & - & 1 \\
\hline Tetracha (P.) femoralis & - & - & - & - & 0 & 1 & - & - & - & - & - & - & - & - & - & - & 1 & 0 & 0 & 2 & 2 & 0 & 1 & 0 & 0 & 0 & 0 & 0 & - & 1 \\
\hline Odontocheila cayennensis & 0 & 0 & 0 & 1 & 0 & 1 & - & - & - & - & - & - & - & - & - & - & 1 & 0 & - & 1 & 0 & 0 & 1 & 0 & 0 & 0 & 0 & 0 & - & 1 \\
\hline Odontocheila nodicornis & 0 & 0 & 1 & 0 & 0 & 1 & - & - & - & - & - & - & - & - & - & - & 0 & 0 & - & 1 & 0 & 0 & 1 & 0 & 0 & 0 & 0 & 0 & - & 1 \\
\hline Cicindela campestris & 1 & 1 & 1 & 1 & 0 & 1 & - & - & - & - & - & - & - & - & - & - & 0 & 0 & - & 0 & 2 & 0 & 1 & 0 & 0 & 0 & 0 & 0 & - & 1 \\
\hline Cicindela hybrida & 1 & 1 & 1 & 1 & 0 & 1 & - & - & - & - & - & - & - & - & - & - & 0 & 0 & - & 0 & 2 & 0 & 1 & 0 & 0 & 0 & 0 & 0 & - & 1 \\
\hline Cyllindera nivea & 1 & 1 & 1 & 1 & 0 & 1 & - & - & - & - & - & - & - & - & - & - & 1 & 0 & 0 & 0 & 2 & 0 & 0 & 0 & 0 & 0 & 0 & 0 & - & 1 \\
\hline Euprosopus quadrinotatus & 1 & 0 & 1 & 1 & 0 & 1 & - & - & - & - & - & - & - & - & - & - & 1 & 0 & - & 1 & 1 & 0 & 1 & 0 & 0 & 0 & 1 & 0 & - & 1 \\
\hline Manticora tuberculata & - & - & & - & 0 & 0 & 1 & 1 & 1 & 1 & 1 & 1 & 1 & 1 & 1 & 1 & - & $?$ & - & $?$ & $?$ & - & 0 & 1 & 1 & 0 & 0 & 0 & - & 1 \\
\hline Euprosopus chaudoiri & 0 & 0 & 1 & 1 & 0 & 1 & - & - & - & - & - & - & - & - & - & - & 1 & 0 & - & 1 & 1 & 0 & 1 & 0 & 0 & 0 & 0 & 0 & - & 1 \\
\hline Ctenostoma formicarium & 0 & 0 & 0 & 0 & 0 & 0 & 1 & 1 & 1 & 1 & 1 & 1 & 1 & 1 & 1 & 1 & 2 & 0 & - & 1 & 1 & 1 & 1 & 1 & 0 & 0 & 0 & 0 & - & 1 \\
\hline Ctenostoma unifasciatum & 1 & 1 & 0 & 0 & 0 & 0 & 1 & 1 & 1 & 1 & 1 & 1 & 1 & 1 & 1 & 1 & 2 & 0 & 0 & 1 & 1 & 1 & 1 & 0 & 0 & 0 & 0 & 0 & - & 1 \\
\hline Tricondyla aptera & - & - & - & - & 0 & 0 & 1 & 1 & 1 & 1 & 1 & 1 & 1 & 1 & 1 & 1 & 2 & 0 & - & 1 & 1 & 1 & 1 & 1 & 1 & 0 & 1 & 0 & & 1 \\
\hline
\end{tabular}

Tabela 6. Matriz de caracteres. Caracteres 150 ao 179. 


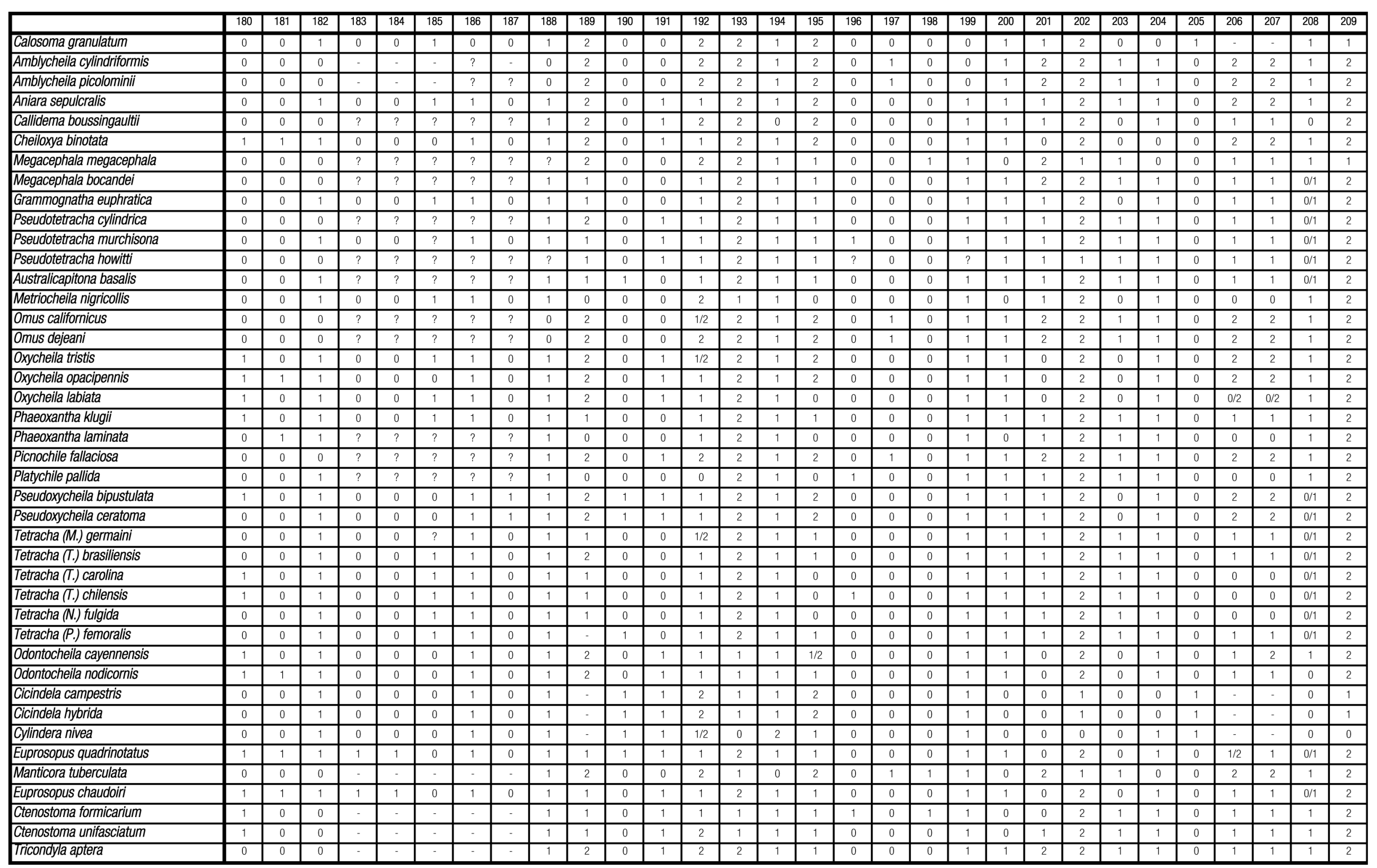

Tabela 7. Matriz de caracteres. Caracteres 180 ao 209. 


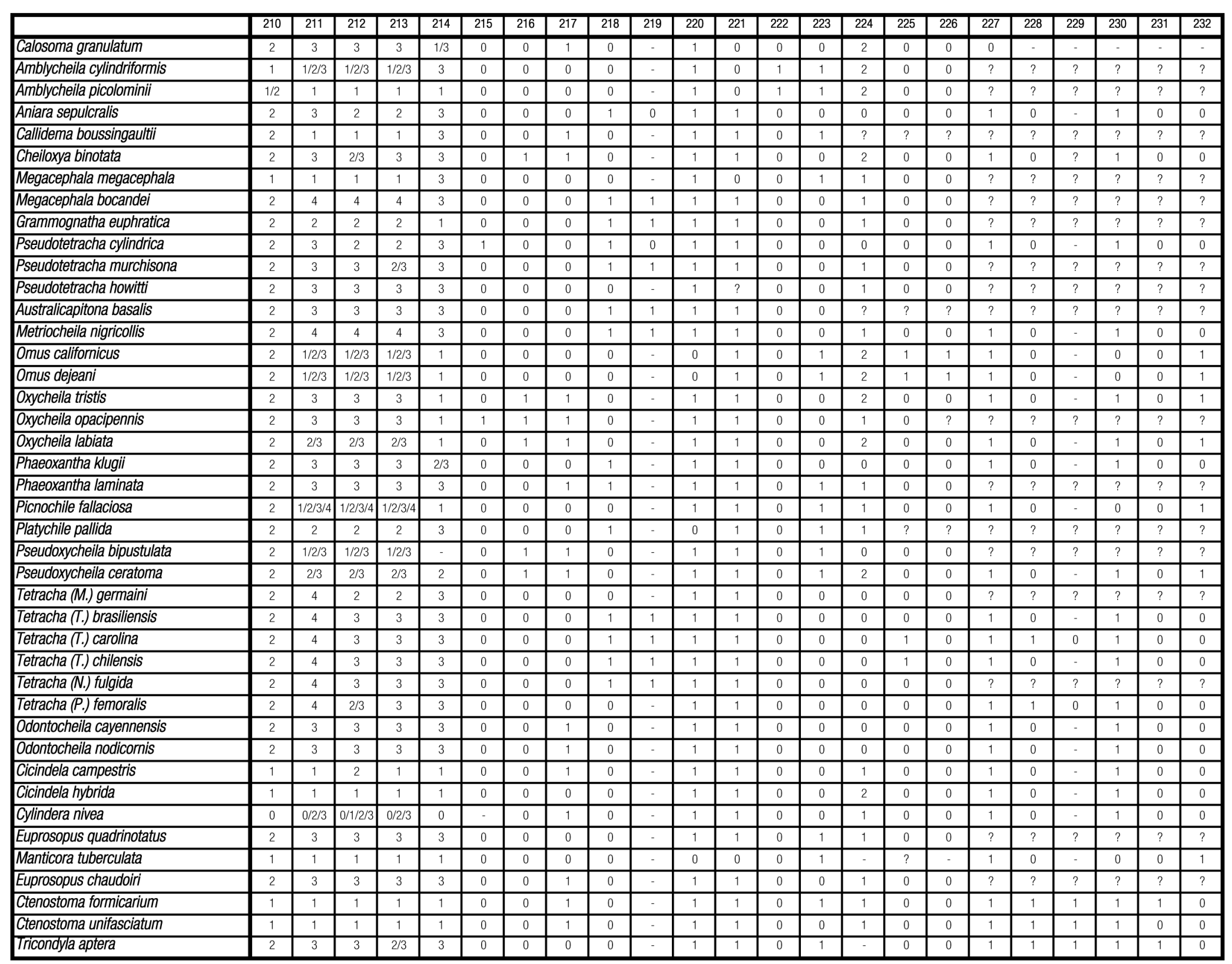

Tabela 8. Matriz de caracteres. Caracteres 210 ao 232. 


\section{ANEXOS}


Anexo 1. Caracteres não utilizados na análise devido a impossibilidade de estabelecer a relação entre seus estados.

1. Habitus, comprimento, relação sobre a altura (distância do mesosterno até sutura do élitro em ângulo reto)

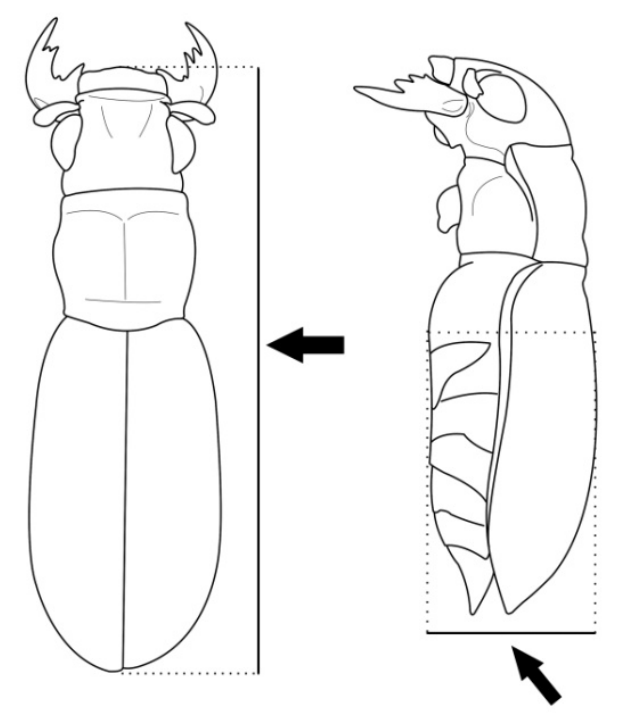

2. Antena, comprimento (distância da base do escapo até o ápice do antenômero 11), relação sobre o comprimento do habitus

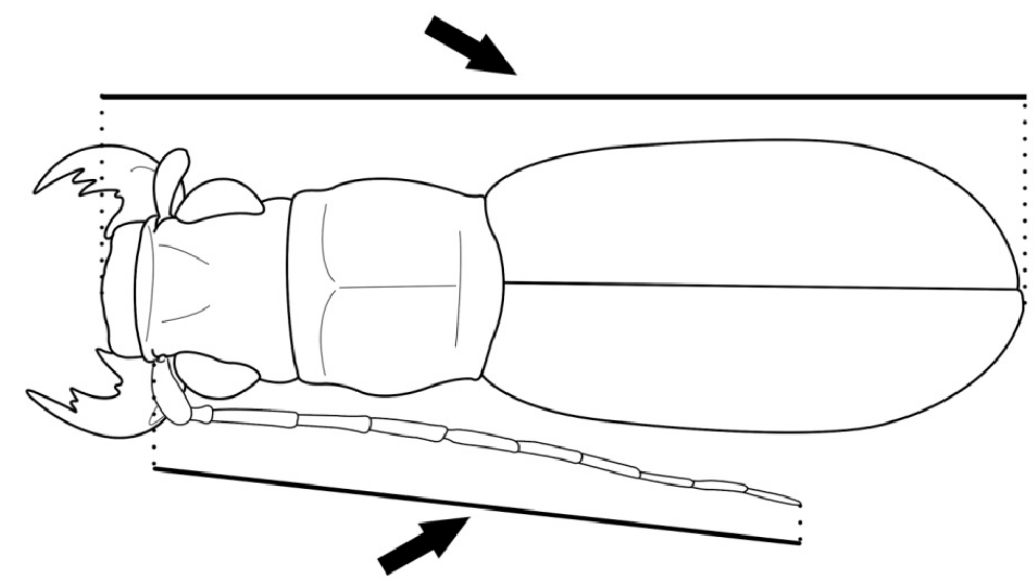


3. Cabeça, vista ventral, gula, margem anterior, largura, relação com a largura da margem posterior

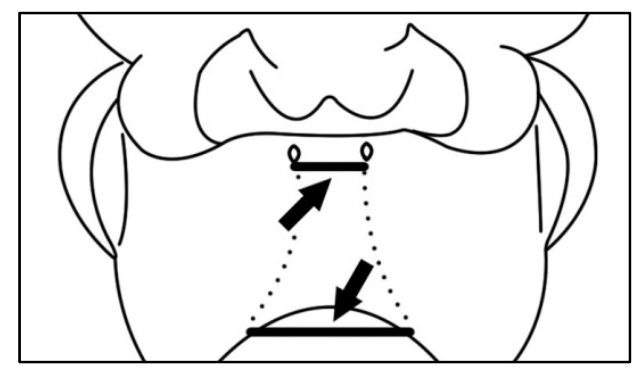

4. Cabeça, superfície dorsal, margem basal, largura, relação sobre a distância entre as margens externas dos olhos

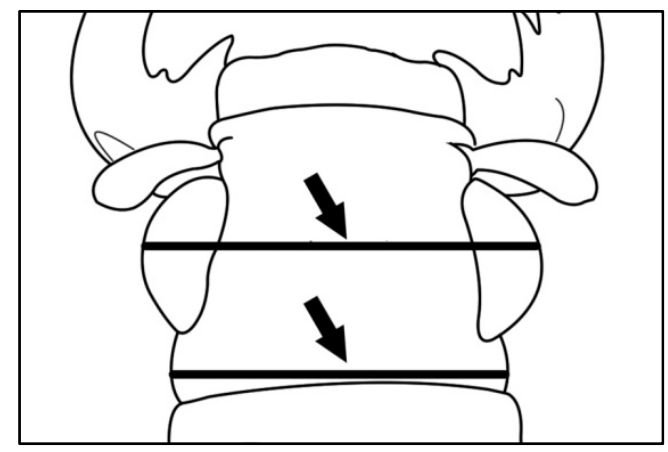

5. Cabeça, ângulo entre eixo da cabeça e ângulo da mandíbula

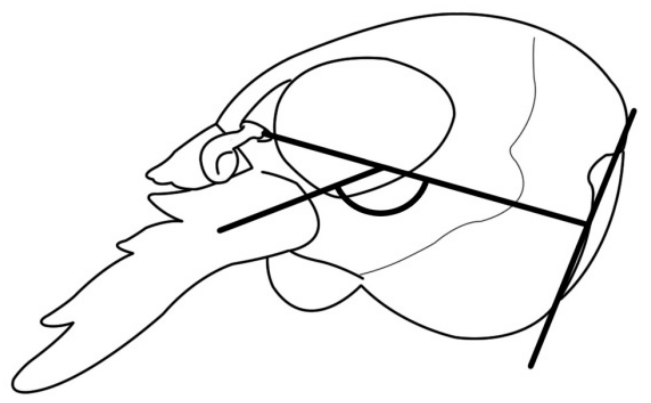


6. Habitus, comprimento, relação sobre o comprimento do pronoto

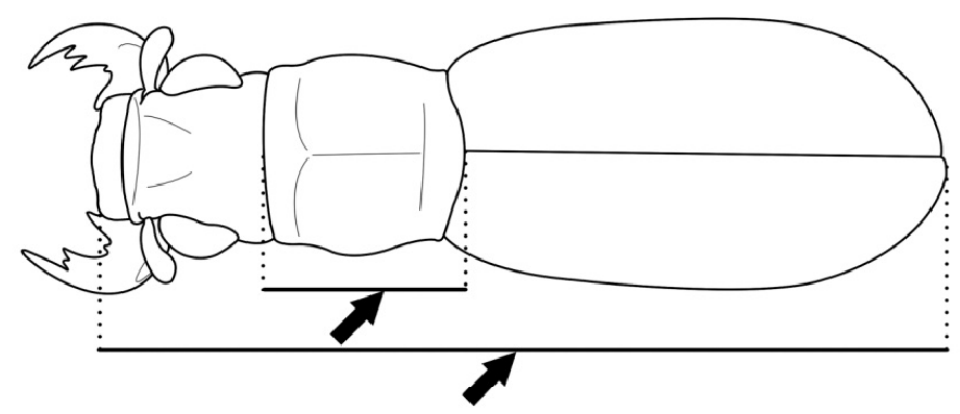

7. Pronoto, comprimento, relação sobre o comprimento da cabeça (excluindo labro)

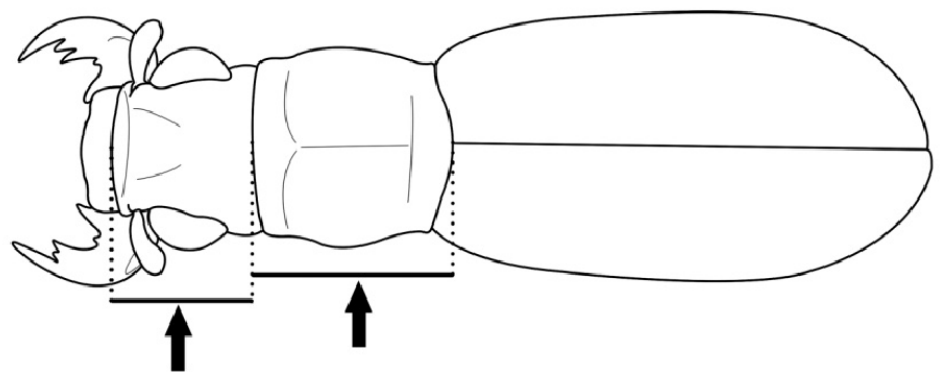

8. Protórax, pronoto, margem anterior, largura, relação sobre a largura da margem posterior

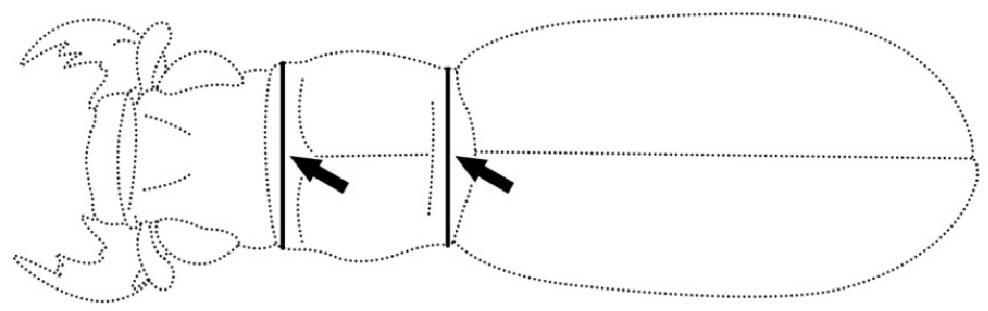


9. Pronoto, comprimento, relação sobre o comprimento do élitro

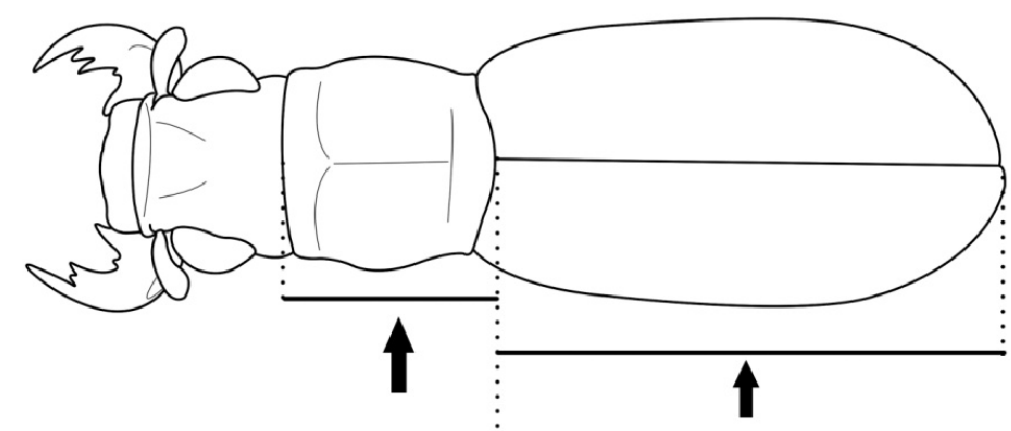

10. Pronoto, maior largura, relação sobre a maior largura do élitro

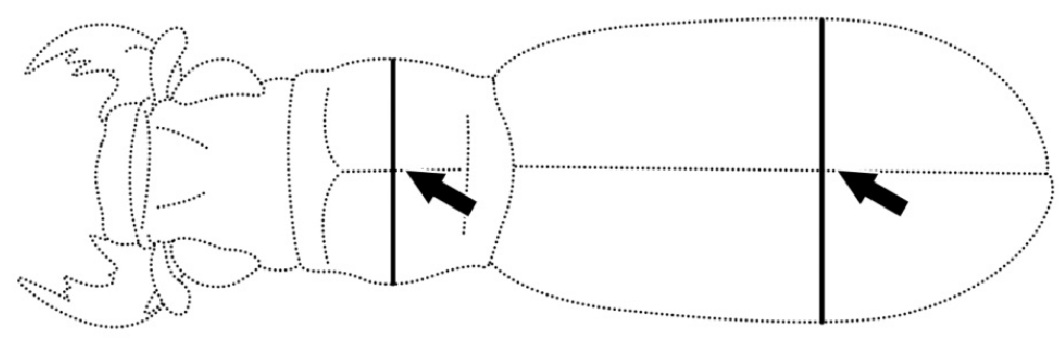

11. Habitus, comprimento, relação sobre o comprimento do élitro

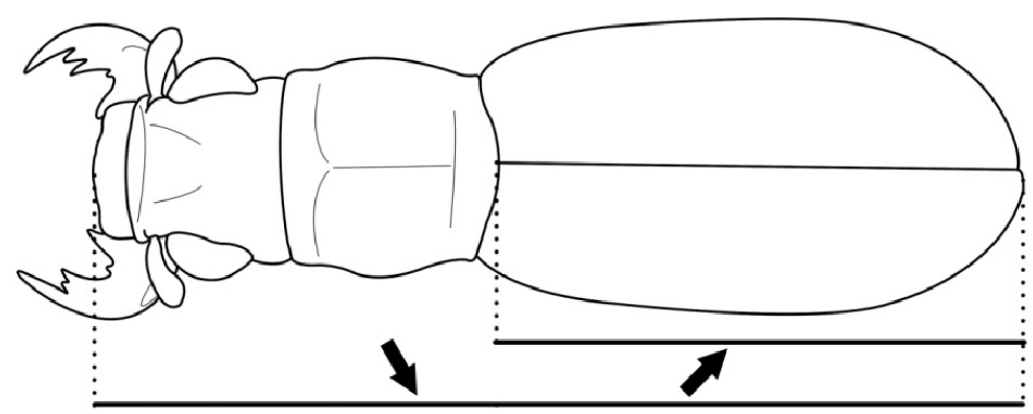


12. Élitro, maior largura, relação sobre a altura (vista lateral)
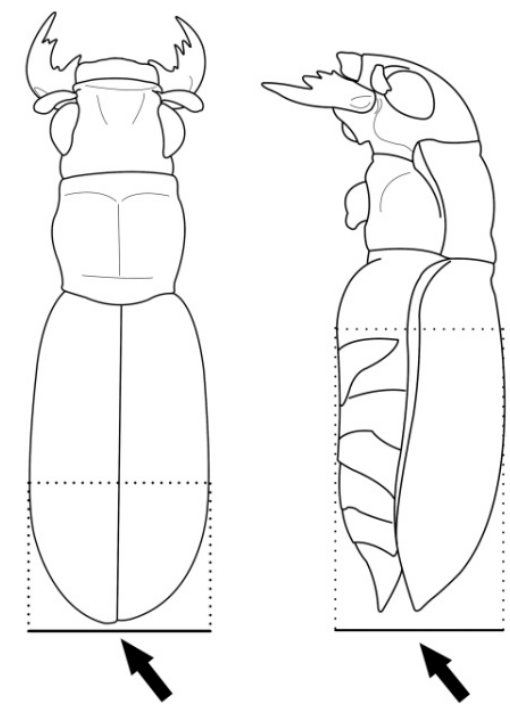
Anexo 2. Sinapomorfias comuns às 4 árvores mais parcimoniosas sem o uso de otimização (número dos nós referem-se aos nós do consenso)

Calosoma granulatum :

Todas as árvores:

Sem autapomorfias.

Amblycheila cylindriformis :

Todas as árvores:

Caráter 214: 1 --> 3

Amblycheila picolominii :

Todas as árvores:

Caráter 24: 0 --> 2

Caráter 126: 1 --> 0

Caráter 175: 0 --> 1

\section{Aniara sepulcralis :}

Todas as árvores:

Caráter 20: 4 --> 5

Caráter 42: 2 --> 0

Caráter 54: 0 --> 2

Caráter 176: 1 --> 0

Caráter 179: 1 --> 0

Caráter 212: 3 --> 2

Caráter 213: 3 --> 2

Algumas árvores:

Caráter 11: 2 --> 1

Caráter 32: 1 --> 0
Callidema boussingaultii :

Todas as árvores:

Caráter 5: 2 --> 1

Caráter 16: 1 --> 0

Caráter 22: 0 --> 1

Caráter 63: 0 --> 1

Caráter 66: 1 --> 0

Caráter 71: 1 --> 0

Caráter 101: 1 --> 2

Caráter 102: 1 --> 0

Caráter 113: 1 --> 0

Caráter 129: 1 --> 2

Caráter 130: 1 --> 0

Caráter 142: 0 --> 1

Caráter 169: 1 --> 0

Caráter 182: 1 --> 0

Caráter 194: 1 --> 0

Caráter 211: 3 --> 1

Caráter 212: 3 --> 1

Caráter 213: 3 --> 1

\section{Cheiloxya binotata :}

Todas as árvores:

Caráter 44: 1 --> 0

Caráter 80: 0 --> 1

Caráter 92: 0 --> 1

Caráter 101: 1 -->0

Caráter 108: 2 --> 0

Caráter 111: 2 --> 1

Caráter 120: 2 --> 0

Caráter 171: 0 --> 1

Caráter 204: 1 --> 0 


\section{Megacephala megacephala :}

Todas as árvores:

Caráter 7: 0 --> 1

Caráter 9: 1 --> 0

Caráter 21: 0 --> 34

Caráter 24: 1 --> 2

Caráter 25: 2 --> 0

Caráter 41: 2 --> 0

Caráter 51: 2 --> 1

Caráter 58: 1 -->0

Caráter 61: 1 -->0

Caráter 80: 1 --> 0

Caráter 91: 2 --> 1

Caráter 98: 2 --> 0

Caráter 116: 1 --> 0

Caráter 122: 1 --> 0

Caráter 126: 0 --> 1

Caráter 132: 1 --> 0

Caráter 142: 0 --> 1

Caráter 143: 0 --> 1

Caráter 174: 0 --> 1

Caráter 189: 1 --> 2

Caráter 192: 1 --> 2

Caráter 198: 0 --> 1

Caráter 200: 1 --> 0

Caráter 202: 2 --> 1

Caráter 204: 1 --> 0

Caráter 209: 2 --> 1

Caráter 210: 2 --> 1

Caráter 211: 4 --> 1

Caráter 218: 1 --> 0

Caráter 221: 1 --> 0

Caráter 223: 0 --> 1

\section{Megacephala bocandei :}

Todas as árvores:

Caráter 5: 1 --> 0

Caráter 42: 2 --> 0

Caráter 54: 0 --> 1

Caráter 60: 0 --> 1

Caráter 102: 1 --> 0

Caráter 173: 1 --> 0

Caráter 175: 0 --> 1

\section{Grammognatha euphratica :}

Todas as árvores:

Caráter 20: 4 --> 123

Caráter 33: 1 --> 0

Caráter 34: 1 --> 0

Caráter 101: 1 --> 0

Caráter 113: 1 --> 0

Caráter 120: 1 --> 2

Caráter 129: 1 --> 0

Caráter 203: 1 --> 0

Caráter 211: 4 --> 2

Caráter 214: 3 --> 1

\section{Pseudotetracha cylindrica :}

Todas as árvores:

Caráter 13: 1 --> 2

Caráter 27: 0 --> 1

Caráter 45: 0 --> 1

Caráter 70: 1 --> 0

Caráter 97: 1 --> 2

Caráter 125: 1 --> 2

Caráter 175: 0 --> 1 
Caráter 189: 1 --> 2

Caráter 212: 3 --> 2

Caráter 213: 3 --> 2

Caráter 215: 0 --> 1

Algumas árvores:

Caráter 11: 2 --> 1
Caráter 190: 0 --> 1

Algumas árvores:

Caráter 31: 0 --> 1

Caráter 37: 0 --> 1

Caráter 40: 3 --> 4

\section{Metriocheila nigricollis :}

\section{Pseudotetracha murchisona :}

Todas as árvores:

Caráter 76: 0 --> 1

Caráter 166: 1 --> 0

Caráter 196: 0 --> 1

Algumas árvores:

Caráter 32: 1 --> 0

\section{Pseudotetracha howitti :}

Todas as árvores:

Caráter 42: 2 --> 0

Caráter 47: 1 --> 0

Caráter 71: 1 --> 0

Caráter 202: 2 --> 1

Caráter 218: 1 --> 0

Algumas árvores:

Caráter 31: 0 --> 1

\section{Australicapitona basalis :}

Todas as árvores:

Caráter 60: 0 --> 1

Caráter 64: 1 --> 0

Caráter 71: 1 --> 0

Caráter 145: 1 --> 0

Caráter 147: 1 --> 0

Caráter 150: 1 --> 0
Todas as árvores:

Caráter 11: 1 --> 0

Caráter 20: 4 --> 5

Caráter 41: 2 --> 3

Caráter 46: 0 --> 1

Caráter 47: 0 --> 1

Caráter 50: 0 --> 1

Caráter 63: 1 --> 0

Caráter 68: 0 --> 1

Caráter 69: 0 --> 1

Caráter 113: 1 --> 0

Caráter 145: 1 --> 0

Caráter 147: 1 --> 0

Caráter 150: 1 --> 0

Caráter 155: 1 --> 0

Caráter 192: 1 --> 2

Caráter 193: 2 --> 1

Caráter 203: 1 --> 0

Caráter 211: 3 --> 4

Caráter 212: 3 --> 4

Caráter 213: 3 --> 4

Algumas árvores:

Caráter 70: 0 --> 1

Caráter 84: 1 --> 0

Caráter 101: 1 --> 0

Caráter 107: 0 --> 1 
Caráter 111: 12 --> 0

Caráter 129: 1 --> 0

Omus californicus :

Todas as árvores:

Caráter 39: 2 --> 3

Caráter 54: 0 --> 2

Omus dejeani :

Todas as árvores:

Caráter 18: 1 -->0

Caráter 42: 2 --> 0

Caráter 174: 1 --> 0

Oxycheila tristis :

Todas as árvores:

Caráter 38: 1 -->0

Caráter 123: 0 --> 1

Oxycheila_opacipennis :

Todas as árvores:

Caráter 123: 0 --> 1

Caráter 172: 1 --> 0

Caráter 215: 0 --> 1

Caráter 224: 2 --> 1

Oxycheila labiata :

Todas as árvores:

Caráter 5: 2 --> 0

Caráter 58: 0 --> 1

Caráter 60: 0 --> 1

Caráter 100: 2 --> 0

Caráter 128: 2 --> 0
Caráter 176: 1 --> 0

Caráter 195: 2 --> 0

Phaeoxantha klugii :

Todas as árvores:

Caráter 1: 1 --> 0

Caráter 16: 0 --> 1

Caráter 25: 2 --> 0

Caráter 133: 0 --> 1

Caráter 171: 0 --> 1

Caráter 180: 0 --> 1

Algumas árvores:

Caráter 21: 0 --> 2

Phaeoxantha laminata :

Todas as árvores:

Caráter 16: 0 --> 1

Caráter 42: 2 --> 0

Caráter 52: 0 --> 1

Caráter 58: 1 --> 0

Caráter 91: 2 --> 1

Caráter 181: 0 --> 1

Caráter 217: 0 --> 1

Algumas árvores:

Caráter 1: 1 --> 2

Caráter 98: 2 --> 0

Caráter 110: 0 --> 1

\section{Picnochile fallaciosa :}

Todas as árvores:

Caráter 18: 1 --> 0

Caráter 20: 4 --> 6

Caráter 25: 2 --> 0 
Caráter 44: 1 --> 0

Caráter 51: 2 --> 0

Caráter 60: 0 --> 1

Caráter 102: 1 --> 0

Caráter 121: 0 --> 1

Caráter 169: 1 --> 2

Caráter 172: 1 --> 0

Caráter 179: 1 --> 0

Caráter 224: 2 --> 1

\section{Platychile pallida :}

Todas as árvores:

Caráter 6: 1 --> 0

Caráter 9: 1 --> 0

Caráter 10: 0 --> 1

Caráter 65: 1 -->0

Caráter 67: 1 --> 0

Caráter 88: 0 --> 1

Caráter 109: 0 --> 1

Caráter 115: 0 --> 1

Caráter 119: 3 --> 0

Caráter 120: 0 --> 1

Caráter 123: 1 --> 0

Caráter 192: 1 --> 0

Caráter 196: 0 --> 1

Caráter 211: 3 --> 2

Caráter 212: 3 --> 2

Caráter 213: 3 --> 2

Caráter 220: 1 --> 0

Algumas árvores:

Caráter 21: 0 --> 12

Caráter 40: 3 --> 4

Caráter 90: 1 --> 0
Caráter 98: 2 --> 1

Caráter 137: 1 --> 0

\section{Pseudoxycheila bipustulata :}

Todas as árvores:

Caráter 172: 1 --> 0

Caráter 173: 0 --> 1

Caráter 224: 2 --> 0

\section{Pseudoxycheila ceratoma :}

Todas as árvores:

Caráter 54: 0 --> 2

Caráter 179: 1 --> 0

Tetracha (M.) germaini :

Todas as árvores:

Caráter 1: 1 --> 2

Caráter 42: 2 --> 0

Caráter 98: 2 --> 1

Caráter 123: 1 --> 0

Caráter 137: 0 --> 1

Caráter 179: 1 -->0

Caráter 218: 1 -->0

Algumas árvores:

Caráter 110: 1 --> 0

\section{Tetracha ( $T$.) brasiliensis :}

Todas as árvores:

Caráter 41: 2 --> 3

Caráter 189: 1 --> 2

\section{Tetracha (T.) carolina :}

Todas as árvores: 
Caráter 228: 0 --> 1

Tetracha (T.) chilensis :

Todas as árvores:

Caráter 42: 2 --> 0

Caráter 115: 1 --> 0

Caráter 121: 0 --> 1

Caráter 196: 0 --> 1

Tetracha (N.) fulgida :

Todas as árvores:

Caráter 11: 2 --> 1

Caráter 123: 1 --> 0

Caráter 137: 0 --> 1

Tetracha (P.) femoralis :

Todas as árvores:

Caráter 37: 0 --> 1

Caráter 42: 2 --> 0

Caráter 50: 1 --> 0

Caráter 65: 1 --> 0

Caráter 70: 1 --> 0

Caráter 90: 0 --> 1

Caráter 113: 1 --> 0

Caráter 176: 1 --> 0

Caráter 190: 0 --> 1

Caráter 218: 1 --> 0

Caráter 228: 0 --> 1

Algumas árvores:

Caráter 11: 2 --> 1

Caráter 31: 0 --> 1

Caráter 139: 1 -->0
Odontocheila cayennensis :

Todas as árvores:

Caráter 66: 1 --> 0

Caráter 135: 1 --> 2

Caráter 152: 1 --> 0

Caráter 207: 1 --> 2

Odontocheila nodicornis :

Todas as árvores:

Caráter 8: 0 --> 1

Caráter 166: 1 --> 0

Caráter 181: 0 --> 1

\section{Cicindela campestris :}

Todas as árvores:

Caráter 39: 0 --> 1

Caráter 52: 1 --> 0

Caráter 57: 5 --> 012

Caráter 58: 1 --> 0

Cicindela hybrida :

Todas as árvores:

Caráter 41: 2 --> 01

Caráter 78: 1 --> 0

Caráter 217: 1 --> 0

Caráter 224: 1 --> 2

\section{Cylindera nivea :}

Todas as árvores:

Caráter 26: 0 --> 1

Caráter 66: 1 --> 0

Caráter 69: 0 --> 1

Caráter 89: 1 -->0 
Caráter 98: 0 --> 1

Caráter 126: 1 --> 0

Caráter 139: 0 --> 1

Caráter 144: 0 --> 1

Caráter 145: 0 --> 1

Caráter 147: 0 --> 1

Caráter 172: 1 --> 0

Caráter 193: 1 --> 0

Caráter 194: 1 --> 2

\section{Euprosopus quadrinotatus :}

Todas as árvores:

Caráter 30: 1 --> 2

Caráter 50: 0 --> 1

Caráter 58: 1 --> 0

Caráter 76: 1 -->0

Caráter 97: 1 --> 0

Caráter 100: 1 --> 0

Caráter 150: 0 --> 1

Caráter 176: 0 --> 1

Caráter 190: 0 --> 1

Caráter 217: 1 --> 0

\section{Manticora tuberculata :}

Todas as árvores:

Caráter 25: 2 --> 0

Caráter 32: 1 --> 0

Caráter 38: 1 --> 0

Caráter 39: 2 --> 01

Caráter 40: 3 --> 0

Caráter 41: 2 --> 1

Caráter 44: 1 -->0

Caráter 46: 1 --> 0
Caráter 51: 2 --> 0

Caráter 54: 0 --> 2

Caráter 64: 1 --> 0

Caráter 69: 0 --> 1

Caráter 79: 0 --> 1

Caráter 85: 1 --> 0

Caráter 86: 0 --> 1

Caráter 87: 0 --> 1

Caráter 101: 1 --> 2

Caráter 129: 1 --> 2

Caráter 172: 1 --> 0

Caráter 173: 0 --> 1

Caráter 193: 2 --> 1

Caráter 194: 1 --> 0

Caráter 198: 0 --> 1

Caráter 200: 1 --> 0

Caráter 202: 2 --> 1

Caráter 204: 1 --> 0

\section{Euprosopus chaudoiri :}

Todas as árvores:

Caráter 1: 1 --> 2

Caráter 5: 2 --> 1

Caráter 40: 34 --> 5

Caráter 60: 0 --> 1

Caráter 65: 1 --> 0

Caráter 66: 1 --> 0

\section{Ctenostoma formicarium :}

Todas as árvores:

Caráter 5: 2 --> 1

Caráter 20: 3 --> 5

Caráter 54: 0 --> 1 
Caráter 91: 2 --> 1

Caráter 98: 1 --> 2

Caráter 140: 0 --> 1

Caráter 192: 2 --> 1

Caráter 196: 0 --> 1

Caráter 198: 0 --> 1

\section{Ctenostoma unifasciatum :}

Todas as árvores:

Caráter 40: 4 --> 5

Caráter 57: 5 --> 0

Caráter 64: 1 -->0

Caráter 68: 1 -->0

Caráter 100: 1 --> 2

Caráter 146: 0 --> 1

Caráter 147: 0 --> 1

Caráter 148: 1 --> 0

Caráter 150: 0 --> 1

Caráter 151: 0 --> 1

Caráter 201: 0 --> 1

\section{Tricondyla aptera :}

Todas as árvores:

Caráter 1: 1 --> 0

Caráter 13: 1 --> 2

Caráter 20: 3 --> 4

Caráter 21: 2 --> 0

Caráter 30: 1 --> 0

Caráter 41: 2 --> 4

Caráter 50: 0 --> 1

Caráter 58: 1 --> 0

Caráter 109: 0 --> 1

Caráter 117: 1 --> 0
Caráter 123: 0 --> 2

Caráter 142: 0 --> 1

Caráter 143: 0 --> 1

Caráter 174: 0 --> 1

Caráter 176: 0 --> 1

Caráter 201: 0 --> 2

Caráter 217: 1 --> 0

Nó 43 :

Todas as árvores:

Caráter 11: 2 --> 1

Caráter 56: 1 --> 2

Caráter 60: 0 --> 1

Caráter 81: 1 --> 0

Caráter 199: 1 --> 0

Caráter 222: 0 --> 1

\section{Nó 44 :}

Todas as árvores:

Caráter 1: 1 --> 0

Caráter 7: 0 --> 1

Caráter 27: 0 --> 1

Caráter 50: 0 --> 1

Caráter 52: 0 --> 1

Caráter 58: 1 --> 0

Caráter 65: 0 --> 1

Caráter 77: 0 --> 1

Caráter 80: 1 -->0

Caráter 82: 0 --> 1

Caráter 89: 1 --> 0

Caráter 95: 1 --> 0

Caráter 117: 1 --> 0

Caráter 210: 2 --> 1 
Nó 45 :

Todas as árvores:

Caráter 56: 0 --> 1

Caráter 108: 2 --> 0

Caráter 176: 1 --> 0

Caráter 191: 1 --> 0

Nó 46 :

Todas as árvores:

Caráter 2: 0 --> 1

Caráter 9: 1 --> 0

Caráter 39: 3 --> 2

Caráter 46: 0 --> 1

Caráter 119: 1 -->0

Caráter 166: 1 --> 2

Caráter 174: 0 --> 1

Caráter 182: 1 --> 0

Caráter 197: 0 --> 1

Caráter 201: 1 --> 2

Caráter 230: 1 --> 0

\section{Nó 47 :}

Todas as árvores:

Caráter 86: 1 -->0

Caráter 106: 1 --> 2

Caráter 111: 0 --> 2

Caráter 118: 0 --> 1

Caráter 139: 0 --> 1

\section{Nó 48 :}

Todas as árvores:
Nó 49 :

Todas as árvores:

Caráter 6: 2 --> 1

Caráter 16: 1 -->0

Caráter 21: 4 --> 0

Caráter 37: 1 -->0

Caráter 65: 0 --> 1

Caráter 119: 1 --> 3

Caráter 123: 0 --> 1

Caráter 218: 0 --> 1

Caráter 224: 2 --> 0

Algumas árvores:

Caráter 31: 1 --> 0

\section{Nó 50 :}

Todas as árvores:

Caráter 17: 0 --> 1

Caráter 50: 0 --> 1

Caráter 98: 0 --> 2

Caráter 126: 1 --> 0

Caráter 192: 2 --> 1

\section{Nó 51 :}

Todas as árvores:

Caráter 13: 2 --> 1

Caráter 52: 0 --> 1

Caráter 55: 1 --> 0

Caráter 68: 0 --> 1

Caráter 88: 0 --> 1

Caráter 132: 2 --> 1

Caráter 135: 2 --> 1 
Caráter 143: 1 --> 0

Caráter 155: 0 --> 1

Caráter 176: 1 --> 0

\section{Nó 52 :}

Todas as árvores:

Caráter 113: 1 -->0

Caráter 143: 1 --> 0

Caráter 168: 0 --> 1

\section{Nó 53 :}

Todas as árvores:

Caráter 2: 0 --> 1

Caráter 12: 1 --> 0

Caráter 120: 1 --> 2

Caráter 201: 1 --> 0

\section{Nó 54 :}

Todas as árvores:

Caráter 10: 1 --> 0

Caráter 14: 0 --> 1

Caráter 15: 0 --> 1

Caráter 20: 4 --> 0

Caráter 25: 2 --> 3

Caráter 30: 1 --> 2

Caráter 35: 2 --> 1

Caráter 58: 1 --> 0

Caráter 70: 1 -->0

Caráter 80: 1 -->0

Caráter 216: 0 --> 1

Algumas árvores:

Caráter 11: 2 --> 0
Nó 55 :

Todas as árvores:

Caráter 1: 1 --> 0

Caráter 6: 1 --> 0

Caráter 27: 0 --> 1

Caráter 52: 0 --> 1

Caráter 182: 1 --> 0

Caráter 201: 1 --> 2

\section{Nó 56 :}

Todas as árvores:

Caráter 71: 1 -->0

Caráter 90: 0 --> 1

Caráter 115: 1 --> 0

Caráter 150: 1 --> 0

Caráter 168: 0 --> 1

Caráter 172: 1 --> 0

Caráter 224: 0 --> 1

Algumas árvores:

Caráter 169: 2 -->1

\section{Nó 57 :}

Todas as árvores:

Caráter 121: 0 --> 1

Caráter 173: 0 --> 1

Caráter 212: 3 --> 2

Caráter 213: 3 --> 2

\section{Nó 58 :}

Todas as árvores:

Caráter 191: 1 --> 0

Caráter 211: 3 --> 4 


\section{Nó 59 :}

Todas as árvores:

Caráter 5: 2 --> 1

Caráter 13: 2 --> 1

Caráter 63: 0 --> 1

Caráter 97: 2 --> 1

Caráter 100: 2 --> 1

Caráter 104: 2 --> 1

Caráter 106: 2 --> 1

Caráter 125: 2 --> 1

Caráter 128: 2 --> 1

Caráter 132: 2 --> 1

Caráter 135: 2 --> 1

Caráter 155: 0 --> 1

Caráter 189: 2 --> 1

Caráter 195: 2 --> 1

Caráter 206: 2 --> 1

Caráter 207: 2 --> 1

\section{Nó 60 :}

Todas as árvores:

Caráter 142: 0 --> 1

Caráter 182: 1 --> 0

\section{Nó 61 :}

Todas as árvores:

Caráter 101: 1 --> 0

Caráter 129: 1 --> 0

Caráter 144: 0 --> 1

Caráter 145: 0 --> 1

Caráter 146: 0 --> 1

Caráter 147: 0 --> 1

Caráter 168: 0 -->1

\section{Nó 62 :}

Todas as árvores:

Caráter 10: 1 --> 0

Caráter 50: 1 --> 0

Caráter 110: 1 --> 0

Caráter 120: 1 --> 2

\section{Nó 63 :}

Todas as árvores:

Caráter 47: 1 --> 0

Caráter 83: 1 --> 0

Caráter 143: 1 --> 0

Caráter 191: 1 --> 0

Algumas árvores:

Caráter 11: 2 --> 1

\section{Nó 64 :}

Todas as árvores:

Caráter 76: 0 --> 1

Caráter 97: 1 --> 0

Caráter 100: 1 --> 0

Caráter 104: 1 --> 0

Caráter 106: 1 --> 0

Caráter 125: 1 --> 0

Caráter 128: 1 --> 0

Caráter 132: 1 -->0

Caráter 135: 1 --> 0

Caráter 189: 1 --> 0

Caráter 195: 1 --> 0

Caráter 206: 1 --> 0

Caráter 207: 1 --> 0

Algumas árvores: 
Caráter 13: 1 -->0

Nó 65 :

Todas as árvores:

Caráter 2: 0 --> 1

Caráter 5: 1 --> 0

Caráter 61: 1 --> 0

Caráter 120: 2 --> 0

Caráter 176: 1 --> 0

Algumas árvores:

Caráter 70: 1 --> 0

Caráter 90: 0 --> 1

Caráter 101: 0 --> 1

Caráter 107: 1 --> 0

Caráter 129: 0 --> 1

Caráter 137: 0 --> 1

\section{Nó 66 :}

Todas as árvores:

Caráter 88: 0 --> 1

Caráter 98: 0 --> 1

Caráter 120: 1 --> 0

Caráter 126: 1 --> 0

Caráter 225: 0 --> 1

Caráter 226: 0 --> 1

\section{Nó 67 :}

Todas as árvores:

Caráter 30: 2 --> 3

Caráter 35: 1 -->0

Caráter 148: 1 --> 0

Caráter 185: 0 --> 1
Nó 68 :

Todas as árvores:

Caráter 56: 0 --> 1

Caráter 111: 2 --> 1

Caráter 142: 0 --> 1

Caráter 154: 0 --> 1

Caráter 156: 1 --> 0

Caráter 157: 1 --> 0

Caráter 164: 1 --> 0

Caráter 165: 1 -->0

Caráter 166: 1 --> 0

Caráter 187: 0 --> 1

Caráter 190: 0 --> 1

\section{Nó 69 :}

Todas as árvores:

Caráter 30: 1 --> 2

Caráter 107: 1 --> 0

Algumas árvores:

Caráter 110: 1 --> 0

\section{Nó 70 :}

Todas as árvores:

Caráter 47: 1 --> 0

Caráter 180: 0 --> 1

Caráter 225: 0 --> 1

\section{Nó 71 :}

Todas as árvores:

Caráter 5: 1 --> 0

Caráter 10: 1 -->0

Caráter 13: 1 --> 0

Caráter 34: 1 -->0 
Caráter 97: 1 --> 0

Caráter 100: 1 --> 0

Caráter 104: 1 --> 0

Caráter 106: 1 --> 0

Caráter 125: 1 -->0

Caráter 128: 1 --> 0

Caráter 132: 1 --> 0

Caráter 135: 1 --> 0

Caráter 195: 1 --> 0

Caráter 206: 1 --> 0

Caráter 207: 1 --> 0

Algumas árvores:

Caráter 139: 1 --> 0

Nó 72 :

Todas as árvores:

Caráter 21: 4 -->0

Caráter 22: 0 --> 1

Caráter 32: 1 --> 0

Caráter 38: 1 --> 0

Caráter 48: 1 --> 0

Caráter 75: 1 --> 0

Caráter 92: 0 --> 1

Caráter 170: 2 --> 0

Caráter 192: 2 --> 1

Caráter 224: 1 --> 0

Nó 73 :

Todas as árvores:

Caráter 3: 0 --> 1

Caráter 4: 1 --> 0

Caráter 28: 1 -->0

Caráter 94: 0 --> 1
Caráter 99: 1 --> 0

Caráter 127: 0 --> 1

Caráter 193: 2 --> 1

\section{Nó 74 :}

Todas as árvores:

Caráter 42: 2 --> 1

Caráter 65: 0 --> 1

Caráter 76: 0 --> 1

Caráter 85: 1 --> 0

Caráter 195: 2 --> 1

Caráter 201: 1 --> 0

\section{Nó 75 :}

Todas as árvores:

Caráter 6: 2 --> 0

Caráter 34: 1 -->0

Caráter 76: 1 -->0

Caráter 113: 1 --> 0

Caráter 123: 0 --> 2

Caráter 166: 1 --> 0

Caráter 195: 1 --> 2

Caráter 204: 1 --> 0

Caráter 211: 3 --> 1

Caráter 213: 3 --> 1

\section{Nó 76 :}

Todas as árvores:

Caráter 7: 0 --> 1

Caráter 13: 1 -->0

Caráter 16: 1 -->0

Caráter 20: 3 --> 5

Caráter 39: 3 --> 0 
Caráter 40: 3 --> 0

Caráter 51: 2 --> 0

Caráter 77: 0 --> 1

Caráter 96: 1 --> 0

Caráter 103: 1 -->0

Caráter 105: 1 --> 0

Caráter 116: 1 --> 0

Caráter 124: 0 --> 1

Caráter 131: 0 --> 1

Caráter 134: 0 --> 1

Caráter 146: 0 --> 1

Caráter 150: 0 --> 1

Caráter 151: 0 --> 1

Caráter 169: 1 --> 0

Caráter 190: 0 --> 1

Caráter 200: 1 --> 0

Caráter 205: 0 --> 1

\section{Nó 77 :}

Todas as árvores:

Caráter 17: 0 --> 1

Caráter 54: 0 --> 2

Caráter 57: 5 --> 6

Caráter 102: 1 --> 0

Caráter 126: 1 --> 0

Caráter 130: 1 --> 0

Caráter 181: 0 --> 1

Caráter 192: 2 --> 1

\section{Nó 78 :}

Todas as árvores:

Caráter 15: 0 --> 1

Caráter 21: 4 --> 2
Caráter 98: 0 --> 1

Caráter 139: 0 --> 1

Caráter 170: 2 --> 1

\section{Nó 79 :}

Todas as árvores:

Caráter 6: 2 --> 1

Caráter 7: 0 --> 1

Caráter 9: 1 --> 0

Caráter 29: 0 --> 1

Caráter 43: 1 -->0

Caráter 48: 1 -->0

Caráter 52: 1 -->0

Caráter 53: 1 -->0

Caráter 69: 0 -->1

Caráter 77: 0 --> 1

Caráter 101: 1 --> 0

Caráter 108: 2 --> 0

Caráter 118: 0 --> 1

Caráter 141: 0 --> 1

Caráter 193: 2 --> 1

Caráter 200: 1 --> 0

Caráter 210: 2 --> 1

Caráter 211: 3 --> 1

Caráter 212: 3 --> 1

Caráter 213: 3 --> 1

Caráter 214: 3 --> 1

\section{Nó 80 :}

Todas as árvores:

Caráter 2: 0 --> 1

Caráter 55: 0 --> 1

Caráter 61: 1 --> 0 
Caráter 70: 1 -->0

Caráter 72: 0 --> 1

Caráter 74: 0 --> 1

Caráter 75: 1 --> 0

Caráter 87: 0 --> 1

Caráter 90: 1 --> 0

Caráter 93: 1 -->0

Caráter 136: 1 --> 0

Caráter 155: 1 --> 0

Caráter 166: 1 --> 2

Caráter 171: 0 --> 1

Caráter 182: 1 --> 0

Caráter 203: 0 --> 1 
Anexo 3. Figuras I e II. 


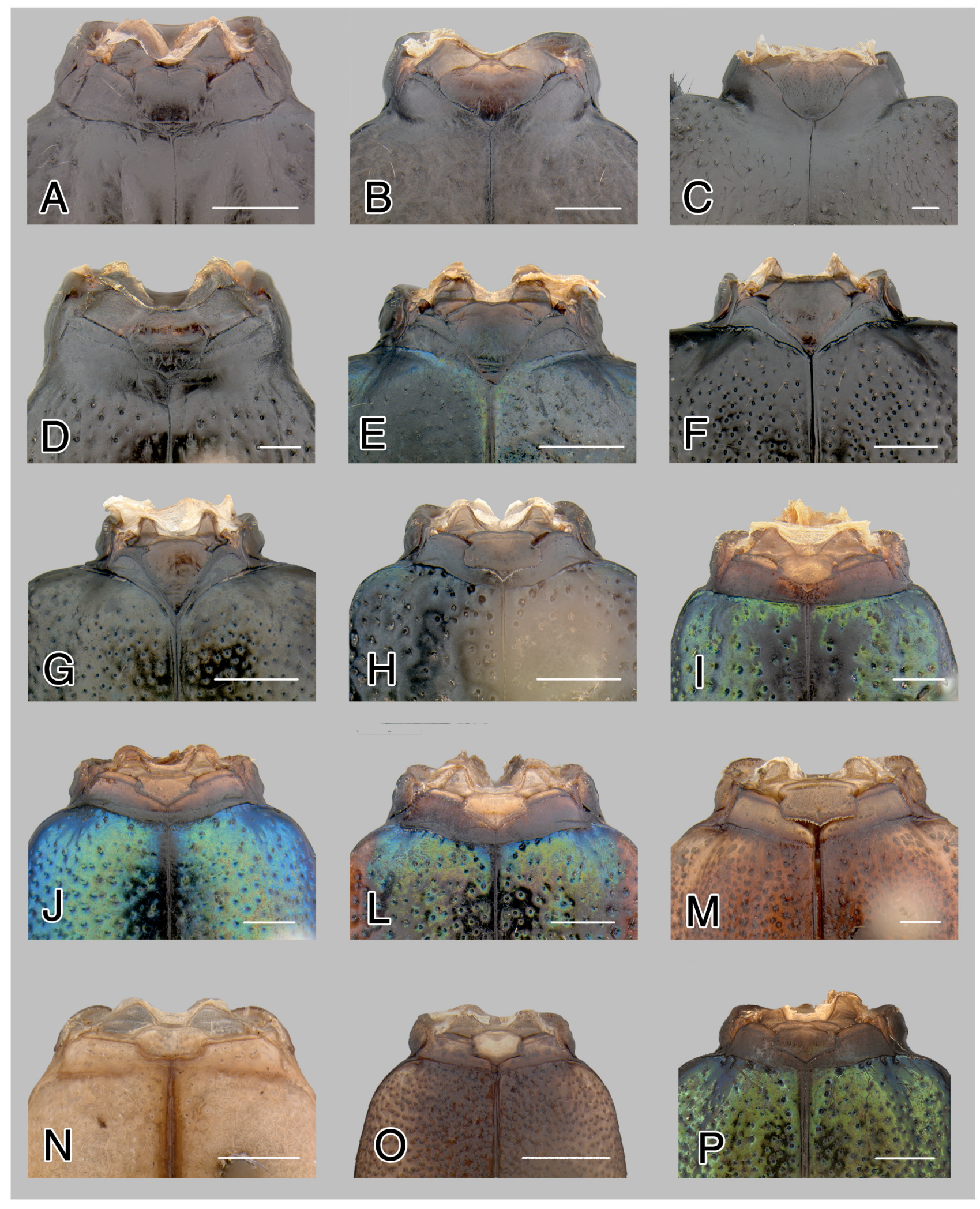

Figura I. Mesotórax (vista dorsal). A. Amblycheila cylindrica; B. Omus dejeani; C. Manticora tuberculata; D. Amblycheila cylindriformis; E. Pseudoxycheila bipustulata; F. Oxycheila tristis; G. Cheiloxya binotata; H. Aniara sepulcralis; I. Pseudotetracha cylindrica; J. Pseudotetracha murchisona; L. Australicapitona basalis; M. Phaeoxantha klugii; N. Platychile pallida; O. Phaeoxantha laminata; P. Tetracha femoralis. As escalas representam $1 \mathrm{~mm}$. 


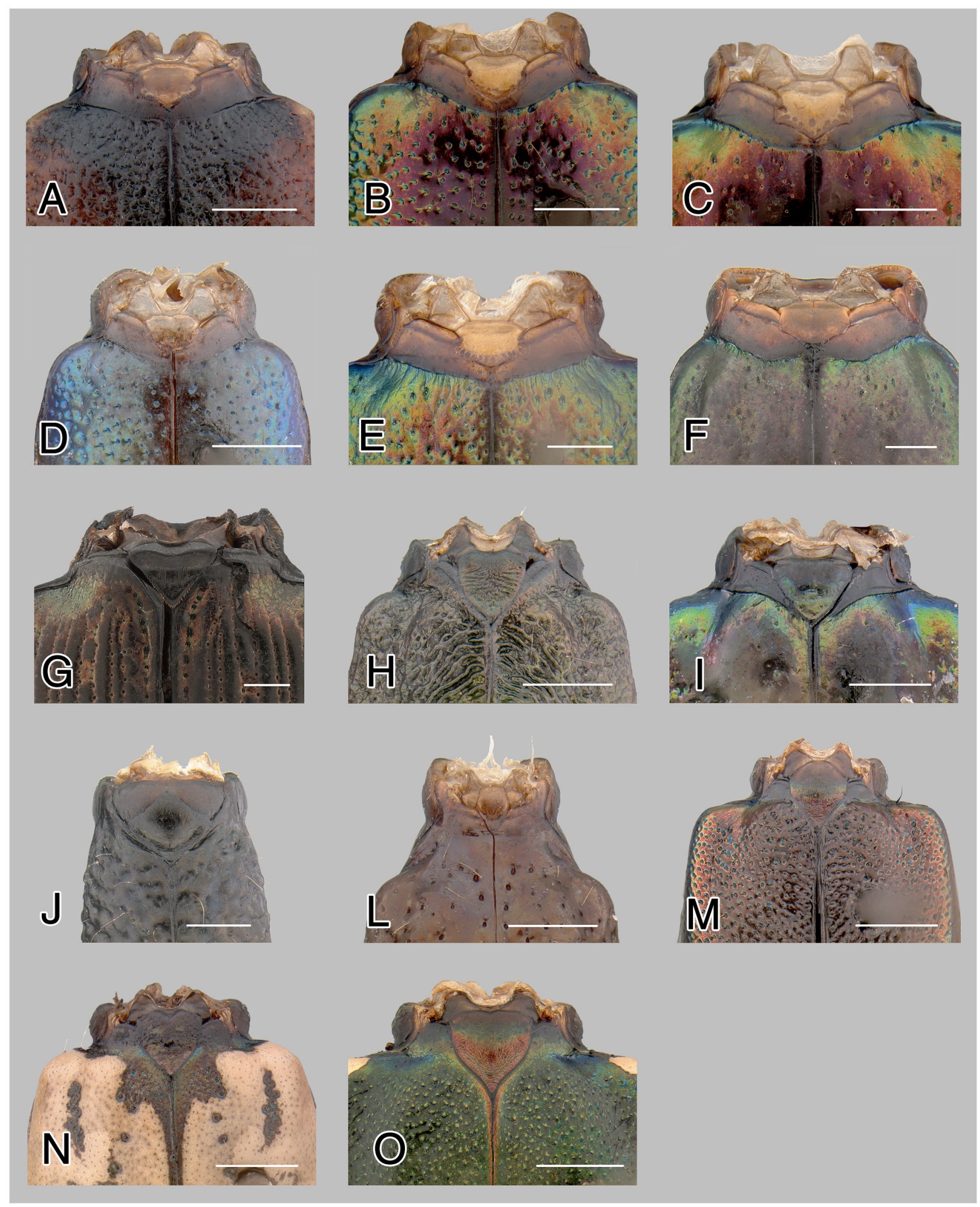

Figura II: Mesotórax (vista dorsal). A. Metriocheila nigricollis; B. Tetracha fulgida; C. T. chilensis; D. T. germaini; E. Grammognatha euphratica; F. Megacephala bocandei; G. Calosoma granulatum; H. Callidema boussingaultii; I. Euprosopus quadrinotatus; J. Tricondyla aptera; L. Ctenostoma formicarium; M. Odontocheila cayennensis; N. Cylindera nivea; $\mathbf{0}$. Cicindela campestris. As escalas representam $1 \mathrm{~mm}$. 